\title{
GENDER AND PRECARIOUS RESEARCH CAREERS
} A COMPARATIVE ANALYSIS

\author{
Edited by \\ Annalisa Murgia and Barbara Poggio
}

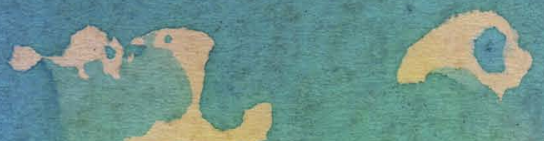




\section{Gender and Precarious Research Careers}

The literature on gender and science shows that scientific careers continue to be characterised - albeit with important differences among countries - by strong gender discriminations, especially in more prestigious positions. Much less investigated is the issue of which stage in the career such differences begin to show up.

Gender and Precarious Research Careers aims to advance the debate on the process of precarisation in higher education and its gendered effects, and springs from a three-year research project across institutions in seven European countries: Italy, Belgium, the Netherlands, Iceland, Switzerland, Slovenia and Austria. Examining gender asymmetries in academic and research organisations, this insightful volume focuses particularly on early careers. It centres both on STEM disciplines (Science, Technology, Engineering and Mathematics) and SSH (Social Science and Humanities) fields.

Offering recommendations to design innovative organisational policies and self-tailored 'Gender Equality Plans' to be implemented in universities and research centres, this volume will appeal to students and researchers interested in fields such as Gender Studies, Sociology of Work and Industry, Sociology of Knowledge, Business Studies and Higher Education.

Annalisa Murgia has coordinated the European FP7 project GARCIA - Gendering the Academy and Research: Combating Career Instability and Asymmetries. She is Associate Professor at the Leeds University Business School, UK.

Barbara Poggio is Co-ordinator of the Centre for Interdisciplinary Gender Studies and Vice Rector for Equality and Diversity at the University of Trento, Italy. 


\section{Routledge Research in Gender and Society}

67 Modern Motherhood and Women's Dual Identities

Rewriting the Sexual Contract

Petra Bueskens

68 Age, Gender and Sexuality through the Life Course The Girl in Time

Susan Pickard

69 The Romani Women's Movement

Struggles and Debates in Central and Eastern Europe

Edited by Angéla Kóczé, Violetta Zentai, Jelena Jovanović, and Enikö Vincze

70 Affective Inequalities in Intimate Relationships Edited by Tuula Juvonen and Marjo Kolehmainen

71 Masculinities, Sexualities and Love Aliraza Javaid

72 Body, Migration, Re/constructive Surgeries Making the Gendered Body in a Globalized World Edited by Gabriele Griffin and Malin Jordal

73 Gender and Migration Intersectional Prospects Anna Amelina and Helma Lutz

74 Gender and Precarious Research Careers A Comparative Analysis Edited by Annalisa Murgia and Barbara Poggio

www.routledge.com/sociology/series/SE0271 


\section{Gender and Precarious Research Careers A Comparative Analysis}

\section{Edited by Annalisa Murgia and Barbara Poggio}


First published 2019

by Routledge

2 Park Square, Milton Park, Abingdon, Oxon OX14 4RN

and by Routledge

711 Third Avenue, New York, NY 10017

Routledge is an imprint of the Taylor \& Francis Group, an informa business

(C) 2019 selection and editorial matter, Annalisa Murgia and Barbara

Poggio; individual chapters, the contributors

The right of Annalisa Murgia and Barbara Poggio to be identified as the authors of the editorial matter, and of the authors for their individual chapters, has been asserted in accordance with sections 77 and 78 of the Copyright, Designs and Patents Act 1988.

The Open Access version of this book, available at www.taylorfrancis.com, has been made available under a Creative Commons Attribution-Non Commercial-No Derivatives 4.0 license.

Trademark notice: Product or corporate names may be trademarks or registered trademarks, and are used only for identification and explanation without intent to infringe.

British Library Cataloguing-in-Publication Data

A catalogue record for this book is available from the British Library

Library of Congress Cataloging-in-Publication Data

A catalog record has been requested for this book

ISBN: 978-1-138-70806-8 (hbk)

ISBN: 978-1-315-20124-5 (ebk)

Typeset in Times New Roman

by Wearset Ltd, Boldon, Tyne and Wear 


\section{Contents}

List of figures vii

List of tables viii

Notes on contributors $\quad$ ix

Introduction

Introduction 3

ANNALISA MURGIA AND BARBARA POGGIO

\section{PART I}

The state of the art

1 Gender and precarious careers in academia and research: macro, meso and micro perspectives

ROSSELLA BOZZON, ANNALISA MURGIA AND

BARBARA POGGIO

2 The gendered diversification of academic career paths in comparative perspective

NICKY LE FEUVRE, PIERRE BATAILLE,

SABINE KRADOLFER, MARIA DEL RIO CARRAL AND

MARIE SAUTIER 
vi Contents

\section{PART II}

Academic and research organisations

3 Gender budgeting to expose inequalities in a precarious academia - and redistribute resources to effect change

FINNBORG S. STEINPÓRSDÓTTIR,

DORGERĐUR EINARSDÓTTIR, THAMAR M. HEIJSTRA,

GYĐA M. PÉTURSDÓTTIR AND THOMAS BRORSEN SMIDT

4 The peril of potential: gender practices in the recruitment and selection of early career researchers

CHANNAH HERSCHBERG, YVONNE BENSCHOP AND MARIEKE VAN DEN BRINK

\section{PART III}

Early career researchers

5 Work-life balance among early career researchers in six European countries

SANJA CUKUT KRILIĆ, MAJDA ČERNIČ ISTENIČ AND DUŠKA KNEŽEVIĆ HOČEVAR

6 A gendered pipeline typology in academia FARAH DUBOIS-SHAIK, BERNARD FUSULIER AND CAROLINE VINCKE

7 Implementing measures to promote gender equality and career opportunities of early career researchers

FLORIAN HOLZINGER, HELENE SCHIFFB ÄNKER, SYBILLE REIDL, SILVIA HAFELLNER AND

JÜRGEN STREICHER 


\section{Figures}

2.1 Graduate rates at doctoral level 2000 and 2011, as a percentage of the reference cohort, selected OECD countries

2.2 Doctorate holders in the working age population, 25-64 years, by sex, 2012

2.3 Percentage of Grade A staff amongst all academic staff, by sex, selected countries, 2013

2.4 Part-time employment rate of researchers in the higher education sector, by sex, selected countries, 2012

2.5 "Precarious" working contracts of researchers in the higher education sector out of total research population, by sex, selected countries, 2012 


\section{Tables}

2.1 Women as a proportion of all researchers and of Grade A positions, by field of science, selected countries, 2013

2.2 Evolution of number of researchers in the HE sector, by sex, selected countries, 2006-2013

2.3 Employment trajectory of $\mathrm{PhD}$ holders five years after doctorate defence (generation 2010), by disciplinary field, France, 2015

4.1 Number of male and female interview and focus group participants per country and department

4.2 Overview of general gender practices and specific gender practices

4.3 Proportion of female academic staff by grade, 2013

5.1 Maternal employment rates by age of youngest child, 2014

5.2 Percentage of part-time and full-time employment amongst men and women aged 25-54, selected countries, 2014

5.3 Fertility rates, mean age of women at birth of first child, and maternity/paternity/parental leave arrangements, selected countries, 2014

5.4 Participation rates in childcare, 2014 (formal childcare by duration and age group) 


\section{Contributors}

Pierre Bataille received his $\mathrm{PhD}$ in sociology at the University of Lausanne. He is now a postdoctoral researcher at the Universite Libre de Bruxelles in Belgium. His main research interests include the sociology of education, sociology of elites, sociology of work, cultural sociology, gender perspective and longitudinal approaches in mixed methods research design.

Yvonne Benschop is Professor of Organisational Behavior at the Institute for Management Research at Radboud University, the Netherlands. She is Head of the Department of Business Administration. Her research interests focus on power in organising, informal organisation processes that produce intersectional gender inequalities and the ways to change these processes and inequalities. She is Co-Editor in Chief of Organization, associate editor of Gender, Work and Organization, and serves on the editorial boards of several other journals.

Rossella Bozzon is Postdoctoral Researcher at the Centre for Employment Relations, Innovation and Change (CERIC) of the Leeds University Business School (UK), and member of the ERC Starting Grant project SHARE 'Seizing the Hybrid Areas of Work by Re-presenting Self-Employment'. Her research interests include welfare state and labour market transformations, nonstandard employment relations, demographic dynamics, gender inequalities and quantitative methods.

Thomas Brorsen Smidt obtained his PhD in Gender Studies from the Faculty of Political Science at the University of Iceland in 2018. He is a sessional teacher and supervisor at the UN University Gender Equality Studies and Training Program (UNU-GEST) as well as an active public lecturer on issues ranging from workplace sexual harassment to politics of sexuality and intimacy.

Majda Černič Istenič is Senior Research Fellow at ZRC SAZU and Associate Professor at Biotechnical Faculty, University of Ljubljana. Her recent research work and publications comprises the issues of gender, intergenerational relations and ageing in rural contexts, knowledge exchange in agriculture, urban agriculture and the well-being of farm populations. 


\section{x Contributors}

Sanja Cukut Krilić, is Research Fellow at ZRC SAZU. She has researched and published on the topics of female migration, care work, transnational families, gender-based violence in migration contexts and the reconciliation of family and working life among different populations.

Maria del Rio Carral, PhD, works as a Lecturer in Health Psychology at the Institute of Psychology at the University of Lausanne, where she teaches qualitative methods in psychology. Her research interests include: psychosocial implications related to the shift towards the digitalisation of health; the use of qualitative and mixed research methods in psychology; and the influence of working conditions upon the construction of subjective health and well-being in daily life.

Farah Dubois-Shaik was Postdoctoral Research Fellow (FP7, Marie Curie Actions) in Sociology, at the IACCHOS institute at the Catholic University of Louvain, Belgium. Her research work mainly comprises knowledge and policy analysis, discourse analysis, political sociology, sociology of organisations and membership studies.

Porgerður Einarsdóttir is Professor in Gender Studies, Faculty of Political Science, University of Iceland. She has been involved in critical equality and gender studies and her research areas cover gender relations on the labour market, welfare and family policies. Her most recent research areas are the gendered dynamics of the financial crises and transgender issues.

Bernard Fusulier is Research Director (National Fund for Scientific Research) and Professor of Sociology at the Catholic University of Louvain (UCL) within the IACCHOS institute. His research deals with work/family/gender relations; social policies; life courses; the sociology of work, organisations and professions; and social transaction.

Silvia Hafellner studied International Business Administration at the Vienna University of Economics and Business as well as International Development at the University of Vienna. Since 2014 she has been working as a researcher at the Institute of Economic and Innovation Research (POLICIES) of Joanneum Research. Her work focuses on social entrepreneurship, innovation and gender equality.

Thamar M. Heijstra is Associate Professor of Sociology at the Faculty of Social and Human Sciences at the University of Iceland. In her research she focuses on the work conditions, work culture, work-family balance and wellbeing of professionals, as well as on gender and gender budgeting.

Channah Herschberg worked as a $\mathrm{PhD}$ candidate at the Institute for Management Research at the Radboud University, the Netherlands. She currently holds a position as policy officer at the Netherlands Organisation for Scientific Research (NWO). Channah received a degree in Psychology and a degree in Human Resource Management and Organisational Analysis. Her research 
interests include gender and diversity, gender practices, academic careers, precariousness and sustainable careers.

Florian Holzinger has been working as a researcher for Joanneum Research, POLICIES - Institute for Economic and Innovation Research since 2007. The current focus of his research interests is on gender issues in innovation systems and processes as well as on governance issues in science, technology and innovation.

Duška Knežević Hočevar is Associate Professor of Anthropology at the Postgraduate School ZRC SAZU and at the University of Nova Gorica, and a Senior Research Fellow at ZRC SAZU. She researched and published on family farming in contexts of radical social change, generations and gender relationships on the farms, community care in rural settings, domestic violence in rural settings, ageing society and the fertility-migration nexus, processes of collective identifications and social boundaries after the dissolution of socialist Yugoslavia.

Sabine Kradolfer is an anthropologist and sociologist. She is currently working at the University of Lausanne (Switzerland) as Equality Officer for the National Centre of Competence in Research LIVES (www.lives-nccr.ch). Her research profile is broad-based, covering areas such as race and ethnicity, indigenous peoples of Latin America, intersections between social inequalities (sex, race, class) and science policies, gender equality in academic careers, etc. She has been trained at the Universities of Neuchâtel, Lausanne (Switzerland), Paris III - Sorbonne Nouvelle (France), Río Negro (Argentina) and at the Autonomous University of Barcelona (Spain). She has been awarded two grants for young researchers from the Swiss National Science Foundation.

Nicky Le Feuvre is Professor of Sociology at the University of Lausanne. As Vice-Dean of the Faculty of Social and Political Sciences, she is in charge of gender equality and early academic careers. She has researched and published extensively on the feminisation of high-level occupations, from a comparative and life-course perspective. She is currently Director of the Gender \& Occupations sub-project of the LIVES programme and is a member of the management committee of the IS1409 COST Action Gender and Health Impacts of Policies Extending Working Lives. She is also Chair of the Gender Research Committee of the International Association of French-speaking Sociologists.

Annalisa Murgia is Associate Professor at the Work and Employment Relations Division of the Leeds University Business School, UK. Her research interests include work trajectories and fragmented careers, with a focus on precariousness, knowledge work, the emerging forms of organising and the social construction of gender in organisations. She has been the Scientific Coordinator of the European FP7 project GARCIA: Gendering the Academy and 
Research: Combating Career Instability and Asymmetries. She is currently the Principal Investigator of the ERC Starting Grant project SHARE: Seizing the Hybrid Areas of Work by Re-presenting Self-Employment.

Gyða M. Pétursdóttir is Associate Professor in Gender Studies at the Faculty of Political Science, University of Iceland. She gained her $\mathrm{PhD}$ in Gender Studies from the University of Iceland in 2009. Her research areas include organisational culture, work and family life, gender relations, masculinities and femininities.

Barbara Poggio is Vice-Rector for Equality and Diversity of the University of Trento and coordinates the Centre for Interdisciplinary Gender Studies of the same university. She is Professor of Sociology of Work and Sociology of Organisation at the Department of Sociology and Social Research. She carried out several studies and international projects on gender, work and organisation, with a special focus on gender and entrepreneurship, gender and science, and work-life balance.

Sybille Reidl studied sociology at the University of Vienna. Since 2003 she has been working as a researcher at the Institute for Economic and Innovation Research of Joanneum Research - POLICIES which is focused on applied research and consulting services in the fields of science, technology and innovation (STI). Her main research areas are gender/diversity and human resources in STI (especially the promotion of equal opportunities and the promotion of young researchers/teenagers in natural sciences and engineering).

Finnborg Salome Steinpórsdóttir obtained her PhD in Gender Studies from the Faculty of Political Science at the University of Iceland in 2018. She is now a post-doctoral researcher and sessional teacher at the same faculty. Her main research interests include gender, gender budgeting, academic careers and organisational culture.

Marie Sautier is a PhD candidate at the Institute of Social Sciences, University of Lausanne, Switzerland. Her research interests include: the trajectories of researchers in life-course perspective, academic careers, gender equality policies and the use of ethnography in sociology. Her $\mathrm{PhD}$ research focuses on the geographical mobility of early career researchers in cross-national perspective.

Helene Schiffbänker joined POLICIES - Institute for Economic and Innovation Research of Joanneum Research in 2001 and works there as a senior researcher and deputy-head of the research group Technology, Innovation and Policy Consulting (TIP). Her main field of expertise is gender and science. Her current research interest is men's and women's career trajectories and the organisational contexts in which they are embedded.

Jürgen Streicher is a researcher in the research group Technology, Innovation and Policy Consulting of Joanneum Research - POLICIES, working in the 
fields of industry analysis, innovation behaviour of small and medium-size enterprises (SMEs), R\&D and technology research. He also engages in national and international cluster analysis studies as well as evaluations of research, technology and innovation (RTI) policies, programmes and institutions. Since 2014, Jürgen is co-coordinator of the annual Austrian Research and Technology Report. He holds a Master's and PhD from WU Vienna.

Marieke van den Brink is Professor of Gender and Diversity at the Institute for Social and Cultural Research at Radboud University, the Netherlands. Her main research interests are gender and diversity in organisations, organisational learning and processes of power and resistance. She is an elected member of the prestigious Young Academy of the Royal Netherlands Academy of Arts and Sciences. Her work has been published in Journal of Management Studies, Organization Studies, Organization, Human Relations, Gender, Work \& Organization, Social Science \& Medicine and Employee Relations.

Caroline Vincke is Professor at the Earth and Life Institute at UCL (Belgium). Her main research interests focus on forest eco-hydrology, the coupling with carbon fluxes and/or radionuclides cycles, and the impacts of environmental conditions (climate change in particular) on forest functioning and vulnerability. She has been PI, or WP leader or (co-)supervisor in about 20 national and international projects of fundamental and applied research. Since 2009, she has also been involved in studies about gender issues in academia and their implementation, specifically as the co-supervisor of the GARCIA project at UCL. 



\section{Introduction}





\title{
Introduction
}

\author{
Annalisa Murgia and Barbara Poggio
}

\section{Project overview}

From a historical standpoint, precariousness tends to be represented as a dimension intrinsic to the female experience and to its unstable vacillation between different life spheres and domains. The etymological root of the adjective 'precarious' dates back to the Latin word for prayer, prex. Therefore, something that is precarious has been obtained by 'praying for it'; consequently it is something that can be done only because someone else has granted permission and, because it is subject to the arbitrariness of the person granting such permission, it is not stable and hardly long lasting. This image immediately underlines how the concept of precariousness is not a neutral one, as well as how there are certain social norms and practices which, as observed by Judith Butler (2004), make some lives more precarious and vulnerable than others. Such an image calls to mind several actions of exclusion and discrimination that have characterised gender relationships in different ages and contexts. Precariousness then can be seen as a suitable perspective for the analysis of gender relations and the ways in which they are constructed and negotiated. On this basis, this volume will discuss the gender implications of the changes experienced by those who undertake academic and research careers. Particular attention will be paid to the academic system and how these dynamics are reproduced in the daily life of faculties and departments, with regard to both the life paths and the experiences of male and female early career researchers.

Studies that have dealt with gender differences in the academic system have thoroughly investigated the persistent existence of a considerable asymmetry in the positions at the top of the ladder, where women seem to be much less represented than men (Bain and Cummings 2000; Probert 2005; Van den Brink and Benschop 2012). Much less investigated is another issue, namely at what stage in a person's career such differences begin to show up. In fact, while female university students perform better than their male counterparts, the situation suddenly changes in postdoctoral fellowship positions, and it further worsens through the next stages of academic and research careers (Blickenstaff 2005; Shen 2013). Women more often occupy precarious positions, either working part-time or working in conditions that lack stability or opportunities for career 
advancement (De Groot 1997; Gill 2009). Therefore, the focus in this edited volume concerns the experiences of early career researchers and the process of precarisation currently affecting higher education, which is also closely related to cultural changes in the research sector, especially in the management models and in the emergent rhetoric within universities, marked by an increasingly widespread neoliberal ideology (Nikunen 2012; Morgan and Wood 2017).

The research presented in the following chapters is based on the outcomes of a three-year project, titled GARCIA - 'Gendering the Academy and Research: combating Career Instability and Asymmetries' - funded by the 7th Framework Programme of the European Commission. The project involved seven universities and research organisations in several European countries - Italy, Switzerland, Iceland, The Netherlands, Slovenia, Belgium and Austria - and was undertaken between 2014 and $2017 .{ }^{1}$

The design of the comparative research has several elements of originality and innovation.

First, the project tackled the issue of gender asymmetries in higher institutions within the framework of the 2008 economic crisis and the neoliberal agenda, where scientific work becomes more market-driven and focused on dimensions such as performativity, competitiveness, project-based working and commodification, with significant impacts in terms of both generations and gender (Archer 2008; Bagilhole and White 2013). Therefore, it was decided to focus on the early stages of academic and research careers, and not just on the topmost positions, as has most of the existing literature on gender and science. In particular, the GARCIA project mainly considered the increase in positions based on unstable and temporary contracts (non-tenured), with important consequences from a gender perspective which, to date, have been insufficiently considered by the literature. Moreover, in order to fully understand the complex and non-linear trajectories of early career researchers, the target population included not only postdocs and lecturers working at the higher education institutions under study, but also $\mathrm{PhD}$ holders who had worked in the past in the departments involved in the project and then changed workplace and/or profession. Therefore, instead of looking at the 'leaky pipeline' phenomenon (Berryman 1983; Alper 1993) only from the point of view of women and men working in academia, our study also focuses on the perspective of postdocs and temporary researchers who left it, because they 'chose' to work outside the academic/ research system or because they were 'forced' to leave it (in response to a failure to recognise their work; organisational gendered constraints; difficulties in work-life balance; unaffordable demand for international mobility, etc.).

The second element of innovation relates to the choice of case studies. The research was carried out in each of the involved higher education institutions both in STEM (Science, Technology, Engineering and Mathematics) and SSH (Social Science and Humanities) departments, institutes and faculties, in order to understand differences but also similarities between disciplines in regards both to how gender is represented and to career opportunities. The fact that women are well represented in the SSH disciplines does not necessarily mean 
that they are immune from gender inequalities and discrimination, as shown by the lack of their presence in prestigious positions, even where women represent the majority of staff members. The project was carried out in the following organisational contexts: University of Trento - Departments of 'Information Engineering and Computer Science' and 'Sociology and Social Research'; the Catholic University of Louvain - Institutes of 'Earth and Life' and for the 'Analysis of Change in Contemporary and Historical Societies'; Radboud University - Institutes of 'Mathematics, Astrophysics and Particle Physics' and 'Management Research'; University of Iceland - Schools of 'Engineering and Natural Sciences' and 'Social Sciences'; University of Lausanne - Faculties of 'Biology and Medicine' and 'Social and Political Sciences'; Research Centre of the Slovenian Academy of Sciences and Arts - 'Fran Ramovš Institute of the Slovenian Language' and University of Ljubljana - 'Biotechnical Faculty, Department of Agronomy'.

The final innovative feature of the GARCIA project concerns the fact that the comparative research that was conducted was not an end in itself, but rather a necessary and crucial step in the design of innovative organisational policies and self-tailored gender action plans, to be implemented in all the involved universities and research centres. ${ }^{2}$ This means that the research findings also represented an organisational diagnosis, based on which different policies in the working environments of the research participants have been implemented. In doing this, a participatory approach was used, since the target population was asked directly about the most useful and effective actions to be introduced in the STEM and SSH departments involved in the project. In particular, the policies designed have aimed to intervene in five main areas: understanding national welfare and gender regimes; gender equality in financial decision making and management; gendered subtexts in recruiting and in defining the criteria of 'excellence'; gender practices and gender stereotypes in universities and research institutions; and the leaky pipeline phenomenon.

In terms of research design, a multi-method and multi-level analytical framework was used, combining cross-national comparative research with a comparative analysis of organisational case studies and an analysis of individual professional and life stories of early career researchers. Therefore, gender differences in the early stages of academic and research careers have been studied at the macro, meso and micro levels, considering national welfare and gender regimes, organisational practices and cultures, and individual career trajectories. The volume is structured according to these different perspectives. The first part is dedicated to pointing out the different levels of analysis in the study of gender and precariousness in academia (Chapter 1), as well as to describing the transformations that have affected academic labour markets in recent decades (Chapter 2). The second part of the volume focuses on organisational analysis, by addressing financial decision-making and managerial practices (Chapter 3) and recruitment and selection practices (Chapter 4). The third part of the volume shifts its focus from the organisational to the individual dimension, by discussing work-life conflicts among early career researchers (Chapter 5) and the 
phenomenon of the leaky pipeline (Chapter 6). Finally, in the last chapter, a set of policies for promoting gender equality and career opportunities for early career researchers is offered.

\section{The chapters}

The first chapter of the volume is dedicated to the discussion of the theoretical challenges and the different levels of analysis - the academic labour market, the organisational context and the subjective experiences - that are useful for exploring the relationship between gender and precariousness in higher education. In the first part, Rossella Bozzon, Annalisa Murgia and Barbara Poggio discuss the main macro and institutional trends affecting the structure of academic careers and the factors that fuel and (re)produce gender asymmetries. In the second part of the chapter, attention is paid to the organisational level; the process of commodification and limited resources, especially in the SSH fields, which have radically changed the management of human resources in higher education and research institutions. Therefore, one needs to understand how gendered practices play out on a daily basis, how the selection and recruitment procedures are thus reconfigured and what constitutes the features of the ideal early career researcher created within higher education institutions. In the last part of the chapter the focus shifts to the experiential and subjective dimension of such experiences, with attention paid to both emotional investment, and to the pressure and competitiveness experienced by early career researchers. More specifically, the authors analyse the ambivalent experiences of female and male early career researchers, who have a job which represents a source of greater freedom and autonomy on the one side, but are also exposed to significant social and economic risks on the other.

In the second chapter, Nicky Le Feuvre, Pierre Bataille, Sabine Kradolfer, Maria del Rio Carral and Marie Sautier offer an overview of the issues involved in studying the gendered precariousness of academic careers from a crossnational comparative perspective. The authors then return to the main changes that have affected the academic world and suggest that research on gendered academic careers needs to adopt a more sophisticated comparative perspective. Such a perspective involves recognising: (i) similarities and differences in precariousness across national contexts, gender categories and disciplinary fields; (ii) that academic institutions do not necessarily offer the most fulfilling and rewarding career options for $\mathrm{PhD}$ holders, particularly from a gender equality perspective; and (iii) that various forms of precariousness may affect researchers at different stages in their life-course. The chapter then focuses on the structure of academic labour markets, following the typology of academic career patterns proposed by Christine Musselin (2005). Building on this typology, the authors show how the changes currently taking place in higher education institutions across Europe actually produce specific forms of precarious employment at different life-stages, according to cross-national variations in academic career structures and normative gender regimes. 
The second part of the volume is composed of two chapters which focus on academic and research organisations, and present project findings related to gendered practices in decision-making and managerial practices, as well as in recruitment and selection procedures.

In particular, in Chapter 3, Finnborg S. Steinpórsdóttir, porgerður Einarsdóttir, Thamar M. Heijstra, Gyða M. Pétursdóttir and Thomas Brorsen Smidt examine how neoliberal managerialism affects budgets and organisational practices in academic institutions and research centres, and how they foster the precarisation of academic employment. Particular emphasis is paid to the gendered consequences of the distribution of funding and resources and its impact on the working conditions and career prospects of early career researchers. Quantitative and qualitative data collected in the six academic institutions and research centres involved in the GARCIA project are then used to compare and contrast how policies and managerial instruments differently affect funding allocation in STEM and SSH departments, institutions and faculties, and how this fuels the precarisation processes. Gender impact assessments of policies, neoliberal management methods, and budgets show how organisational practices tend to favour male-dominated fields, with a significant impact on the positions and conditions of early career researchers and their career prospects in research and academia. Moreover, the chapter introduces gender budgeting as a theoretical and methodological instrument to demonstrate how the academic system creates inequalities while simultaneously encouraging academic institutions to reconstruct their budgetary policies and the distribution of resources to achieve a more gender-equal academic sphere.

The fourth chapter presents a comparative analysis of the gendered construction of excellence in recruitment and selection practices for early career researchers in the STEM and SSH institutes, departments and faculties involved in the project. Using a variety of data, such as job postings, appointment reports, HR documents, interviews and focus groups with male and female committee members in the six countries under study, Channah Herschberg, Yvonne Benschop and Marieke van den Brink explore what it takes for early career researchers to be perceived as potentially excellent candidates, and whether there are gender practices at work in the criteria and assessment of candidates. Delving deeper into the practices of recruitment and selection, the chapter analyses how gender is part and parcel of the construction and application of excellence criteria for male and female candidates, and what consequences this has for academics with precarious positions. In particular, two gender practices - welcoming women and assessing potential for excellence - are illustrated and analysed in their interconnections with multiple specific gender practices in the evaluation of early career researchers. Moreover, the authors point out the discrepancies in the various criteria and their application, showing how gender inequalities are embedded in the construction of the 'ideal candidate'.

In the third part of the volume, the focus shifts from the organisational dimension to the professional and life trajectories of early career researchers, with attention paid to both those who complete their $\mathrm{PhD}$ and try for an academic career, and to those who abandon the world of research. 
In the fifth chapter Sanja Cukut Krilić, Majda Černič Istenič and Duška Knežević Hočevar discuss how, in the six national case studies, the proliferation of national and organisational policies to better reconcile the work and family lives of academics is struggling to challenge assumptions about the 'ideal worker' - a full-time, all-encompassing devotion to academia - also because of the gendered expectations of family obligations. Early career researchers are thus of interest not only due to increasingly precarious employment conditions, but also due to the fact that crucial decisions about private and family life are usually taken at this life stage. Drawing on the concept of both academia and family as 'greedy institutions', the focus of the chapter revolves around the questions of how early career researchers, in the six higher institutions under study, reconcile their academic career with their family life, and whether and in what ways such balancing is gendered. Both the organisational culture related to family arrangements of academics and the micro politics of their everyday family lives are illustrated. The focus then moves to the complex effects of work-life balance policies on the individual biographies, and on the ways in which such policies may differently influence men and women in increasingly precarious research environments and across different welfare regimes.

The sixth chapter offers another perspective on the analytical construct of the gender pipeline, using a multidimensional and multilevel approach, thus underlining how such a phenomenon highlights different typical features according to varying social and organisational contexts. On the basis of a meta-analysis of the case studies conducted in the GARCIA project, Farah Dubois-Shaik, Bernard Fusulier and Caroline Vincke develop a typology where social, organisational and career-based dimensions are combined with costs at stake, i.e. those costs that each specific configuration generates for science, for organisations and for individuals, particularly in terms of gender balance and inequality. In particular, three types of careers and experiences are identified: (i) persisting in precarious career paths, at a high cumulative cost; (ii) continuing in ambivalent career paths, at moderate cost; and (iii) striving to win in competitive career paths, at a specific cost. Such a typology can be a useful tool for research institutions to allow them to think about their own leaky pipeline situation and to identify strategies that can reduce relative costs through the re-thinking of how work is organised, in particular in terms of workforce casualisation and its conditions, as well as that pertaining to its female components.

The final chapter focuses on policies and measures to promote gender equality, career opportunities and working conditions of early career researchers. In the first part of the chapter, Florian Holzinger, Helene Schiffbänker, Sybille Reidl, Silvia Hafellner and Jürgen Streicher consider and compare different kinds of policies developed in different European national/regional and organisational contexts to enhance career development and stability for early career researchers. In the second part, the authors present and discuss findings from an accompanying evaluation of implementation activities within the GARCIA project, summarising the main characteristics of the implementation project and highlighting tools and actions which have proved to be successful, as well as the 
weaknesses and the resistances encountered. Finally, recommendations for implementing policies and measures to support early career researchers from a gender sensitive perspective are formulated.

\section{Final remarks}

Fighting gender inequalities and precarisation processes is a goal that goes beyond borders, both in terms of geography and in terms of production sectors. However, the academic sector exemplifies certain specific features and paradoxes that need to be taken into consideration. In fact, those who are driving forward research on precariousness from a feminist perspective and who use gender as their main point of view - and the same goes for those engaged in projects for gender equality - are in most cases women and/or gender-queer and gender non-conforming people, and are often early career researchers with vulnerable and unstable working conditions.

From this point of view, the GARCIA project was no exception. Being aware of this situation, an attempt was made to include all members of the project in the research part, as well as in the publishing stage and the presentation of the findings, so that everyone's work would be visible. Writing this book was largely a demonstration of this approach. However, now that the project is over, what has become of the researchers who developed it? Some of them have attained a permanent position at university, even though they had to move to another country in order to find more stable working conditions. Others obtained a scholarship or were hired for other new projects in order to advance on their academic path. Some have changed jobs, in some cases because university had nothing to offer, whereas others decided to start a professional career that would leave room for other parts of their lives, be it friends, family, the time to relax or political activities. The GARCIA project, like most projects, was then able to open opportunities for its members, and to fund $\mathrm{PhD}$ and postdoctoral trajectories, but at the same time it has contributed to swelling the ranks of early career researchers who have no idea whether they can have a future in the academic system, being therefore unable to offer any concrete perspective about their professional career.

The world of academia and research is not necessarily where the subjects find their professional fulfilment. In addition, one cannot expect to have an endless number of positions that grant free access to whoever is interested in an academic career. At the same time, it falls to us, as feminist scholars, to continue questioning the practices which can counter the casualisation in higher education that disproportionately affects women. What are the expectations awaiting new generations of researchers? What kind of investment is expected of them? How can one challenge and change a research system that is still governed by old-boy networks and which is still based on the grant rush, on competition, on hyperproductivity and on the fact that subjects are expected to be fully available at all times? The answers to these questions are to be found on multiple levels, from institutional reforms, organisational practices and policies to the subjective 
dimension - all topics which will be discussed in this volume. Before approaching various analyses and thoughts about the matter at hand, though, one needs to point out once again how much the relationship between gender and precariousness was not simply the focus of the research and analysis of the GARCIA project, but was also part of the daily life and experience of the researchers who contributed to this project. Such people include brilliant scholars, passionate researchers, team-players and civically and politically engaged people, with a life full of experiences, love, friends and family, all features which are hard to keep within the neoliberal academia. It is important then to keep academic networks that are able to support early career researchers and workers who experience workforce casualisation in academia alive. In addition, the problem needs to be tackled directly, trying to fight and change the system itself, starting from gender inequalities to other types of inequalities, such as those based on sexuality, class and ethnicity. In short, it is about changing the very roots of the system. This is a struggle that can be won together, and which can no longer be postponed.

\section{Notes}

1 All information about the project is available at: http://garciaproject.eu. There were six participating institutions (University of Trento; the Catholic University of Louvain; Radboud University; University of Iceland; University of Lausanne and University of Ljubljana) from, respectively, Italy, Belgium, the Netherlands, Iceland, Switzerland and Slovenia. The seventh partner was the Joanneum Research Forschungsgesel based in Austria - which was in charge of the internal evaluation of the project.

2 The implemented gender action plan is described in detail in the GARCIA working paper 'Supporting Early Career Researchers through Gender Action Plans. A Design and Methodological Toolkit', downloadable for free at: http:/garciaproject.eu/?page $\mathrm{id}=52$.

\section{References}

Alper, J. (1993). The pipeline is leaking women all the way along. Science, 260, 409-411.

Bagilhole, B. and White, K. (2013). Generation and Gender in Academia. Basingstoke, UK: Palgrave Macmillan.

Bain, O. and Cummings, W. (2000). Academe's glass ceiling: societal, professionalorganizational, and institutional barriers to the career advancement of academic women. Comparative Education Review, 44(4), 493-514.

Berryman, S. E. (1983). Who Will Do Science? Minority and Female Attainment of Science and Mathematics Degrees: Trends and Causes. New York: Rockefeller Foundation.

Blickenstaff, C. J. (2005). Women and science careers: leaky pipeline or gender filter? Gender and Education, 17(4), 369-386.

Butler, J. (2004). Precarious Life. The Powers of Mourning and Violence. New York, London: Verso.

De Groot, J. (1997). After the ivory tower: gender, commodification and the 'academic'. Feminist Review, 55(1), 130-142. 
Gill, R. (2009). Breaking the silence: the hidden injuries of neo-liberal academia. In R. Flood and R. Gill (eds), Secrecy and Silence in the Research Process: Feminist Reflections. London: Routledge, pp. 228-244.

Morgan, G. and Wood, J. (2017). The 'academic career' in the era of flexploitation. In E. Armano, A. Bove and A. Murgia (eds), Mapping Precariousness, Labour Insecurity and Uncertain Livelihoods: Subjectivities and Resistance. London: Routledge, pp. 82-97.

Musselin, C. (2005). European academic labour markets in transition. Higher Education, 49, 135-154.

Nikunen, M. (2012). Changing university work, freedom, flexibility and family. Studies in Higher Education, 37(6), 713-729.

Probert, B. (2005). 'I just couldn't fit it in': gender and unequal outcomes in academic careers. Gender, Work \& Organization, 12(1), 50-72.

Shen, H. (2013). Mind the gender gap. Nature, 495(7439), 22.

Van den Brink, M. and Benschop, Y. (2012). Gender practices in the construction of academic excellence: sheep with five legs. Organization, 19(4), 507-524. 



\section{Part I}

The state of the art 



\title{
1 Gender and precarious careers in academia and research
}

\section{Macro, meso and micro perspectives}

\author{
Rossella Bozzon, Annalisa Murgia and \\ Barbara Poggio ${ }^{1}$
}

\section{Introduction}

Over the past few decades, the world of academia and research has undergone substantial transformations, which have deeply affected both the production models and practices of science, as well as on-the-job experiences within this sector. In particular, a commodification process has occurred, which has gradually turned higher education into fertile terrain for marketisation agendas (Levidow 2002) and has changed universities from education institutions into business organisations with accompanying productivity targets (McNair 1997).

This process has been highlighted by the progressive decrease in public investment, which has subsequently led to a greater need to search for funds and external funding. On one hand, this has resulted in an increase in competition between and within the organisations, whilst on the other hand it constitutes the cause of growing instability in terms of working conditions and careers.

What are the implications of such transformations for those who work in the world of academia and research, and above all for those who are approaching this world today? Early career researchers - who despite the low chances of success still try to enter this particular job market - will have to make a significant investment, both in terms of time availability and in identity construction. On one hand, if research as a job has always been known for its strong overlap between working hours and time devoted to the rest of life, the current processes have put researchers under even more pressure, with the working environment becoming all the more frantic and frenetic. On the other hand, the emerging organisational models contribute to defining specific subjectivities, able to respond to and comply with the demands of individualisation, competition and complete dedication to work imposed by the new agenda and the increasing casualisation of the academic workforce.

This chapter therefore focuses on how such processes tend to intensify the already significant gender inequalities present within the academic context. To understand the processes of precarisation, different levels of analysis need to be adopted. First, the focus is on precarious work as a condition that is atypical and contingent, characterised by uncertainty, unpredictability of income streams, insecurity, vulnerability and lack of protection and regulation (Crompton, Gallie 
and Purcell 2002). Second, attention is paid to precarisation conceptualised as a major trend of the entire corpus of social relationships, now destructured by the diffusion of risk (Beck 1992), and on precariousness as "an experiential condition investing a person's life as a quality inherent to that person and his/her specific position" (Armano, Bove and Murgia 2017, p. 4). Focusing on academia, the aim is then to examine the increase of temporary jobs, but also how early career researchers experience precariousness in their everyday organisational lives, biographical contingencies and personal aspirations, and to explore the ambiguous and composite processes that underpin academic careers. Researchers, in fact, are required to be the work that they do, without distinction between work time and other times, between home and work. They must devote relational and emotional skills to production, and must equally be voluntarily and wholeheartedly committed to the fulfilment of their professional goals. In this scenario, on the one hand, early career researchers experience significant degrees of freedom, in which research is seen as a 'dream job'. On the other, they are confronted with strict rules of competition, combined with an 'extensification' and 'overflow' of work, finding themselves alone in dealing with uncertainty about the future. In order to understand how gender differences are embedded in these ambivalences, the growing phenomenon of precarisation in higher education needs to be further investigated.

This chapter will thus emphasise the relationship between gender inequality and precariousness in the world of research on three different levels of analysis, which are deeply interwoven. This will allow the reader to examine gender differences among early career researchers from different perspectives: first, from the point of view of the academic labour market, second from an organisational standpoint, and finally by looking at the experiential and subjective dimension. The conclusions will include a reflection on the policies and practices that can counter the reproduction of gender inequalities in the world of research which - for early career researchers - are tightly interwoven with current precarisation processes.

\section{Gendered careers in the academic labour market}

Higher education and research have to cope with the conflicting pressures embedded in long term trends in modern societies. University systems are undergoing a global process of change that affects the economic and social role played by higher education institutions, their organisation and inner structure (Maassen and Stensaker 2011; Reale and Primeri 2015), as well as the position of the academic profession (Machado-Taylor, Meira Soares and Teichler 2017). Such transformations are related to the phenomena of globalisation, the expansion of a knowledge society, the growing importance of education systems - which are taking on an increasingly central role - and the transformation and decline of the welfare systems and the renewed relevance of the 'market forces' in defining economic and social policies (Scott 2009). The increase in the number of people, especially women, who pursue a $\mathrm{PhD}$ and try for a career in the world of 
academia and research (European Commission 2016) is compounded by levels of competition generated by recent transformations in the academic labour market, in the management of higher education institutions, and in the regulation of academic careers. On one hand, a number of transformation processes involve all countries, such as the commodification of research activities, higher investments in the STEM field, the preponderance of applied scientific knowledge that fits the demands of the market, as well as the spread of diversification and specialisation processes related to academic work. On the other hand, the results of such trends and their effect on both early career stages and gender inequality in academia are mediated by how the previous institutional structures, the regulation of academic careers, the labour market(s), and the welfare and gender regimes act as a 'filter' for these global pressures (Marginson and van der Wende 2007; Enders and de Weert 2009; Le Feuvre 2015).

This section is thus dedicated to describing how the main macro and institutional trends affecting the regulation and management of higher education systems and institutions are in fact redefining the demand for academic work. Attention is also paid to the ways in which different scientific disciplines are appreciated and considered more or less prestigious in the process of knowledge production, division of labour and flexibilisation during the early stages of academic careers, thus affecting the conditions and factors fuelling and (re)producing gender asymmetries.

\section{The transformations of the demand for work between marketisation and growing competition}

National university systems in general, as well as academic institutions in isolation, are confronted by contexts of an increasingly competitive and globalised nature. On one hand, the establishment of a knowledge-based society has strengthened the role of academic institutions in the 'production' of highly specialised skills, which are necessary to face the challenges of such a knowledge-based economy (Marginson and Rhoades 2002). On the other hand, the increased availability of a highly educated workforce and the importance of scientific and technical knowledge have facilitated the generation of new market areas, where one can develop and endorse research and educational activities. Such new areas go beyond national, disciplinary and institutional borders, and challenge the leadership position held by higher education institutions in this field (Enders and Musselin 2008; Marginson 2011). In this very same context, the crises faced by welfare systems, along with cuts to public spending, have had various effects, including the reduction of public investment in the higher education sector (De Boer, Enders and Leisyte 2007). From the mid-1980s onwards, in fact, there has been a growth in the neoliberalisation and corporatisation of academia (Olssen and Peters 2005; Rhoades and Torres 2006). Academic policies and practices have become increasingly dependent on market forces and values, while higher education institutions have been progressively characterised by management models which fit the New Public Management principles 
(Kogan and Teichler 2007; Lynch 2014). Such principles are oriented towards productivity, performance and excellence - principally defined in terms of the number and quality of publications produced, levels of funding obtained by both public and private bodies, and by the number of graduates 'produced' by universities (Teelken 2012). On top of that, higher education institutions are being constantly evaluated, validated and controlled (Enders and de Weert 2009).

In the face of the growth in the number of $\mathrm{PhD}$ holders and researchers, academic institutions are experiencing a decrease in their capability to absorb this new workforce and a simultaneous increase in workforce casualisation affecting academic staff, which takes place in a context of spending cuts and cost rationalisation of academic and research work (Kogan and Teichler 2007). At the same time, there has also been an increase in the demand for research competences coming from non-academic institutions and from the private sector - although this dynamic is not homogeneous among different research fields and countries (Le Feuvre 2015). It is important to consider these alternative areas in order to better understand the position of $\mathrm{PhD}$ holders in national labour markets. Some countries, such as Germany, Switzerland and the UK, stand out for how well they can place $\mathrm{PhD}$ holders in qualified positions within the non-academic labour market (Science Europe Working Group on Research Careers 2016). The situation in other countries, on the contrary (such as Italy and Portugal), demonstrate how qualified job opportunities for their $\mathrm{PhD}$ holders are still to be found, all too frequently, exclusively in higher education institutions. In general, the availability of qualified positions in a non-academic context strengthens the position of those approaching an academic career, and therefore dictates that universities maintain competitive working conditions compared to those from other, nonacademic sectors, all in order to keep the most skilled people inside the world of academia. When working conditions available outside become better than the ones offered by a university, the latter becomes less attractive. This facilitates something akin to 'male-defection' with men leaving the academic world, resulting in a consequent increase in the number of women (Le Feuvre 2015). As a matter of fact, competition with non-academic fields is clearly marked by the type of discipline studied, and by gender. Non-academic research areas typically attract scientific, mathematical and engineering knowledge (Auriol, Misu and Freeman 2013) while the number of women in the private research sector is markedly low. The Innovation Union Competitiveness Report 2013 highlights that, despite the fact that 33 per cent of researchers in Europe are women, they make up just 20 per cent of researchers within industry.

The increase in competition within and between higher education systems, coupled with the marketisation of academic and research activities, have imposed the 'academic enterprise model'. This model affects how university rankings are developed, and has consequences for the type of knowledge produced, and the way knowledge is produced. Higher education institutions are exhibiting a declining interest in developing basic, discovery-oriented research, and thus focus more attention on applied research with more practical and market-oriented concerns, especially in the scientific, engineering and technological disciplinary 
sectors. This happens at the expense of the already scarce resources in the humanities and social sciences (Kogan and Teichler 2007; Scott 2009).

These dynamics are central in the definition of academic and scientific prestige criteria between higher education systems and institutions. In fact, the increased importance of STEM fields has led to the import of performance evaluation and scientific recognition practices, which are typical of this field, into the SSH field. Such criteria play a significant role in scientific competition on a global scale (Marginson and van der Wende 2007; Sadlak and Liu 2009), which is oriented towards the pursuit of an ideal 'world-class university' (Shin and Kehm 2013; Paradeise and Thoenig 2015) and towards the allocation of resources (scholarships, postdoctoral fellows, grants and awards) between fields of study (Blackmore 2015).

The internationalisation process concerning prestige and academic recognition is not, however, symmetrical across countries and different areas of the world. Indeed, it is influenced by a country's history, culture and language, and all these factors play different roles within their national academic systems. Although higher education institutions are pushed towards conforming to international standards in terms of performance, evaluation and international reputation, the situation in many countries reveals that their parameters regarding university and research evaluation are still rooted in specific national practices when it comes to how a career is structured and how academic institutions are financed. This tension between internationalisation and specific national features produces a fragmentation of the academic market and a disadvantage for nonEnglish speaking countries, where scientific knowledge is produced in a certain language, and where the practices concerning scientific recognition are not aligned with the ones that are widespread in natural, engineering and medical science fields (van Raan 2005; Marginson and van der Wende 2007).

Even though increased marketisation, levels of competition and standards are perceived as objective and neutral, the main transformations of the demand for academic work - and for non-academic research work, too - are driven forward by scientific, engineering and technological disciplinary sectors. This then, far from being neutral, fuels old gender inequalities in the jobs available in these sectors (Lynch 2010; O'Connor et al. 2015). The object of research, the way research is conducted, and the value assigned to a specific activity also expose how gender relationships, power and knowledge within the world of academia, and within society in general, actually work (Connell 2006). In this sense, the academic (and non-academic) labour markets offer more chances for development and better working conditions in male-dominated disciplinary sectors. A trend is consequently evident in the investment of resources, and in attracting scientific and technical competences that are more easily found among male PhD holders (O'Connor et al. 2015). This dynamic is facilitated by persistent gender horizontal segregation and female under-representation in the educational programmes available in the STEM fields (European Commission 2016; O'Connor, O'Hagan and Gray 2017). Where scientific recognition and the evaluation of excellence are increasingly focused on productivity, performance and 
entrepreneurship in the context of research, one can also see a gradual devaluation and subordination of SSH competences, compared with the ones that can be found in the STEM fields (European Commission 2012).

\section{Flexibilisation and fragmentation of academic work}

If the focus shifts to academic careers, empirical evidence reveals how such careers have never been as unstable and competitive as they are now (Kwiek and Antonowicz 2015). The early stages of a career - i.e. the phase between completing a $\mathrm{PhD}$ and obtaining a stable position in academia - are particularly delicate (LERU 2014; Science Europe Working Group on Research Careers 2016). Such a phase stands out for its increasing instability levels and the gradual exclusion of most early career researchers from the academic career system (Le Feuvre 2015).

The current transformation of academic work is fuelled by two central processes: diversification of academic activities, and specialisation of academic work, both of which are reshaping career trajectories and the division of labour within the academic profession (Enders and de Weert 2009).

In terms of 'diversification of academic activities and tasks', there now exists a much broader and more formalised variety of options compared to the situation in the past, when academic work could be divided into two main categories: teaching and research (Bourdieu 1988; Musselin 2007). Activities involving faculty members nowadays consist of writing proposals, developing contracts, designing teaching programmes, developing e-learning programmes or being engaged in technology transfers (Enders and Musselin 2008). When it comes to processes related to starting a career, being selected for some activity and advancing one's career, management competences (planning, managing and coordinating projects and research teams) have become just as relevant as indices certifying the scientific research profile of candidates. The range of requirements has thus become much broader in order to access permanent positions.

Alongside the diversification process of academic activities, we see another practice advancing, namely the process of "specialisation of academic work" (Musselin 2007), commonly manifested in the fragmentation of job positions related to specific tasks (either teaching, research or administrative tasks). This specialisation of academic work represents one of the vehicles used by academic institutions to manage costs. Such cost-cutting has been undertaken by assigning teaching and research activities from permanent staff to temporary staff, thus fulfilling the increased demand for such activities (Teichler and Höhle 2013; Blackmore 2015). These positions are regulated with non-standard contracts, either temporary or part-time, which generally tend to prove more unstable and less remunerated than open-ended positions.

Academic contract fragmentation has been facilitated by deregulation and flexibilisation processes, which in turn have exemplified national labour markets over the past few decades. This has led to a growing number of non-standard 
jobs across the board (Eichhorst and Marx 2015). Doherty and Chalsege (2014) show how many of the short-term research positions available in academia have no social security coverage (e.g. statutory/supplementary pension rights, healthcare, parental and unemployment benefits, and sabbatical leave). Such lack of security becomes particularly evident in those contexts where national welfare systems offer weak and residual support in the management of employment instability, and where little unemployment benefit is available. Such meagre benefits do not allow for effective management of transition periods when changing jobs, which proves to be the case in Southern European welfare systems. A typical, or rather, extreme, case is the Italian one, where the 'assegno di ricerca' - a form of contract used to manage the early stages of an academic career after completing a $\mathrm{PhD}$ - consists of a scholarship which does not permit access to the majority of social protection measures (Bozzon et al. 2017). In the long run, the prolonged use of such contracts leads to a limited accumulation of social rights. The most extreme cases concern people with a lack of accrual rates for those years of service when contributions were found to be irregular. Such a shortfall in contributions is often attributed to frequent job changes, periods without paid contracts, as well as to the difficulties met in transferring pension benefits, which have been accumulated in different countries. This often proves impossible, given how geographic mobility is a distinguishing feature of research careers (LERU 2014).

The ways in which both diversification processes on one hand, and specialisation of work on the other, are affecting and changing career trajectories of early career researchers, are mediated by national academic career models. This is possible due to both the availability of tenured positions, and of regulation, in terms of how one can access such positions (Musselin 2005). While they are all very different from each other, all academic career tracks share one typical feature: an early stage (which can be of varying length) based on temporary research positions and short-term teaching duties. During this time, one can improve one's professional and scientific profile (publications in accredited journals, access to research funds, national and international research networks, teaching experiences) in order to be able to compete for a permanent position. In most cases, open-ended contracts lie at the top of the academic ladder, between full and associate professors, and can therefore be accessed only after a long time spent strengthening one's scientific career track from one job position to another. In some contexts, such as in France and Italy, obtaining the first stable position is related to a national accreditation system, a formal procedure certifying the preparation of the aspiring academics, which can be obtained after pursuing a $\mathrm{PhD}$ (Lissoni et al. 2011; Marini and Meschitti 2018). In other cases, such as Germany, the Netherlands, Switzerland and Belgium, the career models are dictated by time limits (academic or biological age), both formal and informal, by which one needs to reach certain goals. Not reaching certain achievements 'in time' entails being excluded from the competition for a permanent position. There are also other situations, such as the US and in the UK where obtaining a tenure-track position is a relatively quick matter, although 


\section{Rossella Bozzon et al.}

building a research-oriented academic path is often reserved for a limited number of early career researchers, due to the high number of teaching-only positions.

The key point is that, regardless of the career model, the number of researchoriented permanent positions is dropping, while the number of requirements which are becoming more formalised - is increasing. In addition, access times are growing ever longer, while competition is becoming ever more ruthless, all with uncertain results. Therefore, most $\mathrm{PhD}$ holders approaching an academic career will still have to resort to alternative career options, regardless of the quality of the scientific and professional profile they have achieved in the meantime (Peterson et al. 2012).

Although the information available on academic careers often does not allow for adequate monitoring of academic temporary positions, since they are characterised by high instability and mobility as well as by a high level of heterogeneity across academic systems (Bozzon 2015), the data available reveals that PhD holders approaching an academic career are exposed to the tangible risk of being trapped between temporary research or teaching appointments (LERU 2014). In most cases, the chance to fulfil one's career aspirations by obtaining a permanent position materialises only after a long time, by which time it becomes difficult to change track. The parameters regarding academic recognition are biased towards academia and are thus not recognised in other sectors. The longer one remains in this situation, the higher the risk of being excluded and forced to accept underqualified positions that do not match the interests and knowledge developed in one's professional and scientific path (Neumann and Tan 2011; Wei, Levin and Sabik 2012), either inside or outside the higher education sector.

\section{Gendered consequences of the transformation of academic careers}

The dynamics that lie at the heart of the precarisation process of academic careers are, typically, those of tough competition, as well as multiplication of tasks and competences, all combined with the fragmentation of employment contracts. Developing a scientific and professional profile - one that is competitive whilst meeting the standards to access a permanent position - is made more complicated by the instability of the conditions of the job offered in the early stages of career. In order to avoid interruptions in their career track, early career researchers need to deal with frequent mobility between jobs (between different institutions and countries). Additionally, they are not well-paid, and are granted little social protection by those short-term positions available. They also need - unless they are supported by their partners or families - to reconcile more than one contract and activity with different tasks and projects, in order to ensure a sufficient income whilst at the same time developing a full academic curriculum. Furthermore, they are constantly exposed to evaluation and performance control processes (Le Feuvre 2015). The combination of these conditions has several gender implications (Cruz-Castro and Sanz-Menendez 2010; Goastellec and Pekari 2013; Blackmore 2015). 
First of all, the academic research positions, teaching jobs and administrative tasks available are not equally accessible to male and female $\mathrm{PhD}$ holders. On one hand, this is due to the fact that, as previously described, male-dominated research fields occupy a better position in the global research market and are better paid (Canal-Dominguez and Wall 2014), and female early career researchers struggle more than their male colleagues to obtain funding for their postdoctoral research (European Commission 2016). On the other hand, this is also because - as will be described later - there are now new forms of the division of labour, which are based on traditional gender orders and which lead women to more frequently find a job in a less prestigious position when it comes to academic selection procedures and scientific accreditation, such as in the case of administrative and teaching positions (Auriol, Misu and Freeman 2013; Thornton 2014).

Contract specialisation and work segmentation therefore lead to the collection of different titles and competences depending on gender, thus influencing actual career chances, career tracks inside and outside academia, as well as the way early career researchers can be 'trapped' in temporary positions. Furthermore, the excessively heavy workload characterising the early stages of a career, combined with the long waiting time before finally obtaining a stable position, together with the instability and uncertainty of results (Ackers and Oliver 2007; Teichler and Höhle 2013) all push women (more frequently than men) to seek their professional fulfilment in a job which is seen as 'easier to control' and less invasive of the private sphere. Such is the case in administrative activities or other tasks supporting research (Blackmore 2015), or even of other job positions outside the world of academia and research (Bozzon, Murgia and Villa 2017).

Moreover, high workloads and high expectations in the early stages of an academic career exacerbate existing incompatibilities between work and life. The interferences between career and private life are felt especially by those experiencing more unstable conditions, with more mobility and reduced career prospects (Lind 2008; Bozzon et al. 2017). Such situations are generally experienced by women (Ackers 2008; Leemann 2010). In addition, the pressures typical of academic careers in their early stages do not come alone: they often occur at that age when one is possibly starting to think of planning a family (Ward and Wolf-Wendel 2004; Nikunen 2012).

Several researchers have demonstrated how such problems, which arise during the early stages of academic careers, affect men and women differently, and that women are at a disadvantage when it comes to career advancement (Palomba and Menniti 2001; Blackwell and Glover 2008). For example, having children is still an obstacle to obtaining a stable position in academia for women, regardless of their scientific profile. It has been estimated that, ceteris paribus all other things being equal - men who have children within five years after completing their $\mathrm{PhD}$ have a 38 per cent greater chance than their female colleagues who have had children over the same period of achieving a permanent academic position (Puljak and Sharif 2009). Furthermore, those women who acquire a permanent position are more frequently single and without children 
compared with their male peers (Palomba and Menniti 2001; Mason and Goulden 2002). This does not mean, however, that women who do not have children have the same career chances as their male colleagues (Palomba 2008).

Academic and research careers, therefore, generally continue to be shaped by traditional gender models, which are binding for female researchers, and this happens more frequently to them than to their male colleagues (O'Connor et al. 2015). It is no coincidence that when considering a job offer, female researchers seem to pay more attention than male researchers to possible gender equity policies and work-family balance services, such as the recognition of maternity and parental leave in the computation of their 'academic age' during selection procedures, as well as when research resources are appointed (Janger and Nowotny 2013). It has been observed that welfare systems and gender regimes that are more inclusive of women in the (academic) labour market prove not to be robust enough to counter gender asymmetries present in academia (Le Feuvre 2009, 2015; Solera and Musumeci 2017). However, the availability of policies to reconcile work and private lives, as well as having to handle the pressures that working and geographic mobility entails, can in fact make a difference in giving direction to career strategies and retain women (and men as well) within the world of academia and research (Tzanakou 2017).

Ultimately, it is necessary to emphasise how gender inequalities in academia and research cannot be analysed only by looking at the transformations occurring within institutional frameworks, market structures and academic employment. Indeed, one needs to include other factors and dynamics which are active on other levels of analysis, both meso and micro. The first step requires shifting the focus of the analysis to organisational and cultural factors and, in particular, to organisational and gendered practices that are typical of contemporary higher education institutions and that outline selection procedures, academic accreditation and recognition (Poggio 2017).

\section{Gendered organisational culture in higher education institutions}

The presence of gender inequalities in scientific organisations is nothing new. The world of academia and research has long been characterised by a view of career, and of intellectual work, modelled on both male traits and life trajectories (Keller 1985; Izraely and Adler 1994). Even though the establishment of neoliberal models often comes with a declaration of adherence to the principles of diversity management and gender mainstreaming (Schunter-Kleemann and Plehwe 2006; Ferree and Zippel 2015), gender inequality is actually no less a typical feature of the new organisational models than it used to be of the old ones.

Although the rise of a management culture oriented towards meritocracy and accountability has been welcomed by some as an opportunity to overcome an academic system designed around a male-dominated community, others have emphasised how its organisational practices and processes are, de facto, strongly 
gendered (Deem 1998; Currie, Harris and Thiele 2000), to the point where they have "restored the gender order that was beginning to be challenged by feminist academic work" (Morley 2018, p. 34). These implications appear particularly cogent for the researchers who are in the early stages of their scientific career, due to the greater pressure they are under to conform their professional life and projects to the bounds and expectations defined by the organisations.

In this section, the focus will be, above all, on organisational practices that are typical of contemporary higher education institutions, and on their gender implications. Paying attention to these practices allows us to shed some light on how gender is rooted and reproduced in daily organisational activities and on how it can contribute to the construction of specific organisational cultures (Poggio 2006) and shape an ideal image of the early career researcher.

\section{Organisational changes and the ideal academic image}

The affirmation of the neoliberal agenda in the scientific world has led to significant consequences on the processes and practices at work in academic and research organisations. The new trend has led to the adoption of managerial methods typical of the private and for-profit sector, with a growing emphasis on managerialism and entrepreneurship to the detriment of independence and collegiality of researchers. Universities and research centres are increasingly becoming 'greedy institutions': they require more and more undivided loyalty, high productivity and emotional engagement of their members. This has resulted in an increase in the pace of work, together with the establishment of an even more prevalent 'long hours culture' (Currie, Harris and Thiele 2012).

The setting of rigorous and binding standards for such activities considered to be priorities - such as high-ranking publications, assessment procedures and fundraising - has led to several changes in how time-management procedures are implemented within academic work and research (Ylijoki and Mäntylä 2003). The request for ever-growing involvement in academic work, both in terms of productivity and of accounting, consequently translates into work intensification and demands on time. This seemingly brings academic endeavours closer and closer to other types of 'extreme work' (Gascoigne, Parry and Buchanan 2015). Research activity becomes increasingly 'boundaryless', not defined by specific working hours, but rather by the necessity to finish the job, regardless of whether the job consists of writing an article, assessing student essays or designing project proposals. In order to underline the growing trend towards productivity, in the mid-1990s Parker and Jary (1995) coined the eloquent term "McUniversity", which highlights the increasing pressure from higher education institutions on academics, who have to produce more and more quickly.

The trend is shifting, as observed by Benschop and Brouns, from a model of science viewed as Agorà - where the social dimension of scholarship plays the main role - to an Olympic model, built around the figure of the researcher as a "a young man in solitude high on top of the Olympus, distanced from all everyday practices" (Benschop and Brouns 2003, p. 207). It is no accident that 
the discourse of 'excellence' is the predominant mantra of the New Public Management paradigm. Excellence is not only the crucial target in the competition between universities, but also the key category through which performances are measured in scientific organisations and staff are selected.

With the establishment of this new paradigm, the recruitment criteria that had been previously adopted in a more informal way by the academic and research community have now been translated and operationalised into measurable performance standards. These criteria have subsequently been used to define career paths and access research funding. The explicit goal is to reward excellence, stimulating competition and endorsing the outstanding scholars (citius, altius, fortius, as the old Latin Olympic motto). However, the transition from informal procedures to standards of excellence does not appear to have reduced the level of discretion and opacity of the recruitment processes. In fact, the concept of excellence presents a fuzzy and composite nature, as it is based on a plurality of dimensions ranging from scientific impact, to level of internationalisation, networking ability, originality and so forth (Addis 2010), whose combination usually is not clearly and transparently defined. Therefore, excellence can be conceptualised as a social construction, subject to different kinds of biases, related to power dynamics and homosocial practices (Morley 2003).

The organisational changes taking place within academic and research institutions inevitably contribute to reconfiguring the image of the "ideal worker" (Acker 1990), or better yet, of the "ideal academic" (Lund 2015). This impact is particularly meaningful for those who have chosen to embark on an academic career path. Indeed, early career researchers typically suffer from a greater pressure to conform to the dominant models, which have been set as the standards in the recruitment process, and which also occurs due to how uncertain and vulnerable their position is.

A first requirement from higher education institutions comes in the shape of a researcher who is completely focused on task and devoted to work, who prioritises academic achievements over all other aspects of life, and who is able to show "a single-mindedness and an unswerving commitment" (Bazeley et al. 1996, p. 27). At the same time, early career researchers are required to build a unidimensional and linear career path (European Commission 2012; Cech and Blair-Loy 2014). With selection procedures based on principles of excellence, the ability to obtain results in the shortest amount of time is highly valued. To be an outstanding researcher, it is therefore important to present a linear and focused career track, with no blank spaces. Interruptions, deviations and pauses are seen as problematic markers, and consequently are viewed as a penalty.

Moreover, increasing competition places greater demand on early career researchers, who are expected to be hyper-productive, in a context of constant antagonism based on the principle of the 'survival of the fittest' (Davies and Bansel 2005). In particular, they are required to focus on fundraising, taking part in calls for tender at different levels, in order to fund their own research activities, but mostly on publications, usually considered to be the primary element in relation to the definition of excellence (Weisshaar 2017). The well-known 
expression 'publish or perish' effectively demonstrates the obsessive demand on academic staff to invest their own time and energy in publishing articles, which becomes a priority, despite the high teaching and administrative workload.

Further important requirements for the 'ideal early career researcher' are scientific networking and internationalisation (Baruch and Hall 2004; Leeman 2010). Contacts and collaborations in the scientific community, closeness to key scholars, and membership of editorial boards, on the one hand, and professional experiences abroad, participation in international scientific networks and committees, involvement in transnational projects, attraction of international funds, on the other, are criteria increasingly relevant in recruitment and evaluation procedures.

Other factors can contribute to defining the qualities of 'ideal early career researchers'. However, they tend to be more influenced by different national frameworks, institutional settings and disciplinary cultures, as in the case of teaching (Matthews, Lodge and Bosanquet 2014). In some systems, teaching experience is included under the criteria related to rewards, while in others it is less recognised. Where it is less valued (and therefore more invisible and less remunerated), it is more likely associated with precarious conditions (Kantola 2008; May, Peetz and Strachan 2013).

\section{Gendered consequences of neoliberal organisational practices}

The organisational changes previously discussed, and the profile of researcher modelled by them are not gender neutral, but appear to have different implications for women and men. The passage from the paternalistic model to the management paradigm has led to a shift in perspective, although the hegemony of masculinity has not changed. There has been a shift from paternalistic masculinity to competitive masculinity, based this time on proving one's competence and on the desire to stand out and well above the others (Kerfoot and Knights 1993).

The idea of science based on an ideal of heroic and complete devotion to science, as well as the assumed linearity of a scientific career path, are both gendered constructions. Some research has shown how female careers, especially at the beginning, are more fragmented (Todd and Bird 2000; Mason, Wolfinger and Goulden 2013), due to the intersections with other biographical trajectories and to different cultural expectations regarding women (Williams 2005). Viewing academic work as something all-encompassing and exclusive (Ward 2000; Ackers and Gill 2005) and a career as a linear path with no interruptions, has some inevitable consequences in terms of work-life balance (Ecklund, Lincoln and Tansey 2012). As long as an asymmetric division of labour in terms of gender in society still remains, the ethic of boundless work - increasingly present in organisations - does not in fact affect men and women in the same way: such a dynamic penalises women more than men or, in any case, it discourages changes oriented towards men participating more in their family life (Currie, Harris and Thiele 2000).

Adopting family-friendly policies and work-life balance programmes within organisations is often seen as the primary way to solve the problem. However, 
such policies, which are often designed as measures and special accommodations only for women caregivers, are not the most effective solution; on the contrary, they run the risk of being counterproductive, contributing to the reproduction of that gendered structure which encourages the long hours culture (Kossek, Lewis and Hammer 2010). On one hand, this limits more flexible working practices as far as maternity-related issues are concerned, whilst on the other often marginalising those who take advantage of such programmes (Williams, Blair-Loy and Berdahl 2013).

Moreover, new lines or gender divisions of labour are rising within academic and research institutions as a consequence of the new dominant organisational frame. Indeed, as both evaluation and merit-based processes have shifted their focus progressively towards criteria such as productivity, performance and entrepreneurship, other important parts of the academic world, such as teaching, administrative activities and other time-consuming tasks have become more feminised, while receiving at the same time less recognition (Thornton 2014). Male and female academics do not find themselves in the same position when it comes to choosing which activities they should focus on: women are more frequently involved in what is termed as "academic housework" (Heijstra, Steinthorsdóttir and Einarsdóttir 2017). Several research studies have underlined how women are more commonly found in teaching roles and/or in support roles for colleagues and students. They are also more likely to take on a heavier administrative workload, while having less time to devote to research and publications (Lynch 2010; Misra, Lundquist and Templer 2012). This division of labour also includes the so-called role of "mothers of the department" (Kantola 2008), meant to create a warmer and more comfortable environment, which also includes organising social events. While these activities are undoubtedly important and crucial in guaranteeing smooth daily management and student well-being, they do however turn out to be marginal and not particularly recognised when it comes to career advancement.

Gender asymmetries in academic and research organisations are also exacerbated by the establishment of the excellence discourse. Although the concept of excellence is apparently neutral, and often referenced just to underline the neutrality of the recruitment and career process, the excellence framework, in particular the micro-practices which in fact implement it, supports and reproduces inequalities based on gender (Addis 2010; Van den Brink and Benschop 2012a), whilst also on ethnicity and class (Özbilgin 2009). In fact, the evaluation standards used to measure excellence apply differently to men and women. This is the case, for example, in how various methods are used to assess CVs and applications during the recruitment processes (Foschi 2006), in how letters of recommendations are formulated (Madera, Hebl and Martin 2009), and how gender inequality practices in recruitment and selection procedures render gender equality practices ineffective, thus undermining sustainable change (Van den Brink and Benschop 2012b). Several studies have underlined, for example, how the bounded transparency and the limited accountability used to measure excellence in academic recruitment processes and selection procedures often 
tend to work against gender equality (Van den Brink, Benschop and Jansen 2010). The formal rules and protocols used to define recruitment procedures are often overshadowed by micro-politics and gender practices reproducing traditional gender models and expectations.

Even considering separately the different dimensions that contribute to defining the construct of excellence, we can highlight the presence of gender biases. This is the case, for example, of publications. There exists an extensive body of literature on the gender gap in scientific publications: it demonstrates that women publish less, participate less in collaborations leading to publications, and are less likely to be first (or last) author. Moreover, the articles with women in key author positions are less cited (Lariviere et al. 2013), and recent research shows that women are also underrepresented in the journals with the highest impact factor and receive fewer citations (Shen 2013). These disparities in turn give rise to gender asymmetries in the opportunities to get grants and to advance up the academic ladder.

As seen above, other crucial factors in defining excellence can be found in participation in formal and informal networks (Bagilhole and Goode 2001; Van den Brink and Benschop 2012a) and in the degree of internationalisation (Morano-Foadi 2005; Ackers 2008). The networking practices (informal relations and interactions) with the 'gatekeepers', that is, those academics in key positions, seem to be particularly relevant. It is through them that the academic élite can make it easier or harder for someone to obtain a top position from the recruitment process, and thus actively contributes to the definition of what is excellent and what is not. Van den Brink and Benschop (2014) have highlighted how gatekeepers, the majority of whom are men, tend to mobilise masculinities, often without being aware of it. It has also been noted how women tend to be excluded from information and informal channels more often than their male peers, and that they are often the victims of exclusion and isolation dynamics. This leads to them having more limited networks, which are less diversified and supportive compared with men's (Etzkowitz, Kemelgor and Uzzi 2000).

The value of networking is in direct proportion to how international it is, especially with its involvement in English-speaking communities. International mobility is a necessary requirement for building a career within neoliberal higher education institutions (Morano-Foadi 2005). Once again, these standards put women at a disadvantage. Data shows in fact that they are less involved in international collaboration and in international publications, and are less likely to have access to funds able to support their mobility (Padilla-González et al. 2011; Vabø et al. 2014). Gendered practices persist in the system of evaluating, rewarding and valuing international collaborations that run the risk of turning into obstacles (or glass fences) mainly for women: having international experience is not a marker of excellence by itself if the network in question does not belong to that one circle defined as relevant by the gatekeepers (Zippel 2018). Moreover, women are less involved in the so-called 'old-boys networks', and considered less attractive in terms of prestige. Additionally, it is far more difficult to strike the right balance between international mobility and family 
commitments. Last but not least, male partners are less inclined towards moving to another city or town to support their woman partner's career as a researcher (Rusconi and Solga 2007).

Finally, it is worth noticing how often gender still plays a role in how other activities are valued in defining the profile of an 'ideal early career researcher'. An example emerges from teaching, an activity - as mentioned above - that is valued differently in various national and institutional frameworks. It is possible to observe that where teaching is included under the rewarded criteria, men are more likely to teach. Such is the case in research conducted by Kantola (2008) among several $\mathrm{PhD}$ students in a Political Science department in Finland, where it was noticed that men are more encouraged to teach as soon as they complete their PhD. Thereby they develop a greater sense of belonging to their department and to the scientific community, thus obtaining more visibility and prestige. Moreover, this allow them to be more financially independent, which is important in order to continue their academic career and to be able to apply for research funding and other positions. The situation is different in Italy, where teaching in the early stages of one's career turns out to be less valued and remunerated, if not invisible. Such is the case in informal substitutions of tenured professors. The fact that these activities are considered less prestigious and sometimes even invisible leads to a different outcome. In this case, the field is not so male-dominated - in fact quite the contrary (Bozzon et al. 2017). The situation is similar in those contexts where teaching is associated with casual, part-time and fixed term positions (May, Peetz and Strachan 2013).

The dynamics described above demonstrate how the establishment of a neoliberal agenda has had a significant influence on the ways in which practices and organisational processes have been redefined. This has subsequently generated situations in which traditional gender inequalities, which have always been typical of the world of academia, have far from disappeared. On the contrary, they have only grown stronger. In the next section we will turn our attention to the consequences of macro and organisational changes on experiential and subjective level, highlighting again the presence of significant gender implications.

\section{Gendered constructions of subjectivity in the neoliberal research system}

The literature concerning identity construction and the subjectivity produced by neoliberal academia constitutes the third level of analysis. In fact, the growth of neoliberalism has not simply affected academic systems and the organisational cultures dominating contemporary universities. The effects of such neoliberal reforms of academic labour have been so pervasive that they have also spread to the identity construction process and, in addition, to transformations of subjectivity. The creation of a subject has become increasingly characterised by the modern individualisation process (Beck 1992), which on one hand has enabled the greater personalisation and enrichment of work, but on the other has also 
produced phenomena of work intensification and self-exploitation (Gherardi and Murgia 2012). In the academic field, this ambivalence exposes subjects to the risk of, on the one hand, internalising the strongly gendered, racialised and classed ideology of merit and excellence without giving it any critical thought. On the other hand, there is also the risk of living with a feeling of guilt and failure when one is unable to meet the standards set by the evaluation system (Gill 2009).

The theoretical perspective focused on subjectivity consequently aims to shift the attention to the creation of subjects that neoliberalism would like to produce, namely academics who adhere to entrepreneurial standards and competitionbased logics and who are willing to accept relatively low wages. Such subjects generally show a reserved attitude towards conflict and are willing to have their academic performance and loyalty tested by a set of technological devices. In terms of empirical research, attention is paid to how the identity construction process is changing and to the experiences of academic workers subsumed within such a system (Davies and Petersen 2005; Archer 2008).

As previously discussed, the research system has not been left untouched by the introduction of logics based on new managerialism and New Public Management, and of governance models based on the belief that running the research world like a business can improve quality and efficiency, whatever this means (Willmott 1995; Shore and Wright 2000). The interiorisation of these logics, together with the rhetoric of the 'passionate researcher' - which have long been the rule in contemporary academia - has its effects: working practices which are in fact the result of structural, cultural and gender constraints appear as individual choices when they are actually not (Gascoigne, Parry and Buchanan 2015). This is how women themselves, especially in those fields of studies where they are most underrepresented, sometimes end up embracing an aggressive and competitive academic culture, where men and women both conform to the dominant gender model and to the hegemonic masculine discourse (Goode and Bagilhole 1998). And it is according to this type of culture that personal identity is constructed in higher education institutions, shaped as it is by the available discourse within occupational and organisational contexts. Du Gay (1996), who was among the first to discuss the rise of the "enterprise culture" that has permeated contemporary society, defined the introduction of the New Public Management as an "identity project", therefore exposing how deeply the transformations of the governance model have affected the status and self-identity of the academic profession (Thomas and Davies 2002).

Several studies have focused on how academic subjectivities are created, governed, embodied and performed in contemporary academia (Parker and Jary 1995; Barry, Chandler and Clark 2001; Thomas and Davies 2002; Clarke and Knights 2015). More recently, however, a more specific debate on the experiences of early career researchers has developed (Archer 2008; Laudel and Gläser 2008; Bristow, Robinson and Ratle 2017) and in particular on the emotional and affective demands and contradictions that non-tenured researchers face (Norkus, Besio and Baur 2016; Thorkelson 2016; Morgan and Wood 2017). In addition, 


\section{Rossella Bozzon et al.}

attention has been paid to how such a precarious situation exacerbates gender differences among researchers (Nikunen 2012; Bozzon, Murgia and Villa 2017; Thwaites and Pressland 2017).

\section{Experiencing precariousness}

Uncertainty, insecurity and stress are currently a transversal experience in the academic and research world (Knights and Clarke 2014; Clarke and Knights 2015). However, one cannot compare the pressure experienced by a person holding a permanent position with that felt by someone with an employment contract for only a few months and with no future prospects. Furthermore, one of the reasons which has led to deteriorating wages and working conditions of nontenured researchers is related to the complicity between tenured staff, university managers and the reforms implemented on a global scale over the last decades (Gill 2009; Morgan and Wood 2017). To quote Rosalind Gill (2010, p. 232):

Precariousness is one of the defining experiences of contemporary academic life in particular, but not exclusively for younger or 'career early' staff (a designation that can now extend for one's entire 'career', given the few opportunities for development or secure employment).

As previously described at the beginning of this chapter, the research sector has also been affected by austerity policies and the reduction of stable positions. Indeed, over the decades, such policies have led to a rapid increase in the number of researchers with temporary contracts, among whom are also PhD students, research assistants, postdoctoral researchers and adjunct lecturers (Ylijoki 2010; Gallas 2018). While there are still some relevant differences between countries and disciplinary sectors, the chance of obtaining a tenured position in a university, and in the world of research in general, has been dramatically reduced something $\mathrm{PhD}$ students commencing their programmes likely already know.

In a system with so few resources, what is it then that motivates those who have obtained a $\mathrm{PhD}$ to try their chances in finding a career in the world of academia? And what are the subjective features which are typical of the precarious researchers' experience? To analyse how subjectivities of precarious researchers are constructed in the neoliberal research system means to consider the process of making people precarious as a mode of subjectivation. In this perspective, after having discussed how precarity is particularly evident in temporary, discontinuous, and uncertain employment settings, in this section attention is not only paid to 'employment precarity', but to the broader experience of 'precariousness', a term which better describes an experiential state that permeates the entire lives of individuals (Armano and Murgia 2013). Precariousness has once again become a significant dimension of the individual's experience, but its phenomenology has changed and now presents some unique features that require new interpretative approaches. In particular, the precarisation processes witnessed over the past few years do not interact neutrally with regard to gender. 
On the contrary, they in turn reproduce old gender asymmetries and generate new ones. As described in the previous sections, this becomes particularly evident if one considers precariousness in academia, where the establishment of fragmented and discontinuous working models, all with the lack of an appropriate social protection, seems to have different consequences, or better yet, consequences which differ in a critical way for men and women. Such consequences do not simply affect the professional world, but rather a variety of different social environments, which range from personal and family choices and relationships to geographic mobility and eventually to the scientific legitimation of one's work within one's own research network.

Moving attention to the formation of subjectivity, the experience of precariousness in the research sector is comparable in many respects to that of knowledge and creative workers (Gill 2009). Indeed, not only does a person with an unstable job need to be able to manage that particular temporary position, but also needs to be continuously on the lookout for the next one, all on their own. The dynamics at play are such that early career researchers find themselves entangled in ambiguous processes, which on one hand offer great satisfaction, while on the other expose them to constant risk. Their individual performance needs to be valued and appreciated, their identity lies very strongly in their activity as researchers and their hope in future rewards for their past efforts. Precarious academic subjectivities are then shaped in a setting made up of ambivalent dynamics. That is to say, being able to enjoy great flexibility while having to act from an entrepreneurial perspective, doing a job which is in some ways represented as some sort of a calling, but which in other ways traps them in an invisible web of subordination. Last but not least, there is the promise of future employment used as emotional blackmail, for which one is even willing to accept invisible and unpaid assignments.

\section{Between success and failure}

In the neoliberal university, subjectivity is constructed on the basis of a number of expectations that emerge from multiple sides: the scientific community, the organisation one is working for, and one's colleagues. The establishment of the so-called "culture of managerialism" (Deem 2009) has led higher education institutions to introduce a series of performance indicators and standards that set the bar for researchers (Parker and Jary 1995; Barry, Berg and Chandler 2006), together with a number of technologies aimed at measuring every aspect of academic activity, from publications to teaching, from citations to fundraising, from participation in editorial boards to public engagement.

The evaluation systems claim therefore to be neutral in applying the same standards to everyone, merely because they are based on measurable data, as if everyone were in the same situation and had the same opportunities. The result is that subjects are classified in a 'productivity ranking', which places them in academic hierarchies (Coin 2017) often based on logics that are not always transparent, especially for those at the bottom of the ladder. 


\section{Rossella Bozzon et al.}

In response to the dominance of these academic rankings, researchers are trying to conform to such evaluation criteria and to reach good performance levels, together with non-tenured ones, who are under even greater pressure. Some of them do it out of ambition, to stand out and to be seen as 'successful researchers', thus uncritically embracing the dynamic of peer competition. Others do it, not because they share its principles, but simply trying not to be expelled from the system or out of fear of being downgraded, of having their research time taken away from them or because they are afraid that their contract may not be renewed.

Even though early career researchers occupy a variety of nuanced and multiple positions in relation to the current academic evaluation systems, such researchers struggle to call these systems into question, in particular because of how vulnerable they are. Not all researchers belong to that one group of subjects who 'show off how hard they work', up to the point where they almost boast about how they spend their weekends sitting at the computer and about how they always carry their laptop with them, even on holiday. There are also those who try to escape the 'Busy Olympics', who will answer their e-mails politely, regardless of the sender, who will have a coffee with their colleagues simply to exchange a few thoughts, who will dedicate the appropriate time to their students, trying to support them in their journey, and who will write articles which may not end up in the top journals, but maybe in some small independent ones. However, the price for avoiding the competitive model and for embracing a different, more cooperative research culture is often high, and it is a price that must be paid individually. For those early career researchers trying to create for themselves an academic career, the attempt to simultaneously reject this evaluation system often leads to them experiencing a 'self-multiplication'. On one side there is the project proposal, the top journal article and the lessons planned with colourful slides full of pictures, whilst on the other the reading group, the feedback sent to colleagues, and the participation in non-academic public events. In other words, the cooperative approach is indeed able to survive in the world of neoliberal academia, but this does not mean that it actually manages to call into question the current ideal of excellence, which - as various researchers have illustrated (Özbilgin 2009; Van den Brink and Benschop 2012) - reproduces the hegemonic structures of inequality based on gender, race, and class.

Within the academic context, it is especially those in more marginal positions who experience a number of difficulties attaining the required 'quality standards'. This makes it even more difficult to challenge the criteria of such an evaluation system, especially because it is the subjects themselves who come to question their own scientific capabilities, because they are afraid of not 'being' successful researchers and of putting their own reputation on the line. This is the mechanism that Rosalind Gill (2010) described as "toxic shame": everyone knows that getting their article published largely depends on the reviewers who will read it, and that grants usually have such low acceptance rates that obtaining one can often be compared to winning the lottery. And yet, those with no funded application or whose paper has not been accepted for publication are not simply 
putting their very own reputation on the line, but also run the risk of being isolated by their colleagues, which is why they rarely share the bad news - such as the rejection of an article or the lack of funding for a project - out of fear of ruining their image as 'successful researchers'.

As in the case of excellence, the feeling of inadequacy and internalised guilt appears to be deeply gender related. As a matter of fact, the perception of failure after seeing an article rejected or finding out they have not obtained a certain grant is not the same for every subject. In the world of academia, upper-class, male, heterosexual and white researchers from highly ranked universities are less exposed to internalising the rhetoric of failure. The feeling of inadequacy often comes from those who do not belong to the main academic networks, in particular women, migrants and people with a temporary or part-time position.

\section{Between passion and overwork}

A number of scholars have discussed how 'passion', especially in creative and knowledge work, has become a dispositive of self-exploitation and neoliberal government (Armano and Murgia 2013; Busso and Rivetti 2014). Also in the academic world, more and more often workers are asked to become the job they do and to be able to put on the line their creative and interpersonal competences. As a consequence, the evaluation focus will not only be on specific skills and abilities, but will go even deeper, namely in examining their subjectivities and lives in general. As Gramsci has already suggested (1971), within this framework one can view work as a somewhat impossible contradiction: on one hand, work encompasses a person's human side, but on the other the very same person can only find their own fulfilment - both as a social and as a political animal only once they are free from that very same work which makes them human.

In order to understand how researchers' subjectivity is shaped, one therefore needs to fully grasp the structural ambivalence of this type of work, which does not allow for any form of detachment from the researchers' own product, thus capturing their efforts that occur beyond their employment workload and formal requirements (Fleming 2012), which is why it is so hard to escape the abovementioned logic of self-exploitation. In this sense, passion is presented as an experience loaded with tension and inner conflicts. After all, as Gherardi, Nicolini and Strati remind us (2007, p. 320):

The term 'passion' does not denote some univocal and easily definable phenomenon. Rather, it is a polysemous term, able in certain respects, to comprise meanings that may even be contradictory: for instance the simultaneous feeling of pleasure and pain.

The experience of early career researchers serves as a typical case of when love for one's own work, involvement and emotional investment becomes deeply intertwined and ensnared with the bounds of an imposed and excessively heavy workload. This mechanism is described as the springing of the "trap of passion" 
(Armano and Murgia 2013): such a trap means that the academic system does not need to impose exclusive and unconditional loyalty to their researchers, because it is the subjects themselves who offer such loyalty spontaneously. And it is exactly this spontaneity which makes this type of subjectivation so particularly insidious and hard to see (Davies and Petersen 2005).

There are many different reasons why a non-tenured researcher may identify with their work and be so strongly invested in academia, even though they know that they have so very few chances to obtain a tenured position. Moreover, different reasons can be found on the same subject (Busso and Rivetti 2014). One of the first types of passion can be described as the act of doing research: investigating, making new discoveries, spending time in a laboratory, doing fieldwork or working in an archive of ancient texts. A second reason refers to the social dimension of research and how this can play a role in the improvement of society, such as finding a cure for a previously incurable disease or planning policies that will improve citizens' living standards. The last type of passion is usually described as 'interpersonal and organisational': in this case the researcher reports to the department they work in, to their research group or to their mentor, typically their own supervisor. Granovetter had to admit, back in the early 1980s, that academia was an exception to his strength of weak ties theory, specifically because of the particular relationship between a mentor and their student. According to him, academic bounds were so strongly relied upon due to "a situation of considerable insecurity for new PhDs who have few useful contacts in their discipline as yet and typically rely on mentors and dissertation advisers who know them and their work well" (Granovetter 1983, p. 211).

The reasons that lie behind passion for one's own work may differ and overlap to various degrees, but - regardless of the object of such passions or of the type of discourse supporting the choice of an academic career - what makes this involvement so ambivalent has to do with the thin line between professional activity and pleasure, between freedom and work. Working times have been growing exceedingly longer, and this phenomenon shows a peculiar relationship with the precarisation of the researchers' paths. This is not however something experienced only by those with a temporary job and a contract with an all-too close deadline. Several studies illustrate how people in the academic world carry out unpaid overtime, and work in the evenings and at the weekends in order to meet the imposed standards. Yet, the reason they do so may also be (and maybe that is indeed the main reason) because they consider their work to be a 'labour of love' (Gill 2009; Clarke, Knights and Jarvis 2012).

This type of activity stretches into and pervades everything. On one hand, work is a source of satisfaction and identity development, but on the other it leads to endless toil (sometimes with no pay at all). It is a two-sided coin, which seems to be an intrinsic feature of the academic world. However, different subjects report different experiences. The overlap between life and work shrinks the spaces outside the academic activities, whether they are linked to leisure, recreational, political activities or to the construction of a family. For those with caretaking duties, this translates into yet another disadvantage (Santos and 
Cabral-Cardoso 2008; Bozzon et al. 2017; Ivancheva and Keating, forthcoming). Those who instead do not have children and would like to have them, or those who would like to engage in other activities outside of work, experience this situation with a sense of sacrifice and of unfulfilled desires. Quite frequently, a total commitment to research means forsaking the idea of a family and accepting that one will have to commute long distances and live apart from their partner and friends (Gill 2009). Considering the strongly gendered division of labour which still persists in contemporary societies, as well as the gendered expectations of the university towards male and female researchers, it becomes evident that the so-called 'long hours culture' (Currie, Harris and Thiele 2000) ends up putting women at a strong disadvantage, in particular when one compares their situation to the one experienced by their male colleagues, especially those in a heterosexual relationship, and this becomes all the more evident when it comes to planning a family.

\section{Between promises about the future and invisible work}

The time and emotional investment made by the researchers is not simply tied to their 'passions', as described in the previous section, but also to their belief (or hope) that voluntary submission to the continuous requests coming from the academic system or sometimes from their supervisor or senior colleagues may eventually bring in exchange certain advantages, both in terms of contracts and of profession. Such a dynamic has been defined as the 'promise dispositive' (Bascetta 2015), which attacks non-tenured researchers on multiple fronts in the world of the university. This dynamic includes several practices, obligations and matters of ethics, which all come together in a process of subjectivation and selfregulation of the individuals. In fact, as Coin (2017, p. 713) points out: "rather than a real plan for the future, such promise feels as a soul-sourcing device, a hook meant to capture desire and transform it into a lever for exploitation". These types of relationships are therefore not simply based on blackmail and on the reproduction of the academic hierarchy, but also extend far deeper, manipulating subjectivity.

The mechanism leading to excessive work hours and carrying out a series of invisible activities, all the while hoping that what is not acknowledged today may be tomorrow, can partially overlap with the concept of "cruel optimism" described by Lauren Berlant (2011). She was questioning the relationships that begin when the object of one's desire becomes an obstacle for one's own growth and fulfilment. Subjects indeed tend to remain attached to long-gone fantasies and promises of equality, social mobility, and job security, even though the liberal-capitalist societies have given ample proof that they cannot guarantee anything of the sort. Moreover, the unpaid work that forms the base of the 'economics of promises' does not simply fuel the fire of hope for future occasions; it also provides an identity remedy to a condition of constant precariousness.

Due to its complexity, the mechanism of promises cannot be considered a simple part of a learning process, where one is 'learning the ropes', because the 
goal here is not to prepare the new-comers for stable and paid jobs, but to replace such jobs with precarious and unpaid ones. And for those few who continue on their academic path, contrary to what the rhetoric of meritocracy would presume, what matters is not only the quality of their work, but also their ability to stay in the system as long as possible. This is how early career researchers can end up doing someone else's job - be it supervising students, reviewing papers, writing projects - because others, especially those in a position of power in the academic hierarchy, claim that they can open the door to future professional opportunities. The 'promise dispositive' then pushes the subject to invest in work based on networking, a sort of investment in the future that can bring to work not just extremely long hours, but does so while remaining invisible. One accepts to work for free while investing in the interpersonal aspect of the employer-employee relationship (in this case, professor-pupil), which is to say that they are working to build a long-term relationship based on (supposedly) mutual trust.

If on one hand, unpaid work seems to be a common experience among all non-tenured researchers, whether one's work is visible or not seems to be a strongly gendered issue. Aside from that presented in this volume, there is other research on this matter, which shows how women are usually given tasks that are typically less recognised and less useful in terms of future employment (Heijstra, Steinthorsdóttir and Einarsdóttir 2017). In terms of disciplinary sectors, this occurs especially in the SSH field: as the amount of resources available is lower, the subjects appear to feel more under pressure, which is the reason why they end up accepting ever more invisible tasks (Honan and Teferra 2001). The relatively better position of early career researchers in the STEM field is also due to a set of factors which range from a higher number of investments and a more team-based approach to research, to higher wages and more trust in one's future perspectives, since the people active in this field are more likely than their SSH colleagues to find a position that meets their qualification even outside of academia (Nikunen 2012).

Thus, this promise dispositive exploits the desires and passions of the subjects, and in so doing uses them as the main leverage to make them accept - or, as is more often the case, to outright impose - an increasingly heavier unpaid workload, which is also often not recognised (especially for female non-tenured researchers and those active in the SSH fields). And all of this in return for the mere hope of the chance of building a future career in the world of academia or research. Furthermore, there is also another process, by which workers are becoming increasingly invisible, and which is happening via technological devices, especially through the auditing procedures and software programs used for monitoring the academic workload. These systems, which are active not only among early career researchers, but on all levels, go on to make academics systemically and deliberately working hours invisible, and hence operate as a "silencing mechanism" in higher education institutions (Gill 2009). All academics know that when they fill in timesheets or other documents related to their workload, they cannot declare more than eight hours a day, and cannot include non-working days. Translated into facts, this means that they have to hide a large 
amount of their work, putting on paper a huge number of activities, all completed at times that are technically impossible. The act of writing this book itself probably equals no more than a few days' work, once it has been translated into data to fill in a timesheet for the European Commission or for our university.

Understanding the mechanics of such subjectivation dispositives described above, the challenge therefore lies not only in how to better understand how neoliberal academia produces identity construction and subjectivity, but above all in understanding how the subjects can break free from the dispositives of precarisation that ensnare their subjectivity, the very same dispositives neoliberal academia is based on.

\section{Conclusions}

The academic and research system, as it has been shaped by those transformations previously described in this chapter, presents some critical traits that require careful observation. The globalisation, marketisation and neoliberalisation processes in the higher education sector have mainly exacerbated the working experiences and conditions of the new generation of researchers, thus creating professional mismatches, whilst causing broken dreams and aspirations. Those early career researchers approaching the world of research today are, in fact, exposed to production standards and competition levels that are relentlessly increasing, with ever fewer chances of securing a stable career, or even career advancement. They have to meet the standards of a working environment that is becoming ever more frantic and demanding. Additionally, they are confronted with models of identity, along with dispositives of subjectivation - both within a precarious framework. These phenomena are not gender-neutral, but tend to put women at a consistent disadvantage. Indeed, women face greater risk of being trapped in precarious conditions, in less prestigious and visible positions, where identity requests seem more contradictory and unfavourable.

The growing recognition of STEM disciplines, in particular those valued in terms of profitability (e.g. software developers, engineers, data scientists) represent another piece of this picture. On one hand, in fact, such recognition contributes to more requests for productivity, performativity and entrepreneurship in the scientific world, but on the other - together with the gradual devaluation of the SSH field - it reveals evident gendered implications, due to the consistent lack of balance in how men and women are represented in different disciplinary sectors.

When reflecting on these processes, it seems useful first of all to underline the opportunity and the importance of resorting to a comparative approach, which enables us to highlight both shared aspects and diverging ones across different institutions and countries. Furthermore, such an approach would allow us to point out how the same trends can sometimes be the result of different dynamics. The opportunity offered by the GARCIA project to analyse the experience of universities and research centres in different countries has been particularly pivotal from this point of view. 
In this chapter the connections between gender inequalities and precarisation processes within neoliberal academia have been analysed through three different levels. First of all, there are institutional forces at play, such as specific gender regimes which shape how early career researchers embrace gender models and the inequalities which are implicit in the neoliberal economic regimes. The organisational perspective, instead, highlights the gendered nature of practices played out in departments, faculties and schools, both in terms of gaining access to academic professions and in terms of expectations from higher education institutions towards early career researchers. Such researchers are required to follow an uninterrupted career history, endure long working hours, demonstrate high-performance work practices, and participate in international networks acknowledged by the organisation in which they are employed. Finally, at the subjective level, three ambivalences have been identified: the need to play by the rules in order not to be excluded by the academic system, while trying at the same time to avoid entrepreneurial logics which are implied within the same system; the fact that they are exposed to self-exploitation dynamics that are strictly intertwined with passion and emotional investment in one's own work; and the need for them to be ready to work in ways that are sometimes invisible and not recognised, because they hope to be able to create for themselves a future academic career. Resorting to a multi-level approach has allowed us to highlight the negative consequences that institutional, organisational and subjective dynamics have both on gender inequalities and on precarisation processes.

This analysis of the gendered nature of academic careers within neoliberal society, together with the implications for early career researchers, allow us the opportunity to offer recommendations for rethinking current policies at different levels. It is in fact necessary to act on a macro level, by introducing and implementing reforms that can reverse the current trend of marketisation and casualisation, and on an organisational level, through new policies and initiatives that can rethink organisational culture, whilst countering the current emphasis on hyper-productivity and complete availability required of its subjects (Poggio 2018). However, in addition to cooperating with management and policy makers in order to design and implement gender equality policies and measures to support early career researchers, we need to speculate as to which practices can be implemented in our everyday working lives. In other words, as Prichard and Benschop (2018, p. 101) eloquently said, we need to ask "why, rather than wait for others to take action and for the university to harvest its theoretical fruits, why the university doesn't leap from its observational balcony and take action itself".

Even though fighting current trends in higher education can appear hard, especially when we consider the scenarios and structures described above, we can also claim that hegemonic systems - including the academic one - are not simply the result of coercive relations of domination (Gramsci 1971). On one hand, this means that its dominance is supported (in different ways and to different degrees) by the academics who are part of it, but on the other hand it also means that there 
is the possibility for criticism and practice, and forms of resistance can be produced, even though they may be partial and fragmented (Mumby 1997). There are in fact a growing number of initiatives and contributions to this debate, which invite us to consider the issues of resistance in universities and which push for the rise of a new kind of academic activism, one which can challenge and subvert the principles that neoliberal academia is based on (Kalfa, Wilkinson and Gollan 2017; Contu 2018; Rhodes, Wright and Pullen 2018).

By questioning neoliberalism in academia, we argue that countering the growing precarisation of work and life, as well as the persistent existence of gender inequalities, is a priority for feminist scholars. The responsibility for dismantling these phenomena (instead of reproducing them more or less consciously) lies in the hands of the next generation of researchers, but also in the hands of those who are already active in academia and enjoy a relatively stable position. This kind of responsibility lies at the core of rethinking dominant cultures and daily practices in university, for example by demonstrating once again an appreciation for the different dimensions of academic work, favouring cooperation instead of competition and evaluating research in terms of its contribution to the public good, rather than its profitability. The issue is not simply about deconstructing and unmasking the contradictions and paradoxes present in the dominant models, but also about actively engaging in building new forms of solidarity and resistance that can support early career researchers, and that are able to question the masculine model of the ideal academic.

\section{Note}

1 This chapter is an entirely collaborative effort by the three authors, whose names appear in alphabetical order. If, however, for academic reasons individual responsibility is to be assigned, Rossella Bozzon wrote section 1, Barbara Poggio section 2, and Annalisa Murgia section 3 and the Conclusions. The introduction has been written jointly.

\section{References}

Acker, J. (1990). Hierarchies, jobs, bodies: a theory of gendered organizations. Gender \& Society, 4, 139-158.

Ackers, H. L. and Oliver, E. A. (2007). From flexicurity to flexsequality? The impact of the fixed-term contract provisions on employment in science research. International Studies of Management and Organization, 37(1), 53-79.

Ackers, L. (2008). Internationalisation, mobility and metrics: a new form of indirect discrimination? Minerva, 46, 411-435.

Ackers, L. and Gill, B. (2005). Attracting and retaining 'early career' researchers in English higher education institutions. Innovation: The European Journal of Social Science Research, 18(3), 27-299.

Addis, E. (2010). Scientific Excellence. Meta-Analysis of Gender and Science ResearchTopic Report. 7th RTD Framework Programme of the European Union.

Archer, L. (2008). The new neoliberal subjects? Young/er academics' constructions of professional identity. Journal of Education Policy, 23(3), 265-285. 


\section{Rossella Bozzon et al.}

Armano, E. and Murgia, A. (2013). The precariousnesses of young knowledge workers: a subject-oriented approach. Global Discourse, 3(3-4), 486-501.

Armano, E., Bove, A. and Murgia, A. (2017). Mapping precariousness. Subjectivities and resistance: an introduction. In E. Armano, A. Bove and A. Murgia (eds), Mapping Precariousness, Labour Insecurity and Uncertain Livelihoods: Subjectivities and Resistance. London: Routledge, pp. 1-12.

Auriol, L., Misu, M. and Freeman, R. (2013). Careers of doctorate holders: analysis of labour market and mobility indicators. OECD Science, Technology and Industry Working Papers, 2013/04. Paris: OECD Publishing.

Bagilhole, B. and Goode, J. (2001). The contradiction of the myth of individual merit and the reality of a patriarchal support system in academic careers. European Journal of Women's Studies, 8(2), 161-180.

Barry, J., Berg, E. and Chandler, J. (2006). Academic shape shifting: gender, management and identities in Sweden and England. Organization, 13(2), 275-298.

Barry, J., Chandler, J. and Clark, H. (2001). Between the ivory tower and the academic assembly line. Journal of Management Studies, 38(1), 88-101.

Baruch, Y. and Hall, D. T. (2004). The academic career: a model for future careers in other sectors? Journal of Vocational Behavior, 64(2), 241-262.

Bascetta, M. (ed.) (2015). Economia politica della promessa. Roma: manifestolibri.

Bazeley, P., Kemp, L., Stevens, C., Asmar, C., Grbich, C., Marsh, H. and Bhathal, R. (1996). Waiting in the Wings: A Study of Early Career Researchers in Australia, Canberra: AGPS.

Beck, U. (1992). Risk Society: Towards a New Modernity. London: Sage.

Benschop, Y. and Brouns, M. (2003). Crumbling ivory towers: academic organizing and its gender effects. Gender, Work and Organization, 10(2), 194-212.

Berlant, L. G. (2011). Cruel Optimism. Durham, NC: Duke University Press.

Blackmore, J. (2015). Disciplining academic women: gender restructuring and the labour of research in entrepreneurial universities. In M. Thornton (ed.), Through A Glass Darkly: The Social Sciences Look at the Neoliberal University. Canberra: ANU Press, pp. 179-194.

Blackwell, L. and Glover, J. (2008). Women's scientific employment and family formation: a longitudinal perspective. Gender, Work and Organization, 15(6), 579-599.

Bourdieu, P. (1988). Homo Academicus. Stanford, CA: Stanford University Press.

Bozzon, R. (2015). Comparative part at national level. In F. Dubois-Shaik and B. Fusulier (eds), Academic Careers and Gender Inequality: Leaky Pipeline and Interrelated Phenomena in Seven European Countries. GARCIA Working Paper 5, http://garciaproject. eu/?page_id=52.

Bozzon, R., Murgia, A., Poggio, B. and Rapetti, E. (2017). Work-life interferences in the early stages of academic careers: the case of precarious researchers in Italy. European Educational Research Journal, 16(2-3), 332-351.

Bozzon, R., Murgia, A. and Villa, P. (2017). Precariousness and gender asymmetries among early career researchers: a focus on stem fields in the Italian academia. Polis, 31(1), 127-158.

Bristow, A., Robinson, S. and Ratle, O. (2017). Being an early-career CMS academic in the context of insecurity and 'excellence': the dialectics of resistance and compliance. Organization Studies, 38(9), 1185-1207.

Busso, S. and Rivetti, P. (2014). What's love got to do with it? Precarious academic labour forces and the role of passion in Italian universities. Recherches sociologiques et anthropologiques, 45(2), 15-37. 
Canal-Dominguez, J. F. and Wall, A. (2014). Factors determining the career success of doctorate holders: evidence from the Spanish case. Studies in Higher Education, 39, $1750-1773$.

Cech, E. A. and Blair-Loy, M. (2014). Consequences of flexibility stigma among academic scientists and engineers. Work and Occupations, 41(1), 86-110.

Clarke, C. A. and Knights, D. (2015). Careering through academia: securing identities or engaging ethical subjectivities? Human Relations, 68(12), 1865-1888.

Clarke, C., Knights, D. and Jarvis, C. (2012). A labour of love? Academics in business schools. Scandinavian Journal of Management, 28(1), 5-15.

Coin, F. (2017). On quitting. Ephemera, 17(3), 705-719.

Connell, R. (2006). Glass ceilings or gendered institutions? Mapping the gender regimes of public sector worksites. Public Administration Review, 66(6), 837-849.

Contu, A. (2018). '... The point is to change it' - Yes, but in what direction and how? Intellectual activism as a way of 'walking the talk' of critical work in business schools. Organization, 25(2), 282-293.

Crompton, R., Gallie, D. and Purcell, K. (eds) (2002). Changing Forms of Employment: Organizations, Skills and Gender. London: Routledge.

Cruz-Castro, L. and Sanz-Menendez, L. (2010). Mobility versus job stability: assessing tenure and productivity outcomes. Research Policy, 39(1), 27-38.

Currie, J., Harris, P. and Thiele, B. (2000). Sacrifices in greedy universities: are they gendered? Gender and Education, 12(3), 269-291.

Davies, B. and Bansel, P. (2005). The time of their lives? Academic workers in neoliberal time(s). Health Sociology Review, 14(1), 47-58.

Davies, B. and Petersen, E. B. (2005). Intellectual workers (un)doing neoliberal discourse. International Journal of Critical Psychology, 13(1), 32-54.

De Boer, H. F., Enders, J. and Leisyte, L. (2007). Public sector reform in Dutch higher education: the organizational transformation of the university. Public Administration, $85(1), 27-46$.

Deem, R. (1998). 'New Managerialism' and higher education: the management of performance and cultures in universities in the UK. International Studies in Sociology of Education, 8(1), 47-70.

Deem, R. (2009). Leading and managing contemporary UK universities: do excellence and meritocracy still prevail over diversity? Higher Education Policy, 22(1), 3-17.

Doherty, R. and Chalsege, L. (eds) (2014). Researchers' Report. Brussels: Deloitte Consulting for DG Research and Innovation.

du Gay, P. (1996). Consumption and Identity at Work. London: Sage.

Ecklund, E. H., Lincoln, A. E. and Tansey, C. (2012). Gender segregation in elite academic science. Gender \& Society, 26(5), 693-717.

Eichhorst, W. and Marx, P. (eds) (2015). Non-Standard Employment in Post-Industrial Labour Markets. An Occupational Perspective. Cheltenham: Edward Elgar.

Enders, J. and de Weert, E. (eds) (2009). The Changing Face of Academic Life. Analytical and Comparative Perspectives, Basingstoke: Palgrave Macmillan.

Enders, J. and Musselin, C. (2008). Back to the future? The academic professions in the 21 st century. Higher Education to 2030. OECD.

Etzkowitz, H., Kemelgor, C. and Uzzi, B. (2000). Athena Unbound: The Advancement of Women in Science and Technology. Cambridge: Cambridge University Press.

European Commission (2012). Meta-Analysis of Gender and Science Research. Luxembourg: European Commission. 


\section{Rossella Bozzon et al.}

European Commission (2014). Innovation Union Competitiveness Report 2013. Brussels: European Commission.

European Commission (2016). She Figures 2015. Brussels: European Commission.

Ferree, M. M. and Zippel, K. (2015). Gender equality in the age of academic capitalism: Cassandra and Pollyanna interpret university restructuring. Social Politics, 22(4), 561-584.

Fleming, P. (2012). 'Some might call it work ... but we don't': exploitation and the emergence of free work. Research in the Sociology of Organization, 37, 105-128.

Foschi, M. (2006). On the application files design for the study of competence and double standards. Sociological Focus, 39(2), 115-132.

Gallas, A. (2018). Introduction: the proliferation of precarious labour in academia. Global Labour Journal, 9(1), 69-75.

Gascoigne, C., Parry, E. and Buchanan, D. (2015). Extreme work, gendered work? How extreme jobs and the discourse of 'personal choice' perpetuate gender inequality. Organization, 22(4), 457-475.

Gherardi, S. and Murgia, A. (2012). By hook or by crook: flexible workers between exploration and exploitation. Research in the Sociology of Organization, 37, 75-103.

Gherardi, S., Nicolini, D. and Strati, A. (2007). The passion for knowing. Organization, 14(3), 315-329.

Gill, R. (2009). Breaking the silence: the hidden injuries of neo-liberal academia. In R. Flood and R. Gill (eds), Secrecy and Silence in the Research Process: Feminist Reflections. London: Routledge, pp. 228-244.

Goastellec, G. and Pekari, N. (2013). Gender in the academia between differences and inequalities, findings in Europe. In U. Teichler and E. A. Höhl (eds), The Work Situation of the Academic Profession in Europe: Findings of a Survey in Twelve European Countries, Dordrecht: Springer, pp. 93-120.

Goode, J. and Bagilhole, B. (1998). Gendering the management of change in higher education: a case study. Gender, Work \& Organization, 5(3), 148-164.

Gramsci, A. (1971). Selections from the Prison Notebooks. New York: International Publishers.

Granovetter, M. (1983). The strength of weak ties: a network theory revisited. Sociological Theory, 1(6), 201-233.

Heijstra, T. M., Steinthorsdóttir, F. S. and Einarsdóttir, T. (2017). Academic career making and the double-edged role of academic housework. Gender and Education, 29(6), 764-780.

Honan, J. P. and Teferra, D. (2001). The US academic profession: key policy challenges. Higher Education, 41(1-2), 183-203.

Ivancheva, M. P. and Keating, K. (forthcoming). The paradox of precarity: life, work, and care in the era of flexible capitalism.

Izraely, D. N. and Adler, H. J. (1994). Competitive forces: tenure discrimination claims against colleges and universities. Journal of Law and Education, April, 349-356.

Janger, J. and Nowotny, K. (2013). Career Choices in Academia, WWWFOREUROPE Working Paper no 36.

Kalfa, S., Wilkinson, A. and Gollan, P. J. (2017). The academic game: compliance and resistance in universities. Work, Employment and Society, 0950017017695043.

Kantola, J. (2008). 'Why do all women disappear?' gendering processes in a political science department. Gender, Work and Organization, 15(2), 202-225.

Keller, E. F. (1985). Reflections on Gender and Science. New Haven, CT: Yale University Press. 
Kerfoot, D. and Knights, D. (1993). Management, masculinity and manipulation: from paternalism to corporate strategy in financial services in Britain. Journal of Management Studies, 30(4), 659-677.

Knights, D. and Clarke, C. A. (2014). It's a bittersweet symphony, this life: fragile academic selves and insecure identities at work. Organization Studies, 35(3), 335-357.

Kogan, M. and Teichler, U. (eds) (2007). Key Challenges to the Academic Profession. Kassel: International Centre for Higher Education Research Kassel.

Kossek, E. E., Lewis, S. and Hammer, L. B. (2010). Work-life initiatives and organizational change: overcoming mixed messages to move from the margin to the mainstream. Human Relations, 63(1), 3-19.

Kwiek, M. and Antonowicz, D. (2015). The changing paths in academic careers in European universities: minor steps and major milestones. In T. Fumasoli, G. Goastellec and B. M. Kehm (eds), Academic Work and Careers in Europe: Trends, Challenges, Perspectives. Dordrecht: Springer, pp. 41-68.

Lariviere, V., Ni, C., Gingras, Y., Cronin, B. and Sugimoto, C. R. (2013). Bibliometrics: global gender disparities in science. Nature, 504(7479), 211-213.

Laudel, G. and Gläser, J. (2008). From apprentice to colleague: The metamorphosis of Early Career Researchers. Higher Education, 55(3), 387-406.

Le Feuvre, N. (2009). Exploring women's academic careers in cross-national perspective. Lessons for equal opportunity policies. Equal Opportunities International, 28(1), 9-23.

Le Feuvre, N. (2015). Contextualizing women's academic careers in cross-national perspective. GARCIA Working Papers 2. University of Trento.

Leeman, R. J. (2010). Gender inequalities in transnational academic mobility and the ideal type of an academic entrepreneur. Discourse: Studies in the Cultural Politics of Education, 31(5), 605-625.

LERU (2014). Tenure and tenure track at LERU universities: models for attractive research careers in Europe. Advice Paper No 17. Leuven: LERU Office.

Levidow, L. (2002). Marketizing higher education: neoliberal strategies and counterstrategies. In K. Robins and F. Webster (eds), The Virtual University: Knowledge, Markets, and Management. Oxford: Oxford University Press, pp. 227-248.

Lind, I. (2008). Balancing career and family in higher education - new trends and results. In S. Grenz, B. Kortendiek, M. Kriszio and A. Löther (eds), Gender Equality in Higher Education. Berlin: VS für Sozialwissenschaften, pp. 193-208.

Lissoni, F., Mairesse, J., Montobbio, F. and Pezzoni, M. (2011). Scientific productivity and academic promotion: a study on French and Italian physicists. Industrial and Corporate Change, 20, 253-294.

Lund, R. W. B. (2015). Doing the Ideal Academic - Gender, Excellence and Changing Academia. Aalto University.

Lynch, K. (2010). Carelessness: a hidden doxa of higher education. Arts and Humanities in Higher Education, 9(1), 54-67.

Lynch, K. (2014). New managerialism: The impact on education. Concept, 5(3), 11.

Maassen, P. and Stensaker, B. (2011). The knowledge triangle, European higher education policy logics and policy implications. Higher Education, 61(6), 757-769.

Machado-Taylor, M. de L., Meira Soares, V. and Teichler, U. (2017). Challenges and Options: The Academic Profession in Europe. Dordrecht: Springer.

Madera, J. M., Hebl, M. R. and Martin, R. C. (2009). Gender and letters of recommendation for academia: agentic and communal differences. Journal of Applied Psychology, 94(6), 1591-1599. 
Marginson, S. (2011). Introduction to Part I. In R. King, S. Marginson and R. Nado (eds), Handbook on Globalization and Higher Education. Cheltenham: Edward Elgar, pp. 3-9.

Marginson, S. and Rhoades, G. (2002). Beyond national states, markets, and systems of higher education: a glonacal agency heuristic. Higher Education, 43(3), 281-309.

Marginson, S. and van der Wende, M. (2007). To rank or to be ranked: the impact of global rankings in higher education. Journal of Studies in International Education, 11(3-4), 306-329.

Marini, G. and Meschitti, V. (2018). The trench warfare of gender discrimination: evidence from academic promotions to full professor in Italy. Scientometrics, 10.1007/ s11192-018-2696-8.

Mason, M. A. and Goulden, M. (2002). Do babies matter? The effect of family formation on the lifelong careers of academic men and women. Academe, 88, 21-27.

Mason, M. A., Wolfinger, N. H. and Goulden, M. (2013). Do Babies Matter: Gender and Family in the Ivory Tower. New Brunswick: Rutgers University Press.

Matthews, K. E., Lodge, J. M. and Bosanquet, A. (2014). Early career academic perceptions, attitudes and professional development activities: questioning the teaching and research gap to further academic development. International Journal for Academic Development, 19(2), 112-124.

May, R., Peetz, D. and Strachan, G. (2013). The casual academic workforce and labour market segmentation in Australia. Labour and Industry, 23(3), 258-275.

McNair, S. (1997). Is there a crisis? Does it matter? In R. Barnett and A. Griffin (eds), The End of Knowledge in Higher Education. London: Cassell, pp. 27-38.

Misra, J., Lundquist, J. H. and Templer, A. (2012). Gender, work time, and care responsibilities among faculty. Sociological Forum, 27(2), 300-323.

Morano-Foadi, S. (2005). Scientific mobility, career progression and excellence in the European research area. International Migration, 43(5), 134-160.

Morgan, G. and Wood, J. (2017). The 'academic career' in the era of flexploitation. In E. Armano, A. Bove and A. Murgia (eds), Mapping Precariousness, Labour Insecurity and Uncertain Livelihoods: Subjectivities and Resistance. London: Routledge, pp. 82-97.

Morley, L. (2003). Quality and Power in Higher Education. Milton Keynes: SRHE \& Open University.

Morley, L. (2018). Gender in the neo-liberal research economy. In H. Kahlert (ed.), Gender Studies and the New Academic Governance: Global Challenges, Glocal Dynamics and Local Impacts. Wiesbedan: Springer, pp. 15-40.

Mumby, D. K. (1997). The problem of hegemony: rereading Gramsci for organizational communication studies. Western Journal of Communication, 61(4), 343-375.

Musselin, C. (2005). European academic labor markets in transition. Higher Education, 49(1/2), 135-154.

Musselin, C. (2007). Transformation of academic work: facts and analysis. In U. Teichler and M. Kogan (eds), Key Challenges to the Academic Profession. Paris and Kassel: UNESCO Forum on Higher Education. pp. 175-190.

Nikunen, M. (2012). Changing university work, freedom, flexibility and family. Studies in Higher Education, 37(6), 713-729.

Norkus, M., Besio, C. and Baur, N. (2016). Effects of project-based research work on the career paths of young academics. Work Organisation, Labour \& Globalisation, 10(2), 9-26.

O'Connor, P., Carvalho T., Vabø A. and Cardoso S. (2015). Gender in higher education: a critical review. In J. Huisman, H. de Boer, D. D. Dill and M. Souto-Otero (eds), The 
Palgrave International Handbook of Higher Education, Policy and Governance. London: Palgrave Macmillan, pp. 569-585.

O'Connor, P., O'Hagan, C. and Gray, B. (2017). Femininities in STEM: outsiders within. Work, Employment and Society, 32(2), 312-329.

Olssen, M. and Peters, M. A. (2005). Neoliberalism, higher education and the knowledge economy: from the free market to knowledge capitalism. Journal of Education Policy, 20(3), 313-345.

Özbilgin, M. F. (2009). From journal rankings to making sense of the world. Academy of Management Learning \& Education, 8(1), 113-121.

Padilla-González, L. E., Metcalf, A. S., Galaz-Fontes, J. F., Fischer, D. and Snee, I. (2011). Gender gaps in North American research productivity: examining faculty publication rates in Mexico, Canada, and the U.S. Compare: A Journal of Comparative and International Education, 41(5), 649-668.

Palomba, R. (2008). In the shadow of stereotypes. In C. M. Hasse, S. Trentemoller and A. B. Sinding (eds), Draw the Line! Tartu: Tartu University Press, pp. 51-56.

Palomba, R. and Menniti, A. (2001). Minerva's Daughters. Roma, Istituto di Ricerche sulla Popolazione e le Politiche Sociali.

Paradeise, C. and Thoenig, J. (2015). In Search of Academic Quality. Basingstoke: Palgrave Macmillan.

Parker, M. and Jary, D. (1995). The McUniversity: organization, management and academic subjectivity. Organization, 2(2), 319-338.

Peterson A. M., Riccaboni, M., Stanley H. E. and Pamolli, F. (2012). Persistence and uncertainty in the academic career. PNAS, 109(14), 5213-5521.

Poggio, B. (2006). Editorial: outline of a theory of gender practices. Gender, Work and Organization, 13(3), 225-233.

Poggio, B. (2017). Women and men in scientific careers: new scenarios, old asymmetries. Polis, Ricerche e studi su società e politica in Italia, 1, 5-16,

Poggio, B. (2018). Gender politics in academia in the neoliberal age. In J. M. Messerschmidt, P. Y. Martin, M. A. Messner and R. Connell (eds), Gender Reckonings. New Social Theory and Research. New York: New York University Press, pp. 173-192.

Prichard, C. and Benschop, Y. (2018). It's time for acting up! Organization, 25(1), 98-105.

Puljak, L. and Sharif, W. D. (2009). Postdocs' perceptions of work environment and career prospects at a US academic institution. Research Evaluation, 18(5), 411-415.

Reale, E. and Primeri, E. (2015). Approaches to policy and governance in higher education. In J. Huisman, H. de Boer, D. D. Dill and M. Souto-Otero (eds), The Palgrave International Handbook of Higher Education, Policy and Governance. London: Palgrave Macmillan, pp. 20-37.

Rhoades, R. A. and Torres, C. A. (eds) (2006). The University, State, and Market: the Political Economy of Globalization in the Americas. Stanford, CA: Stanford University Press.

Rhodes, C., Wright, C. and Pullen, A. (2018). Changing the world? The politics of activism and impact in the neoliberal university. Organization, 25(1), 139-147.

Rusconi, A. and Solga, H. (2007). Determinants of and obstacles to dual careers in Germany. Zeitschrift für Familienforschung, 19(3), 311-336.

Sadlak, J. and Liu, N. C. (eds) (2009). The World-Class University as Part of a New Higher Education Paradigm: From Institutional Qualities to Systemic Excellence. UNESCO-CEPES. 
Santos, G. G. and Cabral-Cardoso, C. (2008). Work-family culture in academia: a gendered view of work-family conflict and coping strategies. Gender in Management: An International Journal, 23(6), 442-457.

Schunter-Kleemann, S. and Plehwe, D. (2006). Gender mainstreaming: integrating women into a neoliberal Europe? In D. Plehwe, B. Walpen and G. Neunhöffer (eds), Neoliberal Hegemony: A Global Critique. London: Routledge, pp. 188-203.

Science Europe Working Group on Research Careers (2016). Postdoctoral Funding Schemes in Europe. www.scienceeurope.org/wp-content/uploads/2016/10/20160922Survey-Postdocs-Final.pdf.

Scott, P. (2009). Markets and new modes of knowledge production. In J. Enders and E. de Weert (eds), The Changing Face of Academic Life. Analytical and Comparative Perspectives. Basingstoke: Palgrave Macmillan, pp. 58-77.

Shen, H. (2013). Inequality quantified: mind the gender gap. Nature, 495(7439), 22.

Shin, C. J. and Kehm, B. M. (eds) (2013). Institutionalization of World-Class University in Global Competition. London: Springer.

Shore, C. and Wright, S. (2000). Coercive accountability: the rise of audit culture in higher education. In M. Strathern (ed.), Audit cultures: Anthropological Studies in Accountability, Ethics and the Academy. European Association of Social Anthropologists series. London and New York: Routledge, pp. 57-89.

Solera, C. and Musumeci, R. (2017). The persisting glass ceiling in academia: a multidimensional cross-national perspective. Polis, 1, 17-44.

Teelken, C. (2012). Compliance or pragmatism: how do academics deal with managerialism in higher education? A comparative study in three countries. Studies in Higher Education, 37(3), 271-290.

Teichler, U. and Höhle, E. A. (eds) (2013). The Work Situation of the Academic Profession in Europe: Findings of a Survey in Twelve Countries. Dordrecht: Springer.

Thomas, R. and Davies, A. (2002). Gender and new public management: reconstituting academic subjectivities. Gender, Work \& Organization, 9(4), 372-397.

Thorkelson, E. (2016). Precarity outside: the political unconscious of French academic labor. American Ethnologist, 43(3), 475-487.

Thornton, M. (2014). The changing gender regime in the neoliberal legal academy. Zeitschrift für Rechtssoziologie, 33, 235-251.

Thwaites, R. and Pressland, A. (eds) (2017). Being an Early Career Feminist Academic. London: Palgrave Macmillan.

Todd, P. and Bird, D. (2000). Gender and promotion in academia. Equal Opportunities International, 19(8), 1-16.

Tzanakou, C. (2017). Dual career couples in academia, international mobility and dual career services in Europe. European Educational Research Journal, 16(2-3), 298-312.

Vabø, A., Padilla-González, L. E., Waagene, E. and Næss, T. (2014). Gender and Faculty Internationalization. Dordrecht: Springer.

Van den Brink, M. and Benschop, Y. (2012a). Gender practices in the construction of academic excellence: sheep with five legs. Organization, 19(4), 507-524.

Van den Brink, M. and Benschop, Y. (2012b). Slaying the seven-headed dragon; the quest for gender change. Gender, Work \& Organization, 19(1), 71-92.

Van den Brink, M. and Benschop, Y. (2014). Gender in academic networking: the role of gatekeepers in professorial recruitment. Journal of Management Studies, 51(3), 460-492.

Van den Brink, M., Benschop, Y. and Jansen, W. (2010). Transparency in academic recruitment: a problematic tool for gender equality? Organization Studies, 31(11), 1459-1483. 
van Raan, A. F. J. (2005). Fatal attraction: conceptual and methodological problems in the ranking of universities by bibliometric methods. Scientometrics, 62(1), 133-143.

Ward, K. and Wolf-Wendel, L. (2004). Academic motherhood: managing complex roles in research universities. The Review of Higher Education, 27(2), 233-257.

Ward, M. (2000). Gender and promotion in the academic profession. Scottish Journal of Political Economy, 48(3), 283-302.

Wei, T. E., Levin, V. and Sabik, L. M. (2012). A referral is worth a thousand ads: job search methods and scientist outcomes in the market for postdoctoral scholars. Science and Public Policy, 39, 60-73.

Weisshaar, K. (2017). Publish and perish? An assessment of gender gaps in promotion to tenure in academia. Social Forces, 96(2), 529-560.

Williams, J. C. (2005). The glass ceiling and the maternal wall in academia. New Directions for Higher Education, 130, 91-105.

Williams, J. C., Blair-Loy, M. and Berdahl, J. L. (2013). Cultural schemas, social class, and the flexibility stigma. Journal of Social Issues, 69(2), 209-234.

Willmott, H. (1995). Managing the academics: commodification and control in the development of university education in the U.K. Human Relations, 48(9), 993-1027.

Ylijoki, O. H. (2010). Future orientations in episodic labour: short-term academics as a case in point. Time \& Society, 19(3), 365-386.

Ylijoki, O. H. and Mäntylä, H. (2003). Conflicting time perspectives in academic work. Time \& Society, 12(1), 55-78.

Zippel, K. (2018). Gendered images of international research collaboration. Gender, Work \& Organization, doi.org/10.1111/gwao.12233. 


\title{
2 The gendered diversification of academic career paths in comparative perspective
}

\author{
Nicky Le Feuvre, Pierre Bataille, Sabine Kradolfer, \\ Maria del Rio Carral and Marie Sautier
}

Higher education has many variants, and the situation of academic staff varies considerably across and within countries.

(Enders and Musselin 2008, p. 142)

\section{Introduction}

It is now widely recognised that women's progressive access to the upper reaches of the socio-professional hierarchy usually coincides with major demographic, organisational or socioeconomic transformations at the national and/or occupational levels (Crompton, Lyonette and Scott 2010; Boni-Le Goff and Le Feuvre 2017). The academic profession is no exception to this rule. A ream of research literature has pinpointed the structural changes currently sweeping across higher education (HE) and research institutions (Enders and de Weert 2009a; Fassa and Kradolfer 2013; Fumasoli, Goastellec and Kehm 2015; Herschberg, Benschop and van den Brink 2018; Musselin 2005, 2009, 2017; Teichler, Arimoto and Cummings 2013; Tuchman 2009). As indicated below, these shifts interact with parallel changes to the gender composition of the academic workforce (European Commission 2016) to produce untoward challenges to the academic professional ethos.

As is now well-documented, recent changes to academic working environments have been demographic, organisational and ideological in nature. From a demographic point of view, academic employment has expanded significantly over the past 50 years. This growth has affected all levels of the academic occupational hierarchy, but has often been more spectacular at the junior levels $(\mathrm{PhD}$ candidates, postdocs) than amongst tenured professors, leading to a widening of the base of the occupational pyramid (Dubach 2014; Ylijoki 2010). In some countries, this expansion would appear to have reached a peak with the Great Recession, whilst it continues to progress - albeit at a slower rate - in other national contexts (Euraxess 2014). From an organisational point of view, HE and research institutions have lost many of their historically specific attributes, including some forms of self-regulation (Henkel 2009), and have been increasingly subject to the expansion of a range of so-called New Public Management (NPM) initiatives (Ferlie, Musselin and Andresani 2008). Although they are 
usually located in the public sector, academic institutions are increasingly being run according to the principles of private enterprise, with a particular emphasis on accountability, competition, transparency, cost-cutting and the maximisation of returns on investment (Deem, Hillyard and Reed 2007). These demographic and organisational evolutions also have an ideological dimension, based on the legitimacy accorded to the introduction of quasi-market conditions to the pursuit of scientific excellence and the management of academic staff at the local, national and trans-national levels.

This somewhat volatile context represents a particular challenge for the comparative analysis of early research careers from a gender perspective. Understanding the multiple and sometimes contradictory forces at work in shaping women's academic careers has progressed significantly over recent years (Ceci et al. 2014; de Cheveigné 2009; Glass et al. 2013; Hunter and Leahey 2010; Krefting 2008; Marini and Meschitti 2018; Marsh et al. 2009; Meulders, O'Dorchai and Simeu 2012; Moss-Racusin et al. 2012; Musselin and Pigeyre 2008; Nittrouer et al. 2017; Pétursdóttir 2009; Rogers and Molinier 2016; Siemienska and Zimmer 2007; Weisshaar 2017; Van Arensbergen, Van der Weijden and Van den Besselaar 2012; Zippel 2017). However, some studies continue to produce somewhat inconclusive or ambivalent results (Barrett and Barrett 2011; Danell and Hjerm 2013; Ecklund, Lincoln, and Tansey 2012; Miller and Wai 2015; Williams and Ceci 2015). To date, research on women's academic careers has tended to focus on the processes that combine to limit their access to the academic labour market as a whole and/or to the most prestigious HE and research positions. However, as the proportion of female $\mathrm{PhDs}$ increases, the international research agenda has tended to shift from concern with women's exclusion from the upper reaches of the academic hierarchy to a growing interest in the conditions under which they have been progressively integrated into a rapidly changing labour market, where formal commitment to gender equality has increased significantly (Brooks and Mackinnon 2001). This shift in focus has implications for the way in which the "women and science question" is framed (Garforth and Kerr 2009; Le Feuvre 2009), particularly in relation to the emerging debate about the quality of academic jobs. Knowledge work in general and the academic career in particular have traditionally been seen as highly desirable areas of employment, associated with a host of material, intrinsic and symbolic rewards, which women were collectively denied (Van den Brink and Benschop 2011; Valian 1999, 2005). However, with the on-going degradation of employment and working conditions in HE and research institutions (Gill 2009), promoting gender equality in academic careers raises new challenges. Should we really be committing resources to encouraging women to invest in academic careers whilst openly recognising that the opportunities for stable employment opportunities in this sector are decreasing? Given potential changes to the relative rewards of academic careers, any serious study of the gendered precariousness of academic employment requires broadening the traditional research perspectives on the "women and science question" in at least three directions. 
First, we need to recognise that the global nature of research and the increasing role of international mobility in academic performance indicators (Herschberg, Benschop, and van den Brink 2018) doesn't necessarily imply the harmonisation of academic career models across national borders. As we will argue in more detail below, similar demographic, organisational and ideological changes to academic institutions do not necessarily result in the emergence of a transnational, globalised and unified academic labour market. Not all national academic labour markets reflect global forces of change in exactly the same ways (Enders and de Weert 2009a, 2009b). We therefore need to adopt an analytical approach that is more sensitive to similarities and differences in precariousness that cut across national contexts, gender categories and disciplinary fields (Le Feuvre 2016). Furthermore, within national academic labour markets, different forms of biographically situated working and employment conditions have potentially varied implications for the young researchers concerned and for the gender scripts they adopt.

Second, we need to recognise that $\mathrm{PhD}$ holders are not restricted to working in $\mathrm{HE}$ and research institutions, although their non-academic employment opportunities may vary considerable by country and disciplinary field. Instead of presuming that academic institutions necessarily offer the most fulfilling and rewarding career options open to $\mathrm{PhD}$ holders of both sexes, we need to take the critical analysis of current working conditions in HE and research institutions seriously. This means considering under what circumstances the intense competition for academic jobs modifies the ability of the sector to provide men and women with long-term career prospects. This also requires a critical reappraisal of the so-called "leaky pipeline" perspective (see Chapter 6, this volume). Instead of focussing solely on the factors that hamper women's chances of progressing up the academic career hierarchy, we also need to consider the ability of women to opt out of those labour market niches that fail to provide the independence, rewards and stability to which they now aspire, on a comparable basis to men (Glass et al. 2013).

Third, we need to recognise the variability of academic precariousness over time. In other words, we must remember that, in a wide range of countries, $\mathrm{PhD}$ holders make up the group that is best and durably protected from the risk of unemployment and precarious employment conditions across the adult lifecourse (Auriol 2010; Calmand, Prieur and Wolber 2017; Phou 2017). At the same time, we have to admit that this is a group that is increasingly likely to experience a more or less extended period of what could be called transitional precariousness, in the form of fixed-term, part-time, low paid, unprotected jobs, before finally gaining access to the permanent and relatively prestigious positions that are commensurate with their qualifications and that they will occupy for the remaining years of their working lives. The time-scale for observing the employment transitions of $\mathrm{PhD}$ holders is thus vital to understanding the variability in the precariousness of early academic careers for men and women, across countries and across time.

In response to just some of these challenges, the chapter is structured around two sub-sections. First, we discuss the tensions between global changes in 
academic labour markets and the survival of nationally specific career models. Second, we demonstrate the insights to be gained from paying more systematic attention to the varying significance of different forms of precarious employment, both within different academic career models and across biographical time-lines.

\section{Academic labour markets: between global convergence and national specificities}

Cross-national comparative research on gender equalities is complex and its epistemological foundations and methodological implications are much debated (Crompton 2001, 2006; Crompton and Le Feuvre 2000). However, these issues are shadowed by the particularities of the academic profession, which is often presented under the guise of a "global labour market". Furthermore, despite recent improvements in the collection of harmonised statistical data (European Commission 2016), much of the "women and science" literature continues to lack a theoretically grounded cross-national analytical perspective (Caprile et al. 2012). Indeed, there seems to be an implicit presumption that the organisational structure and requirements of a (successful) academic career must be similar across time and place. The fact that the specificities of national academic labour markets are often overlooked in much of the gender and science research literature has analytical consequences (Le Feuvre 2015), which are compounded by the relative homogeneity of women's access to the most prestigious jobs in the academic hierarchy across national boundaries. Because women represent approximately a quarter of Grade A professorships in most Western societies, there is a marked tendency to presume that this under-representation must be the result of similar social processes across national contexts and over time, despite the contrasting levels of feminisation observed in a given country, across disciplinary fields (Table 2.1). Increasing attention to the internationalisation of academic occupations and critical appraisal of the widespread adoption of socalled New Public Management (NPM) principles within HE and research institutions has undoubtedly heightened this focus on the commonalities of academic careers, to the detriment of factors that are potentially specific to certain national, regional, institutional or disciplinary contexts (Enders, de Boer and Leisyte 2009). From this point of view, the distinction proposed by Simon Marginson (2009) between the "internationalisation" of academic labour markets and their "globalisation" is particularly useful. Marginson identifies three distinct levels of trans-national change to HE and research institutions. First, the formation of a trans-national, global market for academic labour that may "crowd out national labour markets" (globalisation). Second, supra-national initiatives that lead to convergence between national HE systems (internationalisation) and, third, parallel reforms adopted more or less simultaneously by different national governments, but which are integrated differently into existing policies, norms or practices, potentially reducing the similarity of outcomes (nationalisation). According to Marginson, not all aspects of academic life are being globalised, 
54 Nicky Le Feuvre et al.

Table 2.1 Women as a proportion of all researchers and of Grade A positions, by field of science, selected countries, 2013

\begin{tabular}{lccccc}
\hline Country & $\begin{array}{l}\text { Natural } \\
\text { Sciences }\end{array}$ & $\begin{array}{l}\text { Engineering } \\
\text { and Technology }\end{array}$ & $\begin{array}{l}\text { Medical } \\
\text { Sciences }\end{array}$ & $\begin{array}{l}\text { Social } \\
\text { Sciences }\end{array}$ & Humanities \\
\hline Austria all & 29.0 & 22.0 & 46.0 & 49.0 & 52.0 \\
Austria Grade A & 11.7 & 7.8 & 14.7 & 24.1 & 33.4 \\
Belgium all & 33.0 & 21.0 & 53.0 & 49.0 & 45.0 \\
Belgium Grade A & 15.3 & 9.3 & 23.3 & 23.5 & 30.0 \\
Germany all & 28.0 & 19.0 & 48.0 & 36.0 & 50.0 \\
Germany Grade A & 11.6 & 7.6 & 11.5 & 16.0 & 28.6 \\
Italy all & 42.0 & 26.0 & 36.0 & 42.0 & 52.0 \\
Italy Grade A & 21.6 & 10.4 & 13.6 & 24.3 & 35.9 \\
Netherlands all (2005) & 26.0 & 21.0 & 39.0 & 38.0 & 42.0 \\
Netherlands Grade A (2005) & 9.7 & 9.0 & 16.4 & 19.1 & 25.7 \\
Slovenia all & 30.0 & 24.0 & 52.0 & 46.0 & 51.0 \\
Slovenia Grade A & 10.9 & 11.6 & 30.7 & 23.9 & 29.1 \\
Switzerland all & - & - & - & - & - \\
Switzerland Grade A & 12.9 & 12.0 & 20.0 & 24.4 & 33.3 \\
UK all & 30.0 & 24.0 & 52.0 & 46.0 & 51.0 \\
UK Grade A & 9.0 & 7.0 & 23.2 & 22.7 & 10.8 \\
\hline
\end{tabular}

Source: European Commission (2016) p. 81 and p. 129. https://data.europa.eu/euodp/data/dataset/ she-figures-2015-gender-in-research-and-innovation.

nationalised or internationalised to the same extent. Thus, for example: "Research-related and doctoral activities $[\ldots]$ tend to be more globally universal in character than the more nation-bound and locally idiosyncratic processes of academic appointment, promotion, performance management and remuneration" (Marginson 2009, p. 99).

Across national contexts, academic labour markets obviously do share a number of characteristics. As Jurgen Enders and Christine Musselin have argued:

While each academic system is embedded in its own national traditions, there are some common realities: increasing financial constraints, processes of differentiation within massified higher education systems, demands for accountability and responsiveness to societal needs, market-like approaches to higher education, and rising international co-operation and competition.

(2008, p. 145)

Of these global tendencies, the demographic expansion of the academic labour market and its increasing fragmentation are probably most relevant to the issues addressed in this volume.

\section{Demographic expansion and internal labour market segregation}

Despite recent improvements in the collection, compilation and dissemination of descriptive data on gendered research careers in the European context (notably 
through the European Commission's regularly up-dated She Figures publications), we still have limited knowledge of the mechanisms through which women exit academic institutions and/or stagnate at intermediary levels of the academic hierarchy to a greater extent than their male counterparts (Dubois-Shaik and Fusulier 2015). In the absence of longitudinal data, it remains unclear which precise combination of push and pull factors might lead women: (a) to aspire to an academic career in the first place; (b) to gain access to a stable academic position; (c) to progress up the academic hierarchy or (d) to contribute to a growing "reserve army" of temporary, precarious academic workers. Furthermore, the transnational similarity or societal specificity of these gendering mechanisms remains largely open to conjecture.

Since holding a doctorate is a near-universal pre-requisite for a research career, it is important to stress that the rise in women's educational credentials was achieved during a period of rapid demographic expansion of the higher education systems of the global North. Over the last decade of the twentieth century, the number of new doctoral graduates from universities in OECD countries increased by almost 40 per cent (Auriol, Misu and Freeman 2013, p. 8). However, female $\mathrm{PhD}$ holders have not replaced or displaced their male counterparts, since the absolute number of male doctoral graduates has also been increasing over time, albeit at a slower rate than for women (Figure 2.1).

Women now represent between 40 per cent and 60 per cent of all advanced research degree graduates in Europe, and their share of $\mathrm{PhDs}$ is particularly high

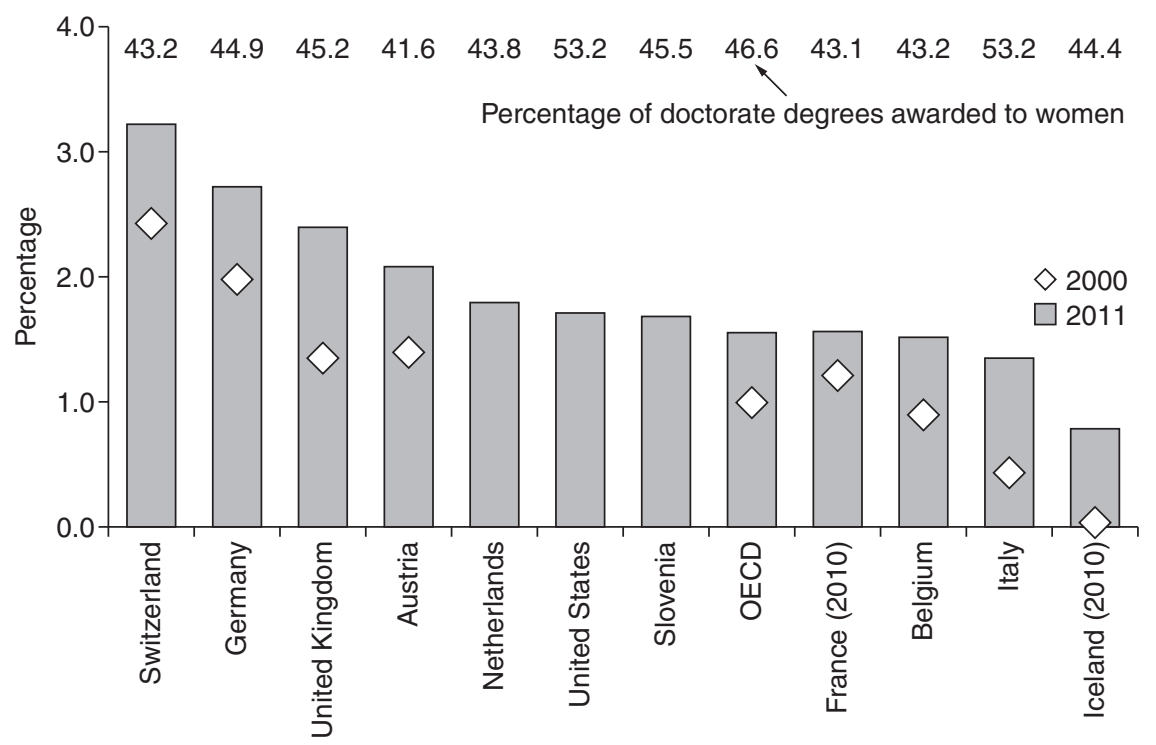

Figure 2.1 Graduate rates at doctoral level 2000 and 2011, as a percentage of the reference cohort, selected OECD countries.

Source: our elaboration based on OECD (2013), Education at a Glance 2013: OECD Indicators, OECD Publishing and OECD Education Database, July 2013. 


\section{Nicky Le Feuvre et al.}

in Iceland, Italy, the Netherlands and Slovenia. However, the overall feminisation of tertiary education has not decreased the horizontal gender segregation within HE and research institutions. Men are still twice as likely as women to earn $\mathrm{PhDs}$ in engineering, manufacturing and computing, whereas as women are twice as likely as men to graduate in Education Studies (European Commission 2016). Although women's access to tertiary degrees has increased across the globe, the proportion of $\mathrm{PhD}$ holders in the total population and in the labour market continues to vary considerably by country (see Figure 2.2). Thus, the large number of doctoral students trained in Switzerland is reflected in the high proportion of $\mathrm{PhD}$ holders in the total Swiss labour force. However, this is largely due to a large share of foreign doctoral graduates, who account for almost half of the PhDs awarded each year (Dubach 2014). Germany, Austria, the US and the UK also have a relatively high proportion of $\mathrm{PhD}$ holders in their total labour force, but with varying shares of foreigners amongst this group.

In line with the expansion of PhD studies, the number of people employed in the $\mathrm{HE}$ and research sector has also increased dramatically in recent years. But, once again, the demographics of this sector vary considerably across national boundaries. In some countries, the annual expansion of academic employment has continued well beyond the Great Recession, whereas numbers had already started to stagnate before 2008 in other contexts (Table 2.2). Both Switzerland

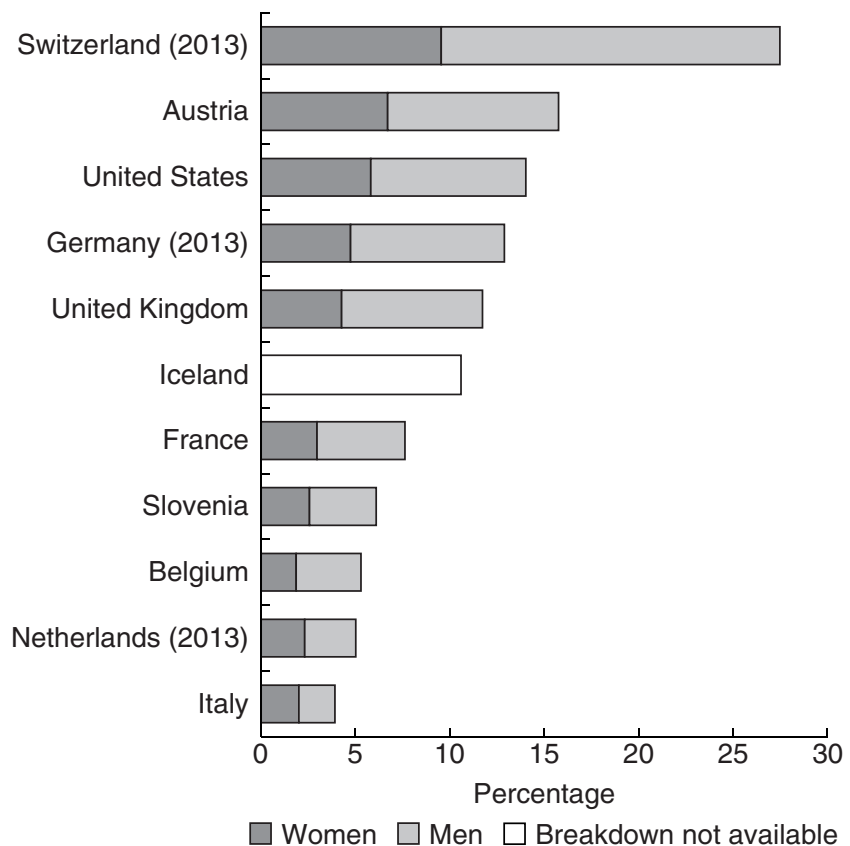

Figure 2.2 Doctorate holders in the working age population, 25-64 years, by sex, 2012.

Source: OECD calculations based on OECD data collection on Careers of Doctorate Holders 2014, www.oecd.org.sti/cdh; and other international sources, June 2015. 
Table 2.2 Evolution of number of researchers in the HE sector, by sex, selected countries, 2006-2013

\begin{tabular}{|c|c|c|c|c|c|}
\hline \multirow[t]{2}{*}{ Country } & \multicolumn{2}{|l|}{2006} & \multicolumn{2}{|l|}{2013} & \multirow{2}{*}{$\begin{array}{l}\text { Evolution } \\
2006-2013\end{array}$} \\
\hline & Women & Men & Women & Men & \\
\hline Austria & 8,190 & 15,419 & 13,412 & 20,369 & $+43.1 \%$ \\
\hline Belgium & 9,998 & 16,831 & 13,139 & 18,938 & $+19.6 \%$ \\
\hline France & 37,538 & 71,225 & 37,546 & 75,512 & $+3.9 \%$ \\
\hline Germany & 57,981 & 126,391 & 99,207 & 162,450 & $+41.9 \%$ \\
\hline Iceland & 606 & 775 & 976 & 934 & $+38.3 \%$ \\
\hline Italy & 25,721 & 46,683 & 31,325 & 46,412 & $+7.4 \%$ \\
\hline Netherlands & 7,124 & 13,728 & 10,183 & 14,407 & $+17.9 \%$ \\
\hline Slovenia & 1,374 & 2,235 & 1,830 & 2,480 & $+19.4 \%$ \\
\hline Switzerland & 9,455 & $20,185^{\mathrm{a}}$ & 15,037 & 26,358 & $+39.7 \%$ \\
\hline United Kingdom & $106,839^{\mathrm{b}}$ & 14,8210 & 147,457 & 182,925 & $+29.5 \%$ \\
\hline
\end{tabular}

Source: Eurostat (own calculation). Last update May 2018.

Notes

a 2012.

b 2005 .

and Iceland have an unusually high proportion of HE sector researchers amongst their workforce, whilst the opposite is true of Italy and the Netherlands. Interestingly, there isn't any statistical correlation between the proportion of $\mathrm{PhD}$ holders in the total labour force and women's share of doctoral qualifications. The differing density of $\mathrm{PhD}$ holders in the labour force would seem to suggest that the degree to which tertiary degrees are a simple prerequisite for an academic career or the extent to which they lead (potentially) to a much wider range of employment opportunities also varies between countries. The very different (relative) size of the academic labour market also suggests that the working conditions and career opportunities of HE teaching and research staff vary considerably according to their national environment (Teichler and Höhle 2013; Kuhm and Teichler 2013). As we will see in more detail later, this question is directly related to the more or less precarious employment perspectives of male and female $\mathrm{PhD}$ holders in different national contexts.

Another important factor to consider when analysing women's access to academic positions is the ratio of tenured (permanent) positions as a share of the total academic labour market. As indicated in Figure 2.3, this ratio varies considerably between countries and shows no clear sign of convergence over time. Thus, in the EU-28 as a whole, 17 per cent of male academics hold a full professorship, as compared to only 7 per cent of their female counterparts. Although levels of formal tenure for full professors have been decreasing recently, there is still reason to believe that these positions offer high levels of employment security. But the percentage of full professorships in relation to the whole academic sector ranges from almost half of all male researchers in Iceland (and a quarter of all females) to just 11 per cent and 4 percent, respectively, in Austria. National academic labour 


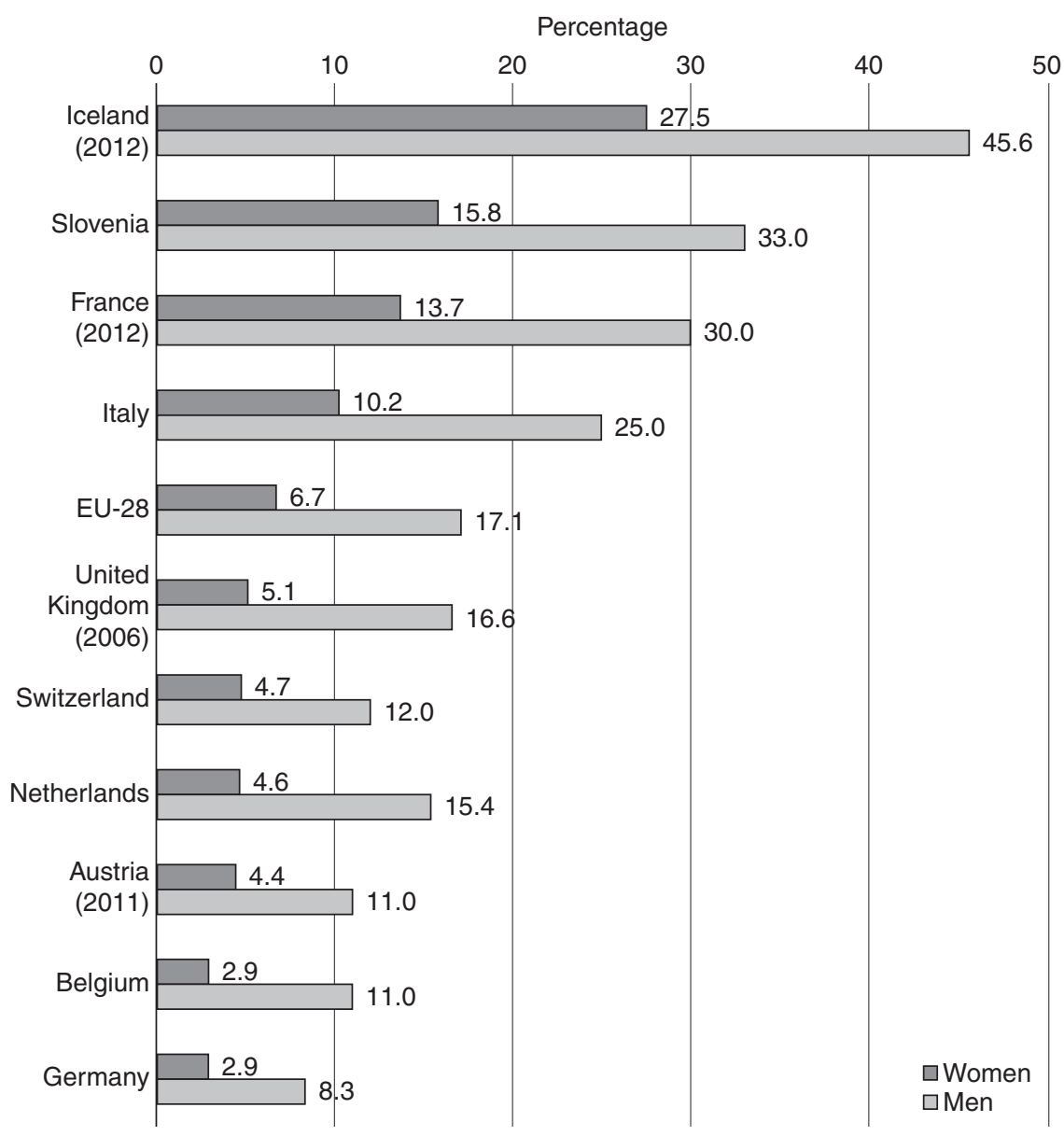

Figure 2.3 Percentage of Grade A staff amongst all academic staff, by sex, selected countries, 2013.

Source: our elaboration on European Commission (2016), She Figures 2015, p. 132. https://data. europa.eu/euodp/data/dataset/she-figures-2015-gender-in-research-and-innovation.

markets are not all "bottom heavy" to the same extent and this also has considerable consequences for the relative chance that men and women have of entering the academic sector and/or of reaching the top of the occupational hierarchy. A much flatter career structure opens up the opportunity for a larger proportion of all academic staff to - eventually - reach the top, but probably reduces the relative advantages associated with becoming a (tenured) professor.

Even in these less fiercely competitive contexts, the ratio of $\mathrm{PhDs}$ to existing permanent positions and the age profile of today's academic staff are important factors to consider. Of course, the relative shortage or abundance of professorships 
in a given national context is subject to considerable change over time and is particularly sensitive to the rate of expansion of tertiary education. Furthermore, the proportion of tenured jobs within the academic sector of a single nation state probably also varies by disciplinary field, although we have not been able to locate any comparative data on this point in the literature.

Even within a very internationalised labour market for academic staff, the total number of research jobs available to $\mathrm{PhD}$ holders in their home country will obviously have an impact on the degree of competition likely to be experienced at the point of entry. However, potentially contradictory forces may be at work here. On the one hand, an academic career may remain attractive to $\mathrm{PhD}$ holders, despite limited objective chances of receiving tenure, thus limiting investment in the acquisition of "transferrable skills" during the postdoc period (Teelken and Van der Weijden 2018). On the other hand, increased competition for stable academic jobs may reduce aspirations for an academic career, as postdocs adapt their job seeking strategies to the economic realities of their immediate environment, sometimes leading them to accept non-academic jobs that are well below their qualifications (Bozzon, Murgia and Villa 2017).

\section{National academic career models}

Beyond the lack of transnational convergence in the demographics of academic labour markets, empirical evidence would seem to suggest that the precise characteristics and requirements of an academic career also vary considerably from one national context to another (Teichler and Höhle 2013). As Christine Musselin has argued: "Salaries, occupational status, recruitment procedures, promotion rules, workload, career paths, etc., tend to vary significantly from one national higher education system to another" (Musselin 2005, p. 135). This French sociologist has identified four aspects of academic labour markets that are particularly sensitive to national variation: (a) selection (recruitment) procedures (e.g. national pre-qualification versus direct competition at the institutional level); (b) length and function of the pre-tenure period (e.g. rapid autonomy for young researchers versus a prolonged (subordinate) apprentice period); (c) relative importance of internal and external labour markets (e.g. importance and acceptability of "local" (same institution) versus national or international career tracks) and (d) relative pay and salary determinants (e.g. relative level of remuneration, in comparison to comparable alternative occupations, and proportion of performance related pay) (Musselin 2005, p. 139). This list of indicators enables Musselin to distinguish between three distinct academic career models, which, she argues, continue to influence conditions of access to employment in $\mathrm{HE}$ and research institutions across the world.

\section{The tenure-track model}

The tenure track academic career model is based on: "an early [competitive] selection of young PhDs, among whom some are offered tenure-track positions, 
i.e. time-limited posts leading, at the end of a given period, to a [...] procedure to decide whether they will be offered a tenured position" (Enders and Musselin 2008 , p. 134). This model is typical of the US academic system and is characterised by an "up or out" selection procedure, whereby those who fail to meet the requirements for tenure within the allocated duration are expected to leave the institution and to seek employment elsewhere. Historically, the tenure-track career model was based on the adoption of a formal or informal numerus clausus at the $\mathrm{PhD}$ level; the number of doctoral students recruited (and funded) being largely determined by the foreseeable availability of early career positions within the academy. The labour market for PhD students could thus be described as largely "internal" to academic research institutions, as in the US and the UK. Competition, although extremely harsh, was traditionally less about access to the academic labour market per se, than about access to the most enviable and prestigious research institutions; precisely those where the opportunity to develop a competitive research profile was the most promising. Those postdocs who failed to meet the stringent criteria for tenure in one of the highest ranked institutions could still expect to pursue an academic career, albeit in a less prestigious establishment, probably at the cost of a heavier teaching load, more administrative duties, a lower salary and with fewer institutional resources (Jaschik and Lederman 2017). Recent changes to this tenure model of academic careers have notably involved (a) the expansion of $\mathrm{PhD}$ certification well beyond the employment capacity of the academic sector; (b) the creation of an increasing number of fixed-term, non-tenure track positions, even within the most prestigious research institutions and (c) the increasing differentiation of temporary teachingbased or research-focussed or administrative positions; thus creating a functional divide within what was previously seen as an integrated profession involving all three aspects of academic work, albeit in varying proportions (Phou 2017). This career model is prevalent in countries characterised by a departmental (as opposed to a chair) structure, where the co-option of new, high performing colleagues is central to strategies to maintain or improve the relative ranking of a collective entity (Institute, Department, Faculty, etc.) within a highly competitive environment (see Fumasoli, Goastellec and Kehm 2015). Among the GARCIA partner countries, this traditionally Anglo-Saxon career model is becoming increasingly prevalent in Iceland and the Netherlands, and is also being adopted in Belgium, particularly in STEM fields.

In parallel to this relatively closed academic labour market, $\mathrm{PhD}$ holders also have the option of an early exit from academic institutions, to alternative jobs in public administration, industry or the professions, where doctoral credentials command a certain degree of recognition and reward (Glass et al. 2013). As the number of $\mathrm{PhD}$ holders has increased beyond the capacity of the academic labour market alone, efforts have been made to promote doctoral studies to a wider audience of potential employers, although with limited success to date (Van der Weijden et al. 2016). In addition, there has also been a notable increase in the number of non-academic positions available to $\mathrm{PhD}$ holders within HE and research institutions, where the widespread adoption of NPM 
principles has led to the development of relatively well-paid, but not always permanent, jobs in research management, quality control, research evaluation and fund-raising.

We would thus expect forms of precariousness that reflect the increasing internal stratification of academic labour markets to be particularly prevalent in countries where the tenure track model of academic careers is dominant. In this case, the extension of the "probationary" or pre-tenure period and the creation of permanently non-permanent teaching, research and administrative positions has introduced a new source of differentiation between what Enders and Musselin (2008) call the "haves and the have nots" of the increasingly "T-shaped" academic labour market (Enders and de Weert 2009b). There is evidence to suggest that in some countries that have adopted the tenure track career model, gender discrimination on the road to tenure persists (Herschberg, Benschop, and van den Brink 2018; Weisshaar 2017), whereas other studies indicate that women's chances of receiving tenure are similar to those of their male counterparts (Phou 2017; Van der Weijden et al. 2016). Whatever the case, the process is highly selective. In the Netherlands, for example, it has been estimated that the number of associate professorships available each year is equivalent to approximately $20 \%$ of the postdoc population in the country, almost half of whom are non-nationals (Van der Weijden et al. 2016). Within this model, postdocs are well aware of the selective nature of the tenure-track, despite the fact that most of them (up to 85 per cent in the Netherlands, for example) aspire to work in the HE and research sector (Van der Weijden et al. 2016). Thus, in the tenure-track model, the postdoc period of uncertainty and unpredictability is intense, involving frequent job changes and geographical mobility. However, this period is generally short-lived. After five years as a postdoc, the chances of ever securing a permanent academic position are considerably reduced. This model is thus particularly problematic for women, who may be considering having children precisely within this limited time-frame (at age 35 or thereabouts). However, some authors have suggested that when gender discrimination is particularly rife in the tenure-track selection process, female doctorate holders may develop exit strategies from the academy in order to seek alternative career opportunities to those they are denied in HE and research institutions (Glass et al. 2013). In such cases, making sense of the "leaky pipeline" phenomenon becomes even more of a challenge (Dubois-Shaik and Fusulier 2015), since even if they have a marginally better chance of receiving tenure than their female counterparts, the majority of male $\mathrm{PhD}$ holders will also end up working outside of the academy.

\section{The survivor model}

A second academic career pattern identified by Christine Musselin is described as a survivor model and is typical of countries where the Humboldt tradition of academic chairs rather than departments is strong (e.g. Austria, Germany, Switzerland and Belgium). In this case, 
After their $\mathrm{PhD}$, candidates for an academic career must [...] wait many years to obtain a permanent position. Only those overcoming the long period of selection and $[\ldots]$ competition involving many candidates, among whom only one or a few $[\ldots]$ have a chance to survive.

(Enders and Musselin 2008, p. 135)

The survivor model of academic careers is thus based on a long tradition of informal career management principles that are not directly related to the introduction of NPM principles (Enders, de Boer and Leisyte 2009). The only "permanent" positions in the system are those located at the very pinnacle of the academic hierarchy and reaching them has always involved occupying a succession of fixed-term and institutionally subordinate positions, and was historically dependent on securing external funding. In parallel to a small number of full professorships, which in some Swiss universities, for example, are themselves based on fixed-term (six year), renewable contracts, academic labour markets based on the survivor model have always offered a majority of fixed-term, often part-time, positions with relatively decent pay, but a lack of academic freedom or promotion prospects. Likewise, it has been standard practice to fund such positions solely on the basis of teaching or research, making it extremely difficult for their incumbents to build up the integrated academic profile required of full professors without multiplying their employment contracts and extending their working hours (Brechelmacher et al. 2015). Not surprisingly, this model of academic career was historically very masculinised, with women representing less than 10 per cent of professorships in many German-speaking countries well into the 2000s (European Commission 2013). However, somewhat surprisingly, the numerous fixed-term, part-time positions that existed within these academic institutions in the past were occupied by men, some of whom were dependent on inherited wealth or even on a "breadwinning spouse" in order to maintain themselves on a highly precarious and unpredictable academic career track, in the hope of one day reaching the "Eldorado" of a full professorship (Schultheis 2000). At the end of the nineteenth century, Emile Durkheim referred to these precarious middle range positions (mittelbau) as the "academic proletariat" of the German university system (Schultheis 2000), and there were almost no women around at the time.

In parallel to the shared belief of access to a professorship as something analogous to "conquering Everest", this Humboldt career model was historically associated with a greater visibility of PhD holders in the non-academic labour market. Far from being reserved for individuals with academic career aspirations, doctoral studies were considered useful for a wide range of other professional and managerial occupations, where individuals could use their academic titles as a source of prestige and recognition. In Switzerland, for example, a doctorate in Law was considered a pre-requisite for training as a lawyer in several cantons (Boni-Le Goff et al. 2018), whereas this was rarely the case elsewhere.

In the early 2000s, some countries who had had a survivor career model (e.g. Germany and, to a certain extent, Switzerland) undertook a series of structural 
reforms, in order to introduce permanent or semi-permanent positions - inspired by the US tenure-track model - at an intermediate level of the academic hierarchy. In some cases, these so-called "C grade professorships" were reserved for female candidates, as a strategy to reduce the drastic under-representation of women at the top of the academic hierarchy (Beaufays and Kraïs 2005). By all accounts, the results of this reform have been modest (BuWIN 2008, 2013), although some studies do show a spectacular improvement in women's relative chances of becoming a professor in specific disciplines, such as sociology in Germany (Lutter and Schröder 2014). However, a recent report on junior scholars in Germany has stressed the difficulties young doctorate holders face in planning an academic career, notably due to the specificities of this particular career model, including "the bottleneck caused by the plethora of junior scholars on the one hand, and the relatively small number of professorships to be filled or becoming vacant on the other" (BuWiN 2017, p. 5). Similar accounts have been published about the situation in Switzerland (Dubach 2014) and Austria (Holzinger and Hafellner 2015; Schwabe 2011).

In the survivor career model countries, one would expect precariousness to appear under rather different guises than under the tenure-track model. Aspiring academics are likely to accept extremely short-term, part-time, low paid forms of academic employment, sometimes in combination with equally unstable or unpredictable jobs outside of academia. The ultimate aim of these so-called "crumb jobs" is simply to enable prospective academics to "keep a foot" (or toe) in the academic labour market long enough to build up (essentially, in their own time and with their own funds) a research and teaching portfolio that could one day qualify them for a permanent academic position, usually not in the institution where they completed their $\mathrm{PhD}$. As the latest She Figures show, part-time employment rates in academic jobs are particularly high - for men and for women - in those countries characterised by the survivor career model (see Figure 2.4). This undoubtedly reflects the precarious employment conditions usually reserved for $\mathrm{PhD}$ students and postdocs. However, it appears that working part-time may not have the same implications for male and female $\mathrm{PhD}$ holders. Although many of the intermediate, non-tenured academic jobs may formally be part-time, aspiring professors are actually expected to combine several such positions and, effectively, to invest in their career well beyond the duration of a full-time working week. Thus, those (mostly female) junior researchers who work only on a part-time basis (whilst taking on most of the unpaid domestic and childcare duties at home) are ultimately disqualified from the highly competitive academic career track. Under such gruelling and longwinded recruitment procedures, it is hardly surprising that many postdocs ultimately decide to give up the wait for a permanent position and to "voluntarily" leave the academic labour market for good (Chlosta et al. 2010). This decision is often facilitated by the relative ease with which their doctoral qualifications are recognised and rewarded on the non-academic labour market; something which appears to be far more problematic in countries that are characterised by the third and final academic career model. 


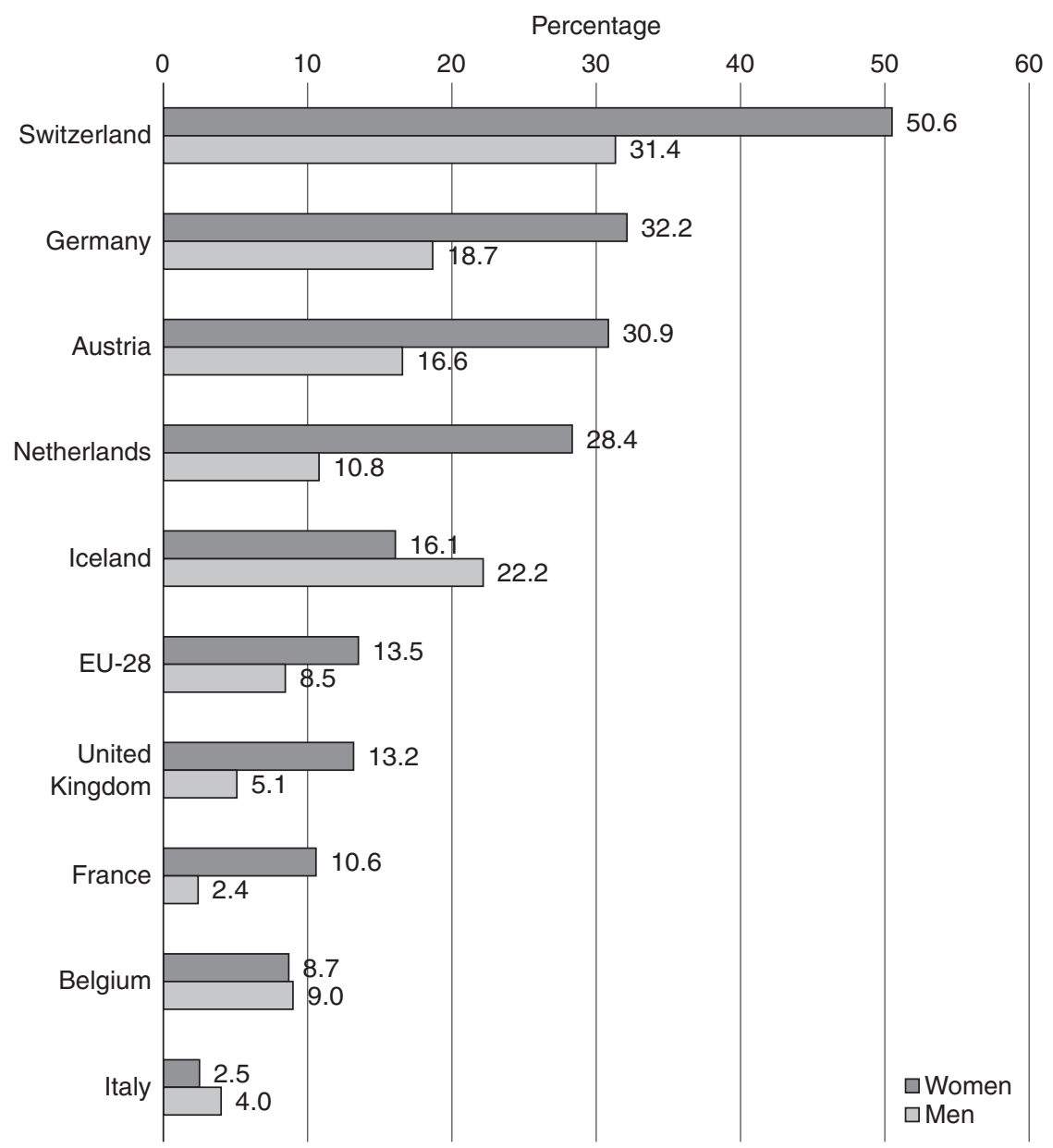

Figure 2.4 Part-time employment rate of researchers in the higher education sector, by sex, selected countries, 2012.

Source: European Commission/She Figures, 2016, p. 102. https://data.europa.eu/euodp/data/dataset/ she-figures-2015-gender-in-research-and-innovation.

\section{The protective pyramid model}

The third academic career pattern identified by Musselin is the protective pyramid model, which is prevalent in countries where academics have historically had civil servant status (e.g. France, Italy, Spain, Slovenia). These countries are usually characterised by nationally organised accreditation procedures. In this case,

access to a permanent position occurs quite early after a highly selective tournament. There then exist different categories of permanent positions 
organised hierarchically with procedures allowing promotion of some from one category to another. There is no assurance that those entering the pyramid can rise to the top: this very much depends on the growth rate of the overall pyramid and the age/seniority of those on the top.

(Enders and Musselin 2008, p. 135)

This model often includes a national accreditation process between the $\mathrm{PhD}$ defence and access to the first permanent academic positions. Based on more or less sophisticated peer-review procedures (Marini and Meschitti 2018), this career model is the most directly dependent on national-level decision-making processes and is the least closely tied to the Human resource (HR) policies and practices of local institutions (universities, faculty departments, research centres, etc.). Thus, academics in countries organised along these lines are more likely to identify with their disciplinary field than with their employing institution, whereas the opposite is true for their those working in countries characterised by the tenure-track career model, like the US (Musselin 2005).

This particular career model is also associated with an internally segmented academic labour market, but where it has traditionally been possible to remain at intermediate levels (equivalent to Reader or Senior Lecturer) for an indefinite period of time (contrary to the historical tenure-track career model), and with a stable and permanent employment contract (contrary to the traditional survivor model). Progression to the higher stages of the career ladder is subject to a new round of examination and accreditation and to the availability of professorial positions at the local or national level. However, the career structure in countries like this tends to be rather flat, with little subordination of the lower ranks of academics to their professorial counterparts and with relatively modest pay gaps at different points in the socio-professional hierarchy. Apart from PhD supervision (for which an additional form of accreditation may be required), lower level academic positions offer relatively similar levels of access to research funds, teaching loads and administrative responsibilities as those at the top of the academic hierarchy (tenured professorships). The stability of these intermediate, permanent non (full) professorial positions, as well as the academic freedom traditionally associated with public-sector employment in those countries characterised by the protective pyramid model has contributed to specific forms of gender segregation and career progression. In France, for example, women have made very significant inroads into the lower levels of the academic hierarchy in almost all disciplinary fields, but their progression onto full professorships has been slower and more varied across disciplines (Hermann 2017; Le Feuvre 2017). As we have seen, within this career model, the fact that women tend to remain longer than men at the Senior Lecturer level can in no way be associated with a "precarious" career path, since these are tenured positions, offering a large degree of professional autonomy and academic freedom, as well as relatively comfortable pay levels. This stands in sharp contrast to the pressure and uncertainty experienced by many of their Grade B counterparts in countries characterised by a survivor career model. 
In the French case, for example, it would be misleading to suggest that those women who remain in tenured Grade B positions throughout their working lives have somehow "leaked" from the academic pipeline. They haven't. They may not have reached the peak of the academic hierarchy, they may indeed have access to fewer material and symbolic resources than their professorial peers, but they nevertheless continue to influence the daily workings of academic institutions, including the definition of teaching and research programmes, the recruitment of future colleagues, the supervision of male and female graduate students and even the management of large research programmes.

In this particular career model, young researchers are more directly dependent on national or regional level policies than on the HR strategies of particular HE and research institutions. Furthermore, there is not a clear hierarchy of employer institutions, since working conditions are defined quite homogeneously for all those who share the same occupational status, irrespective of the prestige of their employer. This means that any decision to reduce the resources available to HE and research institutions will have a blanket effect on a whole generation of prospective academics. Thus, in Italy, a country with extremely high youth unemployment rates, the decision to cut the national HE budget by replacing only half of the retiring tenured academic staff has had a huge impact on the internal career structure of all public universities (Bozzon et al. 2017). Between 2008 and 2013, the number of teaching and research staff in Italian universities increased by 5.2 per cent, while the number of permanent academic positions (full, associate and assistant professors) fell by 18.5 per cent. This drop is almost exclusively due to the non-replacement of retirees and is particularly visible at the very top of the occupational hierarchy $(-26.6$ per cent for full professors, -15.4 per cent for associate professors, -13.4 per cent for assistant professors). In parallel, the number of non-permanent research positions has increased by a staggering 71.2 per cent (Bozzon et al. 2015, pp. 36-37). In 2013, nonpermanent positions accounted for 37 per cent of the teaching and research staff in Italian universities; a figure that rose to 50 per cent if $\mathrm{PhD}$ students were included in the calculations. More than 60 per cent of these fixed-term positions are research fellows, who are often not covered by Italian labour laws and employment rights. Indeed, only 10 per cent of these fixed-terms contracts provide standard employment conditions (Bozzon et al. 2015, pp. 36-37). Furthermore, women are slightly under-represented amongst the most stable of these precarious academic positions (43.3 per cent of fixed-term researchers), whereas they represent half of the fixed-term research fellows and scientific collaborators (ibid.).

Given the relatively low number of $\mathrm{PhD}$ graduates in these countries, there is no tradition of doctoral employment in non-academic jobs, leaving a relatively small number of postdocs with little option for exit to alternative, non-academic jobs and with limited opportunities for "protective" forms of employment in the $\mathrm{HE}$ and research sector (Bozzon et al. 2017). So, although highly qualified PhD holders within this third career model are always better protected against the risk of unemployment than other groups of young knowledge workers, they are 
nevertheless affected by what Robert Castel (2007) has called the precariat, a phase of capitalism where jobs lose their capacity to provide workers with a living wage and with a full range of social protection, including unemployment benefit, health care and pension rights (Armano and Murgia 2013).

In a number of countries, research has shown the national accreditation procedures to be relatively egalitarian from a gender point of view (Marini and Meschitti 2018), whilst the local recruitment procedures to professorships may introduce some form of gender bias (ibid.), or not (Musselin and Pigeyre 2008).

As several authors have argued, despite the overriding structural challenges facing $\mathrm{HE}$ and research institutions, there is a degree of "path dependency" in the type of academic career model that prevails in a given national context. Few countries have abandoned their traditional academic career models, although most have aimed to "modernise" those elements of their national career systems that are perceived as the most problematic in the new academic environment (Enders and Musselin 2008, p. 135). Although all of the academic career models listed above are currently undergoing a degree of restructuring, there is no clear sign of convergence around a single career model: "national labour markets are not so much being displaced as subordinated and stratified" (Marginson 2009, p. 110). In sum, whatever the definition of precariousness used in studies of academic employment (see Chapter 1, this volume), it is important to note that the reference point for current changes is likely to influence the subjective experiences of the young academics concerned and the theoretical interpretation of the increased diversification of career trajectories within a given (national) career model.

\section{Mapping the gendered diversification of academic career paths}

Considering the gendered employment prospects of early career stage academics immediately raises an analytical challenge: acquiring the qualification required for entrance into the academic profession significantly reduces the risk of unemployment over the entire life-course, but the positive effect of a $\mathrm{PhD}$ on male and female employment rates doesn't automatically guarantee protection against various forms of precariousness employment or vulnerability, at least in the short term. In reality, a limited number of studies have shown that the relative position of academic occupations in the socio-professional hierarchy is highly variable from one national context to the next, as are the monetary and other rewards associated with working in public or private sector research institutions (European Commission/CARSA 2007; Studer 2012). Thus, it is not only important to consider the employment and working conditions of early career stage academics in comparison to those in other labour market sectors, it is also vital to consider their evolution over the life-time, from a biographical perspective. These distinct career models have very direct consequences for the interaction of professional and family events (Dubois-Shaik and Fusulier 2017), since they each imply relatively specific biographical time-lines. For example, the OECD 
Careers of Doctorate Holders $(\mathrm{CDH})$ study shows that the median age at $\mathrm{PhD}$ graduation ranges from 29 years old in Belgium to more than 39 years in the Czech Republic (Auriol 2010, p. 6).

\section{Gendered academic labour markets in comparative perspective}

One of the most important points to take into consideration when comparing the precariousness of $\mathrm{PhD}$ holders must certainly be the alternative employment opportunities available to them - or not - at the local, national and international level. The consequences of the demographic, organisational and ideological transformations of academic labour markets outlined above will clearly vary considerably according to the national economic climate, and particularly the levels of unemployment or precarious employment facing the younger generations of university-educated men and women in different national contexts. Indeed, gendered patterns of youth unemployment and labour market discrimination may influence the relative likelihood that men and women in certain national contexts will envisage studying for a $\mathrm{PhD}$ and/or aiming for an academic career in the first place. Thus, in the Swiss case, Matthias Studer (2012) has shown that the proportion of women who decide to embark on a $\mathrm{PhD}$ after their Master's Degree varies considerably according to the alternative employment opportunities available in the local labour market for graduates from particular fields of study. The more limited the non-academic employment possibilities in a given field, the higher the proportion of women amongst graduate students. At this early stage in their life-course, women thus tend to protect themselves from the risk of discrimination in the local labour market by staying in the (relatively) "safe haven" of the academy. Their excellent educational results enable them to compete successfully with their male counterparts for publicly-funded $\mathrm{PhD}$ positions, particularly in the humanities and life sciences. In his study, Studer found no significant gender differences in the success rate or duration of doctoral studies (once disciplinary field had been controlled for), a finding often replicated elsewhere. However, in a country with very low youth unemployment rates, ${ }^{1}$ female $\mathrm{PhD}$ graduates in Switzerland are significantly less likely than their male counterparts to obtain a professorship within the 10 years following their doctorate, particularly in those disciplinary fields where they were well represented.

The internal structure of the Swiss academic labour market shows that the number and relative weight of the Mittelbau increased considerably over the period under study. Growth was particularly rapid in those jobs where the chances of being engaged on a fixed-term contract are higher than in any other case. This group, which includes doctoral students employed as teaching assistants and postdocs, represented almost half of the academic population in Swiss universities in 2014, as against 40 per cent in 1980. This increase is partly due to the fact that the number of (funded) PhD positions has doubled since 1990 (SERI 2015 , p. 32). However, the number of fixed-term postdoc positions has also increased, to approximately 8000 in 2011 (SERI 2015, p. 25). Over the same 
period, the more stable category of full professors decreased by 5 per cent. The Swiss academic career structure has thus become increasingly "bottom heavy" over time: in 1980 there were four (temporary) assistantships or scientific collaborator positions for every full professorship. By 2014, this ratio was eight temporary positions for every full professorship (SERI 2015).

However, cross-national comparative data on the gendered configuration of precarious employment contracts (Figure 2.5) can be misleading. Although they may enable us to gauge the extent to which women are particularly vulnerable to unfavourable employment conditions, as is clearly the case in Austria, Belgium and Switzerland, these figures fail to account for the fact that access to any kind of funding during the $\mathrm{PhD}$ phase of an academic career may vary significantly, by country and by disciplinary field. Thus, in Iceland, for example, $\mathrm{PhD}$ students in

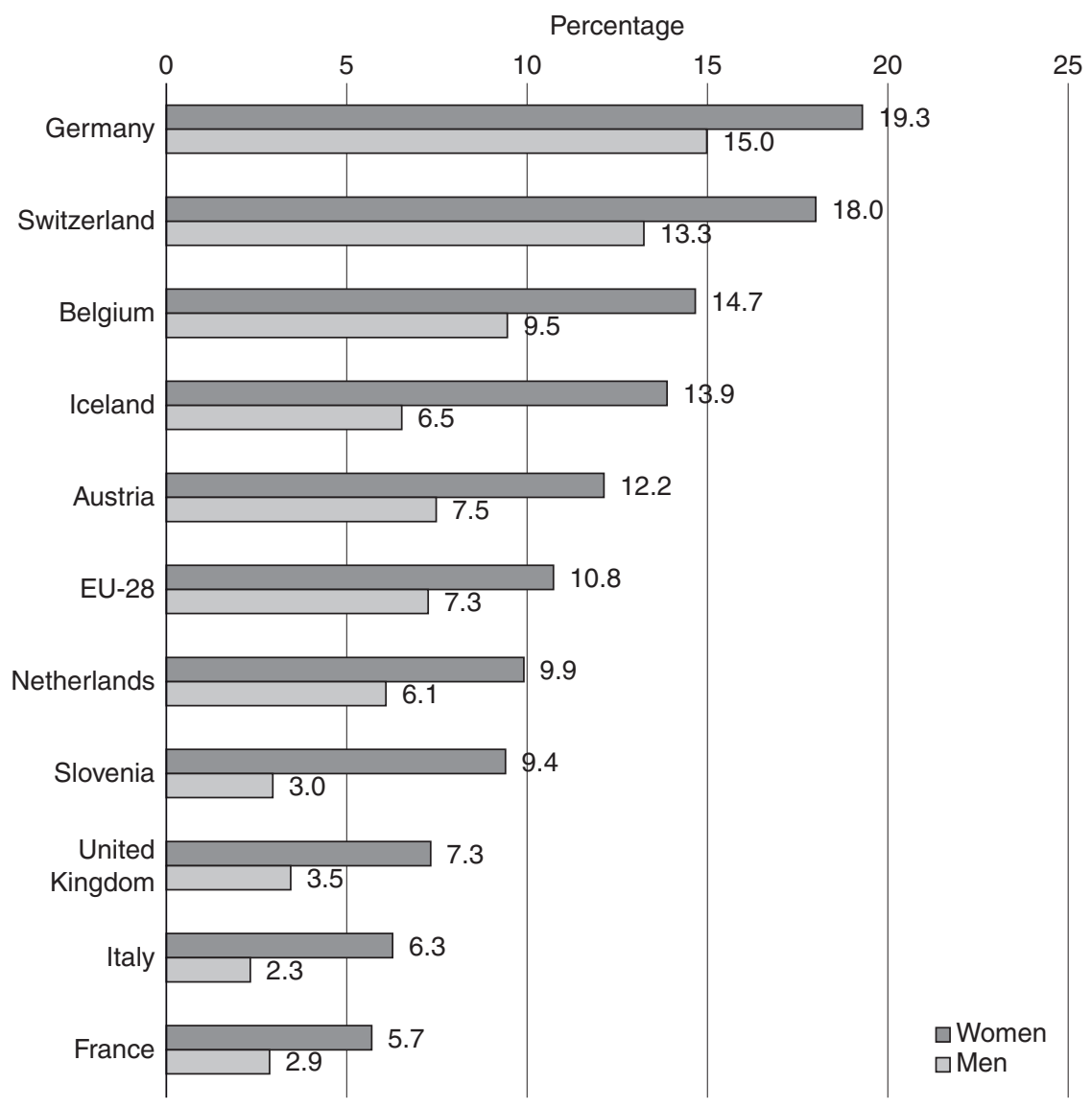

Figure 2.5 "Precarious" working contracts of researchers in the higher education sector out of total research population, by sex, selected countries, 2012.

Source: European Commission/She Figures, 2016: p.104. https://data.europa.eu/euodp/data/dataset/ she-figures-2015-gender-in-research-and-innovation. 
the male-dominated STEM are far more likely to have an employment contract with a university - even on a fixed-term and/or part-time basis - than their counterparts in the humanities and social sciences, where a larger proportion of $\mathrm{PhD}$ students are effectively "self-funded", either by working in fixed-term academic (usually teaching) jobs or by working elsewhere (Steinthorsdóttir et al. 2018).

As other studies on the gendered configuration of precarious early academic careers have shown (Bataille, Le Feuvre, and Kradolfer 2017), the nature of societal level gender arrangements can also affect the ability or willingness of male and female researchers to accept precarious employment conditions over an extended period of time. Thus, in Switzerland, a country with a modified male breadwinner model of gender arrangements (Bühlmann, Elcheroth, and Tettamanti 2009), male $\mathrm{PhD}$ holders (particularly in male-dominated fields) only remain in the academy if they are ensured of obtaining a tenured position within what they consider to be a "reasonable" length of time. This usually corresponds to their likely entry into parenthood, requiring them to adopt a "male/primary breadwinning" role. Female PhDs, on the other hand, are more willing to accept a succession of fixed-term research and/or teaching contracts, often on a parttime basis and with no immediate prospect of tenure. This is particularly the case in the most feminised fields of study, where the relatively numerous, alternative (non-academic) employment opportunities are judged to be less intrinsically satisfying and/or family-friendly than the available fixed-term, often part-time research and/or teaching positions. Since mothers of young children are not expected or encouraged to work full-time in the Swiss context (Bütler 2006), the expansion of temporary, non-tenured employment opportunities within the academic sector has led to a rather paradoxical situation. With the support of their male partners working full-time, in well-paid jobs, Swiss female PhD holders manage to maintain themselves within the academic sector, even during their child-rearing years, thanks to a continued supply of temporary, part-time, subordinate and competitively-funded research positions, which provide minimum levels of social protection. However, due to the extended time commitment expected of tenured professors, they generally fail to progress up the academic hierarchy and/or to achieve financial and intellectual autonomy (Bataille, Le Feuvre, and Kradolfer 2017). Those women who do eventually receive tenured academic positions in Switzerland are often recruited internationally (only half of all university professors in the country are Swiss; see Goastellec and Pekari 2013), after having previously worked (continuously and full-time) in other national academic labour markets. As Matthias Studer has noted, in the most feminised fields of study, female $\mathrm{PhD}$ holders in Switzerland often experience their first risk of unemployment or involuntary underemployment up to 10 years after they obtained their initial postdoc appointment, only once they are no longer eligible for many of the fixed-term positions that had paved their entry into an (ultimately diverted or dead-end) academic career path. It is thus with a considerable time lag that these highly experienced academics are required to look outside the academy for a permanent job that is compatible with their family obligations and with their past work experience (Studer 2012). 
In countries where the under $25 \mathrm{~s}$ have borne the brunt of the Great Recession, the logic behind the development of precarious jobs within academic institutions is rather different. In Italy, for example, various recent labour market reforms have resulted in a significant increase in the share of precarious jobs, particularly amongst the younger generations and for women. About one in four people aged 15 to 34 has a temporary or collaboration contract, with the proportion increasing to 31.7 per cent amongst university graduates (Bozzon et al. 2015, pp. 8-10). A third of workers aged 35 to 49 years are also recruited to these kinds of precarious jobs. University graduates are much harder hit by the recession in Italy than in most other EU countries; the employment rate for recent graduates was below 70 per cent in 2014. Graduates in the Humanities and in the Sciences have experienced huge labour market transition problems: 12 months after graduation, unemployment rates stand at more than 40 per cent, as compared to less than 10 per cent in the Health sciences and about 30 per cent in Engineering. Within this difficult context, male graduates tend to fare better than their female counterparts: five years after graduation, almost 80 per cent of them have a permanent contract, compared to 67 per cent of the women graduates. Their average wages are also 22 per cent higher than those of similarly qualified women (Bozzon et al. 2015, pp. 8-10).

\section{Academic labour markets in biographical perspective}

However, despite rather alarming media references to the "wasted generation" of $\mathrm{PhD}$ holders in many national contexts, the reality is a little more complex. Conclusions as to the relative employment and working conditions of $\mathrm{PhD}$ holders fluctuate wildly according to the time-scale of measurement and observation. For example, data from the French Ministry of Education show that, between 1992 and 2013, the number of temporary workers in HE and research institutions increased by 111 per cent, as compared to +39 per cent for professorships and +74 per cent for senior lecturers (Maîtres de conférences). Since 2004, the number of permanent academic positions available to new recruits has fallen slightly. This had led to fears about the precariousness of early academic careers in a country where the unemployment rate for $\mathrm{PhD}$ holders was actually higher than that of Masters graduates; something rarely observed elsewhere. However, more recent longitudinal studies have changed this vision of $\mathrm{PhD}$ holders as "over qualified" and poorly adapted to the labour market. When the labour market transition of highly qualified male and females is observed over a longer period of time than was previously the case, the relative disadvantage of $\mathrm{PhD}$ holders disappears. Overall, about 42 per cent of people who received a $\mathrm{PhD}$ in France in 2010 were working in the $\mathrm{HE}$ and research sector five years later. Among this population, the share of permanent public-sector academic positions increases over time, from 11 per cent in the year following graduation to 36 per cent five years after the $\mathrm{PhD}$. Thus, approximately two years after the $\mathrm{PhD}$ defence, the number of permanent public sector academic positions was higher than the number of fixed-term positions (Calmand, Prieur, and Wolber 2017, p. 2). As suggested by the figures in Table 2.3, competition for academic 
Table 2.3 Employment trajectory of PhD holders five years after doctorate defence (generation 2010), by disciplinary field, France, 2015

\begin{tabular}{|c|c|c|c|c|c|c|}
\hline Employment profile at $\mathrm{PhD}+$ five years & $\begin{array}{l}\text { Maths } \\
\text { Physics } \\
\text { Chemistry }\end{array}$ & $\begin{array}{l}\text { Engineering } \\
\text { Computer Studies }\end{array}$ & $\begin{array}{l}\text { Health and } \\
\text { Life Sciences }\end{array}$ & $\begin{array}{l}\text { Law } \\
\text { Economics } \\
\text { Business } \\
\text { Social Sciences }\end{array}$ & $\begin{array}{l}\text { Arts and } \\
\text { Humanities }\end{array}$ & Total \\
\hline $\begin{array}{l}1 \text { Rapid access to a stable position in a public sector } \\
\text { HE/research institution }^{\mathrm{a}}\end{array}$ & 18 & 26 & 7 & 30 & 26 & 20 \\
\hline $\begin{array}{l}2 \text { Delayed access to a stable position in a public sector } \\
\text { HE/research institution }\end{array}$ & 12 & 9 & 9 & 14 & 14 & 11 \\
\hline $\begin{array}{l}3 \text { Temporary/fixed-term position in a public sector } \\
\text { HE/research institution }\end{array}$ & 10 & 6 & 24 & 7 & 5 & 11 \\
\hline $\begin{array}{l}4 \text { Rapid access to a stable non-academic position in the } \\
\text { public sector }\end{array}$ & 6 & 2 & 7 & 11 & 18 & 8 \\
\hline $\begin{array}{l}5 \text { Temporary/fixed-term non-academic position in the } \\
\text { public sector }\end{array}$ & 2 & 1 & 9 & 8 & 10 & 6 \\
\hline $\begin{array}{l}6 \text { Rapid access to a stable } R \& D \text { position in the } \\
\text { private sector }\end{array}$ & 27 & 30 & 15 & 3 & 2 & 17 \\
\hline $\begin{array}{l}7 \text { Rapid access to a stable non-R\&D position in the } \\
\text { private sector }\end{array}$ & 13 & 19 & 9 & 17 & 11 & 14 \\
\hline 8 Not in employment or only in temporary jobs & 12 & 7 & 19 & 9 & 15 & 13 \\
\hline Unemployment rate in 2015 & 4 & 4 & 12 & 6 & 9 & \\
\hline
\end{tabular}

Source: Calmand, Prieur and Wolber 2017, p. 2.

Note

a Permanent research position reached by September 2011. 
positions and opportunities for non-academic jobs also vary considerably by disciplinary field. Thus, in 2013, the ratio of newly recruited senior lecturers (Maîtres de conférences) to qualified PhD holders was 1:25 in Health and Life sciences, as compared to 1:6 overall. Interestingly, this study reported no significant gender differences in the employment transitions of French PhD holders; women were proportionally represented in all the categories of employment, including permanent academic positions.

\section{Conclusions}

Somewhat paradoxically, the fact that women are universally under-represented in practically the same proportions at the top of the academic professional hierarchy in every national context, and the fact that academic institutions are currently undergoing apparently global influences, has tended to foster the belief that the pattern of precariousness of early career stage academic jobs must be relatively similar across national boundaries (Le Feuvre 2016). Although we have no desire to deny the potentially common experiences of women in academia in different national (or local) contexts, this chapter reflects our conviction that research on gendered academic careers would benefit from a more sophisticated conceptually comparative perspective. As we have demonstrated here, women (and men) in the early stages of an academic career may not be facing exactly the same structural and normative opportunities and constraints in

all national or regional contexts. In this chapter, we have focussed on just some of the societal communalities and specificities that can be observed with regard to precariousness among early career stage academics.

First, we have argued that, despite convergent international trends in favour of accountability and competition in academic evaluation procedures, what it means to be an academic and the criteria used to select and promote members of this occupation still manifest a considerable degree of national (or local) specificity. Academic career models continue to demonstrate a high level of path dependency (Enders and Musselin 2008). The proportion of fixed-term and precarious jobs, along with the percentage of permanent and tenured positions is highly variable, both between countries, between disciplines and over time. It would therefore be misleading to compare women's early stage career trajectories across countries without taking the structural, nationally specific characteristics of the academic labour market into consideration.

Second, academic occupations do not occupy the same position in the socioeconomic hierarchy in all national contexts. The relative attractiveness of a research career, in comparison to the alternative employment opportunities open to male and female $\mathrm{PhD}$ holders, can't be presumed to be equivalent across national boundaries, or even across disciplines. Indeed, the relative rewards and opportunities offered by academic careers must be analysed in relation to the specific internal structure of the academic labour market (duration of the pretenure career stage, requirement to be geographically mobile, relative levels of pay and other perks, length of the working week, opportunities for flexible 
employment practices, etc.) and in relation to the dominant model of gender relations (sexual division of paid and unpaid labour, availability of affordable childcare solutions, moral stigmatisation or acceptance of full-time working mothers and/or of family-committed fathers, tolerance of homosexuality and/or nonnormative living arrangements, etc.).

So, just as there is not a universal set of gender norms that influence women's access to scientific jobs and their ability to progress (or not) up the academic hierarchy, so there is not a universal academic career structure that condemns all young $\mathrm{PhD}$ holders to a long-term future of professional uncertainty and vulnerability. Gender regimes and academic labour markets need to be carefully contextualised before descriptive data on the current precariousness of academic labour markets can be analysed and interpreted correctly. Although we would not go so far as to suggest that increasing rates of feminisation are necessarily a reflection of worsening of employment conditions in the academic sector (Bourdieu 1998), it is nevertheless important to remember that female $\mathrm{PhD}$ holders can sometimes represent what the Polish sociologist Renata Siemienska (2001) has called "winners amongst losers". In those cases where early career academic jobs can be equated to a form of precariat, we obviously need to revise the celebratory discourse that traditionally accompanied any increase in the feminisation rates of academic occupations.

However, the main conclusion to be drawn from this study is that the $\mathrm{PhD}$ holders who are now confronted with unprecedented levels of competition for access to academic labour markets are not experiencing the same level of precariousness, or indeed the same consequences of precarious employment conditions, across all countries and all disciplinary fields. Likewise, the reactions of those confronted with precarious employment and working conditions are likely to vary significantly (Vallas and Christin 2018), by national context, disciplinary field and according to societal gender configurations.

In most national contexts, the academic profession is becoming increasingly fragmented and internally segmented. Although there is clearly a gender dimension to this re-segregation, it would be misleading to conclude that this is a case of plus ça change, plus c'est la même chose (Le Feuvre 2010). In a context where the promotion of gender equality has been fully integrated into the rhetoric of NPM monitoring and benchmarking activities, the gendered reconfiguration of academic careers will certainly depart from a straightforward binary divide and will require the elaboration of analytical tools that are able to capture the complex and partly contradictory processes at work.

\section{Note}

1 See: http://ec.europa.eu/eurostat/web/macroeconomic-imbalances-procedure/youthunemployment-rate. 


\section{References}

Armano, E. and Murgia, A. (2013). The precariousness of young knowledge workers: a subject-oriented approach. Global Discourse. http://dx.doi.org/10.1080/23269995.2013. 865313.

Auriol, L. (2007). Labour Market Characteristics and International Mobility of Doctorate Holders: Results for Seven Countries. OECD STI Working papers 2007/2.

Auriol, L. (2010). Careers of Doctorate Holders: Employment and Patterns. OECD Science, Technology and Industry Working Papers, No. 2010/04, Paris: OECD Publishing.

Auriol, L., Misu, M. and Freeman, R. A. (2013). Careers of Doctorate Holders: Analysis of Labour Market and Mobility Indicators. OECD Science, Technology and Industry Working Papers, No. 2013/04, Paris: OECD Publishing.

Barrett, L. and Barrett, P. (2011). Women and academic workloads: career slow lane or cul-de-sac? Higher Education, 61, 141-155.

Bataille, P., Le Feuvre, N. and Kradolfer, S. (2017). Should I stay or should I go? The effects of precariousness on the gendered career aspirations of postdocs in Switzerland. European Educational Research Journal, Special Issue: Work-Life Interferences in Scientific Careers, 16(2-3), 313-331.

Beaufays, S. and Kraïs, B. (2005). Femmes dans les carrières scientifiques en Allemagne, les mécanismes cachés du pouvoir. Travail, genre et sociétés, 14, 49-68.

Bourdieu, P. (1998). La domination masculine. Paris: Seuil.

Boni-Le Goff, I. and Le Feuvre, N. (2017). Professions from a gendered perspective. Oxford Research Encyclopedia of Business and Management, Oxford: Oxford University Press.http://business.oxfordre.com/view/10.1093/acrefore/9780190224851.001.0001/ acrefore-9780190224851-e-89?print=pdf.

Boni-Le Goff, I., Le Feuvre, N, Mallard, G. and Lépinard, E.(2018). Do gender regimes matter? A study of early legal careers in France and Switzerland. In M. Choroszewicz and T. L. Adams (eds), Gender, Age and Inequality in the Professions. London: Routledge (in press).

Bozzon, R., Donà, A., Villa, P., Murgia, A. and Poggio, B. (2015). Background policy report on Italy. In N. Le Feuvre (ed.), Contextualizing Women's Academic Careers: Comparative Perspectives on Gender, Care and Employment Regimes in Seven European Countries. Trento: GARCIA Working Papers 2, 3-60. http://garciaproject.eu/ ?page_id=52.

Bozzon, R., Murgia, A., Poggio, B. and Rapetti, E. (2017). Work-life interferences in the early stages of academic careers: the case of precarious researchers in Italy. European Educational Research Journal, 16(2-3), 332-351.

Bozzon, R., Murgia, A. and Villa, P. (2017). Precariousness and gender asymmetries among early career researchers: A focus on STEM fields in Italy. Polis, XXXI(1), 127-156.

Brechelmacher, A., Park, E., Ates, G. and Campbell, D. F. J. (2015). The rocky road to tenure. Career paths in academia, In T. Fumasoli, G. Goastellec and B. M. Kehm (eds), Academic Work and Careers in Europe: Trends, Challenges, Perspectives. Dordrecht: Springer, pp. 13-40.

Brooks, A. and Mackinnon, A. (2001). Gender and the Restructured University. Changing Management and Culture in Higher Education, Buckingham: Open University Press.

Bühlmann, F., Elcheroth, G. and Tettamanti, M. (2009). The division of labour among European couples: the effects of life course and welfare policy on value-practice configurations. European Sociological Review, 26(1), 49-66, doi.org/10.1093/esr/jcp004. 
Bütler, M. (2006). Le rendement effectif du travail pour les familles avec des petits enfants. St Gallen: Département d'économie publique, St Gallen University.

BuWiN - Bundesbericht Wissenschaftlicher Nachwuchs (2008). 1st National Report on Junior Scholars in Germany. Bielefeld: Consortium for the National Report on Junior Scholars.

BuWiN - Bundesbericht Wissenschaftlicher Nachwuchs (2013). 2nd National Report on Junior Scholars in Germany. Bielefeld: Consortium for the National Report on Junior Scholars.

BuWiN - Bundesbericht Wissenschaftlicher Nachwuchs (2017). 3rd National Report on Junior Scholars in Germany. Bielefeld: Consortium for the National Report on Junior Scholars.

Calmand, J., Prieur, M. H. and Wolber, O. (2017). Les débuts de carrière des docteurs: une forte différenciation des trajectoires. CEREQ Bref, 357.

Caprile, M., Addis, E., Castaño, C., Klinge, I., Larios, M. and Meulders, D. (2012). MetaAnalysis of Gender and Science research. Synthesis Report. Brussels: European Commission, DG Research and Innovation.

Castel, R. (2007). Au-delà du salariat et en-deçà de l'emploi? L'institutionnalisation du précariat, In S. Paugam (ed.), Repenser la solidarité: l'apport des sciences sociales. Paris: Presses universitaires de France, pp. 416-433.

Ceci, S. J., Ginter, D. K., Kahn, S. and Williams, W. M. (2014). Women in academic science: a changing landscape. Psychological Science, 15(3), 75-141.

Chlosta, K., Pull, K., Fiedler, M. and Welpe, I. (2010). Should I stay or should I go? Warum nachwuchswissenschaftler in der Betriebswirtschaftslehre das Universitassystem verlassen, Zeitschrift fur Betreibswirtschaft, 80(11), 1207-1229.

Crompton, R. (2001). Gender, comparative research and biographical matching. European Societies, 3(2), 167-190.

Crompton, R. (2006). Some issues in cross-national comparative research methods: a comparison of attitudes to promotion and women's employment in Britain and Portugal. Work, Employment and Society, 20(2), 403-414.

Crompton, R. and Le Feuvre, N. (2000). Gender, family and employment in comparative perspective: the realities and representations of equal opportunities in Britain and France. Journal of European Social Policy, 10(4), 334-348.

Crompton, R., Lyonette, C. and Scott, J. (eds) (2010). Gender Inequalities in the 21st Century. New Barriers and Continuing Constraints. London: Edward Elgar.

Danell, R. and Hjerm, M. (2013). Career prospects for female university researchers have not improved. Scientometrics, 94(3), 999-1006.

De Cheveigné, S. (2009). The career paths of women (and men) in French research. Social Studies of Science, 39, 113-136.

Deem, R., Hillyard, S. and Reed, M. (2007). Knowledge, Higher Education, and the New Managerialism. Oxford: Oxford University Press.

Dubach, P. (2014). La relève scientifique dans les universités suisses: indicateurs statistiques concernant les conditions de travail et les perspectives de carrière. Bern: SERI.

Dubois-Shaik, F. and Fusulier, B. (eds) (2015). Academic Careers and Gender Inequality: Leaky Pipeline and Interrelated Phenomena in Seven European Countries. GARCIA Working Paper 5, http://garciaproject.eu/?page_id=52.

Dubois-Shaik, F. and Fusulier, B. (2017). Understanding gender inequality and the role of the work/family interface in contemporary academia. An introduction. European Educational Research Journal, Special Issue Work-Life Interferences in Scientific Careers, 16(2-3), 1-7. 
Ecklund, H. E., Lincoln, A. E. and Tansey, C. (2012). Gender segregation in elite academic science. Gender and Society, 26(5), 693-717.

Enders, J. and de Weert, E. (eds) (2009a). The Changing Face of Academic Life. Analytical and Comparative Perspectives. Basingstoke: Palgrave Macmillan.

Enders, J. and de Weert, E. (2009b). Towards a T-shaped profession: academic work and career in the knowledge society. In J. Enders and E. de Weert (eds), The Changing Face of Academic Life. Analytical and Comparative Perspectives. Basingstoke: Palgrave Macmillan, pp. 251-272.

Enders, J. and Musselin, C. (2008). Back to the future? The academic professions in the 21st Century. In OECD (ed.), Higher Education in 2030. Volume 1: Demography, Paris: OECD.

Enders, J., de Boer, H. and Leisyte, L. (2009). New Public Management and the academic profession: the rationalization of academic work revisited. In J. Enders and E. de Weert (eds), The Changing Face of Academic Life. Analytical and Comparative Perspectives. Basingstoke: Palgrave Macmillan, pp. 36-57.

Euraxess (2014). Researcher Country and Synthesis Reports. Brussels: DG Research. https://euraxess.ec.europa.eu/content/researcher-report-2014.

European Commission (2013). She Figures 2012. Statistics and Indicators on Gender Equality in Science. Brussels: DG Research and Innovation.

European Commission (2016). She Figures 2015. Statistics and Indicators on Gender Equality in Science. Brussels: DG Research and Innovation.

European Commission/CARSA (2007). Remuneration of Researchers in the Public and Private Sectors. Brussels: DG Research and Innovation. www.carsa.es.

EUROSTAT (2017). Tertiary Education Statistics. http://ec.europa.eu/eurostat/statisticsexplained/index.php/Tertiary_education_statistics.

Fassa, F. and Kradolfer, S. (2013). The gendering of excellence through quality criteria: the case of the Swiss national science foundation professorships in Switzerland. Tertiary Education and Management, 19(3), 189-204.

Ferlie, E., Musselin, C. and Andresani, G. (2008). The steering of higher education systems: a public management perspective. Higher Education, 56(3), 325-348.

Fumasoli, T., Goastellec, G. and Kehm, B. (eds) (2015). Academic Work and Careers in Europe: Trends, Challenges, Perspectives. Dordrecht: Springer.

Garforth, L. and Kerr, A. (2009). Women and science: what's the problem? Social Politics, 16(3), 380-403.

Gill, R. (2009). Breaking the silence: the hidden injuries of neo-liberal academia. In R. Flood and R. Gill (eds), Secrecy and Silence in the Research Process: Feminist Reflections. London: Routledge, pp. 1-21.

Glass, J. L., Sassier S., Levitte Y. and Michelmore K. M. (2013). What's so special about STEM? A comparison of women's retention in STEM and professional occupations. Social Forces, 92(2), 723-756.

Goastellec, G. and Pekari N. (2013). The internationalization of academic markets, careers and profession. In U. Teichler and E. A. Höhle (eds), The Work Situation of the Academic Profession in Europe: Findings of a Survey in Twelve Countries. Dordrecht: Springer, pp. 229-248.

Henkel, M. (2009). Policy change and the challenge to academic identities. In J. Enders and E. de Weert (eds), The Changing Face of Academic Life. Analytical and Comparative Perspectives. Basingstoke: Palgrave Macmillan, pp. 78-95.

Hermann, C. (2017). Enquête sur le statut des chercheur.e.s et enseignant.e.s chercheur.e.s dans divers pays d'Europe, Report from the European Platform of 
Women Scientists (EPWS) to the French Ministry of Higher Education, Research and Innovation, Paris.

Herschberg, C., Benschop, Y. and van den Brink, M. (2018). Selecting early-career researchers: the influence of discourses of internationalization and excellence on formal and applied selection criteria in academia, Higher Education, 1-19 https://doi.org/ 10.1007/s10734-018-0237-2.

Holzinger, F, and Hafellner, S. (2015). Background policy report on Austria. In N. Le Feuvre (ed.), Contextualising Women's Academic Careers: Comparative Perspectives on Gender, Care and Employment Regimes in Seven European Countries. GARCIA Working Papers 2, http://garciaproject.eu/?page_id=52, 243-285.

Hunter, L. A. and Leahey, E. (2010). Parenting and research productivity: new evidence and methods. Social Studies of Science, 40(3) June, 433-451.

Jaschik, S. and Lederman, D. (2017). Making the Cut: Getting Hired in Higher Education Today. Inside Higher Education webinar, 30 March. http://event.on24.com/wcc/ r/1389569/BC957FD93199D8AF17A1DC5E6893B2D8?mode=login\&email=nicky. lefeuvre@unil.ch.

Krefting, L. A. (2008). Intertwined discourses of merit and gender: evidence from academic employment in the USA. Gender, Work and Organizations, 10(2), 260-278.

Le Feuvre, N. (2009). Exploring women's academic careers in cross-national perspective: lessons for equal opportunity policies. Equal Opportunities International, 28(1), 9-23.

Le Feuvre, N. (2010). Feminising professions in Britain and France: how countries differ. In R. Crompton, C. Lyonette and J. Scott (eds), Gender Inequalities in the 21st Century. New Barriers and Continuing Constraints. London: Edward Elgar, pp. 126-149.

Le Feuvre, N. (ed.) (2015). Contextualising Women's Academic careers: Comparative Perspectives on Gender, Care and Employment Regimes in Seven European Countries. GARCIA Working Paper 1. http://garciaproject.eu/wp-content/uploads/2014/07/GARCIA report_wp1D1.pdf.

Le Feuvre, N. (2016). "Femmes et sciences": Apports et écueils des comparaisons internationals. In R. Rogers and P. Molinier (eds), Les femmes dans le monde académique: Perspectives comparatives. Rennes: Presses universitaires de Rennes, pp. 65-79.

Le Feuvre, N. (2017). La féminisation des enseignant·e·s-chercheur.e.s en France: entre conformité et transgression de genre. In H. Buisson-Fenet (ed.), École des filles, école des femmes. L'institution scolaire face aux parcours, normes et rôles professionnels sexués. Bruxelles: de Boeck supérieur, pp. 207-220.

Lutter, M. and Schröder, M. (2014). Who Becomes a Tenured Professor and Why? Panel data evidence from German sociology, 1980-2013, Max Planck Discussion Paper 14/19. Cologne: Max Planck Institute for the Study of Societies. November.

Marginson, S. (2009). The academic profession in the global era. In J. Enders and E. de Weert (eds), The Changing Face of Academic Life. Analytical and Comparative Perspectives. Basingstoke: Palgrave Macmillan, pp. 96-113.

Marini, G. and Meschitti, V. (2018). The trench warfare of gender discrimination: evidence from academic promotions to full professor in Italy. Scientometrics, 115(2), 989-1006.

Marsh, H. W., Bornmann, L., Daniel, H.-D., Mutz, R. and O'Mara, A. (2009). Gender effects in peer reviews of grant proposals: a comprehensive meta-analysis comparing traditional and multilevel approaches. Review of Educational Research, 79(3), 1290-1326.

Meulders, D., O'Dorchai, S. and Simeu, N. (2012). Alma Mater, Homo sapiens II - Les inégalités entre femmes et hommes dans les universités francophones de Belgique. Brussels: Editions DULBEA. 
Miller, D. and Wai, J. (2015). The bachelor to PhD STEM pipeline no longer leaks more women than men: a 30-year analysis. Frontiers in Psychology, 6. www.ncbi.nlm.nih. gov/pmc/articles/PMC4331608/.

Moss-Racusin, C. A., Dovidio, J. F., Brescoll, V. L., Graham, M. J. and Handelsman, J. (2012). Science faculty's subtle gender biases favour male students. PNAS. www.pnas. org/content/early/2012/09/14/1211286109.

Musselin, C. (2005). European academic labour markets in transition. Higher Education, 49, 135-154.

Musselin, C. (2009). The Markets for Academics. London: Routledge.

Musselin, C. (2017). La Grande course des universités. Paris: Presses de Sciences Po.

Musselin, C. and Pigeyre, F. (2008). Les effets du recrutement collégial sur la discrimination: Le cas des recrutements universitaires. Sociologie du travail, 50, 48-70.

Nittrouer, C. L., Hebl, M. R., Ashburn-Nardo, L., Trump-Steele, R. C., Lane, D. and Valian, V. (2017). Gender disparities in colloquium speakers at top universities. PNAS early edition.

Pétursdóttir, G. (2009). Within the Aura of Gender Equality: Icelandic Work Cultures, Gender Relations and Family Responsibility, a Holistic Approach. PhD thesis. University of Iceland, Faculty of Political Science.

Phou, K. (2017). Profile of Early Career Doctorates in 2015. National Science Foundation NSF InfoBrief, 17-303, 1-6.

Rogers, R. and Molinier, P. (eds) (2016). Les femmes dans le monde académique: Perspectives comparatives, Rennes: Presses universitaires de Rennes.

Schultheis, F. (2000). Chacun sa chimère, le privatdozent, ou l'"illusio" académique faite homme. In M. O. Gonseth, J. Hainard and R. Kaehr (eds), La grande illusion. Neuchâtel: Musée d'ethnographie, pp. 41-55.

Schwabe, M. (2011). The career paths of doctoral graduates in Austria. European Journal of Education, 46(1), 53-168.

SERI (2015). L'enseignement supérieur et la recherche en Suisse. Bern: Swiss State Secretariat for Education, Research and Innovation.

Siemienska, R. (2001). Women in the academe in Poland: winners among losers? Conference paper 01/04 of the EU Research Training Network "Women in European Universities", University of Meunster, pp. 1-13.

Siemienska, R. and Zimmer, A. (eds) (2007). Gendered Career Trajectories in Academia in Cross-National Perspective. Warsaw: Scholar.

Studer, M. (2012). Étude des inégalités de genre en début de carrière académique à l'aide de méthodes innovatrices d'analyse de données séquentielles, $\mathrm{PhD}$ Thesis, Geneva University.

Steinthorsdóttir, F., Brorsen Smidt, T., Pétursdóttir, G. M., Einarsdóttir, T. and Le Feuvre, N. (2018). The gender bias of new managerialism in the academy, Gender, Work \& Organization, early on-line publicaton, doi:10.1111/gwao.12286.

Teelken, C. and Van der Weijden, I. (2018). The employment situations and career prospects of postdoctoral researchers. Employee Relations, 40(2), 396-411.

Teichler, U. and Höhle, E. A. (eds) (2013). The Work Situation of the Academic Profession in Europe: Findings of a Survey in Twelve Countries. Dordrecht: Springer.

Teichler, U., Arimoto, A. and Cummings, W. K. (eds) (2013). The Changing Academic Profession. Major Findings of a Comparative Survey. Dordrecht: Springer.

Tuchman, G. (2009). Wannabe U. Inside the Corporate University. Chicago, IL: Chicago University Press. 


\section{Nicky Le Feuvre et al.}

Vallas, S. and Christin, A. (2018). Work and identity in an era of precarious employment: how workers respond to "personal branding" discourse. Work \& Occupations, 45(1), 3-37.

Valian, V. (1999). Why So Slow? The Advancement of Women. Cambridge, MA: MIT Press.

Valian, V. (2005). Beyond gender schemas: improving the advancement of women in academia. Hypatia, 29(3), 198-213.

Van Arensbergen, P., Van der Weijden, I. and Van den Besselaar, P. (2012). Gender differences in scientific productivity: a persisting phenomenon? Scientometrics, 93, 857-868.

Van den Brink, M. and Benschop, Y. (2011). Gender practices in the construction of academic excellence: sheep with five legs. Organization, 19(4), 507-524.

Van der Weijden, I., Teelken, C., de Boer, M. and Drost, M. (2016). Career satisfaction of postdoctoral researchers in relation to their expectations for the future. Higher Education, 72(1), 25-40.

Weisshaar, K. (2017). Publish and perish? An assessment of gender gaps in promotion to tenure in Academia. Social Forces, 96(2), 529-560.

Williams, W. M. and Ceci, S. J. (2015). National hiring experiments reveal 2:1 faculty preference for women on STEM tenure track. PNAS 121(17), 5360-5365.

Ylijoki, O. H. (2010). Future orientations in episodic labour: short-term academics as a case in point. Time and Society, 19(3), 365-386.

Zippel, K. (2017). Women in Global Science. Advancing Academic Careers through International Collaboration. Stanford, CA: Stanford University Press. 


\section{Part II}

\section{Academic and research organisations}





\title{
3 Gender budgeting to expose inequalities in a precarious academia - and redistribute resources to effect change
}

\author{
Finnborg S. Steinpórsdóttir, \\ Dorgerður Einarsdóttir, Thamar M. Heijstra, \\ Gyða M. Pétursdóttir and Thomas Brorsen Smidt
}

\section{Introduction}

Academic and scientific institutions are deeply gendered in both their practices and outcomes (Acker 2006), with men historically having disproportionally held positions of power (Lynch 2010). In the 'era of global competition' (Marginson and van der Wende 2007) there are signs of growing precariousness in higher education (Jongbloed 2012). This phenomenon is also gendered, with men dominating the most prestigious positions while women occupy the more precarious positions (European Commission 2016). Moreover, as we will demonstrate in this chapter, there are further gendered aspects to the precarisation of higher education and research, with academics in the more feminised fields being trapped in more precarious positions than academics in the male-dominated fields. This is a trend that sustains the historically gendered power relations in higher education.

Closely related to this growing precarisation are the organisational and cultural changes in the academic and scientific sector. The idea of the 'world-class university' has enabled the marketisation of higher education and research, a process that started in the 1980s, although with different variations across countries (Paradeise and Thoenig 2016). Academic and scientific institutions have increasingly been introducing private sector financial and managerial techniques and ideologies, often referred to as new managerialism, in which performance is being monitored in the name of efficiency, productivity and excellence (Chandler et al. 2004; Barry et al.; 2012; Butler and Spoelstra 2014) through performance indicators that are perceived as objective and gender neutral (Lynch 2010).

In this chapter we examine these financial and managerial methods and instruments and their impact on the gendered dimensions of precariousness in higher education and research from a gender budgeting perspective. Gender budgeting is a relatively new approach to the study of gender inequality in higher education and research, which has its roots in feminist macroeconomic theory (Waring 1988). 


\section{Finnborg S. Steinpórsdóttir et al.}

Previous research has focused on the possibility of utilising university budgets to facilitate equality (Rothe et al. 2008) and connecting gender equality goals to budgetary instruments (Erbe 2011, 2015). In the GARCIA project we coordinated the research on gender biases in management methods and decisionmaking, and we developed a toolkit for gender budgeting in academia (Steinpórsdóttir, Heijstra et al. 2016b). In our work gender budgeting is employed both as a theoretical and a methodological tool. As such, it becomes a way of following the money in an effort to map out how new managerial approaches and instruments impact the position and conditions of early career academics from both STEM and SSH academic fields, with the aim of finding ways to reconstruct the academic financial system and to work towards equality. As this approach to research on precariousness and gender equality in higher education is innovative and still explorative, difficulties in the data collection process were expected. Due to lack of transparency and accessibility, the GARCIA academic and scientific institutions were differently equipped to perform this part of the research. Access to key documents and gender disaggregated data is a necessary, although not sufficient, condition for gender budgeting analysis, and not all the research teams could meet this requirement, as discussed further below. The University of Iceland was in a unique position as its Equal Right Policy includes a provision on the implementation of gender budgeting, an advantage that facilitated the data collection process. Hence, drawing on different sources of data, obtained by means of multiple data collection methods, we compare and contrast the academic and scientific institutions involved in the GARCIA project to the case of the University of Iceland.

The academic and scientific institutions have various backgrounds, historically and culturally, and they differ in their organisation. Most of them are medium sized comprehensive research and teaching universities. Moreover, they have in common that they are all participating in global competition and are influenced by new managerialism at national and institutional levels. The University of Iceland is especially interesting in this context, as a comparison of the academic institutions in question indicates that it has taken the operationalisation of new managerial techniques the furthest in its effort to efficiently work towards their goals in order to move upward in the international rankings. As such, the administrative and budgetary system at the University of Iceland has in recent years developed a strong tradition for far reaching 'bean counting', in which everything from teaching, research and publication down to the square metres of classrooms have been allocated a price tag and an administrative process to match. The situation at the University of Iceland can therefore facilitate a contextual understanding of the broader international phenomenon of new managerialism in academia.

By approaching precariousness from a gender budgeting point of view and assessing the financial and managerial procedures and processes as well as its impact on the position of early career researchers, the hierarchies of power within academia become visible. These power hierarchies tend to privilege men and the 'masculine' while devaluing women and the 'feminine' as they manifest 
themselves in the financial system and organisational practices of higher education institutions. We will argue that the financial and managerial procedures and processes employed in higher education favour STEM subjects rather than SSH subjects in relation to research and teaching, and as such carry a distinct gender bias in favour of masculinised subject areas. The research criteria are built on STEM focused performance measurements and the system undervalues the heavy workload related to teaching, especially within SSH faculties, where the student/teacher ratio is the highest. This bias impacts early career researchers in STEM and SSH unequally, with STEM being able to provide more advantageous positions and conditions for early career researchers than SSH. By rewarding male-dominated fields and male-dominated positions over the more feminised fields and positions, it preserves the gendered precariousness and in turn gender inequality in academia.

By highlighting these gendered implications and consequences we want to direct the attention to gender in the financial and managerial procedures and processes in higher education and research. In order to do so we put forward the following research question: How can gender budgeting help to reveal the different manifestations in which new managerialism in higher education and research has gendered consequences for the positions and conditions of precarious researchers? Before examining this research question in more detail, we first discuss gender budgeting, gendering of higher education institutions and new managerialism in gendered academia and research.

\section{Gender budgeting}

In 1984 gender budgeting emerged from feminist practical politics in Australia (Sharp and Broomhill 2002) but it did not gain international recognition until in 1995 when the United Nations' Beijing Platform for Action called for 'the integration of [the] gender perspective into [the] budgetary decision on policies and programmes" (United Nations 1995). Currently it is found in over 100 countries in various forms and applied in different settings. One of the key insights of gender budgeting is that budgets represent the power relations in society. As Pregs Govender MP in the first women's budgets in South Africa rightly points out, "The budget reflects the values of a country - who it values, whose work it values and who it rewards and who and what and whose work it doesn't" (Budlender 1996, cited in Elson 1999, p. 11). Furthermore, budgets mirror gender relations and have different effects on women and men due to their different socioeconomic positioning. In this way, it can therefore "(re)produce gender inequalities and [an] unequal distribution of power between the genders" (Klatzer and Mader 2008, p. 2). Gender budgeting can therefore be seen as a response to these power and gender relations as it is concerned with how a government's actions to raise and allocate funds serve to advance or prevent gender equality. Gender budgeting aims to integrate a gender analysis into economic policy, government spending and revenue proposals, and identifies possibilities for the redistribution of resources to correct imbalances in women's and men's 
use of, access to and benefits gained from public services (Addabbo et al. 2015a).

In recent years, gender budgeting has also been related to institutional settings, such as in higher education. After Rothe et al. (2008) conducted transnational gender budgeting research in Austria, Germany and Poland, the knowledge on how to apply gender budgeting in scientific institutions has increased. A few years later, Erbe (2015) discussed the public financing of universities and the effect of linking gender equality to two funding tools - the performance-based allocation of funds and the target agreements. Her research in 13 public universities indicates that linking fund allocations to progress in gender equality, together with external pressure, increases higher education institutions' willingness to work towards gender equality. Addabbo et al. (2015b) use the capability approach, that is, the "individual's opportunities to achieve functioning" (p. 196), to evaluate budgets and policies in two higher education institutions in Spain and Italy from a wellbeing and gender budgeting perspective. They do so by comparing the university's expenditures to how students rank the capabilities that the higher education institution is able to foster in their personal development.

In our own work on gender budgeting in higher education institutions (Steinpórsdóttir, Einarsdóttir et al. 2016; Steinpórsdóttir et al. 2017; Heijstra, Steinpórsdóttir et al. 2017; Heijstra, Einarsdóttir et al. 2017; Steinpórsdóttir et al. 2018) we have utilised gender budgeting as a lens to evaluate the financial and managerial processes and procedures. By "standing back" (Bacchi 2012) and looking at the overall system, we can assess what activities are valued and what activities are undervalued within the academic work environment. We have found that new managerial methods and instruments create gendered structural hindrances that generate and foster gender inequality. In addition, our study gave rise to the concept of 'academic housework', that is "all the academic service work that is performed by all academic staff, both women and men, but which receives little recognition within the process of academic career making or within the definition of academic excellence" (Heijstra, Steinpórsdóttir et al. 2017 , p. 765). The burden of academic housework comes down disproportionately on the shoulders of women, as well early career researchers (Heijstra, Steinpórsdóttir et al. 2017; Heijstra, Einarsdóttir et al. 2017). Our findings point to the importance of investigating financial and managerial systems in order to assess if gendered values and norms and gender relations are mainstreamed into all the managerial procedures and processes that direct the flow of money within academia.

\section{Gendered higher education institutions}

Academic and scientific institutions are "gendered institutions" (Acker 1992). For a very long time, men have disproportionally held positions of power within higher education and science (Acker 1992; Morley 2006), often referred to as the "leaky pipeline" (Alper 1993; Dubois-Shaik and Fusulier 2017) and the 
"glass ceiling" (Hymowitz and Schellhardt 1986). The relative absence of women from senior management and professorial posts is in part a function of inequalities arising from gender-based discriminations, both direct and indirect, institutionalised and personalised (Knights and Richards 2003). It is also an outcome of long-standing inequality regimes in higher education, systems of organisation, and control and promotion processes that are more favourable to particular classes of men than to women (Acker 2006). Further segregation is visible in the gendering of subjects' studies, with women and men being educated and working in different fields and the 'masculine' fields being considered of higher value, and hence more respected, than the more 'feminine' fields. A key to gendered power relations that maintain gender inequality is the hierarchical distinction of femininity and masculinity, where what is associated with men and the masculine is valued more highly than what is related to women and the feminine (Walby 1990; Van den Brink and Benschop 2012a).

Many studies provide examples about the different manifestations of gendering within higher education institutions (e.g. O'Connor and O'Hagan 2016), on excellence in the evaluation of academic staff (e.g. Porvaldsdóttir 2004), on hiring and promotion processes within academia (e.g. Van den Brink and Benschop 2012b), and on the systematic underestimation and minimisation of women's qualifications in academia, or the so-called 'Matilda effect' (e.g. Rossiter 1993; Knobloch-Westerwick et al. 2013). Furthermore, extensive literature shows lower publication rates among women and offers various explanations for this trend, such as fewer co-authoring possibilities (Long et al. 1993; Lee and Bozeman 2005), quantitatively orientated scientific journals (Özbilgin 2009), extensive teaching responsibilities (Suitor et al. 2001), unequal resource distributions of space, equipment and time (Xie and Shauman 2003), and differences in level of research specialisation (Leahey 2006). The gendered structures and processes of the academic financial system that create the inequalities are worth investigating; however, they have so far been largely overlooked. By directing our attention to gendered financial and managerial procedures and processes that are often considered to be objective and gender neutral, we aim to further increase the awareness of gender inequality within academia, where precariousness exaggerates and maintains the inequalities.

\section{New managerialism in higher education}

The fact that gender budgeting has been related to academia and research is not least because of the marketisation of higher education in Europe in which competition and efficiency are playing an increasing role. Gender budgeting can be utilised as a critique on new managerial methods, as they are generally presented as objective and gender neutral. The idea of a 'world-class university' and the aspiration of national governments to have their universities in the top position of international rankings have inspired higher education policy makers worldwide. Higher education was and continues to be formulised as a management issue that has to be dealt with by new managerial approaches, that is, instruments 
that are tied to the political project of neoliberalism (Lynch 2014). Neoliberalism here does not mean that higher education institutions are autonomous and free, but rather that it is a type of governance that encourages institutions to conform to the norms of the market (Larner 2000; Keisu and Carbin 2014), a trend that has also been described as "neo-liberal market governance" (Keisu and Carbin 2014), "McUniversity" (Parker and Jary 1995), "corporate University" and "academic capitalism" (Slaughter and Rhoades 2004).

The ideology and instruments of new managerialism are utilised to allocate resources both at national and institutional level in an effort to maximise the use of resources. At the national level, governments are increasingly employing performance indicators as well as incentives and evaluation procedures to steer the allocation of resources (Paradeise and Thoenig 2015). As such, in the name of efficiency, productivity and excellence, higher education institutions are increasingly run like corporations (Gouthro 2002; Chandler et al. 2004; Lynch 2006; Rothe et al. 2008; Barry et al. 2012; Välimaa 2012; Butler and Spoelstra 2014), and because of performance measurements, academics are now required to turn their work into auditable documents, which has led Power (1997) to label the university as an "audit society". The monitoring of academic and scientific performance tends to privilege research (rather than teaching) by validating publication rates, journal rankings, citation indexes and funding success rates. At the same time, it tends to undervalue teaching and other necessary and important tasks of academic work, such as engaging in dialogue with civil society (Lynch 2006) and academic housework (Heijstra, Steinpórsdóttir et al. 2017; Heijstra, Einarsdóttir et al. 2017; Steinpórsdóttir, Einarsdóttir et al. 2016; Steinpórsdóttir et al. 2017).

Moreover, performance indicators encourage a process of self-monitoring in which the individual academic becomes responsible for their own knowledge production and well-being (Keisu and Carbin 2014) as well as for the success of the higher education institution, even though it has little to no control over the wider processes that measure this success. If an academic is not performing well enough within this system, there are consequences in the form of lower salaries, being exempt from bonus schemes, or even job loss (Berg et al. 2016). These financial and managerial procedures and practices that are utilised to reach the goal of excellence are commonly perceived as objective and gender neutral, and presented as "rational, efficient, accountable and giving value for money" (Lynch 2010, p. 55).

In what follows we will first discuss our methodology and then our findings, beginning with how higher education institutions involved in the GARCIA project have set the stage of international rankings, followed by a section on how academics, researchers and $\mathrm{PhDs}$ in precarious positions are performing on a precariously set stage. 


\section{Methods}

Gender budgeting is relatively unexplored in the academic and scientific context. To our best knowledge the strategy has not been approached with the objective of assessing the gendered implications and consequences for the positions and conditions of precarious researchers. Therefore, our research was designed around mapping the financial and managerial systems at the academic and scientific institutions involved in the GARCIA project. The research was conducted between September 2014 and May 2015 and draws on empirical data collected in six organisational contexts. The data collection process was designed around two central structures: the organisational structure, management and financial framework of the institutions and potential gender biases; and decision-making bodies and decision-making processes in selected STEM and SSH departments.

The project relies on secondary data collected in each of the participating countries, comprising statistical data, public and institutional documents, as well as fact-finding interviews with key administrators in order to acquire information otherwise unavailable and to capture any ideological underpinnings. Qualitative content analysis (Schreier 2012) was applied to the secondary and statistical data, in order to assess the gender impact of the institutional financial and managerial procedures and practices. The objective of the gender impact assessment was to compare and assess the trends resulting from policies. Gender impact assessments take multiple pieces of information into account, including existing gender differences in participation, distribution of resources, norms, values and rights (European Commission 1998). To further understand the precarious position of early career academics, semi-structured interviews were conducted to understand if there are signs of "double bind in the area of service" for women and minority faculty within the institutions (Gómez 2012; Stockdill and Danico 2012; Võ 2012).

\section{Mapping of the organisational structure, management and financial framework of the institutions and potential gender biases}

In order to explore the organisational structure, management and financial framework of the institutions and potential gender biases, the data collection was developed around three main parts: a brief introduction and the history of the institution; the current managerial procedures and processes of the institutions; and the financial framework the institutions.

As the participants in the research project were from different institutions, from six different countries in Europe, it was important to have knowledge of each national and institutional context. In order to do so, each beneficiary was requested to make a brief report on their institution, which included the structure of the institution, information on recent legislations and regulations, recent developments, including a short overview of the history of the institution. A checklist of gender equality measures in science at the national and the institutional levels was provided. Measures on the national level included an equal 
treatment legislation, commitment to gender mainstreaming and/or gender budgeting, publication of sex disaggregated statistics, development of gender equality targets or benchmarks, gender balance targets in public committees, women and science unit in the ministry of education/science, national committee on women and science and a national centre on women and science. Measures at the institutional level included a gender equality plan, gender balance targets on university committees, gender quotas on university committees, gender/women's studies and research as well as programmes on women and science with special funding available.

The managerial procedures and processes of the institutions were mapped. Data included information on the management structures and practices, such as governance and financial management of the overall institution, the gender of the decision makers and key players of the budgeting process, how they are appointed or hired, their formal and/or informal decision-making powers. Whether or not the budgeting decision is a technical procedure carried out by financial experts or if there are any stakeholders or gender experts involved in the decision-making process was also considered. Data further included information on the institution's visions and strategies, such as the overall vision, policy and strategic planning, as well the ideological underpinnings. Other factors were: if objectives such as gender equality and international rankings are part of the policy, what measures are to be taken to reach the policy objectives and how the institutions will monitor the progress. Also, whether the policy making process, is a bottom up or top down process.

The financial framework of the institutions was also analysed. Data included information of the funding of the institution, the foundation of the public or governmental and third-party funding allocated to the institution, such as contracts and/or performance agreements, competitive funding, registration/tuition fees and contracts with the business community. Information on the degree of autonomy the institution has over the finances is included, as well as if the funding processes are transparent and information publicly available. Furthermore, data included information on the premises of the funding procedures within the institutions, i.e. if performance measurements or targets are connected to the funding, such as number of students; success in obtaining external research grants or gender equality bench marks, as well if the same conditions apply to all units (faculties, departments, centres). Data included information on the gender equality projects and/or programmes funded, as well the degree of transparency of the allocation processes. Information was also collected about the evaluation and monitoring of the academic and scientific staff performance in teaching and research, its connection to funding procedures and the individuals position within the institution, such as wages, promotion and sabbaticals.

In order to capture the process and ideological underpinnings of the managerial and financial framework of the institutions and to collect data that was not publicly available, $3-5$ semi-structured interviews were conducted in each of the studied institutions with administrative key players working at either at the central or the school/faculty level administration. 


\section{Mapping of decision-making bodies and decision-making processes in selected STEM and SSH departments}

In order to explore the decision-making bodies and decision-making processes in selected STEM and SSH departments, the data collection was developed around two main parts: a brief introduction to the selected STEM and SSH departments and their location within the institution; and the conditions for academic career within the departments.

Data on the selected STEM and SSH departments included their location within the organisational structure, information on the decision-making bodies and key managerial and financial players, by gender; on their appointment procedures and the formal and information decision making powers. Information was collected on the allocation of funding within the department/unit and the degree of transparency with regards to management and financing. Statistical data on academic demographics from the years 2010 to 2013 were collected, containing information regarding the number of tenured academic staff, other staff employed on non-tenured contract and temporary contracts. All data were segregated by gender.

Data on the condition for academic career within STEM and SSH included statistical data from the years 2010 to 2013 on PhD students and graduations, job opening on $\mathrm{C} / \mathrm{D}$ level, student/teacher ratio. Information on the $\mathrm{PhD}$ programmes of the departments, the financing (funded, pair or non-paid) and conditions of the $\mathrm{PhD}$ positions (such as teaching and/or assistance obligation and tuition fees) was provided. Furthermore, statistical data for the year 2013 on number of funded research projects by type of research projects (international, European, national, local), amounts awarded, success rates, application rates as well information of the pool of potential applicants. Finally, data from the year 2013 on student/teacher ratio, academics' performance (such as research points), salary (gross and/or net) and composition of salaries (net, overtime, bonuses) was collected.

\section{Consequences of financial and managerial decisions on early career researchers}

In order to understand the consequences of financial and managerial decision on early career research and in order to develop the concept of "academic housework" (Heijstra, Steinpórsdóttir et al. 2017; Heijstra, Einarsdóttir et al. 2017) semi-structured interviews were conducted with female and male scholars in the early stages of their academic career. All scholars were either employed or had been employed as assistant professors, postdocs or sessional instructors at the selected STEM and SSH departments of the six observed institutions. The GARCIA teams wrote an analysis in English on the main outcomes to two interview questions, which was part of a broader interview guide: "Do you think that you are (were) adequately paid for the work you do (did)?" and "Are (were) you expected to be engaged in extra undervalued work?" Each institution's analysis 


\section{Finnborg S. Steinpórsdóttir et al.}

is based on data from approximately 20-35 interviews and summaries of the interviews were made available to the Icelandic team. The summaries were thematically analysed using Atlas.ti, version 1.0.2(68) research software, by focusing on common codes and themes as well as dissimilarities within the country reports.

\section{Compare and contrast}

As gender budgeting is a relatively new approach to gender equality in the academic and scientific context, difficulties in the data collection process were to be expected. Overall the financial and managerial procedures and processes were considered to be objective and gender neutral technical measure. Some of the GARCIA partners had great difficulty acquiring the relevant data, and overall there was lack of publicly available data as well as lack of transparency regarding the distribution of funding within the academic institutions, with the degree of non-transparency varying between institutions. Furthermore, in some cases, researchers were met with resistance in the data collection process. The participating institutions delivered their findings in the following reports: University of Lausanne (Bataille and Goastellec 2016); Radboud University (Benschop et al. 2016); the Catholic University of Louvain (Dubois-Shaik et al. 2016); ZRC SAZU in Ljubljana (Hofman and Knežević Hočevar 2016); University of Trento (Rapetti et al. 2016); University of Iceland (Steinpórsdóttir, Heijstra et al. 2016a).

Drawing on the reports, in this chapter we compare and contrast the University of Iceland with the other participating institutions in the GARCIA project. The University of Iceland is especially interesting in this context as it is the only institution within the project that is implementing gender budgeting. The comparison of the academic institutions in question also indicates that the University of Iceland has taken the operationalisation of new managerial techniques the furthest in its effort to efficiently work towards their goals in order to move upward in the international rankings. In what follows we will discuss our findings. First, we examine the international rankings and new managerialism, which is a common ground for the GARCIA institutions, followed by presentations of the findings on how this impacts the conditions of early career academics who have to perform on the precariously set stage.

\section{International rankings and new managerialism: the common ground}

\section{The ranked and gendered academic and scientific institutions}

All the GARCIA higher education institutions have in common an aim to improve their position in international rankings and to receive recognition within the international academic community. This is reflected in the words of the rectorate of the University of Lausanne, an academic institution that strives to 
become one of the top European universities: "[The rankings] must be taken seriously - despite their faults - because they serve as a reference tool abroad to position the [University] in the 'global' university worlds" (Service de relations internationals 2009). This quote shows that global competition has enabled the marketisation of higher education in the GARCIA participating countries, just as it has in the rest of Europe (Paradeise and Thoenig 2015).

In line with the quest for a high academic ranking, the elements of competition and efficiency are underlined in all GARCIA institutions, and echoed in the words of a Slovenian key player: "Good work is achieved by competitiveness" (Hofman et al. 2016). This seems to be a common perception within the institutions - that competition can both create efficiency as well as better or improved outcomes. In the case of the University of Iceland we see a clear focus on new managerial strategies and tools that are utilised to enhance the productivity of the academic staff by emphasising both individual and group responsibility. That is to say, these strategies not only make the individual academic responsible for their own career advancement, salary increase and funding probabilities, but for a larger burden still, namely that of the greater good, the financing of the faculty they are employed in. An agreement between the University of Iceland and the Icelandic Ministry of Education makes this bond very explicit: "Little research activity is no longer a private matter of the academic staff member in question, [...] but little activity also reduces the income of the faculty in question" (Agreement on Teaching and Research 2012-2016, Appendix 1, p. 34).

Turning to the decision-making bodies within the GARCIA institutions, the findings reveal that there is a strong observable gender imbalance in the highest management positions, with women forming the minority. At the University of Lausanne for instance, men in governing decision-making organs are never less than 75 per cent, and are usually around 80 per cent, but those number increase as we go further up the hierarchy. The percentage of male deans and presidents is above 90 per cent. A similar pattern is visible at the other GARCIA institutions. At the University of Iceland, although a woman occupied the position of rector for a decade, there is a visible underrepresentation of women in nearly all other decision-making bodies. As such, men make up 85 per cent of heads of the University Council's committees and commissions, as well as 60 per cent of deans and 70 per cent of faculty heads. A further gendered aspect can be observed in the case of the University of Trento. Men dominate the more prestigious and influential positions (representing 65-90 per cent of members), such as those on boards dealing with research funding, promotion, recruitment and evaluation, with the exceptions of the Board of Directors (40 per cent) and the Board of Auditors (20 per cent). The few women that hold responsibility are concentrated in the areas dealing with equal opportunities, ethical issues and quality of teaching.

Moreover, not only we do find the academic fields to be highly gendered, which is in line with the historical trend of men dominating positions of power within higher education institutions (Acker 1990; Bagilhole 2002), but vertical segregation is also still prevalent at all the higher education institutions. Men 
dominate the full-time and the most prestigious academic positions while women are more frequently found in part-time and precarious positions. This is also the case at the University of Iceland, despite the fact that women have constituted more than half of the students for the last four decades.

The effect of this gender imbalance is also visible within different academic fields and sometimes the imbalance is even intensified because of the gendering of academic fields. For instance, at the University of Trento, 10 per cent of the members of the STEM department are women, and to make the imbalance even worse only two thirds of them are in permanent positions and none of them has decision-making power. At the SSH department women are more numerous than in the STEM department (40 per cent), but also here only a few of them have decision-making powers. The situation at the University of Iceland resembles that of the University of Trento. Women at the University of Iceland are also underrepresented in STEM (25 per cent), and the SSH department has more female representation (45 per cent). Moreover, at the University of Iceland men also occupy higher academic positions than women in both schools.

Similar gender patterns are visible among $\mathrm{PhD}$ candidates. In the Catholic University of Louvain two-thirds of the PhD candidates in STEM are men (65 per cent in 2013), while the gender representation is more equal in the SSH department (55 per cent men). At the University of Iceland, men also form the majority of $\mathrm{PhD}$ students (60 per cent in 2013) and $\mathrm{PhD}$ graduates (60 per cent) in STEM, but the University of Iceland differs from Louvain in that women form the majority of the $\mathrm{PhD}$ students (70 per cent) and $\mathrm{PhD}$ graduates ( 75 per cent) in the SSH department.

\section{Allocation of funding: lack of transparency and the impact of austerity}

There is an overall lack of transparency regarding the allocation of funding to and within the GARCIA institutions, although the degree of non-transparency varies between institutions. The University of Trento has the most transparent system with all financial information available and accessible, and it is followed by Radboud University, the Catholic University of Louvain and the University of Iceland, institutions that only provide partial transparency when it comes to financial information. In case of ZRC SAZU and the University of Ljubjana, information on financial means flowing towards the institutions is more or less accessible while the distribution within the institution is opaque, as is the rationale for the distribution. Even less transparent however, is the situation at the University of Lausanne where the allocation information is opaque and inaccessible.

What is also interesting in this context is not only the level of transparency but also the fact that at both the Catholic University of Louvain and Radboud University the history of the academic fields is of significant importance and plays a role in the allocation of funding, something that up until now has not been questioned by the parties involved. At Radboud University many of the administrative key players revealed that it was not completely clear on which 
grounds the different faculties receive their annual budget, except for that much of it is fixed on 'historical grounds'. As an example, the budget for research is based on these historical grounds, with a much larger fixed and stable amount being allocated annually to STEM than SSH. There seems to be a general acceptance for this given, and little willingness among key players to start digging into the historical grounds behind the budget. As reflected in the words of a key player at Radboud University, who suggests that changes in the budget will cause a heated discussion within the institution: "No, we never dig into the history of how the budget is allocated [...] If we are going to make changes in the budget, hell will break loose".

Nevertheless, transparency is a very important part of the gender budgeting process, especially when the gendered effects of precariousness are to be challenged. On several occasions, key players from different institutions insinuated that the allocation of funding between different fields was either arbitrary or decided upon behind closed doors by an unaccountable governing body. These key players also believed that any attempt to map out this process in one way or another is going to have disastrous consequences.

All higher education institutions in this comparative study rely on public funding in the form of teaching and research agreements and/or governmental calls for research projects. Austerity measures have had great impact on the working conditions in academia, and this becomes especially apparent when looking at the situation of early career researchers in both Italy and Slovenia. In Italy, due to fiscal consolidation, budget constraints have been imposed at the higher education institutions. As such, within the individual higher education institutions in Italy, there is lack of resources for creating new positions and allowing promotions. Furthermore, since 2011 pay increases related to seniority have been frozen. Not only does this affect the whole higher education system, but as well the career possibilities, work- and life conditions of early career researchers. The same results of austerity measures are visible in the case of Slovenia, where the Act on Balancing Public Finances has been effective since 2012. In the SSH department, the number of academics working at the institution has decreased while in STEM temporary contracts have replaced permanent employment. The necessity of these measures is emphasised by some of the key administrative players. One justifies the increased use of temporary contracts by stating that "one tends to get lazy when permanently employed" (Hofman et al. 2016, p. 15). As such, this particular key player expresses, and in turn, perpetuates a discourse reiterating a market preference as an administrative model in which job precarity becomes an incentive to work harder and thereby contributes to the neoliberal project of global competition in the academic sphere.

\section{Uneven distribution of public funding}

Overall budgeting decisions are most often perceived as technical procedures that are objective and gender neutral. Nevertheless, gender budgeting analyses reveal that allocations tend to be STEM focused. In Belgium and Iceland, the 
state funding allocated to the higher education institutions depends largely on the discipline the students opt for, with a 'price category/tag' for each discipline regarding payments per full-time equivalent student. Although the two countries apply different values to the academic disciplines, the state funding is considerably higher for STEM students than for SSH students. In Belgium, the funding is two to three times higher for a STEM student than for an SSH student, while in Iceland, the state allocates $60-100$ per cent higher funding for STEM students than for SSH students. However, no clarification is provided explaining the basis for the allocation and there do not seem to be any empirical grounds for the price categories either. A common argument for the higher allocation is nevertheless that STEM needs more expensive materials and equipment than other fields. Among administrative key players this argumentation is unquestioned and often put forward without any concrete evidence, as is the case both at Radboud University and the University of Iceland. Another argument that is used in this context is related to the notion of 'excellence'. For instance, in the case of Radboud University, the STEM faculty receives earmarked funding for top researchers in order to invest in 'renowned' scientists. The funding can be used for facilities, salaries and even the salaries of $\mathrm{PhD}$ students and assistant professors "so [the higher education institution] can offer a nice package to the new professor". Such packages or deals never came up in any of the conversations regarding SSH faculties.

If we dive deeper into the allocation of funding we find that the allocation of funding within the GARCIA institutions varies, considerably; from negotiating the funding as in the case of the University of Lausanne, to intense performance measurements as in the case of the University of Iceland. At the University of Lausanne, the criteria of allocation are not precisely defined, and each Faculty Dean has to negotiate the budget of its own faculty on an annual basis and directly with the Rectorate. At the University of Iceland funding to the academic schools and their faculties is allocated according to a distribution formula. The formula is based on productivity in teaching and research. Allocations in relation to teaching are based on the discipline of the full-time equivalent student, and the University of Iceland tends to follow the proportional value of the state's price category for a full-time equivalent student. The allocation of funding based on these criteria can impact the student-teacher ratio. In interviews with key players at the University of Iceland it became apparent that with less funding the disciplines have fewer opportunities to hire full time academic staff, which leads to an unfavourable student/teacher ratio especially within the disciplines that are situated in the lowest price category. A high student/teacher ratio can therefore affect both the academic staff and the students. Not only do the students need to share the available teacher time with more students, but with more teaching responsibilities and teaching related academic housework, academics are likely to experience higher workloads and work pressure, which leaves them less time to attend to research.

This is a clear drawback as research activities weigh more heavily in the University of Iceland in terms of the allocation of funding to the faculties than 
teaching. Allocations in relation to research take three elements into account: the number of graduates with Master's and $\mathrm{PhD}$ degrees, the academic staff's performance in research and the faculty's success in raising third-party funding. The academic schools receive financial compensation for the graduated Master's and $\mathrm{PhD}$ students and for the points (based on publications) obtained by their academic staff. Moreover, they receive matching funds for their success in raising third-party funding. The schools receive 60 per cent of the value of the grant for international competitive grants, 35 per cent matching funds for national competitive grants and 20 per cent matching funds for other grants. According to a key player at the University of Iceland the finance committee can tamper the teaching segment of the distribution formula in order to make ends meet: "if we need money we just lower the proportions of the funding formula that each school gets for teaching". This means that the faculties that attain grants will get additional funding as a matching fund from the academic institution, which is taken from the governmental appropriation. Other faculties that receive no, or few, grants, especially from international competitive funds, therefore do not get this financial compensation based on the matching fund.

Competition for third-party funding is also a pressing issue at the other GARCIA institutions, not only it is important to receive recognition for the institutions' research contribution but it is also crucial to increase resources during times of declining public resources. Similar to the University of Iceland, the University of Trento utilises the awarded grants as performance indicators to distribute research funding to the academic departments or research centres. However, not all GARCIA higher education institutions do so. At Radboud University, for example, research grants are not directly related to the distribution of the public funding among the faculties.

Overall, these findings reveal that the male-dominated STEM fields not only receive more public funding but that it seems fairly easy for administrators to argue for higher allocations to STEM. While this is particularly clear in the case of the University of Iceland, for which we have the most detailed information, similar patterns but in different shapes and sizes are visible in the other GARCIA institutions as well. This imbalanced allocation to fields enhances the vertical gender segregation and limits the opportunities for precarious knowledge workers, especially in the field of SSH.

\section{Performing on the precariously set stage}

\section{Precarious work in higher education is gendered work}

As it is generally challenging to obtain a permanent contract within academia, precarious work is a widespread problem in all of the academic and research institutions under study. Moreover, there is a tendency for women to occupy these unfavourable positions more often than men. This is for instance visible in the positions of adjunct and sessional teacher; these positions are based on temporary employment contracts with women occupying these positions more 
frequently than men. In Iceland, due to the financial crisis, the number of adjuncts increased by 25 per cent and the work of sessional teachers equivalent to full time adjunct positions increased by 35 per cent between 2008 and 2011. Most of these positions were indeed taken care of by women.

In the case of the University of Iceland, adjuncts get a 6 or 12-month contract and have access to some of the University's funds if their role is a 50 per cent position or more, but sessional teachers are paid per session with no rights and benefits to paid vacation or sick leave. Sessional teachers are a very diverse group; some are experts working elsewhere and only teach a couple of classes per semester, while others teach one to three courses for the whole semester and make a living out of teaching. SSH relies heavily on the latter group while STEM relies more on the experts. The pay is low, but in order to compensate its experts STEM adds 15-25 per cent additional remuneration to the formal rate.

Sessional teachers are a very hidden group; this is the case, for instance, at Radboud University where teachers can be contracted for a fixed number of hours and without benefits. However, information on who is performing those tasks and their conditions is not collected. In some cases, however, even if not allowed by law, the practice of informal teaching and student supervision persists, this is the case, for instance, for postdocs at the University of Trento. Despite this kind of situation, most of the early career researchers in the GARCIA institutions seem to be reluctant to criticise their precarious position and rather look upon it as a necessary temporary situation. Criticising aspects of the academic profession can easily be explained away as a lack of dedication, not least in very competitive fields, which is a label newcomers do not want to be associated with (Heijstra, Steinpórsdóttir et al. 2017; Heijstra, Einarsdóttir et al. 2017).

\section{Prestige or perish: performance measurements}

In all the institutions there is pressure on the academic staff, either formal or informal, to produce 'scientific excellence'. In some institutions, like the University of Trento, Radboud University and the University of Iceland, there is formal pressure by means of the evaluation of the academic's performance but the direct impact differs. At the University of Trento academic productivity is measured through a performance index and does not impact the individual directly in terms of higher wages or bonuses. Individual academic performance, however, directs the allocation of research funds within their faculties. At Radboud University, performance in teaching is measured through student evaluations and research through output overviews. The academic's progress is monitored in the annual performance interviews with the head of department and if they function within a set of parameters they receive a periodic raise. Furthermore, academics can be awarded one-time bonuses or salary increase for exceptional performances, e.g. for obtaining prestigious research grants. At the University of Iceland the performance measurements not only impact the academic's salary, annual bonuses, promotion, sabbaticals, teaching responsibilities (which can be decreased or 
increased temporarily as a result of the academics high or low productivity in research) and their chance of obtaining funding, but also the amount of funding the faculty is entitled to. As has been discussed earlier, academics are assigned points for their work in terms of research, teaching, administration and service. Moreover, extramural grants are rewarded in terms of points. The higher the endowment, the more points are awarded, with grants from international competitive funds generating twice as many points than other grants.

This pressure of global competition for research grants is present in all the GARCIA institutions. However, a comparison of research funding obtained by $\mathrm{SSH}$ and STEM academics indicates that the grant system is biased towards STEM fields and men. For every international competitive grant awarded to a SSH project manager in 2013 STEM project managers received two grants in Radboud University (1:2), four in the Catholic University of Louvain (1:4), seven in Slovenia (1:7) and 24 in the University of Trento (1:24). Moreover, male project managers received 95-100 per cent of all grants, except in Slovenia where women and men received equal numbers of grants. A similar trend is observable when it comes to national competitive grants. For every grant awarded to an SSH project manager in 2013, STEM project managers received two to seven more grants (Radboud University 1:7; The University of Trento 1:4; The University of Iceland 1:4; the Catholic University of Louvain 1:3; Slovenia 1:2.8; The University of Lausanne 1:1.5), with 70-100 per cent of the grants going to male project managers, except in Slovenia where women and men received equal numbers of grants. This bias has a great impact on the position of early career researchers in SSH. This for instance becomes clear in SRZ ZASU in Slovenia. As an SSH research centre that depends on success in international and national calls for research projects, as well governmental research policy and national budget, the research positions, the majority of which are occupied by women, are increasingly comprised of temporary contracts.

At the University of Iceland, the importance of research activity, apart from obtaining grants, is further emphasised by special points, referred to as 'major points', which were introduced into the academic environment in 2010 to intensify the focus on research related practices. The publication outlet is here of great importance, with publications in high ranked journals on the Thomas Reuters/ISI Web of Science List (ISI) and books and chapters from the most 'prestigious' publishing houses being most rewarded. Furthermore, if an article is published in a 'superior' journal, that is Nature, Science, Cell and the New England Journal of Medicine, the scholar can receive up to double the amount of points. This is in line with the demands of other higher education institutions, e.g. The Biotechnical faculty at the University of Ljubljana, where everything apart from publishing in high indexed scientific publications is poorly valued. However, all the 'superior' journals have in common that they are journals that mostly publish work from STEM and Health Sciences and hardly any from SSH fields.

Evaluating academic work is a practise utilised everywhere, but in some academic institutions, such as in the University of Lausanne and Radboud 
University, it does not have a direct impact on the position and work conditions of the employees. At both institutions, academics who want to progress up the career ladder usually do so by applying for a higher position that is advertised publicly. This means that both internal and external candidates can apply. On the other hand, at Radboud University there is also the possibility of internal promotion for academics that have demonstrated 'exceptional performance'. In terms of career, at the University of Iceland the future of assistant professors is instead entangled with performance measurements, and if they do not fulfil a minimum number of 'major points' within the first five years of their academic career they lose their position at the University. There is a gender dimension to this demand of performance and productivity, as there are indications that the evaluation of work is more beneficial for academics working in the male dominated fields than in the more feminised fields. This is reflected in the performance measures, where the mean number of points per academic in STEM was 27 per cent higher than in SSH even though academic fields had a similar number of academics in 2013 ( $\mathrm{N}=110$ in STEM and $\mathrm{N}=106$ in SSH). Moreover, the mean number of major points per academic in STEM was 60 per cent higher than in SSH. What is noteworthy is that in STEM 70 per cent of the points fall in the category of 'major points' compared to 55 per cent for SSH academics. Further signs of a gendered process derive from journal rankings and can be reflected in the points awarded to academics in SSH and STEM. For every point in 2013 awarded to $\mathrm{SSH}$ for a publication in the top ranked journals, STEM received nine (1:9), while a much smaller difference in points awarded to SSH and STEM for publication in the 'middle ranked' journals (1:1.2). However, the opposite emerged from the 'lowest' ranked journals, for every point awarded to STEM for publications SSH receive two $(1: 2.1)$. The fact that STEM academics have more major points than $\mathrm{SSH}$ academics implies that the requirement to reach a minimum amount of major points will be more difficult for an assistant professor in SSH than in STEM. This can be reflected in the words of a female SSH assistant professor who is worried she will lose her position because her points are not seen as "noteworthy":

I just don't think I've been doing enough. I got plenty of points, but not interesting enough points [major points] ... because I've always been around here writing in the national context and done work for the ministry ... so, as I say, you don't really get anything for that.

This assistant professor, like so many others, is stuck in a rut with not enough major points, and even though she has been working full-time and to the best of her ability, her research work simply does not count as much in this incentive system as research done in an international context. The performance indicators are built on STEM focused performance measurements and traditions, that have the tendency to strongly undervalue teaching, administration and academic housework. 


\section{Teaching and academic housework}

When it comes to academic housework, interviewees within all GARCIA institutions could relate to the notion of undervalued tasks within their own academic and scientific institutions. STEM interviewees associated undervalued tasks with research-orientated chores, such as reviewing scientific articles, writing safety instructions for laboratories, administrative tasks that were related to international research projects, and the organisation of alumni clubs. SSH participants, on the other hand, connected it to tasks relating to teaching, recruitment of students, supervision, student interactions, and the development of new teaching programmes. There is increased pressure on early career researchers to perform these undervalued tasks, and be "entirely invested" in their work, as the rector of the Catholic University of Louvain phrased it. In the case of the Catholic University of Louvain it does not only mean that the researchers have to meet high demands in research and teaching, but also that they participate and have a presence in the institutional culture.

The number of students has a great influence on the teaching loads and work conditions of early career academics, and in some institutions the difference in student/teacher ratios between STEM and SSH are considerable. For instance, at Radboud University the ratio was 0.9:1 in the STEM department as compared to 40:1 in the SSH department in 2013. In the case of the University of Iceland there are unbalanced workloads within different fields that can be reflected in the student/full-time teacher ratio, which was 21:1 in STEM compared to 43:1 in SSH in 2013. At the University of Iceland, the high student/teacher ratio affects the working conditions of all the academic staff in SSH, but especially newcomers. As one key player in SSH shared: "Because there is much need for these newly recruited teachers, it always results in them getting buried in teaching". All the SSH academics interviewed had experienced an intense workload in relation to teaching. For academics with extensive teaching responsibilities, it can be difficult to find time to do research and collect the points you need to advance. A male SSH assistant professor reflects on how this impacts his career advancement within the academic institution:

How am I supposed to do the research needed to get the associate professorship and the tenured position? Because teaching is eating up my time. I have 14 research projects, some big, some small, at least four articles based on my thesis, I am seeing all of them sort of being delayed or destroyed because of too much teaching.

In the case of the University of Iceland, STEM acknowledges the heavy workload of teaching by giving their newly hired assistant professors a teaching discount and funding to support the development of their academic career. The fact that they can set aside resources for this reflects the trickle-down effect of the unbalanced budget allocation within the University. The key players in SSH realise this and talk about how the school would like to support the assistant 
professors to reach the minimum requirements for research as STEM does, but the school's lack of funding is standing in the way of that. This support is reflected in the interviews with newcomers in STEM, where few newcomers mention stress in relation to teaching, and most describe that they experience a clear balance between research and teaching. A different understanding of the heavy workloads of teaching and institutional activities is visible at the University of Trento, where these activities are included in the performance index in STEM, but not in SSH.

\section{The precarious PhDs}

Up till now we have discussed the influence of new managerial ideology and instruments on academic staff in adjuncts positions and higher. However, the impact of this ideology and accompanying instruments on $\mathrm{PhD}$ students should not be underestimated. There is intensified emphasis among GARCIA institutions on producing $\mathrm{PhD}$ graduates, even though there are signs that opportunities for full-time academic positions are reducing and becoming unstable, and temporary contracts are becoming much more common (Jongbloed 2012). This is also apparent in the University of Iceland's strategy for 2016-2021, where the institution aims to take measures to "promote the continuation of a graduation rate of 70 doctoral students per year" (University of Iceland 2016, p. 10). Putting this number in context, there were on average eight to nine academic positions advertised annually in SSH and STEM in the years 2010-2013. Therefore, this is a clear indication that precariousness starts early for $\mathrm{PhD}$ students.

Nevertheless, and in order to complicate matters further, the status of $\mathrm{PhD}$ students differs between countries and higher education institutions. At some higher education institutions, such as Radboud University, the $\mathrm{PhD}$ candidates are considered employees: they receive a salary and have a temporary employment contract. At the University of Trento, the $\mathrm{PhD}$ candidates receive a scholarship. At the Catholic University of Louvain, the University of Iceland and the University of Lausanne the status of $\mathrm{PhD}$ candidates can vary from being a paid employee, to receiving grants for the whole or part of the $\mathrm{PhD}$ programme, to relying on student-loans or/and other paid jobs either within or outside the academic institution. In Slovenia, the ZRC SAZU (SSH) does not have any $\mathrm{PhD}$ students, and within the STEM department of the University of Ljubljana the number of $\mathrm{PhD}$ students depends on extra-mural funding which has been decreasing during the economic crises. The status of the $\mathrm{PhD}$ candidates varies, but around half of the candidates are defined as young researchers and receive a grant from National Research Agency for the whole period of their programme. However, in all studied institutions, the financial conditions of a $\mathrm{PhD}$ programme differ between SSH and STEM, with candidates in STEM tending to be better off financially. For instance, at the University of Iceland almost all $\mathrm{PhD}$ candidates in STEM receive a salary or have a grant, while the $\mathrm{PhD}$ candidates in SSH are more often not funded or paid and have to provide for themselves as sessional teachers or with student loans. This bias towards the male-dominated 
STEM is reflected in the University of Iceland's PhD grants. For every grant awarded to SSH in the years 2010-2015, STEM received 2.2-3.3 grants. This is a trend that is observable among other GARCIA institutions as well. In the case of the University of Lausanne, around half of the $\mathrm{PhD}$ students do not have an employment contract. Having a contract varies between faculties, with a majority of PhDs in STEM having a contract (70 per cent), while only one-third of the $\mathrm{PhDs}$ had a contract in SSH (35 per cent). What is furthermore interesting is that one of the key players from Slovenia emphasises teaching tasks as predominantly beneficial to the $\mathrm{PhD}$ student. This key player also believes that the limit set by the Slovenian Research Agency regarding teaching hours prevents $\mathrm{PhD}$ students from exploitation.

However, it is known that many factors, among which a heavy teaching load, can affect the length of a $\mathrm{PhD}$ programme. According to the interviewees at the University of Iceland, funding strongly impacts the duration of the $\mathrm{PhD}$ programme. The $\mathrm{PhD}$ duration of SSH candidates is longer than for STEM candidates. Of the PhDs that graduated in the years 2010 to 2013, 6 out of 10 STEM candidates finished their programme within 5 years compared to 2 out of $10 \mathrm{SSH}$ candidates. There is a further gendered aspect to this matter; the duration of a programme is on average longer for women than for men in both schools. In STEM almost half of the female PhDs finished the programme within five years, compared to two-thirds of men. However, in SSH 15 per cent of women finished the $\mathrm{PhD}$ programme within five years compared to 20 per cent of men. This seems to be the case in the University of Lausanne as well, where the average duration of a $\mathrm{PhD}$ programme is four and a half years for STEM candidates, while almost five years for SSH candidates. By having a secure and sufficient income during the $\mathrm{PhD}$, students are more likely to spend their time on research and writing rather than on finding a different income source, by e.g. teaching and/or applying for grants, which are time-consuming activities.

At the end of a doctorate the precarity continues. In the case of the University of Lausanne, restrictive regulation on the employment of local $\mathrm{PhD}$ holders has been adopted, and early career researchers have to work for another institution for at least one year before they can be eligible for a position at Lausanne. Furthermore, a gender dimension to the precarious position of $\mathrm{PhD}$ holders is also apparent, as can be revealed in the case of the University of Iceland, where the $\mathrm{PhD}$ graduates from the male-dominated fields and the more feminised fields do not have the same opportunities inside and outside the academic institution. Chances of obtaining a position in academia after a $\mathrm{PhD}$ programme are small, which is reflected in the words of a key player interviewed at the University of Iceland: "I want to believe that the business community will gradually want $\mathrm{PhD}$ educated staff. I want to believe it. In reality we have nothing to do with all these people within the academic system". Opportunities in the private sector are more likely to apply to STEM graduates, hence men, than to SSH graduates, who are more likely to be women. These opportunities for STEM graduates outside the university are also said to be much better paid than positions within the academic environment, as a male assistant professor in STEM at the University of Iceland 
puts it in the simplest possible terms: "This is the worst paid job I could get with my education. Everything else I could do, I'd get better paid".

After the $\mathrm{PhD}$, there is a possibility of obtaining a postdoc position, but that is a very precarious position among all the GARCIA institutions. This is seen in the case of Italy, where postdocs do not have a formal status in the labour market and therefore do not have access to the welfare system, including unemployment benefits after the termination of their funding. ${ }^{1}$ Within the academic institutions, the postdocs are not considered employees even though, in some cases, they have informal (not recognised) responsibilities such as administrative and teaching duties. Because of this, the postdocs have a weak position in terms of access to university services and rights, such as research and mobility funds, even though their productivity in terms of publications and grants obtained contributes to the department performance evaluation. At the University of Iceland postdoc and researcher positions are temporary and often dependent on funding from outside the university. These positions are very rare in SSH, but more common in STEM. However, even though STEM PhD holders might be able to secure a funded postdoc position, retaining such a position and being able to secure adequate external funding can put them in a precarious situation. A female STEM postdoc from the University of Iceland reflected on that:

I have to apply for funds constantly ... I've made seven applications in the four years I've been here, and some of them take a month to write if I want to do it properly ... And if I want to qualify for a permanent position ... I need to do this, but at the same time this means I don't publish enough, so I will actually never reach the level where I become interesting [as a prospective candidate for a permanent position].

As will be discussed in Chapter 6, precarious working situations might also partly explain why some of the STEM PhD holders we interviewed had left academia for a better pay and better work conditions in the private sector. Throughout our interviews, higher salary was never a standalone reason for a STEM researcher to leave academia, but often seemed to function as that last 'push' towards a career change. To some degree, SSH PhD holders have the opposite experience to STEM PhD holders. While there are few opportunities to obtain a postdoc or a research position within the academic institution, opportunities outside academia are also rare. As we have demonstrated, the financial and managerial procedures and processes highly impact the position and conditions of early career researchers, with further gender consequences. This is important to acknowledge as the objective of gender budgeting is not only to create knowledge, but also to restructure procedures and processes to facilitate gender equality. 


\section{A way forward: towards the implementation of gender budgeting and redistribution of resources}

By means of gender budgeting we have uncovered both implicit and explicit impacts of the budget on women and men in precarious positions within academia and science. We have brought to light the increased reliance on performance measurements to emphasise excellence and to legitimate an unequal distribution of funding allocations within the institutions. We have shown that new managerial methods lead to precariousness within the higher education institution. Many of the arguments for why the budget is allocated in the way it is do not seem to be based on objective grounds. Instead they are built on gendered premises and historical traditions and these arguments have become so ingrained into the system that there are few that openly question them. In the light of our findings, we claim that they can be integrated in the tools of gender budgeting. However, in order for gender budgeting to have a transforming effect in academia it has to be used as a form of feminist policy change that aims to "dismantle hierarchies of power that privilege men and the masculine, and the sexual division of labour that devalues women and the feminine" (Htun and Weldon 2010, cited in O'Hagan 2015, p. 235). Consequently, it is deemed insufficient to merely assess the gender biases, instead there is a need for identifying possibilities for redistribution and actively correcting imbalances and utilising gender budgeting as an instrument for advancing gender equality.

The gender budgeting toolkit for academia elaborated within the GARCIA project (Steinpórsdóttir, Heijstra et al. 2016b) is intended as a guide for integrating gender into financial and managerial processes and procedures to achieve more gender equal outcomes. In order to transform academia we have to identify possibilities for redistribution. In order to work towards a fairer system, we have to start by acknowledging that the academic fields in the current system are valued differently and that the system is fostering inequality, as we have so vividly illustrated. Gender budgeting can increase transparency, that has the potential to improve decision making and increase accountability. In order for the implementation to be successful, a good project management and reasonable completion date for achievement of the objectives need to be established. To be able to follow up, the implementation has to be measured and evaluated from a gender perspective, e.g. by collecting sex-disaggregated data on the number of staff and students.

Another possibility to advance gender equality and improve the position of early career researchers is through the performance measurements utilised in various higher education institutions. The basis for the indicators needs to be examined from a gender perspective, that is, what is valued and what is undervalued and why it is so. Building on that evidence we have to consider if the criteria are acceptable or if there is a possible bias towards gender, gendered academic and scientific fields, academics in different positions and with different employment contracts. When reforming the performance evaluation system, or any other financial and managerial procedures and processes, we have to put 
forward clear objectives and we have to have a clear vision of what the ultimate goal is. Is it to adjust women, early career researchers, and academics from feminised fields, to a system that is designed around men, high ranked academics, and academics from male-dominated fields - in other words to 'help' these groups jump onto the treadmill? Or is time to utilise gender budgeting and make it our object to change the system and work towards a more gender equal and fair academia and science for all?

\section{Note}

1 After the end of the GARCIA project, in July 2017, the Italian government approved a reform which allows postdocs to receive an unemployment benefit similar to the one allocated to freelancers. If a postdoc works for one year, they will be entitled to an allowance of maximum six months of 700-900 euro per month, according to the amount of the scholarship.

\section{References}

Agreement on teaching and research between University of Iceland and the Ministry of Education, Research and Culture 2012-2016, Appendix 1.

Acker, J. (1992). From sex roles to gendered institutions. Contemporary Sociology, 21(5), 565-569.

Acker, J. (2006). Inequality regimes gender, class, and race in organizations. Gender \& Society, 20(4), 441-464.

Addabbo, T., Gunluk-Senesen, G. and O'Hagan, A. (2015a). Gender budgeting: insights from current methodologies and experiences in Europe. Politica economica, 31(2), $125-134$.

Addabbo, T., Rodríguez-Modroño, P. and Gálvez-Muñoz, L. (2015b). Gender budgeting in education from a wellbeing approach: an application to Italy and Spain. Politica economica, 31(2), 195-212.

Alper, J. (1993). The pipeline is leaking women all the way along. Science, 260(5106), 409-412.

Bacchi, C. (2012). Why study problematizations? Making politics visible. Open Journal of Political Science, 2(1), 1-8.

Bagilhole, B. (2002). Challenging equal opportunities: changing and adapting male hegemony in academia. British Journal of Sociology of Education, 23(1), 19-33.

Barry, J., Berg, E. and Chandler, J. (2012). Movement and coalition in contention: gender, management and academe in England and Sweden. Gender, Work \& Organization, 19(1), 52-70.

Bataille, P. and Goastellec, G. (2016). University of Lausanne, Switzerland. In F. S. Steinpórsdóttir, T. M. Heijstra, P. Einarsdóttir and G. M. Pétursdóttir (eds), Gender budgeting in academia, GARCIA Working Papers 8 . University of Trento.

Benschop, Y., Van den Brink, M. and Berger, L. (2016). Radboud University, the Netherlands. In F. S. Steinpórsdóttir, T. M. Heijstra, P. Einarsdóttir and G. M. Pétursdóttir (eds), Gender budgeting in academia, GARCIA Working Papers 8. University of Trento.

Berg, L. D., Huijbens, E. H. and Larsen, H. G. (2016). Producing anxiety in the neoliberal university. The Canadian Geographer/le géographe canadien, 60(2), 168-180. 
Budlender, D. (1996). The Women's Budget. Cape Town: Institute for Democracy in South Africa.

Butler, N. and Spoelstra, S. (2014). The regime of excellence and the erosion of ethos in critical management studies. British Journal of Management, 25, 538-550.

Chandler, J., Barry, J. and Berg, E. (2004). Reforming managerialism? Gender and the navigation of change in higher education in Sweden and England. In R. Thomas, A. J. Mills and J. H. Mills (eds), Identity Politics at Work: Resisting Gender, Gendering Resistance. London: Routledge, pp. 123-140.

Dubois-Shaik, F. and Fusulier, B. (2017). Understanding gender inequality and the role of the work/family interface in contemporary academia: an introduction. European Educational Research Journal, 16(2-3), 99-105.

Dubois-Shaik, F., Fusulier, B. and Vinke, C. (2016). Université Catholique de Louvain, Belgium. In F. S. Steinpórsdóttir, T. M. Heijstra, P. Einarsdóttir and G. M. Pétursdóttir (eds), Gender budgeting in academia, GARCIA Working Papers 8. University of Trento.

Elson, D. (1999). Gender Budget Initiative: Background Papers. London: Commonwealth Secretariat.

Erbe, B. (2011). Gender budgeting as a management strategy for gender equality at universities - with the examples of Austria, Germany and Poland. In H. Macha, C. Fahrenwald and Q. J. Bauer (eds), Proceedings of Gender and Education: Towards New Strategies of Leadership and Power. Second International Conference of the Women Leading Education (WLE) Network. Berlin: Druck und Verlag: epubli GmbH, pp. 57-62.

Erbe, B. (2015). Gender mainstreaming in public financing of universities: central findings for Germany. Politica Economica, 31(2), 213-232.

European Commission (1998). A Guide to Gender Impact Assessment. Luxembourg: Office for Official Publications of the European Communities Retrieved from http:// bookshop.europa.eu/en/a-guide-to-gender-impact-assessment-pbCE1698788/.

European Commission. Directorate-General for Research and Innovation (2016). She Figures 2015. Luxembourg: Publications Office.

Gómez, C. (2012). Telling our stories, naming ourselves: the lost María in the academy. In B. C. Stockdill and M. Y. Danico (eds), Transforming the Ivory Tower: Challenging Racism, Sexism, and Homophobia in the Academy. Honolulu: University of Hawai' $\mathrm{i}$ Press, pp. 53-65.

Gouthro, P. A. (2002). What counts? Examining academic values and women's life experiences from a critical feminist perspective. CJSAE/RCÉÉ A, 16(1), 1-10.

Heijstra, T. M., Einarsdóttir, P., Pétursdóttir, G. M. and Steinpórsdóttir, F. S. (2017). Testing the concept of academic housework in a European setting: part of academic career-making or gendered barrier to the top? European Educational Research Journal, $16(2-3), 200-214$.

Heijstra, T. M., Steinpórsdóttir, F. S. and Einarsdóttir, P. (2017). Academic career making and the double-edged role of academic housework. Gender and Education, 29(6), 764-780.

Hofman, A. and Knežević Hočevar, D. (2016). ZRC SAZU, Ljubljana, Slovenia. In F. S. Steinpórsdóttir, T. M. Heijstra, P. Einarsdóttir and G. M. Pétursdóttir (eds), Gender budgeting in academia, GARCIA Working Papers 8 . University of Trento.

Htun, M. and Weldon, S. L. (2010). When do governments promote women's rights? A framework for the comparative analysis of sex equality policy. Perspectives on Politics, $8(1), 207-216$. 
Hymowitz, C. and Schellhardt, T. D. (1986). The glass ceiling: why women can't seem to break the invisible barrier that blocks them from the top jobs. The Wall Street Journal, 24(1), 1573-1592.

Jongbloed, B. (2012). Academic salaries in Western Europe. International Higher Education, 68, 5-6.

Keisu, B.-I. and Carbin, M. (2014). Administrators or critical cynics? A study of gender equality workers in Swedish Higher Education. NORA - Nordic Journal of Feminist and Gender Research, 22(3), 204-218.

Klatzer, E. and Mader, K. (2008). Expanding the Theoretical Foundations and Methodological Approach of Gender Budgeting: Feminist Democratic Implications. Paper presented at The First International Conference on Gender Responsive Budgeting and Social Justice, Vilnus.

Knights, D. and Richards, W. (2003). Sex discrimination in UK academia. Gender, Work \& Organization, 10(2), 213-238.

Knobloch-Westerwick, S., Glynn, C. J. and Huge, M. (2013). The Matilda Effect in science communication an experiment on gender bias in publication quality perceptions and collaboration interest. Science Communication, 35(5), 603-625.

Larner, W. (2000). Neo-liberalism: policy, ideology, governmentality. Studies in Political Economy, 63, 5-25.

Leahey, E. (2006). Gender differences in productivity: research specialization as a missing link. Gender \& Society, 20(6), 754-780.

Lee, S. and Bozeman, B. (2005). The impact of research collaboration on scientific productivity. Social Studies of Science, 35(5), 673-702.

Long, J. S., Allison, P. D. and Mcginnis, R. (1993). Rank advancement in academic careers - sex-differences and the effects of productivity. American Sociological Review, 58(5), 703-722. Doi 10.2307/2096282.

Lynch, K. (2006). Neo-liberalism and marketisation: the implications for higher education. European Educational Research Journal, 5(1), 1-17.

Lynch, K. (2010). Carelessness: a hidden doxa of higher education. Arts and Humanities in Higher Education, 9(1), 54-67.

Lynch, K. (2014). New managerialism: the impact on education. Concept, 5(3), 1-11.

Marginson, S. and van der Wende, M. (2007). To rank or to be ranked: the impact of global rankings in higher education. Journal of Studies in International Education, 11(3-4), 306-329.

Morley, L. (2006). Hidden Transcripts: The Micropolitics of Gender in Commonwealth Universities. Paper presented at the Women's Studies International Forum.

O'Connor, P. and O'Hagan, C. (2016). Excellence in university academic staff evaluation: a problematic reality? Studies in Higher Education, 41(11), 1943-1957.

O'Hagan, A. (2015). Favourable conditions for the adoption and implementation of gender budgeting: insights from comparative analysis. Politica Economica, 31(2), 233-252.

Özbilgin, M. F. (2009). From journal rankings to making sense of the world. Academy of Management Learning \& Education, 8(1), 113-121.

Paradeise, C. and Thoenig, J. (2016). In Search of Academic Quality. Basingstoke: Palgrave Macmillan.

Parker, M. and Jary, D. (1995). The McUniversity; organization, management and academic subjectivity. Organization, 2(2), 319-338.

Power, M. (1997). The Audit Society: Rituals of Verification. Oxford. New York: Oxford University Press. 
Rapetti, E., Villa, P., Murgia, A. and Poggio, B. (2016). University of Trento, Italy. In F. S. Steinpórsdóttir, T. M. Heijstra, P. Einarsdóttir and G. M. Pétursdóttir (eds), Gender budgeting in academia, GARCIA Working Papers 8. University of Trento.

Rossiter, M. W. (1993). The Matthew Matilda effect in science. Social Studies of Science, 23(2), 325-341.

Rothe, A., Erbe, B., Fröhlich, W., Klatzer, E., Lapniewska, Z., Mayrhofer, M., Neumayr, M., Pichlbauer, M., Tarasiewicz, M., Zebisch, J. and Debski, M. (2008). Gender Budgeting as a Management Strategy for Gender Equality at Universities: Concluding Project Report. Munich: Frauenakademie München e.V. München.

Schreier, M. (2012). Qualitative Content Analysis in Practice. Los Angeles, CA: Sage Publications.

Service des relations internationales (2009). International Strategy of the University of Lausanne. Lausanne: UNIL. www.unil.ch/international/files/live/sites/international/ files/shared/International_strategy/UNIL_International_Strategy_2009-.pdf [accessed 16 June 2015]

Sharp, R. and Broomhill, R. (2002). Budgeting for equality: the Australian experience. Feminist Economics, 8(1), 25-47.

Slaughter, S. and Rhoades, G. (2004). Academic Capitalism and the New Economy: Markets, State, and Higher Education. Baltimore, MD: The Johns Hopkins University Press.

Steinpórsdóttir, F. S., Brorsen Smidt, T., Pétursdóttir, G. M., Einarsdóttir, P. and Le Feuvre, N. (2018). New managerialism in the academy: gender bias and precarity. Gender, Work \& Organization, 1-16. Doi 10.1111/gwao.12286.

Steinpórsdóttir, F. S., Einarsdóttir, P., Heijstra, T. M. and Pétursdóttir, G. M. (2016). Money talks: gender budgeting in the University of Iceland. Stjórnmál og Stjórnsýsla, 12(1), 171-194.

Steinpórsdóttir, F. S., Heijstra, T. M. and Einarsdóttir, P. (2017). The making of the 'excellent' university: a drawback for gender equality. Ephemera, Theory \& Politics in Organization, 17(3), 557-582.

Steinpórsdóttir, F. S., Heijstra, T. M., Einarsdóttir, P. and Pétursdóttir, G. M. (2016a). University of Iceland, Iceland. In F. S. Steinpórsdóttir, T. M. Heijstra, P. Einarsdóttir and G. M. Pétursdóttir (eds), Gender budgeting in academia, GARCIA Working Papers 8. University of Trento.

Steinpórsdóttir, F. S., Heijstra, T. M., Einarsdóttir, P. and Pétursdóttir, G. M. (2016b). Gender budgeting in academia - toolkit, GARCIA Working Papers 14. University of Trento.

Stockdill, B. C. and Danico, M. Y. (2012). The ivory tower paradox: higher education as a site of oppression and resistance. In B. C. Stockdill and M. Y. Danico (eds), Transforming the Ivory Tower: Challenging Racism, Sexism, and Homophobia in the Academy. Honolulu: University of Hawai' i Press, pp. 1-30.

Suitor, J. J., Mecom, D. and Feld, I. S. (2001). Gender, household labor, and scholarly productivity among university professors. Gender Issues, 19(4), 50-67.

United Nations (1995). Beijing Declaration and Platform of Action: Fourth World Conference on Women, Beijing, China 4-15 September 1995. New York: United Nations.

University of Iceland (2016). Strategy of the University of Iceland 2016-2021. Reykjavík: Háskóli Íslands.

Välimaa, J. (2012). The corporatization of national universities in Finland. In B. Pusser, K. Kemper, S. Marginson and I. Ordorika (eds), Universities and the Public Sphere: Knowledge Creation and State Building in the Era of Globalization. New York: Routledge, pp. 101-119. 


\section{Finnborg S. Steinpórsdóttir et al.}

Van den Brink, M. and Benschop, Y. (2012a). Slaying the seven-headed dragon: the quest for gender change in academia. Gender, Work \& Organization, 19(1), 71-92.

Van den Brink, M. and Benschop, Y. (2012b). Gender practices in the construction of academic excellence: sheep with five legs. Organization, 19(4), 507-524.

Võ, L. T. (2012). Transformative disjunctures in the academy: American Studies as praxis. In B. C. Stockdill and M. Y. Danico (eds), Transforming the Ivory Tower: Challenging Racism, Sexism, and Homophobia in the Academy. Honolulu: University of Hawai'i Press, pp. 120-144.

Walby, S. (1990). Theorizing Patriarchy. Oxford: Blackwell Publishers.

Waring, M. (1988). If Women Counted: A New Feminist Economics. San Francisco, CA: Harper Collins Publishers.

Xie, Y. and Shauman, K. A. (2003). Women in Science: Career Processes and Outcomes. Cambridge, MA: Harvard University Press.

Porvaldsdóttir, P. (2004). Engendered opinions in placement committee decisions Gender and Excellence in the Making. Brussels: European Commission. Directorate-General for Research, pp. 101-107. 


\title{
4 The peril of potential
}

\section{Gender practices in the recruitment and selection of early career researchers}

\author{
Channah Herschberg, Yvonne Benschop and \\ Marieke van den Brink
}

\section{Introduction}

Despite efforts to reduce gender inequality in European academia, figures show that the number of women researchers is still disproportionally lower at every step of the academic career ladder than the number of men researchers (EU 2016). Previous research on gender in academia has demonstrated that various practices in academia are causing this gender inequality, such as the masculine organisation of academia (Teelken and Deem 2013), academic networking (Van den Brink and Benschop 2014), a lack of role models and informal support systems for women (Bagilhole and Goode 2001), the substantial allocation of academic housework to women (Heijstra et al. 2016), and the way academic excellence is constructed (Van den Brink and Benschop 2012a).

The studies that analysed how the perpetuation of gender disparities is imbued in the rhetoric of meritocracy have shown the crucial role played by recruitment and selection practices at full professor level (Van den Brink 2010; Van den Brink et al. 2010; Van den Brink and Benschop 2012a). However, gender practices in the recruitment and selection have hitherto not been studied for the early stages of the academic career. We argue that it is important to fill this void as the specific characteristics of the early academic career stage, such as the growing number of precarious positions (Wöhrer 2014) and the more equal gender balance among junior staff (EU 2016), point to the relevance of examining gender practices in this phase. The recruitment and selection processes for assistant professors need more scrutiny as these early career researchers find themselves in strong competition for relatively scarce positions (Nikunen 2014). Yet, we do not know how gender plays a role in who wins or loses in this competition, but we do see that the numbers of women drop at the level of assistant professor (EU 2016). Therefore, a critical analysis of the recruitment and selection of early career researchers is needed in order to understand how gender inequalities are constructed.

In this chapter, we apply a practice approach, which enables us to study gender as a social and relational construction (Poggio 2006). We will examine the gendering process of evaluating assistant professor candidates, an endeavour 


\section{Channah Herschberg et al.}

mainly carried out by the academic elite. We draw on unique information from a qualitative study on gatekeepers across six European countries and reveal how gender practices emerge in the construction of selection criteria when gatekeepers discuss their recruitment and selection practices.

The aim of this study is to contribute to theory on gender in academic organisations by showing which gender practices characterise the evaluation of candidates' potential for assistant professor positions with a prospect of a more permanent contract. We draw on empirical material of recruitment and selection procedures and criteria, such as job descriptions, HR documents, interviews and focus groups with selection committee members both in social sciences and humanities (SSH) departments and in science, technology, engineering, and mathematics (STEM) departments of six European higher education institutions. A critical comparative analysis of the data resulted in the identification of two general gender practices in the recruitment and selection of assistant professors: welcoming women and assessing potential for excellence. Additionally, we find that the two general gender practices are composed of six specific gender practices. Our analysis shows that for early career researchers, judgements are based on potential instead of long track records of academic performance. We provide insight into the way the 'ideal assistant professor' is constructed, and how gender inequalities are ingrained in criteria such as excellence, international mobility and academic citizenship.

\section{Precarious academic positions}

Today's academic labour market is characterised by precariousness in employment, referring to high employment insecurity and possibly low wages (Campbell and Price 2016). Spurred by financial incentives, many European countries produce more PhDs than the academic labour market can accommodate (Cyranoski et al. 2011) as numbers of academic positions stagnate or decline (Fiske 2011). As a result, permanent positions, job security and career prospects are increasingly rare in the neoliberal academy, and early career researchers are faced with strong competition for scarce jobs (Nikunen 2014; Morgan and Wood 2017). An increase in temporary contracts throughout European universities is found (Wöhrer 2014), for example fixed term contracts and hourly paid contracts (Bryson 2004). The focus of this chapter is on non-tenured assistant professor positions.

The temporality of fixed term assistant professorships (sometimes on a tenure-track) generally involves the principle of 'up or out', which substantially prolongs the probationary period post- $\mathrm{PhD}$ and constitutes the risk of a negative evaluation (Schiewer and Jehle 2014). Furthermore, such precarious academic positions are intended to form "a bridge to more secure employment, but universities across the world are growing the casual workforce to the point where the prospects of a stable academic career are becoming more and more remote" (Morgan and Wood 2017, p. 86). The potential impact of precarious work can differ across individuals and societies (Campbell and Price 2016), but also across 
academic systems (see Chapter 2, in this volume), for example in terms of a degeneration of career structures (Bryson 2004), lack of access to employment conditions and opportunities (Harney et al. 2014), and a declining desirability of academic positions (Huisman et al. 2002). Precariousness in academia also shows a gendered division, with more women employed on fixed term contracts than men and a higher likelihood of women to remain on such contracts (Bryson 2004). Yet, Bryson (2004) found that for both women and men it is difficult to make "the transition from researcher on [a fixed term contract] to a more secure post" (p. 198). In this chapter, we uncover which gender practices play a part in evaluating candidates' potential for precarious positions with a prospect of a more permanent contract.

\section{Recruitment, selection and gender practices}

Recruitment and selection practices determine who get access to assistant professor positions. Recruitment is the process concerned with attracting suitable candidates (Newell 2005) and selection is the process of choosing one candidate out of the pool of candidates based on (predefined) criteria (Van den Brink 2010) and based on the 'fit' between the individual and the job. Members of the dominant academic elite play a critical part in both the recruitment and selection of candidates. Previous studies on gender and academic recruitment have shown the importance of examining what gender practices are at play 'at the gate', where researchers are allowed or denied entrance (Van den Brink 2010; Van den Brink et al. 2010; Van den Brink and Benschop 2012a; Van den Brink and Benschop 2014; Nielsen 2015; O’Connor and O’Hagan 2015). However, as most studies concern higher positions in the academic hierarchy, we know little about the gender practices that affect the recruitment and selection of early career researchers, such as non-tenured assistant professors.

Studying gatekeeping at the early stages of the academic career is particularly interesting because in this phase is decided who are included or excluded from (precarious) positions with a prospect of a more permanent contract, and eventually a career in academia. A few studies note that the assessment of potential plays a role in the evaluation of researchers (Van Arensbergen et al. 2014; O'Connor and O'Hagan 2015), particularly for early career researchers (Bazeley 2003) who have recently entered the academic labour market. To identify "those who are researchers of promise" is primarily a subjective endeavour (Bazeley 2003 , p. 271). Subjectivity tends to come with gender practices and therefore the recruitment and selection of assistant professors need further scrutiny. Studies in social psychology that focus on cognitive bias in the evaluation of men and women have shown, for example, that male students are evaluated as more competent for a position (Moss-Racusin et al. 2012) and that men are favoured in hiring decisions (Biernat and Fuegen 2001). What these studies do not show is how these biases become manifest in the construction of recruitment and selection criteria and the assessment of a candidate's potential to meet those criteria. Therefore, we will study how committee members practice gender when 


\section{Channah Herschberg et al.}

constructing recruitment and selection criteria for assistant professorships, where the potential of early career researchers is evaluated.

Our point of departure is the conviction that "workplaces are infused with gender" (Martin 2003, p. 343). We use the notion of gender practices to grasp the practices that happen in action and on many organisational levels (Martin 2003). We define gender practices as "the intentional or unintentional and often un-reflexive way of distinguishing between women and men, femininity and masculinity" in daily work situations (Van den Brink 2010, p. 24). Central to the practice approach is the notion that "social life is an on-going production and thus emerges through people's recurrent actions" (Feldman and Orlikowski 2011, p. 1240). In line with Dick and Nadin (2006), we argue that selection criteria and their meaning are socially constructed in ways that mirror the interests of a particular group, which can produce inequalities for other groups, notably women. Therefore, selection criteria are not neutral, but defined and interpreted in a certain context (Dick and Nadin 2006). The framework of gender practices will help to uncover gatekeepers' gendered constructions of selection criteria in the recruitment and selection practices for non-tenured assistant professor positions.

\section{Methods}

\section{Data}

The research for this chapter is based on a qualitative study conducted in six higher education institutions involved in the GARCIA project. The national research reports written by the six research teams that comprise the primary data we used for our analysis are part of a larger data set collected during the course of the GARCIA project. Each research team wrote a research report that centred on formal and applied criteria in the recruitment and selection of early career researchers for academic positions (Herschberg et al. 2015) and a report that centred on gender practices in the recruitment and selection of early career researchers (Herschberg et al. 2016). Our analysis is mostly based on the research reports that focus on gender practices in recruitment and selection. In addition, every research team made summaries in English of all interviews and focus groups they had conducted. These summaries were written to provide the authors with primary data to strengthen the analysis.

The national research reports are based on various data sources. All data that are comparable across institutions in the six countries - have been collected in one SSH and one STEM department per institution. Previous studies have shown how SSH and STEM subfields vary considerably with regard to the gender compositions of students and staff, career patterns, recruitment and selection practices (Van den Brink 2010) as well as gender practices (Van den Brink and Benschop 2012b). The data consisted of documents such as university policy documents, HR documents, job postings, and appointment reports, published in the period 2010-2014. All six research teams collected these documents, 
dependent on the availability in their institution. Furthermore, in 2014 every research team conducted semi-structured interviews and focus groups with selection committee members (hereafter committee members). The interview and focus group participants were selected because they had taken part in a hiring committee that was involved in the recruitment and selection of at least one temporary (tenure-track) assistant professor in the period 2010-2014. To ensure comparability, every team used the same interview guide for the interviews. Interviews were based on three themes: selection criteria for assistant professor positions, a selection process in which the research participants had taken part, and department policies regarding recruitment and selection of early career researchers. Interviews were conducted with 47 men and women committee members and five focus groups with 35 men and women committee members. In total 55 men and 27 women participated in this study. The majority of our research participants (two thirds) are men. This reflects the number of men on selection committees in the countries of this study. We find in our data that decision-making power regarding the appointment of assistant professors mainly lies in the hands of male researchers. The majority of committee members as well as the committee members in powerful positions (e.g. the chair of the committee) are men. Even though the skewed division of men and women among our research participants reflects the current situation in selection committees for assistant professor positions, it could have influenced our findings. See Table 4.1 for more information on the research participants.

The interviews and focus groups were recorded with participants' permission and transcribed verbatim. Thus, our data are primarily textual accounts that allow us to capture detailed accounts of recruitment and selection practices. It is in these accounts that we found multiple gender practices. Ideally, we would have gathered observational data as well, to be able to capture the practices in the doing. Unfortunately, we were denied access to actual recruitment and selection processes in all but one country because of privacy and confidentiality concerns.

\section{Data analysis}

The research reports of the GARCIA teams were centred on recruitment and selection of early career researchers including both postdocs and assistant professors. For this chapter we focused on the sections of the research report that involved the research findings on assistant professor positions. We applied thematic coding as a method for analysing our data (Flick 2009). We first read the research reports on gender in recruitment and selection and open coded the texts. We produced short descriptions of each 'case' (national report) according to the themes in the reports (Flick 2009): 'context', 'power in the recruitment and selection of assistant professors in the STEM department', 'power in the recruitment and selection of assistant professors in the SSH department', 'gender in the recruitment and selection of assistant professors in the STEM department', and 'gender in the recruitment and selection of assistant professors in the SSH 
Table 4.1 Number of male and female interview and focus group participants per country and department

\begin{tabular}{|c|c|c|c|c|c|c|c|c|c|c|}
\hline \multirow[t]{2}{*}{ Country } & \multicolumn{2}{|c|}{ SSH interviews } & \multicolumn{2}{|c|}{ STEM interviews } & \multicolumn{2}{|c|}{ SSH focus group } & \multicolumn{2}{|c|}{ STEM focus group } & \multicolumn{2}{|c|}{$\begin{array}{l}\text { Combined STEM-SSH } \\
\text { focus group }\end{array}$} \\
\hline & $M$ & $F$ & $M$ & $F$ & $M$ & $F$ & $M$ & $F$ & $M$ & $F$ \\
\hline Iceland (IS) & 4 & 1 & 1 & 3 & 3 & 2 & 2 & 1 & - & - \\
\hline Slovenia (SO) & 2 & 2 & 2 & 1 & 2 & 2 & 3 & 2 & - & - \\
\hline Belgium (BE) & 3 & 2 & 3 & 0 & - & - & - & - & 2 & 3 \\
\hline Switzerland (CH) & 3 & 1 & 2 & 1 & 4 & 2 & - & - & - & - \\
\hline Italy (IT) & 4 & 1 & 2 & 0 & - & - & - & - & - & - \\
\hline The Netherlands (NL) & 2 & 2 & 5 & 0 & 2 & 1 & 4 & 0 & - & - \\
\hline Total & 18 & 9 & 15 & 5 & 11 & 7 & 9 & 3 & 2 & 3 \\
\hline
\end{tabular}


department'. This way, the central topics documented in the reports were summarised. Next, we compared the different 'cases', which revealed many similar recruitment and selection practices and gender practices (e.g. international mobility, gender stereotypes). We then deepened our analysis by applying selective coding through rereading all reports and looking for "further examples and evidence for relevant categories" (Flick 2009, p. 312) regarding gender practices. At all times the cases (national reports) were compared. This resulted in a thematic structure of the gender practices found in the research reports. After multiple deliberations between the authors we ended up with two general gender practices, composed of six specific gender practices (see Table 4.2 for an overview). Selected passages of the research reports as well as interview quotes were analysed in greater detail. Repeatedly, we went back to the original research reports as well as the interview and focus group summaries to get additional information needed for our analysis. Our findings are illustrated with quotes from the interviews. The participant's country (see Table 4.1 for country abbreviations), department (SSH or STEM) and sex are provided. Quotes were translated into English by the respective research teams.

In the remaining part of the chapter we will use country names instead of the names of the participating institutions to facilitate reading. For example, when we refer to Switzerland, we refer to the participating institution in Switzerland. Also, we will use the terminology "SSH department" and "STEM department" in reference to to the various departments in the six higher education institutions. See Table 4.1 for more information on the participating countries and the country abbreviations.

\section{Research context}

Even though the proportion of women academics in assistant professor positions is more than double the proportion of women on full professorships in the EU-28 countries, we already see a decrease in the proportion of women academic staff from postgraduate/post-PhD positions to assistant professor positions (EU 2016). This decrease is also visible in the countries included in this study (see Table 4.3).

A general tendency of Western governments has been to decrease the amount of public money spent on public services (De Boer et al. 2007) and the direct

Table 4.2 Overview of general gender practices and specific gender practices

\begin{tabular}{ll}
\hline General gender practices & Specific gender practices \\
\hline Welcoming women & Women contribute to the working environment \\
& Role models \\
Assessing potential for excellence & Confidence \\
& Commitment \\
& International mobility \\
& Academic citizenship \\
\hline
\end{tabular}


Table 4.3 Proportion of female academic staff by grade, 2013

\begin{tabular}{lcl}
\hline Country & Grade D & Grade C \\
\hline Iceland (IS) & - & 51.2 \\
Slovenia (SO) & 52.6 & 45.5 \\
Belgium (BE) & 48.3 & 35.8 \\
Switzerland (CH) & 41.5 & 38.5 \\
Italy (IT) & 50.3 & 45.4 \\
The Netherlands (NL) & 45.6 & 37.8 \\
\hline
\end{tabular}

Source: EU 2016.

Note

Grade C represents assistant professors, Grade D represents either postgraduate students not yet holding a $\mathrm{PhD}$ degree who are engaged as researchers (on the payroll) or researchers working in posts that require a $\mathrm{PhD}$.

investments in higher education. All universities in our study have been confronted with decreasing budgets, except for the Swiss university. In Slovenia, budget cuts have been so severe that professors have to fund part of their own position by acquiring external funding. In all universities in our study there is an increasing pressure on academic staff to obtain external research funding. Particularly for postdocs, this funding is needed to sustain their employment, often leading to an accumulation of multiple precarious contracts. At the same time, successfully obtaining external funding is increasingly becoming a selection criterion for academics, also at the early career stages. In Switzerland and in the Dutch STEM department, having obtained a grant is a selection criterion for tenure-track assistant professors positions. This not only signals a difference in selection criteria between the various countries but also a difference regarding academic maturity of candidates for assistant professorships. In Switzerland, Italy and the Dutch STEM department, candidates for assistant professor positions are expected to have obtained years of (postdoc) experience before going into a track that gives prospects for a more permanent position. This is in contrast to other countries and departments where early career researchers can apply for an assistant professorship right after their $\mathrm{PhD}$ or after fewer years of postdoc employment.

Decreasing university budgets also have an effect on the availability of tenure-track positions. Particularly in Italy and Slovenia, the number of available positions that may become permanent in the long run is extremely low. Yet, in all countries we find increasing numbers of $\mathrm{PhD}$ and postdoc positions but stagnating or declining numbers of assistant professor positions. As a result, the competition for assistant professorships is high and the pressure on appointed candidates to succeed tremendous.

\section{Recruitment and selection procedures}

We briefly describe the committee composition and recruitment and selection procedures in the institutions that are part in this study to provide some context. 
In Belgium, the recruitment and selection of assistant professors follows university policy that comprises a four-stage process. The first stage involves advertising the vacancy for the position. Then, all the applications are collected and sent to the selection committee appointed by the Executive Board. The second stage involves the selection. Each committee member makes a shortlist with applicant(s) they would like to interview, followed by the actual interviews. Then, the first ranked candidate is nominated for the position. In the third stage the Executive Board confirms the selection. The fourth and final stage is when the Board of Governors and then the Board of Trustees confirm the appointment.

In Iceland the selection procedure for assistant professor positions takes place in three stages, as determined by university policy. First, the position is publicly advertised and the applications are collected. Second, an evaluation committee evaluates if candidates fulfil the minimum requirements for the position. This committee consists of three members, two members appointed by the university council and one specialist appointed by the faculty. The evaluation committee evaluates candidates after which the applications of qualified candidates are sent to the selection committee. Third, the selection committee makes the final decision on who is going to be suggested for the position. The selection committee consists of five members: the head of the faculty who is also the chair of the committee, one standing member appointed by the faculty, two specialists appointed by the faculty, and one Rector's representative. The role of the Rector's representative is to make sure that rules and regulations (also the Gender equality law) are followed.

In Italy, the selection procedure for assistant professors is formalised. It initially involves a public announcement, followed by the appointment of a committee composed of three full or associate professors: one selected by the university, one by the department concerned, and one by the university recruitment committee. At least one member must be from another university. The STEM and SSH department differ in their recruitment approach in the sense that external networks (national and international) are more important in the STEM department, whereas the SSH department relies more on internal networks and membership of specific groups. Several evaluation phases follow after recruitment: a pre-selection consisting of a comparative evaluation of qualifications, $\mathrm{CVs}$ and three reference letters; the advice of three external referees appointed by the university recruitment committee; the consequent admission to the next phase where at least six candidates are interviewed. At the end of the interview phase the committee makes a ranking. Then, the department council deliberates on the candidate who will be nominated for the post. The council takes account of the committee's evaluation, although this is not binding.

In the Netherlands, the selection process for an assistant professor starts when a position becomes vacant. A job description is created based on the tasks the assistant professor has to conduct. When composing the selection committee, the main tasks the assistant professor will have to fulfil are taken into account. For example, the coordinator of bachelor programme will take part in the committee when the assistant professor has to do a lot of teaching in the bachelor 
programme. Also, policy prescribed that the committee should have a least one woman member with a position comparable to the one in the vacancy. After the committee has been installed, the job description is advertised on academic job websites and distributed via mailing lists. When all letters of application have come in, the committee makes a short list of candidates to interview, either via e-mail or during a face-to-face meeting. Based on interviews with shortlisted candidates, committee members evaluate the candidates and decide on the preferred candidate. Next, they write an appointment report, which is an advice to the faculty board. Then, the faculty board decides on the final appointment.

In the Slovenian SSH department, the Scientific Council of the Institute serves as the selection committee for research fellows (equivalent of assistant professor). These positions fall under the promotion system in which candidates who meet the official criteria are promoted, but candidates who do not meet the criteria are rejected. In the Slovenian STEM department the procedure for recruiting and selecting assistant professors is slightly different. After candidates have submitted their applications, the secretary of the human resources office and the secretary of the department review the candidates' CVs. The candidates who do not meet the official criteria are rejected, while others are invited to an interview with the committee members. The selection committee should consist of three members, one of which from an institution outside the university. Usually the members from the faculty are the associate dean or/and the head of the departmental chair and a retired professor.

In Switzerland, it is obligatory to publish assistant professor jobs on the university website. University policy insists on formal recruitment procedures. Selection criteria are explicitly left up to the employing faculty/department to determine, according to their teaching and/or research needs. For the assistant professor position the committee is composed of up to six persons (with one or two external members). During the procedure, an 'equality delegate' is present to observe the selection process, with the aim of sustaining equality. The committee members interview the shortlisted candidates and make a ranking of candidates. The Faculty Councils are free to follow the recommendations of the selection committee or to propose a new ranking of the short-listed candidates. In turn, the Rectors' Office is entitled to follow the vote of the Faculty Council, or not.

We recognise the differences in career systems and recruitment and selection practices in the countries we study. Yet, when it comes to the gender practices, we found remarkable similarities across the various institutions and contexts that will be discussed in the next section.

\section{Findings}

In this section, we present the gender practices in the evaluation of men and women candidates that we identified throughout the STEM and SSH departments in six European higher education institutions on the basis of the interviews and focus groups conducted with committee members. Two general gender practices 
stand out in our data: welcoming women and assessing potential for excellence. We will show how these two gender practices are conflated with multiple specific gender practices.

\section{Welcoming women}

The first general gender practice we derived from the data is discursively welcoming women in assistant professor positions. Most research participants throughout the various countries and disciplines expressed that they are in favour of a more equal representation of men and women in the department, which in most departments entails advocating an increase in women researchers. We identified two specific gender practices pertaining to the discourse of welcoming women that all relate to the aim for a gender balance among academic staff.

One key argument for welcoming women given by committee members is numerical: the number of women staff members lags behind the number of men and this breaches the ideal of gender balance. In all countries, except for Slovenia and Italy, recruitment and selection policies prescribe that in case of equal qualification of two candidates, women are preferred over men candidates for positions in which women are underrepresented. Research participants gave two reasons for why they would like to have a gender balance in their department, which both contain specific gender practices. The first reason is because an increase in women staff is expected to positively influence the working environment.

If there are two candidates that are pretty similar, and it is not clear from the selection committee point of view who is better, then we have to take [gender] into account. If there are more men in the faculty, it strengthens it if there are more women [hired].

(IS, SSH, M)

This interviewee refers to the recruitment and selection policy in Iceland. However, he states that the assessment of quality comes first and only then "we have to take gender into account". This practice is known in the literature as the "tie-break" selection (Noon 2012) where the "under-representation of people with certain demographic characteristics" (such as gender) is taken into account "in order to make the final choice between equally qualified candidates when appointing or promoting" (pp. 77-78, emphasis added). However, Swiss, Dutch, and Icelandic research participants argue that they have never seen this measure put in practice because they never consider two candidates equally qualified. We also learn from the quote that "it strengthens it if there are more women" in a faculty where men are in the majority. By saying this, he makes a very general statement about the added value of women, without explaining why more women will strengthen the department and what will be strengthened. However, it implicates that women have a special contribution to make. 
A Slovenian interviewee illustrates his preference for a mix of men and women researchers in his group: "I have a very balanced working group. [...] The best solution is - and that can be seen from the communication itself - that in a big group both genders are represented" (SO, STEM, M). This committee member argues that in a "balanced working group" the "communication" is better than in a non-balanced working group. Therefore, balance is "the best solution" to him. Multiple committee members see a benefit in having more women in a group because they think this facilitates the communication and collaboration in a group. A Swiss interviewee stated: "It's very important that there should be more women, a lot more, and that they should be completely at ease there in the way that I am at ease in science" (CH, STEM, M). The explanation he gave for his position in favour of "more women" is that women are more collaborative, something he values highly.

Welcoming women based on a generic ideal of women is what Glick and Fiske (1996) call 'benevolent sexism'. They define this as "a set of interrelated attitudes toward women that are sexist in terms of viewing women stereotypically and in restricted roles but that are subjectively positive in feeling tone (for the perceiver)" (p. 491). Thus, the rhetoric of the committee members in our study, promoting higher numbers of women in academia, can be interpreted as well-intentioned, yet it is conflated with stereotypical perceptions of women (and men) researchers. Such stereotyping can be damaging to the receiver of benevolent sexist remarks because it can threaten the feelings of being taken seriously (Glick and Fiske 1996). It could also be damaging to women who do not fit the stereotype that is projected on them.

The second reason for wanting a more gender-balanced group is the role model argument (cf. Van den Brink and Stobbe 2014). A Dutch STEM committee member explains his positive stance towards increasing the number of women in his department:

INTERVIEWEE: And of course I have a plan. But well, if that will succeed, I don't know! Time will tell. But one of the arguments in that plan is that I think we should hire another two women here in the department. To get a bit more of a balance. A bit! [...] I would also like fifty-fifty, yes, great! Why not?

INTERVIEWER: Why would you like that?

INTERVIEWEE: Well, because I think that is a good reflection of the balance overall in the world. It is [at this moment] a very bad reflection of the number of students that enter here.

(NL, STEM, M)

This committee member explains that he made a plan for hiring more women because he wants to get the numbers more in "balance". So, besides discursively welcoming women, this interviewee also says that he acts upon the wish for more women in the department. Even though he explained later that reaching "fifty-fifty" in the short term will be impossible, he argues that an equal number of men and women in the department would be a better "reflection" of the world 
population. He then touches upon an issue that we found more often in the STEM interviews. The interviewee argues for a gender balance among staff members because that will also better reflect the gender balance among the students in the department. Many Dutch STEM committee members make the plea for more women colleagues with the argument that women function as role models for both students and aspiring academics. They perceive role models necessary for increasing the number of women students and staff members but also for signalling to younger women that having a career in science is "a very normal career choice, also for women" (NL, STEM, M).

In summary, committee members practice gender by discursively welcoming women in their department, arguing that the number of men and women employees should be (more) balanced. They give two reasons for this welcoming stance towards women researchers, which represent two specific gender practices. The first reason is that women contribute to the department by their communication skills and collaborative behaviour. The second reason concerns the perceived need for women role models. Overall, the responses suggest that committee members are not at ease with an imbalance in men and women staff, implying that (a greater) balance is the norm. It should be noted that the interviewers and the research topic could have influenced these results, as research participants were aware that they were interviewed about gender in academia and possibly felt the need to position themselves positively towards the topic. In this section we found that research participants actively reflect on their point of view with regard to unequal numbers of men and women researchers. In the next sections we will present gender practices in the recruitment and selection of assistant professors that happen less reflexively.

\section{Assessing potential for excellence}

The second general gender practice we identified is assessing candidates for assistant professorships based on their potential for excellence. This practice is constructed around a complex interplay of four specific gender practices. We distinguish between two sets of criteria: formal criteria and tacit criteria. We start by showing the formal selection criteria used in the selection of assistant professors, followed by the tacit criteria. It is the latter category that we found most conflated with specific gender practices.

\section{Formal selection criteria}

Most research participants across countries and disciplines argue that during recruitment and selection procedures for assistant professorships they should take the junior level of candidates into account. We find that candidates for assistant professor positions are primarily assessed on three formal criteria: research, teaching and administration. Of these criteria, committee members across countries and disciplines equally argue that research is the most important selection criterion. 
When it comes to the criteria for selection, the most primary and indispensable criterion is scientific excellence, which normally is reflected in the research conducted, the number of publications, type of publications, peer reviewed, what the person has actually done in previous research.

(BE, SSH, M)

For this committee member "scientific excellence" is the most important selection criterion, which to him means research and publications. However, not just any publication counts. According to this interviewee, as most interviewees in our study, publications should be in (international) "peer reviewed" journals.

Our analysis shows that committee members try to make an assessment based on formal selection criteria, however, due to the early career stage of applicants they only have a limited track record to rely on.

Publication is an indication of what the researchers are capable of doing, but evidently a young researcher is not able to publish as much as experienced ones can do. So we have to project the profile of a person and see what the person is capable of in the future.

(BE, STEM, M)

Very often they are at the end of their $\mathrm{PhD}$, and I mean, sometimes they have already a publication, maybe two, depends also on the discipline. [...] Um, but very often they only have a pipeline, right? So, they have a couple of [pipeline] papers. [...] So, it's - it's on the committee to decide what they think, what this is actually worth, so to have a good understanding of the publication market, and the chances of publication - publishing something, and whether they think this pipeline - that the quality of the $\mathrm{PhD}$, so to speak, of the chapters are publishable, and where, how good, how well.

$(\mathrm{NL}, \mathrm{SSH}, \mathrm{M})$

These committee members illustrate that, generally, candidates for assistant professor positions do not have many publications compared to more senior academics. According to the first interviewee a publication can indicate what a candidate is "capable of in the future". The second interviewee argues that candidates for assistant professorships usually have none or just a limited number of published papers at the time of application. Therefore, he explains, the committee will look at papers in the "pipeline" and "the quality of the $\mathrm{PhD}$ " in order to assess the "worth" of the research in terms of the potential to get the work published in academic journals. The quote reveals that it is at the discretion of the selection committee to decide "whether they think this pipeline" is "publishable, and where, how good". So committee members make a prediction about chances of getting the work published in the future. Most committee members confirm that a candidate's research potential can be predicted by the track record of publications, even though this track record tends to be fairly limited. 
Selection committees are thus charged with the task of evaluating the potential of applicants for assistant professorships. From the data we learn that this is not a straightforward endeavour. Some committee members reflected on the difficulty of assessing potential:

Anyone can say this is a young person with good hopes. But how can I make hopes accountable and codify them?

(IT, SSH, F)

But the aim is clearly just the best scientist of that generation with, of which ... the selection committee thinks, the best potential to grow into a really good scientist. But that is really difficult to judge. So that is a very subjective process. That is absolutely clear. That is really absolutely very much constituted with all kinds of judgements, prejudices.

(NL, STEM, M)

The first interviewee acknowledges that she does not know how to measure "hopes" and implies that she struggles with applying this as a selection criterion for a "young person". The second interviewee first argues that the aim of a selection procedure is to "just" select the "best scientist of that generation" who has "the best potential to grow into a really good scientist". He then realises that this is not as easy as it seems and acknowledges that assessing potential is a "subjective process" inherent with various "prejudices". Nevertheless, committee members suggest that they do not have other ways of assessing early career researchers than making predictions about their potential. Such "subjective" assessment influences if a candidate will be selected or not and can therefore have major implications for candidates.

Teaching qualities are also among the formal selection criteria for assistant professorships and thus assessed during the selection process. Again, research participants across all countries argue that candidates generally do not have much teaching experience. Therefore, committee members often evaluate the teaching qualities or potential of external candidates during a lecture or presentation that candidates have to provide during the selection process. Our data show that the criterion 'administration' is not assessed during selection procedures, because committee members argue that early career researchers usually do not have previous experience concerning administration.

All in all, the formal selection criteria for assistant professorships seem hard to work with because of the short track record of early career researchers. Therefore, the decision-making on whom to hire for an assistant professorship that might give a way out of precariousness in the long run, is based on a limited assessment of formal criteria, and an assessment of potential instead. Due to the short track records, committee members rely on other factors to evaluate a candidate's suitability for the position. Our analysis reveals that multiple tacit criteria come into play when committee members discuss their preferred candidates, which give room for assumptions and subjectivities. Next, we will describe the complex interplay of gender practices found in the application of tacit criteria. 


\section{Tacit selection criteria - survival in the competitive academic world}

In this section we elaborate on the four specific gender practices found in the tacit criteria committee members use to assess the potential and suitability of candidates for assistant professorships as well as academic work more generally. These practices are geared towards the assessment of candidates' potential for surviving in what research participants call 'the competitive academic world'.

Confidence. The first specific gender practice related to the general gender practice of assessing potential for excellence we found in the data is the perceived lack of confidence of women candidates. For example, interviewees in Switzerland argued that modesty and a lack of competitive behaviour of women researchers is a reason for their limited survival in what research participants argue to be 'the competitive academic world'. Modesty is often put forward as an argument for why women are expected to be unable to deal with the competitive culture in academia.

Especially in Switzerland, I find that Swiss women have a humility that ill serves them at work. This humility frankly does them no good, when they have all the potential to assert themselves. They have a very, very strong super-ego; putting oneself forward is seen as something negative.

(CH, STEM, F)

The interviewee perceives Swiss women as modest and argues that this "humility" negatively affects their work, implying that humility reduces the possibility to excel. The quote illustrates that the committee member attributes women's perceived modesty to the internalisation of gender roles ("super-ego" behaviour) and that "putting oneself forward" is considered negative, as it implies nonfeminine behaviour.

We find that also during the selection procedure confidence, or the lack thereof, is something that plays a role. This reveals that tacit criteria come into play in the evaluation of candidates.

For example, it has to do with: you have to take into account, but that obviously is less and less the case, that women applicants could make a less how do you say - assertive impression, will be less assertive. So that has to do with socialisation and the way you are.

(NL, SSH, F)

This focus group participant reproduces the common held belief that women candidates are less assertive, which she gives as an example of the way gender can play a role in recruitment and selection procedures for early career researchers. She argues that selection committees should "take into account" that women do not often make an "assertive impression" but she does not explain how to do so. It does imply that assertive behaviour is the norm and thus the preferred style. She argues that "socialisation" is to blame for women's lack of assertiveness. 
Many interviewees blame women for not being confident, but they do not acknowledge that men can also lack confidence.

Research participants in the Slovenian STEM department perceive women as more obedient, patient and hardworking than men but less noticeable, ambitious and confident. According to them, it is the traditional masculine dominant, ambitious and confident attributes that facilitate climbing the academic career ladder. Van den Brink and Stobbe (2014) showed that, especially in STEM disciplines like physics, "confidence and directness are needed to demonstrate high motivation and true skills" (p. 171).

The quotes in this section show that committee members argue that gender roles and socialisation cause women to behave non-confident or non-assertive. They do not reflect on the role they themselves play in the construction of women candidates as modest or non-assertive. Particularly in STEM department, research participants explicitly put the responsibility on women. We learn that in the Slovenian STEM department almost all research participants stressed that it is the women who bear responsibility if they are not sufficiently self-confident to progress in academia. In the STEM department in Iceland an interviewee similarly puts the responsibility for gender equality on women researchers and stressed that they have to be more like men.

Across the six higher education institutions, committee members construct competition as an inherent aspect of contemporary academic work and expect excellent early career researchers to be able to deal with this competition. Because of the precarious, competitive academic environment, committee members require early career researchers to be confident, and show that confidence in the job interview. The perceptions and expectations about modest women researchers most likely negatively influence committee members' assessment of women candidates as researchers who have the potential to make a career in academia. Moreover, committee members generally attributed nonconfident behaviour to all women researchers and made women responsible for not 'surviving' in academia.

For some research participants the lack of confidence of women candidates is also connected with women's communication style. We found that they expect of researchers a certain style of articulating ideas, which reflects a masculine, bold way of communicating.

Yes, when they come for an interview they have to just show it. Yes, then I want to just know: what drives someone? What I realise now is that there might be a gender bias there. [...] At least what I have learned is that women say what they really think to a lesser extent and less often go on thin ice. Because they are a bit more worried that they will fall through. While I can appreciate that; if someone does that in a conversation. [...] I think that men feel less embarrassed to just yell and shout it out occasionally. And by doing so they are more open to criticism, because they can have their heads chopped off. But on the other side, that gives me a better idea of what is on their mind. And I have noticed that during conversations with female stu- 
dents, $\mathrm{PhD}$ students, and postdocs. In a longer conversation I suddenly found out. Why didn't you say that an hour ago? Yes, and if you are in a job interview that lasts one hour, yes, then it is possible that you miss the opportunity.

(NL, STEM, M)

The interviewee argues that he experienced women having another style of communicating than men during selection interviews and in regular conversations. During the interview, he realises that there can be a "gender bias" in his own evaluation of women, however, in the remaining part of the quote he continues reproducing this gender bias. So, he refers to the term 'gender bias' but he does not succeed in unpacking this bias in practice. He argues that women do not express what is on their mind whereas men are not bound by feelings of embarrassment and be explicit about their ambitions. He explains that he appreciates the communication style of men better, which shows a 'cloning' effect (Essed 2004 ) - the preference for candidates who behave in a similar way as committee members themselves. The interviewee perceives the way ideas are being communicated as an indicator of the quality of those ideas. Because women express their ideas more hesitantly, according to the interviewee, they could "miss the opportunity" in a selection interview that only lasts for one hour. Thus, the interviewee holds women accountable and does not think about possibly changing his own interview style during selection procedures. The non-sensitivity towards communication styles other than the ones the interviewee attributes to men can have serious consequences for women candidates during selection interviews.

Commitment. A second specific gender practice we identified is the construction of women as lacking commitment to the profession. The responses of committee members imply they perceive women as deficient for an academic career (or non-excellent) because of their supposed lack of commitment. A Swiss interviewee argues:

Generally speaking, the guys, they're ready for [pauses] I mean, you sense immediately that they're ready to work 20 hours a day [laughs], to scrub the floor, if you ask them to. [...] Usually, the women, they're more [sighs] careful, reserved.

$(\mathrm{CH}, \mathrm{SSH}, \mathrm{M})$

The quote shows that the committee member perceives the self-presentation of men in selection interviews as committed to do whatever it takes whereas women candidate's demeanour as "careful, reserved". He suggests that women do not display commitment to go the extra mile ("scrub the floor"). Moreover, the interviewee reproduces the long-hour rhetoric in academia by stating that men are "ready to work 20 hours a day", something that clearly appeals to the interviewee.

An interviewee in the Netherlands reported a situation in which aspiring women researchers are made insecure about the possibilities to pursue an 
academic career due to the traditional masculine notion of commitment that is constantly reproduced. The following quote illustrates this:

And I think that quite more often in this kind of procedures, where women who are made insecure appear as candidates in front of a committee that consists of just or mainly men, it can go wrong. [...] One of those full professors in that committee, $[\ldots]$ he really lives in the fifties constructions. He comes home and the dinner is served and he does not do anything, so he can totally focus on his career. So he thinks that if you for example work part time in the end you cannot meet the written and unwritten criteria to make a career, so become an associate or full professor. And if you are confronted with such a statement, on request or not, during a job interview or a performance appraisal - what happened to me once during a conversation with him - then you think: should I just quit now, so to speak, because I do not have such a situation at home. At home we divide things or try to do that as fair as possible, so I won't be [working] 70, 80 hours, that is just not possible. So at the moment that, yes, that kind of professors with fossil ideas still take part in committees, that kind of messages are still being conveyed.

(NL, SSH, F)

This committee member illustrates how selection procedures with all men committees "can go wrong". She argues that senior men (committee members) can make women insecure about a future career in academia because of their opinions on the impossibility of combining a career in academia with "other aspirations". The interviewee explains how her boss expressed his opinion that a career in academia infers (more than) full time commitment to the career. Through the interviewee, the boss reinforces the prevailing notion of an excellent academic career as a profession that entails working 70 to 80 hours per week. The interviewee explains that women who cannot fulfil these "unwritten criteria" because of other obligations outside work can become insecure because of these expectations and discouraged to pursue an academic career. She argues that having men on selection committees who hold these "fossil ideas" (i.e. old fashioned ideas) can be problematic for women candidates.

A related reason given by research participants for women's perceived lack of commitment has to do with motherhood and care responsibilities. Many committee members expect an excellent researcher to be available full-time, devoted to the job and to put in long hours of work. When research participants throughout all countries talk about recruitment and selection of assistant professors, they ascribe difficulties to women early career researchers to meet these expectations, as they equal women with mothers. Most committee members seem to be convinced first of the given that all women are (future) mothers, and second of the incompatibility of motherhood and a successful academic career. An Italian interviewee explains: 
A woman has an objective disadvantage, but not because we men are sexist ... in our department there's no-one like that ... but because in any case, if you have a child, you can put it how you like, but you have to do it, and this is intrinsic. So there's this disadvantage ... that if there are no proactive policies, which in Italy are not made ... in the end, simply because someone has a child and wants to be with that child ... it is clear that in the end she publishes less, travels less, because she has a two- or three-year old child ... so the only real disadvantage is structural.

(IT, STEM, M)

The interviewee points towards an "intrinsic" issue - motherhood - that he calls an "objective disadvantage". By doing so, he constructs a disadvantage for women. First he says "because someone has a child" and then continues by using the pronoun "she". He takes for granted that women will take care of the child and expects them to renounce part of their academic activities, such as publishing and travelling, when they are mothers. This way, he constructs women as less suitable to deal with the competition in academia and as candidates for an assistant professor position. Furthermore, he emphasises that men in his department are not "sexist", and presents the "disadvantage" as an objective fact. Thus, the interviewee puts the responsibility on the individual woman researcher to deal with this perceived "disadvantage". Also, he blames the lack of proactive policies for this "disadvantage". In contrast to Italian men research participants who perceived motherhood as a hindrance to women researchers' careers, none of the Italian women research participants made reference to it, referring instead to the gendered professional culture that characterises Italian academia as the main barrier to their advancement.

Committee members reproduced the stereotype of women as mothers who cannot dedicate sufficient time to their academic career regardless of whether or not the women in question actually had children. Since more than full time availability is expressed very often during interviews and focus groups across countries and disciplines, as something needed to build an academic career, women candidates suffer from the perceptions held by committee members about their dedication to the profession. They discursively construct women as researchers who do not have what it takes to make a career in academia. This might be even more pronounced for women at the early career stage as committee members might expect women are at a point in life where they possibly become mothers or have young children.

A committee member in Iceland argues that there is unequal distribution of unpaid work within the homes of his men and women colleagues which complicates women researchers' entry into an academic position:

I see that family conditions are enormously important when it comes to how [academics] perform [the first years in academia]. I see it is really tough for women with children to enter a competitive academic position. I see that they are under a lot more pressure than the men [...] overall I see that [the 
women] have to leave at four to pick up the kids, I see the difference how [women] have more responsibilities than the guys and this can be very difficult.

(IS, STEM, M)

This interviewee argues that women researchers who are mothers "have more responsibilities" than men researchers who are fathers. Like many other committee members, he also argues that academic work is "competitive" and states that "it is really tough for women with children" to perform the job. The committee member thus argues that mothers have difficulties dealing with competition. The expected difficulties for mothers but not for fathers are pervasive, despite the Icelandic legislation that each parent gets three months of maternity/ paternity leave and three months to share among the two parents. Parenthood is only problematised for women and not for men, contributing to the precariousness of women early career researchers and not men. Committee members expect mothers to not be "100 per cent active in writing up research" (IS, SSH, F) and imply that therefore women do less well in the competition. Overall, committee members assume that motherhood will create difficulties for women assistant professors and by doing so construct women as less excellent candidates.

Furthermore, motherhood assumptions not only influence perceptions of committee members of women's devotion to the job but also of women's contract hours. For example, Swiss committee members in both departments expect most women to work part time. Some interviewees problematised part time work, which the following excerpt illustrates:

I know well that her [a young mother who requested to work a four-day week] productivity rate will be reduced by at least $50 \%$. In a competitive international research context, that's not a very good thing. I don't really like this idea of a percentage reduction, because it just doesn't fit in with the way work is organised. [...] I mean, people are here, they organise their experiments, and the kind of experiments we do here, they last three days, three or four days. Something like that. Once you've started, you just have to see it through. So that means that if we have someone who stops work on a Thursday, with an experiment that lasts three days; she's going to start work normally on the Monday, and then after Wednesday, she's not going to be able to do anything else, even if she's paid until Thursday evening!

(CH, STEM, M)

This interviewee also refers to the "competitive" context in which (early career) researchers operate. Furthermore, he argues that part time work "just doesn't fit in with the way work is organised" and thus connects full time availability with the nature of academic work. He also states that a four-day workweek, an 80 per cent appointment, will in practice lead to "at least 50\%" productivity reduction and then further elaborates on his conviction that experiments cannot be done 
when working part time. We learn from this that excellence and part time work are decoupled, as full time availability is the norm.

Our results corroborate earlier studies on the evaluation of academics who are also parents (Cech and Blair-Loy 2014; Herschberg et al. 2014). Our study shows that most committee members across the countries problematise parenthood for mothers but not for fathers. They reproduce the cultural expectation of women as main caregivers. Even though "the lived experiences of both men and women in academia may no longer match the ideal academic norm of having no care obligations" (Herschberg et al. 2014, p. 205) our findings show that still women researchers are predominantly expected to have care responsibilities. Research participants do not take into account that young men may face the same obstacles whilst being fathers, or that not every woman is or will be a mother. Two decades ago Bagilhole (1993) already stated that "the academic profession as it stands does not appear to accept married women with children" (p. 272). This study shows that bias against women with children still holds, but that women without children suffer from this bias too. The image of women as mothers who are involved in caring for their children is problematic as committee members imply that this creates a lack of commitment to the profession (cf. Grummell et al. 2009). This adds to the precariousness of women early career researchers as it evokes expectations that women are less suitable for assistant professor positions.

International mobility. A third specific gender practice we identified in the data is the gendered construction of the criterion of international mobility. Before explaining the gender practice inherent in the criterion of international mobility we will first briefly illustrate how the criterion is defined and how it is applied in selection procedures.

Our data show that committee members throughout the various countries require that young researchers go abroad for a period of time early in their careers. Even though internationalisation has become increasingly important in all countries under study, in more than half of the departments we studied, this has not led to formalised criteria with regard to international mobility. In Belgium, Slovenia, Iceland and the Dutch SSH department, international work experience is not a formal selection criterion, but committee members do consider it an important criterion in the selection of early career researchers. In most institutions committee members connect international mobility to candidates' perceived excellence. So next to precarious working conditions and limited prospects of a stable academic career, early career researchers are expected to spend part of their employment across country borders. This might further their precariousness even more as moving abroad comes with (additional) instability as well as personal risks (Richardson and Zikic 2007).

A committee member in the STEM department in Iceland argues that going abroad is "sort of an unwritten rule". When this requirement remains tacit, as is the case in most departments, applicants can suffer from this lack of transparency by being rejected for not fulfilling the criterion. Icelandic SSH research participants confirm that international mobility of staff trained at their university 
is considered important and perceived as a qualifier, however it is not a decisive criterion.

Overall, we find that the criterion of international mobility is more pronounced and more decisive in the STEM departments. In the Dutch STEM department, international postdoc experience is a formal selection criterion for assistant professor positions. The recruitment protocol articulates this criterion as: "Some years of postdoc experience, also abroad". In Switzerland it is an institutional obligation for candidates who received their PhDs from that same university to have spent at least one year abroad during their postdoc. In Italy, a formal criterion for assistant professorships is to have spent at least one year of doctoral or post-doctoral research abroad, yet, candidates who lack this experience are also considered for assistant professorships.

Because in most countries the criterion of international mobility is not formalised or specified, uncertainties and ambiguities emerge in the criterion's application. This leaves room for committee members to select candidates based on their interpretations of the concept.

Because they're clear but not detailed criteria, it's obvious that there are interpretative sensitivities of various types. I'll give you a banal example. We all agree that international activity is important, but what is meant by international activity? Does it mean having been frequently abroad? Having taught abroad? Having published in foreign journals? Or does it mean staying at home but being part of international networks, and so on and so forth?

(IT, STEM, M)

The quote reveals that "international activity" can encompass many endeavours and that the committee member does not know what can be interpreted as international activity and what does not count as such. Because various committee members have multiple interpretations of the criterion due to a lack of definition, they can apply it at their discretion.

Even though some committee members argued that the mobility criterion is difficult to meet for all early career researchers, most research participants throughout the countries and disciplines in our study expect that women researchers have a harder time fulfilling the international mobility criterion because of family or motherhood responsibilities. Committee members' assumptions about women's decreased mobility can influence their evaluations of women candidates because they anticipate that women cannot fulfil the requirement. Therefore, they practice gender when applying the criterion of international mobility.

For example, Italian committee members argued that women researchers will have to renounce part of their mobility in order to care for their child(ren). Men, on the contrary, are never mentioned in relation to family and children, so research participants assume that they will continue with their work and career plans regardless of their family status. This is similar in the Slovenian SSH 


\section{4}

Channah Herschberg et al.

department where two women research participants noted that living abroad should not be required from young female researchers at the beginning of their career, when they may have small children. An interviewee explains:

A woman has difficulty to go abroad with her family. Her husband is not ready enough to go with her; he will be ridiculed by the social environment. In Slovenia that is less acceptable, if we want to confess it or not.

$(\mathrm{SO}, \mathrm{SSH}, \mathrm{F})$

The committee member argues that women with families experience difficulties going abroad, which she relates to the Slovenian "social environment". She states that the environment will most likely not accept and even "ridicule" men going abroad with their partners. In the interview she continues speaking about the criterion of international work experience and wonders: "why don't we think of some alternative?". This implies that the criterion is fixed and that alternative ways of meeting the criterion are not used in the interviewees' work environment.

A STEM committee member in the Netherlands also considers the required mobility of early career researchers a reason for the small number of women in his field and links this to family circumstances:

INTERVIEWEE: But I think that is the big problem. Yes, the whole system how you get such a job, right? You cannot plan it and say: Now you do a postdoc there. And then I will become full professor there. It is more of a random walk. You get a postdoc position there, then you get your second position in another country. And then finally you get a [permanent] job, but this is maybe in a third country, right? Or at least not in the same city. And if then both, men, women have a job, it is going to be very, very difficult of course. And if you go in such a random walk through the entire world, or at least Europe. And I think that is one of the reasons why we do not have so many women.

INTERVIEWER: And how do you mean that? Because they can allow that randomness less?

INTERVIEWEE: Yes. But I think there is no solution. We want candidates who have that international experience. It is expected that they do a postdoc here and there and then this random component is inherent. And yes, that is of course very hard to combine with a family.

(NL, STEM, M)

The interviewee calls the career system in academia "a random walk" that demands multiple moves across positions and countries. He thinks women are less able to deal with this "random" component because for women (and not men) mobility is "of course very hard to combine with a family". This interviewee puts the responsibility of meeting the international experience criterion on the (women) candidates, as he argues "there is no solution" for the (women) 
candidates who do not meet that criterion, as the requirement prescribes to do "a postdoc here and there". He treats the criterion as a strict demand and does not acknowledge alternative ways of obtaining international experience, such as short research stays abroad or international collaborations. The interviewee considers the system as the problem without being reflexive about his own position within this system as someone involved in the construction of selection criteria and thus as someone who can apply criteria less rigidly and strict.

Academic citizenship. A fourth and final specific gender practice connected to the general gender practice of assessing potential for excellence is the request for academic citizens. In the previous sections, we showed that an ideal candidate for assistant professor positions is constructed primarily as an excellent researcher who is competitive, productive, and confident. However, our data reveal that most committee members do not want these characteristics to carry too far because they want to hire a candidate who is a collaborative team player, an academic citizen, too. We find implicit gender connotations in the tacit criterion of academic citizenship.

We build on teamwork. Of course, individual scientific excellence is important for us, but as our ambition is to build a strong and prosperous research group, we consider the social dimension - sociability of the researcher - an important dimension as well. Someone who has problems working in a group despite being scientifically excellent can break the team. Therefore, sometimes we accept a person, that is not so scientifically excellent, but a socially intelligent individual, since our ambition is to build a strong team.

$(\mathrm{SO}, \mathrm{SSH}, \mathrm{F})$

According to this committee member "individual scientific excellence" is important in her group but the "social dimension" seems even more important. She argues that a candidate who is scientifically excellent however not able to work in the team will not be hired. On the contrary, someone who is not scientifically excellent but "a socially intelligent individual" can be hired. She emphasises the team component that seems decisive in hiring decisions.

Interestingly, many committee members throughout the various countries and disciplines consider scientific excellence and teamwork as two opposite characteristics that cannot be held by one and the same person. We find that committee members consider "a whiz kid with a super impact factor" $(\mathrm{CH}, \mathrm{SSH}, \mathrm{F})$ incompatible with being "a good colleague" because they argue that whiz kids are "wrapped up in [their] own thing" (CH, SSH, M). A Swiss research participant refers to this as a "paradox" which reflects an opposition between the requirement of individual development in the area of research and the desire of a team for collaboration. Or as a Belgian interviewee argued: "there are two types of researchers/academics: there is the collaborator and the individualist" (BE, SSH, M).

Moreover, research participants suggest that being excellent in research not only restricts collaboration but also resembles having a problematic character. 
They argue that "brilliant researchers" are "very difficult to work" with (BE, $\mathrm{SSH}, \mathrm{M})$ as they cannot "work with others" and have "a difficult character" $(\mathrm{CH}$, $\mathrm{SSH}, \mathrm{F}$ ). We notice that this stereotypical image is connected to researchers who are extremely productive. Moreover, this stereotypical belief causes committee members to look at "brilliant researchers" with suspicion.

We find that committee members construct the criterion 'collaboration' as important in selection decisions, even though this criterion often remains tacit and non-formalised. When committee members speak about situations where they will actually hire someone, they prefer a candidate who is a so-called 'academic citizen', someone who contributes to the 'housework' of the department (Heijstra et al. 2016). Thus, early career researchers are expected to demonstrate loyalty to the department, but they seem to receive little guarantee for permanence in return. In our data we found that the value of collaboration is often ascribed to women candidates but not to men.

Outside of here I know a lot of people, men, who, when you ask them to collaborate, reply: "No, I don't collaborate, I compete". I've never heard a woman say that. [...] You could imagine science becoming more collaborative [when an interactive web tool is implemented in science] and women getting on much better in that, and men being pissed off because they find it hard to show off their egos.

(CH, STEM, M)

According to this committee member, men want to compete rather than collaborate. On the contrary, he portrays women as collaborative. He predicts that when science becomes "more collaborative" in the future, women will succeed "much better" than men. Yet, this also implies that science is not there yet, and that it is still is more competitive based. Most committee members throughout the countries and disciplines argue that women have better relational skills and are more prone towards collaboration. This suggests that women candidates may score higher on the criterion of academic citizenship than men candidates.

Overall, the concern of hiring a colleague with whom it will be possible or even pleasant to cooperate, rather than the scientific best candidate, was found throughout the countries. Because committee members perceive women candidates as more collaborative and relational, the academic citizenship criterion could benefit women during selection procedures. However, such stereotypical expectations can also work against women when they do not display the prescribed feminine behaviour (Rudman and Phelan 2008), possibly invoking bias in the evaluation of women candidates.

In summary, in the assessment of potential for excellence, committee members base their judgements on limited track records of candidates for assistant professor positions and therefore they rely heavily on tacit criteria. They predict the future potential of candidates for surviving in the academic world, a gender practice that is conflated with multiple specific gender practices. Committee members perceive a lack of confidence and commitment as well as 
limited international mobility opportunities for women early career researchers and by doing so render women less suitable for assistant professor positions. This makes the position of women early career researchers more precarious than that of their male counterparts. We found that only the criterion of academic citizenship could work to the advantage of women candidates. But, being evaluated as an academic citizen depends on the department at hand and thus might not help in securing a permanent position on the long run.

\section{Discussion and conclusion}

Despite a "veneer of equality" (Teelken and Deem 2013, p. 520) our critical comparative analysis revealed two general and six specific gender practices in the recruitment and selection of temporary assistant professors throughout six European countries and both STEM and SSH disciplines. The gender practices are subtle yet omnipresent in the constructions of recruitment and selection practices of men and women committee members. We found that gender practices are rather similarly over the various countries and disciplines. Our study sheds light on the gender practices present in selection criteria that affect aspiring young researchers' entrance to precarious assistant professor positions. Even though non-tenured assistant professorships are precarious in nature because of its temporality and insecurity, we found that committee members assess candidates' potential to succeed in academia in the long run. Therefore, temporary assistant professorships, which could possibly lead to a more permanent position, are distinct from casual or hourly paid academic positions that often do not create chances for leaving precarious employment. We contribute to theories of gender in academic organisations by uncovering the complex interconnections of gender practices and recruitment and selection practices for early career researchers where judgements are based on potential. We have illustrated multiple gender practices, some beneficial and others detrimental for women academics. Furthermore, we identified three discrepancies in the various criteria and their application that we will elaborate on in this section.

We showed how gender practices relating to welcoming women might work to the benefit of women candidates for assistant professor positions. Yet, we found a first discrepancy when analysing the tacit selection criteria used in the assessment of early career researchers. In their discourses and reflections on women in academia, committee members argue that they want to have more women in their department in order to get a more balanced staff composition. Even though most of them do not seem to take up an active role in increasing the number of women researchers, they do give arguments for why they think science or their departments would benefit from more women colleagues. Reflexively most committee members express this wish for hiring more women. However, welcoming women seems more a general principle than an actual practice because in committee members' construction of tacit criteria they unreflexively portray women as less competent for what they call the competitive academic world. Committee members discursively construct women academics 
as lacking necessary survival skills such as confidence, commitment and international mobility, which can render women candidates as unsuitable for academia. Committee members reproduce the image of an ideal candidate that resembles a traditional masculine profile. In line with Van den Brink and Stobbe (2014) and Bleijenbergh and colleagues (2013) we found that although our research participants say they value (some) feminine qualities, the image of the ideal early career researcher fits men and masculinity more.

In their accounts, committee members predominantly depict their ideal candidate for assistant professorships as an excellent researcher who has the potential to survive in the competitive academic world by being productive, confident, committed to the profession, and internationally mobile. This profile resembles the Olympus model that "situates the scientists [...] at the top of the pyramid, far removed from the concerns of everyday life" (Brouns 2004, p. 151). However, we also found that when committee members talk about their recruitment and selection practices, they state that hiring excellent academics can disadvantage team dynamics, as they tend to construct excellence as incompatible with and the opposite of collaborative. A second discrepancy is thus constructed between the criteria of excellence and academic citizenship. Several research participants argue that they consider teamwork of such importance that they would rather hire an early career researcher who is somewhat less excellent but a good, collaborative colleague. This implies that there are committee members who prefer the Agora model of science, which is not focused exclusively on the production of knowledge for the scientific community but also aims at creating an inspiring intellectual work climate based on other principles such as exchange (Brouns 2001; Benschop and Brouns 2003). The Agora model is supposed to fit a traditional feminine behavioural repertoire more (Benschop and Brouns 2003). We showed how being a collaborator and a good colleague seems to indeed fit the (stereotypical) image of women researchers better, according to our research participants. Yet, our findings imply that overall the individual competition criteria that fit the neoliberal Olympus model seem to prevail over the exchange criteria of the Agora model.

A third discrepancy we found is between the welcoming stances towards hiring more women academics and committee members' ostensible unwillingness to change or look for alternative ways of defining selection criteria. Committee members generally construct selection criteria as if they are etched in stone. Such practices safeguard committee members from any responsibility. Even research participants in power positions argue that they could not change criteria, as they have to abide by the rules and regulations defined by either the faculty board or the university board. None of the research participants seem to want or to perceive themselves able to change the recruitment and selection criteria for assistant professor positions. Therefore, our study shows that selection criteria are socially constructed, subjective, and fluid, yet, committee members present the criteria as 'common-sense', taken for granted criteria in selection decisions (Van den Brink and Benschop 2012a) without reflecting on their own role in the construction of these criteria. Furthermore, our findings reveal that 
committee members have no or limited awareness of the gendered construction of selection criteria and the consequences nor do they reflect on their gendered assumptions about the qualities of women candidates. Hardly anyone questioned or challenged the current academic system or the beliefs that an academic career requires long hours, devotion, confidence, and competition. Neither did committee members contemplate the responsibility of others beside women to deal with possible difficulties. They put the responsibility of solving gender inequalities on the individual woman researcher making women responsible for limited success in acquiring assistant professor positions. This adds to women researchers' precariousness who, in the increased competition for jobs, are made responsible for fighting the stereotypical images that committee members hold. This logic fits the neoliberal postfeminist ideal, which epitomises 'self-responsibility' for women's own lives and careers (Rottenberg 2014) "without questioning the underlying masculine and capitalist norms of that ideal" (Benschop and Verloo 2016, p. 102).

We conclude that a few gender practices can be beneficial for women academics. However, these practices around welcoming women and the alleged collaborative qualities of female academic citizens, portray women as different from men, convey generic ideas of women, and reproduce feminine characteristics as innate or essential (Crompton and Lyonette 2005). Therefore, we question whether these 'beneficial' practices are strong enough to drive change. We have seen that the detrimental practices around assessing potential and constructing an ideal, confident, committed and international mobile early career researcher are so ubiquitous that they predominantly affect evaluations in the competition for assistant professor positions. This can cause committee members to make biased selection decisions, attributing more potential to male researchers. As a result, women researchers can be excluded from the competition, which can lead them to be forced into longer periods of job insecurity and a lack of career prospects.

In conclusion, gender practices in the recruitment and selection at the early stage of academic careers show how tacit criteria are more decisive and that assessments of potential are particularly perilous for women. Overall, many committee members depict women as non-competitive, modest, non-committed, and non-mobile, which hampers women's career development and impedes their escape from precariousness. Future research could examine how these generic ideas affect individual women applicants, by studying the literal practicing of gender on the spot, for example during selection committee deliberations.

\section{References}

Bagilhole, B. (1993). How to keep a good woman down: an investigation of the role of institutional factors in the process of discrimination against women academics. British Journal of Sociology of Education, 14(3), 261-274.

Bagilhole, B. and Goode, J. (2001). The contradiction of the myth of individual merit, and the reality of a patriarchal support system in academic careers. European Journal of Women's Studies, 8(2), 161-180. 
Bazeley, P. (2003). Defining 'early career' in research. Higher Education, 45(3), 257-279.

Benschop, Y. and Brouns, M. (2003). Crumbling ivory towers. Academic organizing and its gender effects. Gender, Work \& Organization, 10(2), 194-211.

Benschop, Y. and Verloo, M. (2016). Feminist organization theories: islands of treasure. In R. Mir, H. Willmott and M. Greenwood (eds), The Routledge Companion to Philosohpy in Organization Studies: Routledge, pp. 100-112.

Biernat, M. and Fuegen, K. (2001). Shifting standards and the evaluation of competence: complexity in gender-based judgment and decision making. Journal of Social Issues, 57(4), 707-724.

Bleijenbergh, I., Van Engen, M. L. and Vinkenburg, C. J. (2013). Othering women: fluid images of the ideal academic. Equality, Diversity and Inclusion, 32(1), 22-35.

Brouns, M. (2001). Wetenschap tussen Olympus en Agora. De vele gezichten van gender in de wetenschappen. Tijdschrift voor Genderstudies, 4(2), 24-33.

Brouns, M. (2004). Gender and the assessment of scientific quality. In European Commission, Gender and Excellence in the Making, pp. 147-152.

Bryson, C. (2004). The consequences for women in the academic profession of the widespread use of fixed term contracts. Gender, Work \& Organization, 11(2), 187-206.

Campbell, I. and Price, R. (2016). Precarious work and precarious workers: towards an improved conceptualisation. The Economic and Labour Relations Review, 27(3), 314-332.

Cech, E. A. and Blair-Loy, M. (2014). Consequences of flexibility stigma among academic scientists and engineers. Work and Occupations, 41(1), 86-110.

Crompton, R. and Lyonette, C. (2005). The new gender essentialism - domestic and family 'choices' and their relation to attitudes. The British Journal of Sociology, 56(4), 601-620.

Cyranoski, D., Gilbert, N., Ledford, H., Nayar, A. and Yahia, M. (2011). The PhD factory: the world is producing more PhDs than ever before. Is it time to stop? Nature, 472, 276-279.

De Boer, H. F., Enders, J. and Leisyte, L. (2007). Public sector reform in Dutch higher education: the organizational transformation of the university. Public Administration, 85(1), 27-46.

Dick, P. and Nadin, S. (2006). Reproducing gender inequalities? A critique of realist assumptions underpinning personnel selection research and practice. Journal of Occupational and Organizational Psychology, 79, 481-498.

Essed, P. (2004). Cloning amongst professors: normativities and imagined homogeneities. NORA - Nordic Journal of Feminist and Gender Research, 12(2), 113-122.

EU (2016). She Figures 2015. Luxembourg: Publications Office of the European Union.

Feldman, M. S. and Orlikowski, W. J. (2011). Theorizing practice and practicing theory. Organization Science, 22(5), 1240-1253.

Fiske, P. (2011). What is a $\mathrm{PhD}$ really worth? Nature, $472,381$.

Flick, U. (2009). An Introduction to Qualitative Research (4th ed.): SAGE Publications Ltd.

Glick, P. and Fiske, S. T. (1996). The ambivalent sexism inventory: differentiating hostile and benevolent sexism. Journal of Personality and Social Psychology, 70(3), 491-512.

Grummell, B., Devine, D. and Lynch, K. (2009). The care-less manager: gender, care and new managerialism in higher education. Gender and Education, 21(2), 191-208.

Harney, B., Monks, K., Alexopoulos, A., Buckley, F. and Hogan, T. (2014). University research scientists as knowledge workers: contract status and employment opportunities. The International Journal of Human Resource Management, 25(16), 2219-2233. 
Heijstra, T. M., Steinthorsdóttir, F. S. and Einarsdóttir, T. (2016). Academic career making and the double-edged role of academic housework. Gender and Education, 1-17.

Herschberg, C., Benschop, Y. and Van den Brink, M. (2015). Constructing Excellence: the Gap between Formal and Actual Selection Criteria for Early Career Academics, GARCIA Working Paper 2. University of Trento. Retrieved 8 August 2017 from http:// garciaproject.eu/?page id $=52$.

Herschberg, C., Benschop, Y. and Van den Brink, M. (2016). Gender Practices in the Construction of Excellence, GARCIA Working Paper 10. University of Trento. Retrieved 8 August 2017 from http://garciaproject.eu/?page_id=52.

Herschberg, C., Vinkenburg, C. J., Bleijenbergh, I. L. and Van Engen, M. L. (2014). Dare to care: negotiating organizational norms on combining career and care in an engineering faculty. In D. Bilimoria and L. Lord (eds), Women in STEM Careers: International Perspectives on Increasing Workforce Participation, Advancement and Leadership: Edward Elgar Ltd, pp. 204-224.

Huisman, J., De Weert, E. and Bartelse, J. (2002). Academic careers from a European perspective: the declining desirability of the faculty position. The Journal of Higher Education, 73(1), 141-160.

Martin, P. Y. (2003). 'Said and done' versus 'saying and doing': gendering practices, practicing gender at work. Gender \& Society, 17(3), 342-366.

Morgan, G. and Wood, J. (2017). The 'academic career' in the era of flexploitation. In E. Armano, A. Bove and A. Murgia (eds), Mapping Precariousness, Labour Insecurity and Uncertain Livelihoods: Subjectivities and Resistance: Routledge, pp. 82-97.

Moss-Racusin, C. A., Dovidio, J. F., Brescoll, V. L., Graham, M. J. and Handelsman, J. (2012). Science faculty's subtle gender biases favor male students. Proceedings of the National Academy of Sciences, 109(41), 16474-16479.

Newell, S. (2005). Recruitment and selection. In S. Bach (ed.), Managing Human Resources: Personnel Management in Transition (4th ed.): Blackwell Publishing Ltd, pp. 115-147.

Nielsen, M. W. (2015). Limits to meritocracy? Gender in academic recruitment and promotion processes. Science and Public Policy, 43(3), 386-399.

Nikunen, M. (2014). The 'entrepreneurial university', family and gender: changes and demands faced by fixed-term workers. Gender and Education, 26(2), 119-134.

Noon, M. (2012). Simply the best? The case for using 'threshold selection' in hiring decisions. Human Resource Management Journal, 22(1), 76-88.

O'Connor, P. and O'Hagan, C. (2015). Excellence in university academic staff evaluation: a problematic reality? Studies in Higher Education, 41(11), 1943-1957.

Poggio, B. (2006). Editorial: uutline of a theory of gender practices. Gender, Work \& Organization, 13(3), 225-233.

Richardson, J. and Zikic, J. (2007). The darker side of an international academic career. Career Development International, 12(2), 164-186.

Rottenberg, C. (2014). The rise of neoliberal feminism. Cultural Studies, 28(3), 418-437.

Rudman, L. A. and Phelan, J. E. (2008). Backlash effects for disconfirming gender stereotypes in organizations. Research in Organizational Behavior, 28, 61-79.

Schiewer, H. and Jehle, C. (2014). Tenure and Tenure Track at LERU Universities: Models for Attractive Research Careers in Europe. Retrieved 8 August 2017 from www.leru.org/files/publications/LERU_AP17_tenure_track_final.pdf.

Teelken, C. and Deem, R. (2013). All are equal, but some are more equal than others: managerialism and gender equality in higher education in comparative perspective. Comparative Education, 49(4), 520-535. 


\section{Channah Herschberg et al.}

Van Arensbergen, P., Van der Weijden, I. and Van den Besselaar, P. (2014). Different views on scholarly talent: what are the talents we are looking for in science? Research Evaluation, 23(4), 273-284.

Van den Brink, M. (2010). Behind the Scenes of Science. Gender Practices in the Recruitment and Selection of Professors in the Netherlands. Pallas Publications, Amsterdam.

Van den Brink, M. and Benschop, Y. (2012a). Gender practices in the construction of academic excellence: sheep with five legs. Organization, 19(4), 507-524.

Van den Brink, M. and Benschop, Y. (2012b). Slaying the seven-headed dragon: the quest for gender change in academia. Gender, Work \& Organization, 19(1), 71-92.

Van den Brink, M. and Benschop, Y. (2014). Gender in academic networking: the role of gatekeepers in professorial recruitment. Journal of Management Studies, 51(3), 460-492.

Van den Brink, M. and Stobbe, L. (2014). The support paradox: overcoming dilemmas in gender equality programs. Scandinavian Journal of Management, 30(2), 163-174.

Van den Brink, M., Benschop, Y. and Jansen, W. (2010). Transparency in academic recruitment: a problematic tool for gender equality? Organization Studies, 31(11), $1459-1483$.

Wöhrer, V. (2014). Introduction: early career researchers and changing working conditions in academia. Higher Education Policy, 27(4), 431-434. 


\section{Part III}

\section{Early career researchers}





\title{
5 Work-life balance among early career researchers in six European countries
}

\author{
Sanja Cukut Krilić, Majda Černič Istenič and \\ Duška Knežević Hočevar
}

\section{Introduction}

The increased labour force participation of women observed in recent decades in almost all 'industrialised' countries has fundamentally challenged the male breadwinner/female caregiver model of work-family relations. In response to such changes, diverse policies aiming at better reconciliation of paid work and other areas of life have been developed in various national contexts, but "powerful gender norms [remain] embedded in working time and care regimes" (Charlesworth, Baines and Cunningham 2015, p. 607). The academic world is no exception in this regard. On the contrary, the 'academic gender gap' (Baker 2010) characterised by lower ranks and salaries for female academics and their underrepresentation in senior academic positions and in more stable and secure forms of employment in academia continues.

It is therefore no coincidence that in recent decades policy and research efforts, as well as public debates on work-life balance in academia, have largely addressed female academics. The question whether and how women can 'have it all' - a high-commitment career, a partner and children - has become a subject of regular debate in the media of most 'industrialised' countries (Seierstad and Kirton 2015). It is rather symptomatic that, in such debates, not only are educated women such as academics often perceived as those who are to 'blame' for a poor demographic picture by not having 'enough' children, but also their role as reproducers and primary carers of individuals, families and communities is strongly highlighted (McDaniel 1996; Krause 2001; Cukut 2007; Knežević Hočevar 2007). Therefore, as Garforth and Kerr (2009, p. 380) have argued, the notion of 'women in science' has been framed in mainstream discourses as "a problem to be solved by particular policies, activities and practices". Correspondingly, the notion of work-life balance needs to be examined in a wider socio-historical context.

Following this argument, the focus of the first part of this chapter is not on a detailed review of research that has examined factors facilitating or hindering work-life balance in academia and has focussed largely on the influence of various factors that might enable such a reconciliation of work and other areas of life. The aim of this chapter is rather to locate the narratives related to both 
temporal and spatial work-life balance by drawing on social, economic and workplace developments and concerns (Lewis et al. 2007; Gregory and Milner 2009) that are reflected in the dominant discourse about work-life balance in various socio-political periods, as well. For this reason, the authors draw also on research that has dealt with the issue of work-life balance in contexts outside academia and has reflected on the notion of work-life balance by examining the implicit assumptions behind different work-life balance policies.

Despite a proliferation of such policies in recent decades, women are still universally underrepresented at the top of the academic professional hierarchy in all national contexts. However, whether the reasons behind this vertical segregation of their careers are similar across national boundaries remains unexplored. Taking this underrepresentation into consideration, we hold that women and men in the early stages of their academic and research careers may not be facing exactly the same structural and normative opportunities and constraints in various national contexts. In this vein, the characteristics of policies aimed at reconciling work and private life in the six European countries involved in the GARCIA project - Belgium, Iceland, Italy, the Netherlands, Slovenia and Switzerland - are presented in the second part of the chapter. By focusing on the statistics on maternal/paternity/parental leaves, this part of the chapter also presents how the nationally available work-life balance policies are mirrored at the level of selected SSH and STEM higher education institutions.

The third part of the chapter focuses on how early career researchers experience work-life balance. The comparison of such experiences in six European countries is based on the secondary analysis of national reports elaborated by the national research teams within the GARCIA project.

The comparison focuses on the feelings towards and experiences of the demands of work and private life in female and male early career researchers interviewed both in SSH and STEM departments in six higher education institutions. Despite various national contexts - various gender, employment and care regimes that might influence work-life balance in different national contexts we hold that gendered perceptions and narratives about this topic can be observed as a transnational shared reality among most interviewees at early stages of their research careers.

\section{The state of the art of studies on work-life balance in academia}

In the male and childless normative model historically present in academia, linearity without interruption or career breaks and total availability and devotion to academia are perceived as the traits of an 'ideal worker' (Wolf-Wendel and Ward 2006; Careless 2012; Bozzon et al. 2017). In such an academic culture, there is practically no boundary between work and other areas of life; total commitment and profound concentration on the research subject in pursuit of scientific knowledge are both presumed and expected (Ylijoki 2013). Such a cultural imperative of total commitment can be interpreted as "a masculine norm, relying on a hidden 
assumption that there are others who take care of the private sphere of life" (Ylijoki 2013, p. 249). Mason and Goulden (2004a, p. 88) argue that such "long working hours and the required time to travel and be mobile precisely at a time when women might choose to start a family have forced some women out of 'fast-track' professions" such as academia. Furthermore, this model does not account for the fact that, in contemporary academic work, the boundary between paid work and other areas of life is becoming increasingly blurred (Currie and Eveline 2011; Bozzon et al. 2017), although the activities performed in each sphere remain "differentially valued and rewarded" (McDowell 2004, p. 148).

In this vein, by drawing on the concept of "greedy institutions" (Coser 1974), researchers have argued that academic organisations and family can both be perceived as greedy institutions that exert pressures on individuals to weaken their ties with other institutions. For example, academic organisations demand academics' all-consuming passion and commitment to a larger (scientific) cause. The family and in particular the institution of parenthood is also greedy, but even more so for women (Currie et al. 2000; Wolf-Wendel and Ward 2006; Careless 2012).

The work-life balance metaphor remains a "social construct located within a particular period of time and originating in a western context" (Lewis et al. 2007 , p. 1). Therefore, research on this topic and the terminology used to describe work-life balance issues has reflected the prevailing socioeconomic situation and concerns in particular time periods. For instance, the growth in the number of women on the labour market observed since the 1960s in most tertiarised countries has resulted in research focusing on the issue of 'working mothers' and 'dual-earner families'. Such an orientation was mirrored in debates on 'family-friendly policies' that implicitly focussed on working women, especially mothers. The contemporary discourse on work-life balance that originated in the 1990s reflects a "broader and more inclusive way of framing the debate to engage men and women with and without children or other caring commitments and was partly a response to backlash against work-family policies by those without obvious family obligations" (Lewis et al. 2007, p. 2).

However, Lewis and colleagues (2007) insisted that the prevailing government, policy and academic work-life balance discourses still overlooked structural and cultural constraints on achieving greater work-life balance by emphasising mainly individual choice and flexibility. The authors identified two main discourses. The first is defined as the "personal control of time work-life balance discourse" and emphasises the individual and to a lesser extent household responsibility for achieving work-life balance. The second, the "flexibility discourse", focuses on the need for flexibility in working arrangements to enable employees to achieve greater work-life balance. Nevertheless, in both discourses, structural and cultural gendered and workplace constraints, norms and assumptions were generally overlooked. Moreover, by claiming gender neutrality, gender inequities might be reinforced and reproduced, and underlying assumptions about paid work remained fundamentally unchallenged. Bloom $(2015$, p. 4) has also maintained that such a discourse tends to "accept and, 
therefore, reinforce established capitalist and quite managerialist assumptions about what constitutes work, on the one hand, and what is the appropriate relationship between 'work' and 'life' on the other'. Similarly, Garforth and Kerr (2009) argue that work-life balance issues are predominantly framed in relation to the ways women can adapt to the traditional ideal of a linear masculine career, while men are assumed to pursue such a career without interruptions.

By challenging this gender bias in most contemporary work-life balance approaches, Smithson and Stokoe (2005) call for greater recognition of the diversity or work-life balance issues which requires that work-life balance be made important for all employees and managers, rather than only adopting policies enabling working mothers to better manage paid work and family needs.

Research that has dealt more specifically with work-life balance in academia has largely considered the gendered expectations and constraints, both in the workplace and at home, that hamper work-life balance of academics. Given the pervasiveness of the unequal gender division of household tasks and the discrimination women continue to face in academic environments, it is no coincidence that such studies have largely targeted the personal and institutional barriers to work-life balance for women in academia, rather than examining the issue in regard to both female and male academics (e.g. Fothergill and Feltey 2004; Wolf-Wendel and Ward 2006; Careless 2012). Yet, in recent years, there has been an upsurge of interest also in the experiences of male academics, and several studies have examined both women's and men's views of the issue (e.g. Baker 2010; Rafnsdóttir and Heijstra 2013; Ylijoki 2013; Lewis 2016).

Besides gender equality issues, the growing research interest in work-life balance in recent decades can also be seen as a consequence of the emergence of new forms of employment and working patterns that mirror global trends and "reveal structural transformations within the academic workplace" (Cannizzo and Osbaldiston 2015, p. 892). Among the most prominent changes observed have been the increasing shift of work into and its interference with non-work time and the consequential blurring of the line between paid work and other areas of academic life (Hawkins et al. 2014; Cannizzo and Osbaldiston 2015). Along this line, the temporal consequences of such changes, in particular the acceleration of time and the blurring of work and non-work contexts, resulting from spatial and temporal flexibility in academic work and the imperative of 24/7 availability and total commitment to academic work, have been examined in some detail (Bell, Rajendran and Theiler 2012; Rafnsdóttir and Heijstra 2013; Ylijoki 2013; Lewis 2016).

Additionally, casualisation of the workforce - the transformation of permanent into temporary short-term contracts - is evidenced as an increasing phenomenon also in academic environments (Cannizzo and Osbaldiston 2015; Carreri 2015; Bozzon et al. 2017). Carreri (2015) argued that the increasing precariousness of work conditions conferred greater responsibility upon individuals to negotiate boundaries between work and family life and affected family choices by encouraging their postponement (see also Gill 2009; Girard 2010). Not surprisingly, several researchers (e.g. Gill 2009; Hawkins et al. 2014) have 
recently questioned the notion of the successful academic in the ever more neoliberal university and research environments. They have drawn attention to the unequal power relations within neoliberal academia that have become normalised and internalised as individual responsibility in the everyday lives of the academics and have pointed to the feelings of guilt, isolation and spill-over of work life into non-work life in most academics' typical daily schedules. In masculinist discourses, as we have demonstrated above, high workload and a prime commitment to the institution became normalised (Gill 2009; Isgro and Castañeda 2015). Although their research was conducted on a sample of graduate students engaged in research work, Hawkins and colleagues (2014) identified such neoliberal practices and discourses on what it means to be professional, productive and worthy in the research environment as white, masculine, middle-class and Anglo-centric constructions that seem to persist in academic environments, as well. In such a model, the possibilities to care for oneself and others are perceived as in direct contrast with the ideals of academic success. Therefore, Isgro and Castañeda have recently (2015) called for developing a "culture of care" as a conceptual framework in order to examine and develop policies and practices acknowledging the multiple forms of caretaking and lived experiences within academic institutions.

Despite these recent structural transformations in the realm of academic work and a proliferation of work-life balance policies in different national contexts, huge national differences remain regarding the formally available possibilities to achieve work-life balance. Such differences in higher education institutions involved in the GARCIA project are discussed below in line with the assumption that both supports for and constraints on work-life balance are influenced by particular gender, care and welfare regimes and institutional arrangements promoting gender equality.

\section{Work-life balance arrangements in different national contexts}

The evidence presented in the national reports on policies towards and experiences of work-life balance across different national and institutional contexts (Le Feuvre 2015a; Le Feuvre 2015b; Cukut Krilić and Rapetti 2015) portray a variety of work-life balance arrangements that are related to their specific gender and welfare state regimes. Such policies focus mostly on leave, career breaks, childcare facilities and flexible time arrangements.

According to Esping-Andersen's (1990) classification of welfare states regimes, ${ }^{1}$ at one end of the spectrum, GARCIA countries could be labelled conservative-corporatist, while at the other end they resemble the social democratic model of the welfare state. Esping-Andersen situated Italy at the first end of this spectrum; there, in the absence of state intervention, families retained a central role in taking care of individuals. Moreover, he identified the male breadwinner model of the family as still prevailing in Italy. Such divisions are also observed in Italy's still lower employment rates among mothers than in other 


\section{Sanja Cukut Krilić et al.}

GARCIA countries, as evidenced in Table 5.1. Similar perceptions of the distribution of the tasks and responsibilities of family life between genders can be found historically in Switzerland, the Netherlands and Belgium, as well. However, in accordance with 'the modified male breadwinner model' of gender relations in these countries, a set of measures has evolved over the past decades - besides the prevalent discourse addressing women as primarily responsible for the care of children and other family members in need - that also allow relatively high economic activity rates for mothers (Table 5.1). To a considerable extent, these rates are the consequence of working part-time, a widespread practice in these countries (Table 5.2).

On the other side of the spectrum, and closer to a social democratic model of welfare regimes, are Iceland and Slovenia. Considerable state support for families and at least declared equality of both sexes with regard to family obligations are emphasised to a greater extent than in other GARCIA countries. Traditionally, high rates of women's economic participation in both Iceland and Slovenia are the result of family policies that, since 1976 in Iceland and during the socialist period in Slovenia, have contributed to the development of widespread

Table 5.1 Maternal employment rates by age of youngest child, 2014

\begin{tabular}{|c|c|c|c|c|}
\hline \multirow[t]{2}{*}{ Country } & \multicolumn{4}{|c|}{ Employment rate (\%) } \\
\hline & $\begin{array}{l}\text { Youngest child } \\
\text { aged } 0-14\end{array}$ & $\begin{array}{l}\text { Youngest child } \\
\text { aged } 0-2\end{array}$ & $\begin{array}{l}\text { Youngest child } \\
\text { aged 3-5 }\end{array}$ & $\begin{array}{l}\text { Youngest child } \\
\text { aged 6-14 }\end{array}$ \\
\hline Belgium & 72.4 & 65.7 & 70.3 & 76.9 \\
\hline Iceland & - & - & - & - \\
\hline Italy & 55.3 & 53.6 & 54.6 & 56.4 \\
\hline Netherlands & 74.8 & 73.5 & 73.0 & 76.3 \\
\hline Slovenia & 79.1 & 71.9 & 79.1 & 84.4 \\
\hline Switzerland & 77.5 & 70.9 & 75.9 & 82.3 \\
\hline
\end{tabular}

Source: OECD family database, www.oecd.org/social/family/database.htm.

Table 5.2 Percentage of part-time and full-time employment amongst men and women aged 25-54, selected countries, 2014

\begin{tabular}{lcclll}
\hline Country & $\begin{array}{l}\text { Total \% } \\
\text { part-time }\end{array}$ & $\begin{array}{l}\text { Male } \\
\text { part-time }\end{array}$ & $\begin{array}{l}\text { Female } \\
\text { part-time }\end{array}$ & $\begin{array}{l}\text { \% ofwomen } \\
\text { amongst } \\
\text { part-timers }\end{array}$ & $\begin{array}{l}\text { \% of women } \\
\text { amongst } \\
\text { full-timers }\end{array}$ \\
\hline Belgium & 22.1 & 6.5 & 39.6 & 84.4 & 36.8 \\
Iceland & 16.6 & 6.0 & 28.3 & 83.3 & 40.7 \\
Italy & 18.3 & 7.2 & 33.3 & 77.6 & 34.9 \\
Netherlands & 43.3 & 16.9 & 73.3 & 79.2 & 22.0 \\
Slovenia & 6.9 & 4.3 & 9.9 & 68.0 & 52.8 \\
Switzerland & 37.0 & 13.6 & 64.4 & 80.5 & 26.4 \\
\hline
\end{tabular}

Source: EUROSTAT, http://ec.europa.eu/eurostat/data/database. 
childcare facilities and the provision of different types of leave of considerable duration for employed parents.

Therefore, the statistics portray the six countries involved in our study as having very different maternity/paternity/parental leave provisions. Table 5.3 shows the various lengths of leave introduced to enable parents to reconcile their family and employment obligations. Switzerland, for instance, with a relatively short duration of paid maternity leave (the right was introduced only in 2005), and no legal paid paternal leave (although some employers offer new fathers one to two days or even one week of leave) and no additional parental leave (except one month for mothers who are still breastfeeding at the end of their legal maternity leave) presents a 'base line' of parental support policy among the studied countries (Le Feuvre 2015, p. 37). In Italy and the Netherlands, where there is no legal provision of (paid) paternity leave, it also seems that parental responsibilities are treated as a task that primarily affects the lives of women. In the rest of the countries, a number of policy interventions have emerged in recent years to share the symbolic and financial costs of parenting more equally between both parents. In Slovenia, Iceland and Belgium, men's rights to leave the labour market at the birth of a child have increased, although the degree of men's use of parental leave still varies across countries and among different professional categories (Le Feuvre 2015a).

In addition to various types of leave available to employed parents, childcare arrangements also facilitate the reconciliation of family and working life and therefore can encourage employment (especially of women) and gender equality. In a cross-national comparative perspective, Italy, Switzerland and the Netherlands appear as countries where pre-school childcare facilities are of least help to employed parents. Considering only the indicator of the total percentage of children enrolled in pre-school childcare could be misleading (Table 5.4), since

Table 5.3 Fertility rates, mean age of women at birth of first child, and maternity/paternity/parental leave arrangements, selected countries, 2014

\begin{tabular}{llllll}
\hline Country & $\begin{array}{l}\text { Total } \\
\text { fertility } \\
\text { rates }\end{array}$ & $\begin{array}{l}\text { Mean age } \\
\text { of women } \\
\text { at birth of } \\
\text { first child }\end{array}$ & $\begin{array}{l}\text { Length of (paid) } \\
\text { maternity leave } \\
\text { (weeks) }\end{array}$ & $\begin{array}{l}\text { Length of (paid) } \\
\text { paternity leave } \\
\text { (weeks) }\end{array}$ & $\begin{array}{l}\text { Length of (paid) } \\
\text { maternity and } \\
\text { paternal leave } \\
\text { (weeks) }\end{array}$ \\
\hline Belgium & 1.7 & 28.6 & 15 & 2 & 28 \\
Iceland & 1.9 & 27.3 & 13 & 13 & 43 \\
Italy & 1.4 & 30.7 & 21.7 & 0 & 47 \\
Netherlands & 1.7 & 29.5 & 16 & 0.3 & 42 \\
Slovenia & 1.6 & 29.1 & 15 & 13 & 52 \\
Switzerland & 1.5 & 30.7 & 16 & 0 & 16 \\
\hline
\end{tabular}

Sources: EUROSTAT, http://ec.europa.eu/eurostat/statistics-explained/index.php/Fertility_statistics; UNECE, http://w3. unece.org/PXWeb/en/Charts?IndicatorCode=34\&CountryCode=578 OECD, www.oecd.org/gender/data/length-of-maternity-leave-parental-leave-and-paid-father-specific-leave. htm; European Parliament, www.europarl.europa.eu/RegData/etudes/ATAG/2014/545695/EPRS_ ATA(2014) 545695_REV1_EN.pdf. 
Table 5.4 Participation rates in childcare, 2014 (formal childcare by duration and age group)

\begin{tabular}{lcc}
\hline Country & $\begin{array}{l}\text { Less than three years } \\
\text { (from 1 to 29 hours per week) }\end{array}$ & $\begin{array}{l}\text { Less than three years } \\
\text { (30 hours or more per week) }\end{array}$ \\
\hline Belgium & 23.3 & 25.6 \\
Iceland & 1.0 & 41.8 \\
Italy & 9.3 & 13.6 \\
Netherlands & 38.5 & 6.1 \\
Slovenia & 3.4 & 34.0 \\
Switzerland & 24.0 & 5.8 \\
\hline
\end{tabular}

Source: EUROSTAT, https://ec.europa.eu/eurostat/tgm/refreshTableAction.do?tab=table\&plugin= $1 \&$ pcode $=$ tps $00185 \&$ language $=$ en

formal childcare arrangements may be of little assistance to parents with children if they cover only a small number of hours (less than 30) per week (European Union 2014). From this perspective, the data for the Netherlands and Switzerland demonstrate that, among all the under-three-year-olds who spend some time in institutional care, only a small minority ( 5 or 6 per cent) of these children are taken care of in crèches or day-care centres for more than 30 hours a week. In Italy, this share is higher, although the entire share of all children under three years old who benefited from day-care, nursery schools or other education services is still below the Barcelona target of at least 33 per cent (Barcelona European Council 2002), mostly because an insufficient number of places is available (Bank of Italy in Le Feuvre 2015b). Among the countries that exceed the Barcelona target are Belgium and, to an even greater extent, Iceland and Slovenia. ${ }^{2}$

The availability of flexible working time arrangements (e.g. part-time work, teleworking, job-sharing, time saving etc.) that can make reconciling work and family life easier is another aspect of work-life balance policies that varies considerably among the GARCIA countries. According to recent data (EC 2014, in Le Feuvre 2015b), the share of workers, irrespective of gender, who can vary the start and end of their working day is much lower (44 per cent) in Italy than in other analysed countries. For example, in Belgium, this share reaches 58 per cent, in Slovenia 61 per cent and in the Netherlands 83 per cent. A similar difference among countries emerges in the percentage of employed people generally able to take whole days off for family reasons (Le Feuvre 2015b, p. 21).

As the national and local policy reports elaborated within the GARCIA project (Le Feuvre 2015b) demonstrate, in some countries innovative policies related to work-life balance have recently been introduced. For instance, in Italy, the law on the reconciliation of work and family life (now included in L. 198/2006) intends to support local projects of flexible working arrangements in terms of hours, teleworking, job-sharing, time saving and the possibility for co-workers to substitute for self-employed females. In Slovenia, the 2013 revisions of the Employment Relationship Act also intend to increase the possibility of work-life balance by introducing a number of measures, for instance, the right 
of parents of school-age children to take at least one week of their annual leave during school holidays, flexible work times, company childcare services, job sharing, adoption leave, part-time work and assistance to care for a disabled family member (Stropnik 2011). However, budget cuts in recent years, driven largely by austerity policies, have not allowed such practices to spread. Furthermore, in the frame of initiatives to make work-life balance more harmonious, a programme of service vouchers was recently introduced in Belgium for the activities at the user's residence (e.g. various household chores) and also outside it (shopping, transportation, escort of persons with reduced mobility, etc.). These services are supposed to contribute to salarisation of household work and therefore to more balanced division of household work among both genders. However, they are more accessible to wealthier socio-economic groups (Le Feuvre 2015b).

The general work-life balance measures implemented in individual GARCIA countries seem to create the basic framework of possibilities of support for employed parents and reveal that, in different national contexts, becoming a mother does not have identical results for women's professional careers. In the academic context, characterised by a high level of competition and pressure to advance one's academic career, this seems an even more distinctive issue.

\section{Methods}

\section{Data and data analysis}

Each project partner carried out semi-structured interviews with selected research participants from November 2014 to March 2015. The interviews followed a common interview guide in all countries and were performed with individuals from two selected departments (STEM and SSH) in each country. Among the interviewees were $\mathrm{PhD}$ holders both currently and formerly employed in academia, with both tenure-track and non-tenure-track positions. In total, 236 interviews were conducted. The interviews worked with a previously defined set of questions about the interviewees' life-courses since the completion of their doctorates; their perceptions of organisational culture in their everyday working lives; their wellbeing and work-life balance; and finally, their career development and perspectives for the future. The comparison of work-life balance experiences in six European higher education institutions situated in different countries is based on the secondary thematic analysis of national reports elaborated within the project. We were interested in capturing both shared academic realities and particularities of the work-life balance of interviewees, whether single or in partnerships whether with or without children.

\section{Research context}

Besides focusing on the personal experiences of research participants, we focus also on the particular work-life balance measures that the analysed institutions 


\section{Sanja Cukut Krilić et al.}

introduced to help academics balance the responsibilities of their professional and personal lives. In Belgium, national legislation is respected, but some organisation-specific initiatives are additionally taken to supplement the lack of work-life balance measures at the national level (e.g. various types of leave, support for young researchers' international mobility, a company's own day-care facilities). In Iceland, the work-life balance policies predominantly mirror the existing generous national family policies. However, since the 2008 financial crisis, the government had to pass severe budget cuts, resulting in a 40 per cent decrease of the maximum payment for parental leave, meaning that fathers were now less likely to take their earmarked parental leave (Gender Equality in Iceland 2017). Furthermore, the characteristic of the Icelandic childcare model is that it is the responsibility of parents to bridge the time-gap between parental leave and kindergarten (where children begin around the age of 2). This reinforces a gendered division of labour seen as it is usually mothers that end up having to extend their parental leave (with decreased pay or no pay) or work part-time (Arnalds, Eydal and Gíslason 2013). At the organisational level, although additional initiatives exist in Iceland (gathering and evaluating the data on the issue, taking family-related leaves into account in the evaluation system, different family-related financial allowances), there are demonstrable inconsistencies between work-life balance policies and evaluation systems as well as between these policies and the lived experiences of academics (Smidt, Pétursdóttir and Einarsdóttir 2017). In Italy, due to limited national support arrangements, several initiatives pertaining to childcare facilities, family-related leave, flexible work arrangements, training and awareness-raising campaigns on the issue of work-life balance have been created at the institutional level. In the Netherlands, relatively limited work-life balance measures at the national level have been supplemented at the institutional level with flexible working-time regulations and measures targeting employers to provide care, family-related leaves and day-care facilities. In Slovenia, in a similar manner to Iceland, work-life balance practices are somewhat in line with the national policies that promote a dualearner family model characterised by quite generous family-related leaves, good provision of childcare facilities and flexible forms of work, but these policies do not necessarily reflect the academic reality. In Switzerland, where the national family policies largely do not favour the dual-earner, full-time work model, a range of measures and initiatives at the organisational level have been established to facilitate the work-life balance of employees (family-related leave support, day-care at the organisational level, extensions in positions, tenure procedures and evaluation procedures when having children, job-sharing etc.). A comparison of various work-life balance policies and practices at the organisational level reveals that additional special programmes and measures to facilitate work-life balance in each institution have been introduced mostly in organisational contexts where national and local regulations do not offer many opportunities to reconcile professional and personal life (Cukut Krilić and Rapetti 2015).

In Iceland and particularly in Slovenia, the available work-family policies within the selected academic institutions are predominantly a reproduction of 
these countries' (relatively generous) national family policies, although academic realities are not always in line with institutional and national policies. The opposite holds true for academic institutions in other countries, particularly in Italy, where, due to limited public institutional/formal support arrangements for working parents/mothers, the involved institutions have launched several initiatives pertaining to childcare facilities (e.g. a university's own day nursery and babysitting, counselling services for parents, special parents-and-children area, sport programmes and summer camps for school children, economic support and subsidies during maternity leave etc.). Additionally, various time schedule flexibility measures have developed, but only for employees with regular work schedules who must guarantee their presence in the workplace, while postdoctoral researchers (and researchers on temporary contracts) are not included in measures of this kind (Cukut Krilić and Rapetti 2015). A range of similar measures and initiatives pertaining to maternity/paternity/parental leave and support for care, childcare or elder care and flexible forms of work are found also in other analysed countries. In Switzerland, for example, based on family support measures provided by the Swiss National Science Foundation (SNSF), 120 per cent support grants are offered to postdoctoral researchers who need to look after children during an important stage in their career and need more flexibility through part-time work or by hiring a support person.

Among the more innovative measures aiming to support work-life balance by preventing stress and improving wellbeing at work, institutions in Belgium and the Netherlands recently introduced job coaching, counselling, courses on stress management, time management etc. Considering the specificities of an academic career, it is worth highlighting the annual evaluation system at the higher education test institution in Iceland, whose scoring procedure takes into account maternity/paternity leave. Therefore, it can be argued that institutions' specific measures supplement the national regulations to improve the work-life balance of researchers at early stages of academic careers. Nevertheless, these recent policy amendments, still do not, for example, take into account that the caring responsibilities are in general shouldered by women, not only during parental leave but also in the years after it.

The aforementioned general framework is also mirrored at the organisational level of academic institutions and universities and in the lives of women in early stages of scientific careers. Aiming to portray the situation of women in early stages of scientific careers in both STEM and SSH research organisations, the statistics on maternity/paternity/parental leave and other types of leaves for family care reasons were also collected for the latest available year, $2013 .^{3}$ These data, as highlighted in the analysis of the Belgian case (Cukut Krilić and Rapetti 2015 , p. 57), should be interpreted with caution, since it was not certain that the administrative system produced an exact picture of the use of all different types of leave. Additionally, the interviews revealed that some mothers on maternity leave continue to work on their research project. Due to different legislative arrangements (type and duration of leaves, see Table 5.3), the data obtained also differ among participating countries. 
Besides the differences described above, some tendencies can be grasped from the analysis, for instance that parental leave is taken more often by women than by men in both SSH and STEM departments. The same is probably true of other types of leave (due to low numbers, these are not presented here), which points to persistent gendered divisions of care work in all the analysed countries.

\section{Experiencing reconciliation of work and private life: unfolding gendered discourse and precariousness}

This part of the chapter discusses the reconciliation of work and private life as represented by the interviewees from Belgium, Iceland, Italy, the Netherlands, Slovenia and Switzerland. Without de-emphasising the messages conveyed by statistics, graphs or surveys, the authors of the chapter agree that interactive interviews can break the silence of those who struggle, and their personal accounts can more easily attract the attention of a wider audience (Bourdieu and Wacquant 1992). Individual quotes employed in the text below are not the expressions of a single person only; they are illustrations of numerous interviewee voices, irrespective of their backgrounds.

Discussing work-life balance, the interviewees construed their understanding of the academic profession or working environment and their creative agency in coping with the reconciliation of work and personal lives either by themselves alone, with assistance from their relatives or by employing the services available at their workplaces or in their respective home environments. Their narratives, however, mirror gendered reflections and lived precariousness.

\section{Under pressure: workloads, working hours and home}

Non-standard and/or never-ending - work schedules, which can be, as argued by Fagnani and Letablier (2009) also perceived as a dimension of precarious employment, were a universal reality of the interviewees. Irrespective of their gender, marital status, academic position or department (STEM, SSH), they believe that, in the context of an increasing pursuit of scientific excellence and intensified competition in academic worlds, standard full-time or part-time working hours are a formality only. They are convinced that research and teaching or both cannot be caught or framed in a standard time schedule. Their musings confirm the formulae according to which you are paid for a certain number of working hours, but you work until tasks are done. Moreover, academic labour is 'always in your head', which the majority of interviewees describe as a constant feeling of guilt because:

You can always do better, you can always publish more, [and] you can always do more research. And there is always a lot of work waiting. I find it difficult always feeling guilty, because I could always do more.

(IS, SSH, F, assistant professor) 
Working on weekends, evenings, during the night, on vacation, on maternity leave, even on sick leave is a common practice of interviewees because they are 'doing science', and science demands 'a total investment'.

I start working at around 7:00 and carry on until I'm hungry ... it may be 14:00, 16:00 or 20:00. In this tour de force, I frequently lose track of time, I work so much and I don't even notice it.

(IT, SSH, F, postdoc)

Moreover, working outside regular working hours because of increased workload is taken for granted.

This is not work in which you feel that you stop after the end of the day. One never really stops. There is not really a clear limit between work at work and work at home.

(BE, STEM, F, assistant professor)

It seems that the majority has internalised such expectations as an inherent imperative of doing an academic job.

There certainly is something wrong with the pressure people put on themselves. And a sort of unspoken 'you have to work hard'. Nobody looks at you strangely when you say all you did was work. Then it's like: 'Everybody does that'. Everybody has the feeling that this is the only way to survive.

(NL, STEM, M, postdoc)

I feel that work is always there, especially with email and Facebook, all the little Facebook chat groups they have for the school here. And I might be on Sunday morning on Facebook, and a question pops up, and I can't even have THAT to myself. I might be sending my sister a TED talk that I find interesting and suddenly I'll have a student yelling at me, like 'I don't understand!!' and I'm like - it's Sunday morning, I'm wearing pyjamas ... LEAVE ME ALONE.

(IS, SSH, F, assistant professor)

The intensified rhythm of work and the pressure to perform several tasks are understood as rarely allowing free or leisure time. It is not surprising that numerous interviewees from all countries and of both genders mentioned health difficulties and poor wellbeing, as they were conscious that 'doing science' under the pressure of constantly producing competitive results and neglecting leisure often led to health difficulties and illness:

When I came to the Institute, I worked whole days for the first two and a half years. I worked in my office and then I would go home and continue 
working. I got terrible health problems with my intestines and digestion. I also did not have a quality relationship with my partner. If I don't have a quality relationship, I also cannot work well.

(SI, SSH, F, postdoc)

It seems that a majority of them sacrificed their wellbeing because they were ardent about science, as the following interviewee argues.

I had some problems last year and the doctor suggested that I find time for myself to go into the mountains and do some sports. I take time for myself during the weekend, but just one day because now I'm fully devoted to research.

(IT, STEM, F, assistant professor)

Discussing the nexus of overwork, paid work and poor wellbeing, the most critical tones come from postdoctoral researchers with part-time employment. They believe that a part-time job in science means lower payment for a full-time job, since doing science is never finished. Part-time employment was even recognised as a farce enabling exploitation by superiors, "an excuse for paying us less", or "an excuse for making our contracts temporary" ( $\mathrm{CH}$, STEM, F, postdoc).

Accounts about workload and long working hours are far from being uniform. Indeed, the majority of interviewees do experience academic overwork as constant tension and anxiety resulting in poor wellbeing. Yet in certain contexts, workload can be experienced as a positive incentive for work-life balance, particularly when intensive work brings satisfaction.

I mean, you are always under pressure, and I work, I really work a lot [yeah] and, but, I'm only doing this because I love to do it and, hmm, I know that I work much more than other people, hmm, working in a company for example [yeah, yeah], so I definitely don't have a 9-to-5 job or anything, and I, but you know if the work atmosphere is ... is great, hmm, there's nothing to complain about.

(CH, STEM, M, assistant professor)

I can survive the first three days on vacation without work, but then I have to do something. Not because I have to, but because I like to, this brings me joy. [...] To have time to read on vacation.

(SI, STEM, M, assistant professor)

I have to admit that somehow this work is also my passion. It is because it interests me far beyond just doing a job. And that is exactly why it is so dangerous.

(IS, STEM, assistant professor)

Some newly tenured early career researchers acknowledged that more intense working periods are usually followed by less demanding ones. However, in the 
context of several successive or prolonged temporary working contracts, they uniformly recognised their doctoral and postdoctoral stages as the most workintensive and anxious time in their academic career. The typical story of an assistant professor conveys how she was always enthusiastic about research, but that during her postdoctoral period, the uncertainty that it brought made her feel as if there was a stopper to her other life projects. The position of a permanent researcher was a relief, although this position did not coincide with a reduction of stress linked to her work (BE, SSH, F, assistant professor).

In spite of all that, the majority of female and male interviewees, irrespective of their early or tenured academic position and department (STEM, SSH), are aware that the academic profession is a way of life and an unceasing activity that influences their personal lives; but in line with the findings of Currie and colleagues (2000), there were also significant sacrifices related to the added demands of work and private lives. Notwithstanding their emphasised passion and devotion to academic work, which after all they chose themselves; all the interviewees - single, those in partnership and parents - see work-life balance as a difficult and challenging endeavour.

\section{How single women and men reconcile work and private life}

In general, early career interviewees without partners or children were not well informed about the repertoire of policies and measures related to work-life balance at their institutions. The majority understood and linked such measures to work-family policies that generally aimed to reproduce the national legislation on achieving work-family reconciliation. However, they listed flexible working hours and working from home as the measures that currently affected their lives the most. Therefore, they discussed the reconciliation of work and life through the discourse about workload, flexible working hours, uncertainty of temporary jobs, delaying parenthood and their passion for doing academic work.

Compared with the interviewees in partnerships or who were parents, the majority of single, early career women and men did not complain openly about the lack of reconciliation of their work and personal lives. However, their descriptions of distress because of workload at the expense of their leisure time support the observation that reconciling work and life is a demanding effort for them, as well. Without exception, they all reported feelings of guilt because of inconclusive work, the feeling that there was always more to do and that they never really took a break. The lack of a clear boundary between work and private life puts them under stress all the time, and they get very tired because "you finish preparing your classes at 3 a.m." (CH, SSH, F, postdoc). There are early career researchers for whom a lifestyle of overwork in a highly demanding but unstable job that requires a lot of mobility is not suitable, particularly when it "slows down [their] own personal development in terms of finding a partner and having children" (BE, STEM, F, postdoc).

Coping with workload, meeting short deadlines and a feeling of never-ending work is reality for both single men and women in academia. However, women 
reported poor wellbeing due to tiredness and constant stress to a greater extent. This applies particularly to women employed in STEM departments, who perceive their workplace as more stressful and rivalrous than men do. Some reported the need to be 'visible' at the workplace because "it was important that [men] colleagues knew that they were working" (IT, STEM, F, postdoc), even though their contract did not require working at the university.

Talk about the flexibility of working hours scheduling and working from home - i.e. the work-life balance policy in all the studied institutions - conveys a somewhat ambivalent message: on the one hand, this policy was understood as a promoter of wellbeing and work-life balance, while on the other hand, it was seen as an accelerator of a 'ruined private life'. To illustrate:

I got very used to a flexible work regime, and if someone would 'put me into a box', I would really feel miserable. I also believe I am more efficient this way.

(SI, STEM, M, assistant professor)

I think [early career researchers in this field] have a hard choice to make. If they want to have a position in academia, if they want to stay, they will risk that their private life is ruined.

(NL, SSH, M, postdoc)

Among the single interviewees, the most critical observations about unfavourable and uncertain positions with a poor work-life balance and poor wellbeing came from postdoctoral researchers. In general, the majority of postdoctoral researchers described this period of intense working requirements (conducting research, project writing and publishing), numerous short-term contracts and frequently changing institutions either in their own country or abroad as a stressful, unstable moment in their career trajectory, in which they sacrificed their personal lives and had difficulties planning a family. In countries where the postdoctoral status is not a fellowship but fixed-term employment, postdoctoral researchers are employees with temporary contracts. In some countries (e.g. Italy), this status is not considered proper employment and does not provide access to social security, economic supports or other benefits (e.g. funds for attending scientific conferences, guest visits abroad, reimbursed travel expenses to the workplace etc.) that are available to other employees of the university. One postdoctoral fellow reflected on the ambiguity of such work contracts:

You don't have duties and rights [...] a postdoc does not have rights to sick leave and holidays, and the possibility to stay at home is like a favour granted by your supervisor.

(IT, STEM, F, postdoc)

Female postdoctoral researchers interviewed during this research stress in particular the issue of delaying parenthood because of demanding academic work. 
Being aware that the postdoctoral period, when you have to prove yourself as the appropriate person to fulfil academic demands, corresponds with the approach of the deadline of their 'biological clock'; they found themselves in the dilemma of how to have both a career and a family 'on time'. Women without a stable job understood postponement of motherhood as a necessary investment in the path to a more stable job. Illustrative in this respect are the cases of a single, female STEM postdoctoral interviewees, such as interviewed postdoc from Belgium, who described her unstable and mostly mobile lifestyle as not very suitable for finding a partner and having children, or another female STEM postdoctoral researcher from Iceland, who perceives that being there for her family as a researcher would be an arduous task. In other cases, female postdoctoral researchers cannot even imagine how to harmonise their job with motherhood.

Yeah it's ... it's crazy! And so, but at the same time I mean it's, uh, enough work that is necessary, so my work-life is really bad right now, yeah, yeah. I go home and I ... I sleep [...] if I was to have children it would really be unsus-unsustainable, I would either have to find a job which was more [?] or stop doing the thing I care about.

(CH, STEM, F, postdoc)

Finally, there were more than a few single women and men who, reflecting on their commitment to academic work, realised that their passion for doing science and teaching at the expense of free time was 'abused', since they were expected to be grateful just because they work in academia.

You should be so grateful that you have work, and that you work at such a great institution, and if you complain about the work you need to do - that is just because you are investing in the future, and even though you need to work a lot, it's just a part of the life of an academic - if you want to be an artist, you have to starve first.

(IS, SSH, M, assistant professor)

Despite the revealed passion for doing science and teaching, narratives of early career single men and women show that work-life balance is not easy. Irrespective of different national and institutional contexts, flexible working hours and working from home remain the main recognised work-life measures; however, they are explained as both a supporter and a rival of work-life balance. The experience of distress and poor wellbeing because of expected academic overwork is reported mainly by single women from STEM departments and postdoctoral researchers who seek to harmonise their intense work requirements and insecure temporary contracts with their personal lives. As Carreri (2015), for example, found in her study of professionals in Italy, precarious work positions undoubtedly negatively influence the health and wellbeing of both individuals and families. Health difficulties and postponed parenthood seem to be a necessary investment on the path to a more stable job for early career researchers, 
particularly women whose 'biological clock' parallels the most demanding and precarious period in their academic trajectory. This finding is quite consistent with the findings of one of the most important and largely quoted studies in this area, the large-scale 'Do babies matter?' studies that compared male and female academics in the USA. The study found that women who had children within five years of receiving their $\mathrm{PhD}$ were less likely to have tenure than either men or women who delayed childbirth or did not have children (Mason and Goulden 2004b; Mason and Goulden 2002 in Wolfinger et al. 2008). The authors of the study (Mason and Goulden 2004b) even conclude that women have changed their family formation patterns to pursue the elusive goal of workplace equality.

\section{How couples without children reconcile work and private life}

Talking about harmonising of work and life, early career women and men in partnerships without children referred mostly to work-time flexibility and working from home, wider support from partners or their families, dual careers and family planning. Nearly all couples viewed work-time flexibility and working from home ambivalently: as a support for and as a barrier to reconciling work and life. In accordance with the findings of Rafnsdóttir and Heijstra (2013), who examined work-life balance in relation to the organisation of time, flexibility was found to be a double-edged sword, as the ability to work whenever and wherever is found to be both a freedom and a constraint on their personal and/or family lives. A flexible working schedule enables interviewees to immerse themselves completely in work, while at the same time it erases the clear boundary between work and home, increasing the feeling of guilt - more often mentioned by women.

I am often driven to despair because of a never-ending job - writing articles. There are moments when this pressure of writing really affects my wellbeing at home. I feel bad. Fortunately, my boyfriend understands this, and he tries to cheer me up that this is not the end of the world.

(SI, STEM, F, postdoc)

I take everything seriously, so I'm easily stressed. So it's not easy to have a balance between work life and social life, even without a baby, even now. It's not easy. So my boyfriend is always complaining; he's trying to get used to it, but he's really had a problem accepting this.

(IT, STEM, F, postdoc)

The social networks of couples and especially support from their families of origin proved to be an important dimension in coping with their working requirements. Yet in some cases, (e.g. the Italian case), women from STEM did not get satisfactory support for their professional choice either from their partners or from both families of origin, who wanted them to be more concerned with parenting. 
Planning a family proved to be an issue of anxiety in dual-career planning, as well. The majority of women have partners with high-intensity and high-profile professions and jobs within or outside of academia. Some of them reported that they were satisfied with their professional and private lives, although they spent relatively little time together during evenings and at weekends. Further discussion, however, revealed that reflecting upon parenthood changed their current satisfaction. Again, more women than men reflected on motherhood as an obstacle to achieving a more stable job in their academic trajectory, as shown by an interviewee in Belgium, who wanted to start a family once she had a certain stability and "greater freedom" during her career (BE, STEM, F, postdoc). More women than men expressed concern about parenthood in dual-career reconciliation, as well.

It can be a serious drawback for starting a family. But I love my work and he also loves his work. So there are some kinds of compromises. It is not a pleasant thing.

(NL, STEM, F, postdoc)

If I'm going to have a family, then I'm going to be there for my family. But if you look at the examples of women [in academia] who have been able to have kids, [been on] maternity leave, then you start giving up a little bit in relation to this project.

(IS, STEM, F, postdoc)

Flexibility in terms of moving abroad and combining a career with other responsibilities was key in postdoctoral researchers, especially in countries where going abroad is required practice after doctoral study (e.g. Switzerland). Not surprisingly, such a practice demands a lot of compromises between partners to find "the best match of places and projects" (CH, STEM, F, postdoc).

Female postdoctoral researchers from abroad were additionally concerned because they could not rely on their families' or friends' assistance and were often financially completely dependent on their partners. Those who live in countries where women are employed part-time because of a lack of institutional childcare (e.g. Switzerland and the Netherlands) plan to take part-time jobs if they become mothers. Yet at the same time, they are aware that such a decision is very risky in terms of 'worsening' their career path.

Dual-career planning seems easier for men than women, and men expressed more optimism about family planning, as well. The majority of them have female partners with unstable working contracts ( $\mathrm{PhD}$ status), and while most of them live alone abroad, they expect their partners with uncertain jobs to join them. Interestingly, some men spoke openly about precariousness and unstable postdoctoral careers as a 'normal and expected' part of their trajectories. Moreover, in spite of being in a partnership, most of the men understood short-term postdoctoral projects as an advantage that enabled them to travel and obtain the valuable experience of temporarily living abroad, as shown by a Belgian postdoc, who was 
optimistic about family planning under such conditions, saying that "work should be accommodated to make this possible" (BE, STEM, M, postdoc).

Women's discourses about the precarious postdoctoral period and the demanding balance of dual careers differ greatly from men's musings. The majority of women debated motherhood as a hindrance to career promotion with great concern because they expected difficulties in reconciling their work and life. The most worried were, once more, those who could not rely on their relatives' assistance because of geographical distance from their homes - as if they were aware that the home remained a field of their work.

Internalised caring activities as a domain of women's work find an echo in the interviewees of early career women and men in partnerships, whether from STEM or SSH departments. Especially when discussing family planning, women from both academic fields believe that parenthood would limit their professional activity and decrease the professional engagement necessary for career advancement. Women openly expressed concern and a feeling of guilt in reconciling the demanding requirements at work and at home, as if they were aware that this was their condition - 'a fact of life'. In contrast - with the exception of Iceland men were optimistic about their work-life balance, even in the most precarious postdoctoral period; they admitted that parenthood could limit their professional career and expressed concerns in this regard, but they mainly did not question their career itself, and their reflections did not express such a feeling of guilt if parenthood was their 'choice' in the future. The same applies to the harmonisation of dual-career planning, either at home or abroad. Men in partnerships generally did not express such anxiety when faced with 'living at distance', but "you have to accept that if you want a job, you cannot live together with your partner" (NL, SSH, M, assistant professor). Finally, the expected and internalised gendered division of labour at home is mirrored in the discourses about wider family support for early career researchers, whether they worked in their home countries or abroad. Again, research recognised women as those who should be more concerned with domestic activities to reconcile work-life balance, which was clearly noticed in their emphasised distress and unease when remaining without any support from a partner or close relatives.

\section{How parents reconcile work and life}

Interviewees who are parents discussed work-life balance in terms of their experience of parenthood and practicing measures and organisational policies provided by their institution. As with the single interviewees and those in partnership, parents - irrespective of their gender, academic position and department (SSH or STEM) - reported feeling distress because of overwork in academia. However, only mothers conveyed the same feeling about home commitments; they suffered because they felt they should devote more attention to their children. Therefore, mothers' interviews convey that reconciling home and work through flexible working hours is indeed a hardship, while fathers' discourses give the impression that they more easily manage work and home. Fathers 
discussed above all the 'difficult' reconciliation in terms of reorganising their working schedule at the workplace and home to meet academic tasks.

I have children, but in fact I can be with them a lot of the time because I can easily work at home.

(CH, STEM, M, assistant professor)

My son is turning four years old, so what happens is that I take him to the kindergarten in the morning and I come here. Then after lunch I can normally stay even until 3 p.m. I pick him up from school at 4:30 p.m. and then I go home with him for the rest of the afternoon. This is how I take care of both the children and the work, at home; this is what they call - in America - the supermom or superdad. My wife works but she has this time off work. I do think I have a good balance, because my family doesn't complain much that I'm not there for them or whatever. I try to play, I try to read, I try to do activities with my son and with my family in general. So yes, up to now - at least - I don't have any complaints.

(IT, STEM, M, assistant professor)

However, as in the Icelandic case, male academics generally underlined the difficulties of being a parent and an academic at the same time. As an example, one participant mentioned that he had got better at structuring his workday after he had children, and this was because he knew he had to leave in the afternoon to pick them up from school.

In the other higher education institutions under study, fathers mainly use the flexibility of their work schedule and working from home to be efficient in their academic working career; they do not view work flexibility as a tool primarily for work-life balance, but for additional academic work at home. On the whole, fathers who take parental leave are rare, and even rarer are those fathers who take paternity leave (i.e. leave allocated to the father only, which cannot be shared with the mother). In such circumstances, it sounds very odd if a working organisation refuses parental leave to a father.

As a woman, everybody has seen it, you are having a baby. As a man, you just go back to work, and you have a baby, and you have cake and then you continue [working].

(NL, STEM, M, postdoc)

The majority of mothers subordinated their free time entirely to commitments to their children; this was not the case with fathers.

We might both be at home, and I have to be playing with my son or attending to him constantly, but his father can, you know, be on the couch and read a book for some time.

(IS, STEM, F, postdoc) 
I adjust my spare time to my children. It is definitely not what I want, but this is the only possible option at the moment, and I am trying to organise things so they suit me. While I am waiting for the kids at music school, I go for a walk.

(SI, SSH, F, assistant professor)

Moreover, the mothers and not the fathers reduced or suspended their academic work after the child's birth. Numerous mothers were even convinced that worklife balance was impossible; insisting that to be a good mother and a good academic at the same time brought psychological burdens and a double feeling of guilt.

I want to spend a lot of time with my daughter, but I also have to work, because otherwise I am not competitive.

(NL, STEM, F, postdoc)

There are so many constraints in all directions, plus the fact that at family level, there's an enormous sacrifice because I'm abandoning my little daughter four days a week and incidentally my partner is doing the same. [...] Basically, I slog from 6:30 a.m. to 9p.m. They are very, very long days and I, I ... It's terribly difficult to be efficient, that's the fact of it. Yeah, I don't know how much longer I can keep going.

(CH, STEM, F, postdoc)

Troubles reconciling work and life were again stressed by foreign postdoctoral researchers - this time mothers. Particularly concerned were those among them who did not have access to a support system in the host country and at the same time could not rely on assistance from their families of origin or from partners who live in another country.

Besides the necessary support from a wider kin network for work-life balance, all mothers stressed the importance of their partners' comprehension of dual-career planning for successful work-life balance. Divorced mothers in particular complained about misunderstandings about this, since their partners' careers were understood as a priority, while mothers were expected to give primacy to motherhood and not a career.

Yes, it is very difficult. I must say that my work suffers. I had quite significant problems with my ex-partner, who is also employed at the university, to get him to understand, although he is an intellectual. We had a sort of a class struggle. One of the reasons we broke up is that he perceives himself as the one having priority. And he feels it is supposedly natural, as I am the one who wanted to have children. He did not actually say it, but in the end, he is the guy who, in addition to other problems, cannot understand a woman having a career or spending more time on something outside the family than he does. That was one of the biggest minuses. Then, I was left 
alone and it was almost impossible because in those eight hours I had to do everything, not only in terms of job obligations, but also everything you cannot manage while you are with children.

(SI, SSH, F, postdoc)

In most cases, the STEM environment proved not to be mother-friendly across the studied institutions. There were more than a few mothers who resorted to the culture of silence, not speaking openly about motherhood, to avoid risking their academic promotion. In the Belgian case, for instance, some newly tenured STEM women spoke about the difficulty of taking parental leave or any kind of leave. It is worth mentioning that, despite the contextual differences, in different countries maternity seemed to be perceived as a taboo topic, especially in the working environment of mainly male colleagues. In particular, young women were overtly advised that pregnancy was not expected during their thesis writing or before they had any published articles. Young mothers were advised by their supervisors to arrange for a nanny and cleaner to be able to work more or were reminded that 'the child also has a father' when their children fell ill. It seems that supervisors 'ignoring' motherhood and pregnancy was quite common practice in STEM departments.

During my pregnancy I ... had a lot of workload and was not coping, and I kind of broke down and I was saying that I was having too much work and it was not taken seriously [by the supervisor].

(IS, STEM, F, assistant professor)

Childbirth renders international mobility a challenge for parents, whether it be shorter trips for conferences or longer research visits. In the majority of cases, neither mothers nor fathers reject requirements for mobility, particularly in the period of their postdoctoral job, when mobility is an imperative for career promotion. However, mothers travel less after the child's birth, and when they decide to go abroad, as a rule mothers take care of their children along with doing academic work. For instance, some newly tenured SSH women from Belgium spoke about difficulties related to childcare. In rare cases, partners were present to take care of children, but usually it was the amount of their scholarship that led to an easier or more difficult family life in the host country. Fathers also reported feelings of regret and uncertainty in close relationships, particularly with partners, when they decided to move. For instance, Swiss fathers who had partners with comparable academic status described this moment as an effort to "keep our tracks together" (STEM, postdoc), "a dual project" (STEM, postdoc), or in which "there's no question of one career having the upper hand over the other" (STEM, assistant professor).

The last theme that parents explicitly associated with work-life balance was childcare services. Irrespective of the availability of or access to public and private kindergartens or other forms of childcare services provided by the department in different national contexts, the nearest kindergarten to parents' residence 
and support from grandparents were among the most frequent practices that enabled parents to reconcile work and family. Such a support system is most welcome in countries where both private and public institutions for childcare are very expensive and finding a place is considered a real fluke. Moreover, for foreigners, the lack of institutional childcare can be very frustrating since "the childcare problem smacks you in the face [...] it isn't complicated, it's complicated beyond belief" (CH, STEM, F, postdoc).

Once again temporarily employed postdoctoral parents found themselves in more challenging circumstances. This is not only because they have to prove themselves in this period in order to secure their position in academia by acceding to the mandatory or recommended international mobility. In certain environments, they are excluded from the system of work-life provisions and services because of their fellowship status. This is the case for postdoctoral fellows from Italy. Italian universities offer services such as nurseries and babysitting to promote the balance between family and work for parents - but only for employees. Therefore, the only male postdoctoral fellow interviewed who had a child could not use this service because of the rigid selection criteria, which disadvantaged parents without a tenure position. It is then not surprising that assistance from grandparents, in the Italian case, was reported as indispensable for meeting work and home commitments, not only for postdoctoral parents, but for the majority of interviewees.

I am lucky to have my parents living close by. This is a great help. There are times when I have so many things to do, and I can't concentrate fully with the children at home. If I panic in dealing with the children, my father is retired and I can call him without any problems. In fact, he's very happy to spend time with them, and so I'm able to work.

(IT, $\mathrm{SSH}, \mathrm{F}$, assistant professor)

The narratives of the interviewed parents also show some differences in terms of their working department (STEM, SSH) and their academic status (postdoctoral or newly tenured). Despite commonly introduced work-life measures in the form of flexible work hours and working from home, these measures are practiced more easily in the SSH than in the STEM environment; the (laboratory) equipment necessary for work usually prevents male and female researchers from working from home, which affects their work-life balance. Some STEM settings are still predominantly 'male', which renders discussions about starting a family difficult, especially for early career women who have to prove themselves to be on a par with men. In some cases (e.g. the Italian case), early career women do not receive satisfactory support from their partners or wider family for their professional decisions because of still-entrenched gender prejudices about the 'proper' division of labour, in comparison with their male colleagues and early career researchers and academics from their SSH department. In general, the STEM environment requires mobility from early career researchers; therefore, proper support configurations are necessary to achieve work-life balance in terms of defined priorities between 
parents or a 'flexible partner' who works part-time or does not seek employment. The latter practices, however, are predominantly those of women and mothers, who are still recognised as more 'appropriate' or 'natural caretakers'.

The postdoctoral period in one's academic path is more uncertain and demands more total personal involvement at the expense of private life in pursuit of a more stable job than a newly tenured one does. Despite intense overwork and fixed-term contracts, assistant professors still enjoy greater autonomy in their work setting and are granted more social rights (e.g. paternity leave, pension, access to institutional childcare) as 'proper' employees than are postdoctoral researchers, especially those who, as grant fellows, are excluded from social provisions and other research benefits (e.g. funds for scientific conferences). Finally, postdoctoral researchers who are mothers risk greater 'setbacks' in their publication record and careers than assistant professors because they take maternity leave and shoulder most of the responsibilities for raising children in the period when they have to prove themselves worthy to continue in academia.

\section{Needs for improving work and life and imagining the future}

In general, the interviewees believe that job uncertainty and increasing competition for scientific excellence will remain the reality of academia in the near future. However, they are aware that such circumstances produce their feelings of anxiety, fear and discomfort. Nevertheless, the majority of them will take the risk and continue their career path, whether they are at its very beginning or already tenured, whether they are single or in partnership and whether they are with or without children. Such an apparent paradox cannot be explained except by their passion and devotion for science and teaching, which are early career researchers' main motivations to persist in the academic world, which as a rule 'ignores' their personal lives. Who, if not a passionate researcher, was determined to render possible both a family and an academic career?

I wake up at, eh, sometimes at 6a.m. sometimes at 5:30a.m. ... I have [x number of children] and I can only work until 4 p.m. three days a week so to compensate for that, I have to just wake up a little bit early, just to, you know, read and be up to speed with what I'm going to do during the day and we all get up at 7:15 a.m. and we're out on the road at 8:00a.m., but I drop my [children] off at school ... at 7:50 a.m. for me to be able to make it to class at 8:20 a.m. when I have to be ... and then I simply ... it's a mixture of preparing for classes, to do the lecturing, interact with students, eh, interact with the department, eh, go to department meetings, quorums, eh, and I also [name of side occupation] that's like an added 25 per cent job, so I have to do that either in the morning, in the evening or during the weekend.

(IS, SSH, F, postdoc)

Unfortunately, in a very competitive academia, this passion is abused rather than used. This bold observation is proved either by the interviewees' readiness 
to work beyond official hours and be less paid for overtime or by their complaining 'behind closed doors', since in no country did the interviewees mention any particular engagement in actions to improve their working conditions and salaries.

Interviewees across all national contexts are quite conscious that available work-life balance measures and services cannot automatically resolve their distress caused and conditioned by the very nature of academic work in the context of intensified competition, pressure to achieve scientific excellence and underfunded public research and teaching. However, they believe that all measures and services introduced to promote work-life balance can indeed mitigate their own burdens. Along this line, they proposed and suggested several improvements, irrespective of whether their institutions anticipated and planned such measures in strategies for and documents about the promotion of gender equality. Worth mentioning is the voiced need to provide equal access to social provisions (e.g. paternity and parental leave), retirement rights and economic benefits to all who work in higher education institutions, irrespective of the type of their working contract (temporary, fixed-term or permanent). According to this proposal, postdoctoral researchers would be understood as having proper employment and not a grant (as in Italian case), which would alleviate their precarious position. Further, the interviewees proposed compensation for maternity leave and underscored the need to consider time spent on maternity leave when deciding on promotion or evaluating a project or grant. In general, the majority of them strove to shift the evaluation of scientific excellence from the sole criterion of publication, which as a rule did not consider time spent on caring responsibilities. Moreover, female interviewees from Slovenia, where the national research agency already excludes time spent on maternity or parental leave from evaluation procedures, warned against ignoring that childcare and care for those in need was almost always women's activity. In this respect, almost universal agreement about persistent gendered caring responsibilities was observed across the different national contexts.

In countries with unfavourable childcare systems, the research participants voiced the need to equalise the criteria for institutional arrangements for all the employees, irrespective of their type of working contract (cf. cases from Italy, Switzerland and the Netherlands). Despite the voiced critique of part-time work, which serves to domesticate women, rather than to promote gender equality in reconciling work and family, some female researchers suggested that in a tenure system this type of job was still necessary assistance for work-life balance (cf. the case of the Netherlands).

Finally, the needs and suggestions voiced by female and male interviewees prove that work pressure and uncertain jobs are not choices made by individuals themselves, but difficulties that are deeply entrenched in the very nature of the contemporary academic system. Therefore, it might be necessary to rethink the entire academic career system because "it is difficult to live in precarious conditions until the age of 45", and "it's unfair to be considered eternal interns" (IT, SSH, F, postdocs). 
It is hoped that presenting such feelings and talk about work-life balance can be a basis for a deeper reflection on this topic in ways that could lead to reforming national academic environments that continue to limit the possibilities for work-life balance.

\section{Discussion and conclusions}

Interviews with research participants have demonstrated that more-or-less supportive work-life balance policy measures, services and caring infrastructures do not automatically improve or hinder work-life balance experiences in academic environments. On the contrary, whether legislation and infrastructure are supportive or not, the countries studied within the GARCIA project share increasingly demanding, competitive and uncertain academic realities. Assumptions about the 'ideal worker', including a full-time, all-encompassing devotion to academia and a strong vertical segregation of women's academic careers, still prevail in institutionally different national contexts. Such is also the predominant working environment of early career researchers - prospective academics whether they are single, partners without children or parents. In most cases, this period corresponds with partnership and/or family formation and with young people's efforts at the beginning of their academic careers to maintain and secure their positions in academic worlds. For this reason, it is not surprising that individuals communicate similar experiences of more and less successful work-life balance, despite different gender, employment and care regimes. Also, in what could be called 'work-life balance enabling and progressive' (Seierstad and Kirton 2015) national regimes (for instance Iceland and Slovenia), it was quite obvious that everyday household tasks and parenting responsibilities were still unequally divided between male and female researchers. This demonstrated that the work-life balance issue does not depend solely on the availability of affordable childcare, but, as Duncan and colleagues (2003) observe, is also linked to "gendered moral rationalities" that constitute right and proper behaviour for persons of different genders.

Additionally, the importance of the organisational context (e.g. support for parents in the workplace, workplace culture), and not only the existence of formal national-level policies, needs to be taken into account (Smithson et al. 2012). It seems that research participants perceive organisational and nationallevel policies as facilitating their work-life balance. However, the extent to which such policies actually challenge the existing gendered assumptions about the division of work both in the public and in the private sphere and the ideology of separate work and private lives remains unexplored.

The most general finding of the cross-cutting comparison is that work-life balance is perceived as a problematic endeavour both for early career researchers, who balance paid work and other areas of their lives more or less successfully, and for those who left academia - who are more thoroughly analysed in the next chapter - and who experienced academic work as largely incompatible with other spheres of life. 
Discourses about work-life balance were far from unambiguous. Research participants, regardless of the type of employment contract, almost universally described an increased workload that cannot be accomplished in the usual working time, which can heighten feelings of guilt due to work never being finished. In this respect, general flexibility of working times and location of the academic profession was viewed as a facilitator of work-life balance, on the one hand, while, on the other hand, the interviewees described the pervasiveness of work in their private lives, which they generally viewed as detrimental to their wellbeing and health. As Girard (2010) observed in his study of the effects of non-standard work on work-family balance, there is a difference between the flexibility required of workers and the flexibility that is designed for workers in different working and family circumstances. The interviews also demonstrate that increased work pressure and employment insecurity cannot be perceived solely as individual choices. The interviewees, regardless of their gender and current employment status, emphasised that the postdoctoral period is the most stressful due to the instability of successive fixed-term and part-time job arrangements and frequent changes of employment institutions, both in their original country and abroad. Female postdoctoral researchers, in particular, generally resort to the strategy of postponing motherhood, which they cannot afford in such insecure employment circumstances. As Mason and Goulden (2004b, p. 14) have argued, "in focusing on professional outcomes as the measure of gender equality, we have failed to notice the widening gap between men and women in forming the families they want, as measured by marriage and children".

Once again, it cannot be an individual choice that precarious postdoctoral researchers are sometimes treated as scholarship holders who are not afforded the same level of social security rights as other employees in the academic environment. Once more, it is a structural issue if mostly women from STEM and to a lesser degree from SSH institutions perceive the academic environment as discriminatory in terms of their ability to have children. The instability and precariousness of their academic work further exacerbate such feelings. The musings of mainly female postdoctoral researchers about resorting to part-time employment when becoming mothers, and the practices of female academics with insecure employment contracts following their partner or husbands abroad, cannot be viewed as merely individual choices, either. Nor can gendered expectations of family obligations and realities, the on-going disparity with which women take on a second shift in family life, their experiences of workload at home and at work and their consequent feelings of guilt and tiredness be perceived as individual choices. Furthermore, it is mainly women who use parental leave, while men are still less likely to use either paternal or parental leave, even in countries where it is formally available to them. To conclude with Lewis and colleagues (2007, p. 11):

[The] 'choice' assumption implicit in the work-life balance discourse neglects not only the gendered contexts in which individuals and household 'choices' are produced and the profound effects on persistent gendered 
assumptions at workplaces, but also the changing nature of work, workloads and employer/manager practices and strategies that constrain choice.

It is no coincidence that such discourses that do not adequately address "highly gendered patterns of living and working" (Smithson and Stokoe 2005) resonate well with the neoliberal ideology of maximising the individual employment and personal choices of supposedly rational and free individuals (McDowell 2004; Gill 2009). As Hawkins and colleagues (2014, p. 340) remind us, those "unable to fulfil and succeed within academia are delegitimised by neoliberal narratives instead of being testimonies for the need of structural and institutional changes towards a more just academia”. Along this line, the narratives of research participants who described the difficulties of achieving work-life balance have to be read not simply as manifesting an inability to cope with the increasing demands of contemporary academic work, but rather as symptomatic of the need for structural change not only in academia, but also in the family as one of the main social institutions.

Female and male early career researchers' determination to continue with academic work despite its insecurity and difficult circumstances could be interpreted also as a result of their passion for academic work - a passion that seems to be abused all too often and not often articulated as class consciousness of people in academia. In this sense, Bozzon and colleagues (2017) speak of the need for the active citizenship of employees in academia, who need to be perceived as subjects engaged in complex relationships of work, affect, caring and leisure. Examples of such resistance to the increasingly oppressive academic environments could be more community engagement, participation in trade unions, critical self-reflection, activism and acknowledging intersectionality (Gill 2009; Hawkins et al. 2014; Isgro and Castañeda 2015). Particularly in increasingly precarious research environments, such a collective engagement and solidarity against existing practices in order to break the silence surrounding them seems of fundamental importance (Andersen 2008). While it is undoubtedly clear that both national- and organisational-level family-friendly policies facilitate work-life balance for women and men in all the analysed countries, our research material does not permit us to study in more detail the extent to which policies actually challenge the existing gender order and to which such policies can be perceived as primarily 'quick fixes' that leave the existing gender power relations intact. The discourse of balance, as Bloom (2015) has argued, could actually be leading to further work intensification as well as masking the highly managerial character of the contemporary workplace.

By situating existing gendered patterns in both working and family life in wider structural transformations that are occurring in all the countries under study, it seems that, despite particularities in different national care, welfare and employment regimes, all the countries share very similar academic realities characterised by increasing workloads, pressure to publish, the intensification of both research and administrative work and spill-over from working to private lives. Both women and men spoke about the hardships of stress, mental health issues 


\section{Sanja Cukut Krilić et al.}

and burnout under the auspices of neoliberalism, although the consequences of a work ethos leading to such issues, remain gendered (Currie et al. 2000). Gendered expectations and the realities of caring and other family responsibilities undoubtedly place female academics in more precarious positions than men. Not only are women more often found in insecure and precarious academic jobs, but due to the all-encompassing and socially expected devotion to the wellbeing of their families, they are particularly vulnerable to experiencing health problems when juggling the complex demands of both worlds. This calls in turn for a fundamental rethinking of current academic and family systems, despite various national- and organisational-level policies that have recently tackled also men's participation in family and caring responsibilities. As Garforth and Kerr (2009) have argued, the discourse about women in science often works to make female difference hyper-visible while masculine epistemic cultures and masculine linear career paths in science remain intact.

\section{Notes}

1 Drawing on reappraisals of Esping-Anderson's classification, it is worth mentioning that gender arrangements are also fundamental to the establishment and the functioning of different welfare state regimes (Lewis 1997; Naldini 2011). While his work did set out to consider the relation between work and welfare, he defined work as paid work and welfare as policies that permit, encourage or discourage the commodification of labour, while excluding the importance of unpaid work in the family that is largely performed by women. In this vein, gender can be perceived as a significant factor in the establishment of modern welfare state regimes (Lewis 1997).

2 However, in Belgium, one of the major publicly debated problems is the availability of affordable childcare centres for low-income groups (Le Feuvre 2015b), while in Slovenia, one of the issues is unsynchronised kindergarten and parental work schedules (Švab et al. in Le Feuvre 2015b). The gap between the parental leave and the pre-school period, which remains unresolved for lack of available facilities, was identified in Iceland (Haraldsdóttir in Le Feuvre 2015b; Ingólfsdóttir in Cukut Krilić and Rapetti 2015).

3 In several cases, it was difficult to identify users of work interruptions or leave, and such data were frequently inaccessible because of confidentiality and technical issues, as was the case for Italy and Iceland. In Belgium, the data on leave beneficiaries were obtained not for the number of days, but only the number of leaves taken only by nontenured researchers.

\section{References}

Andersen, G. (2008). Mapping academic resistance in the managerial university. Organization, 15(2), 251-270.

Arnalds, Á. A., Eydal, G. B. and Gíslason, I. V. (2013). Equal rights to paid parental leave and caring fathers - the case of Iceland. Iceland Review of Politics and Administration, 9(2), 323-344.

Baker, M. (2010). Choices or constraints? Family responsibilities, gender and academic career. Journal of Comparative Family Studies, 41(1), 1-18.

Barcelona European Council (2002). Presidency conclusions, 15-16 March 2002, document SN 100/1/02 REV 1. Available at: http://ec.europa.eu/invest-in-research/pdf/ download_en/barcelona_european_council.pdf [accessed: 21 May 2017]. 
Bell, A. S., Rajendran, D. and Theiler, S. (2012). Job stress, well-being, work-life balance and work-life conflict among Australian academics. Electronic Journal of Applied Psychology, 8(1), 25-37.

Bloom, P. (2015). Work as the contemporary limit of life: capitalism, the death-drive and the lethal fantasy of 'work-life balance'. Organization, 23(4), 588-606.

Bourdieu, P. and Wacquant, L. (1992). Invitation to Reflexive Sociology. Chicago, IL: University of Chicago Press.

Bozzon, R., Murgia, A., Poggio, B. and Rapetti, E. (2017). Work-life balance in the early academic career stages. The case of precarious researchers in Italy. European Educational Research Journal, 16(2-3), 332-351.

Cannizzo, F. and Osbaldiston, N. (2015). Academic work-life balance: a brief quantitative analysis of the Australian experience. Journal of Sociology, 52(4), 890-906.

Careless, E. J. (2012). Dueling clocks: mothers on the path to tenure. The Canadian Journal for the Study of Adult Education, 25(1), 31-46.

Carreri, A. (2015). Italian parents in precarious work: how normative beliefs affect social understandings of the work-family boundary. In S. K. Ammons and E. L. Kelly (eds), Work and Family in the New Economy, Research in the Sociology of Work, Volume 26, Bingley: Emerald, pp. 1-33.

Charlesworth, S., Baines, D. and Cunningham, I. (2015). 'If I had a family, there is no way that i could afford to work here': juggling paid and unpaid care work in social services. Gender, Work \& Organization, 22(6), 596-613.

Coser, L. A. (1974). Greedy Institutions: Patterns of Undivided Commitment. New York: The Free Press.

Cukut, S. (2007). Understanding fertility, work and family through a gender lens: a case study. Anthropological Notebooks, 13(2), 95-110.

Cukut Krilić, S. and Rapetti, E. (eds) (2015). Mapping organisational work-life policies and practices. Garcia Working Papers 4. University of Trento.

Currie, J. and Eveline, J. (2011). E-technology and work-life balance for academics with young children. Higher Education, 62(4), 533-550.

Currie, J., Harris, P. and Thiele, B. (2000). Sacrifices in greedy universities: are they gendered? Gender and Education, 12(3): 269-291.

Duncan, S., Edwards, R., Reynolds, T. and Alldred, P. (2003). Motherhood, paid work and partnering: values and theories. Work, Employment and Society, 17(2), 309-330.

Esping-Andersen, G. (1990). The Three Worlds of Welfare Capitalism. Cambridge: Polity Press.

European Union (2014). Use of Childcare in the EU Member States and Progress Towards the Barcelona Targets. Short Statistical Report No. 1 http://ec.europa.eu/ justice/gender-equality/files/documents/140502_gender_equality_workforce_ssr1_ en.pdf.

EUROSTAT (2017). Population and Social Conditions. http://ec.europa.eu/eurostat/data/ database.

EUROSTAT (2017). Fertility Statistics. http://ec.europa.eu/eurostat/statistics-explained/ index.php/Fertility_statistics.

EUROSTAT (2017). Formal Child Care by Duration and Age Group. http://ec.europa. eu/eurostat $/$ tgm $/$ refreshTableAction.do?tab=table\&plugin $=1 \&$ pcode $=$ tps $00185 \&$ language $=$ en.

Fagnani, J. and Letablier, M. T. (2009). Working paper - France: precariousness, gender and the challenges for labour market policy. http://libgwd.cns.yorku.ca/cpdworking papers/fagnani-letablier.pdf. 


\section{Sanja Cukut Krilić et al.}

Fothergill, A. and Feltey, K. (2004). 'I've worked very hard and slept very little': mothers on the tenure track in academia. Journal of the Association for Research on Mothering, $5(2), 7-18$.

Garforth, L. and Kerr, A. (2009). Women and science: what's the problem. Social Politics: International Studies in Gender, State and Society, 16(3), 379-403. Available at: https://doi.org/10.1093/sp/jxp015 [accessed: 19 December 2016].

Gender Equality in Iceland: Information on Gender Equality Issues in Iceland (2017). Available at: www.jafnretti.is/D10/_Files/Gender_Equality_in_Iceland_2017.pdf [accessed: 26 April 2018].

Gill, R. (2009). Breaking the silence: the hidden injuries of neo-liberal academia. In R. Flood and R. Gill (eds), Secrecy and Silence in the Research Process: Feminist Reflections. London: Routledge, pp. 228-244.

Girard, M. (2010). Effects of non-standard work on the work-family balance: a literature review. McGill Sociological Review, 1, 46-58.

Gregory, A. and Milner, S. (2009). Editorial - work-life balance: a matter of choice? Gender, Work \& Organization, 16(1): 1-13.

Hawkins, R., Manzi, M. and Ojeda, D. (2014). Lives in the making: power, academia and the everyday. ACME: An International Journal for Critical Geographies, 13(2), $328-351$.

Isgro, K. and Castañeda, M. (2015). Mothers in U.S. academia: insights from lived experiences. Women's Studies International Forum, 53, 174-181.

Knežević Hočevar, D. (2007). A diploma and children; having both. A case study. Anthropological Notebooks, 13(2), 73-94.

Krause, E. L. (2001). 'Empty cradles' and the quiet revolution: demographic discourse and cultural struggles of gender, race and class in Italy. Cultural Anthropology, 16(4), 576-611.

Le Feuvre, N. (2015a). Contextualizing women's academic careers in cross-national perspective. GARCIA Working Paper, 3. University of Trento.

Le Feuvre, N. (ed.) (2015b) Contextualizing women's academic careers: comparative perspectives on gender, care and employment regimes in seven European countries, GARCIA Working Paper, 1. University of Trento.

Lewis, R. A. (2016). Work-life balance in academia: experiences of lecturers in Switzerland. International Journal of Business and Management, 4(1), 69-84.

Lewis, S. (1997). Gender and welfare regimes: further thoughts. Social Politics, 4(2), 160-177.

Lewis, S., Gambles, R. and Rapoport, R. (2007). The constraints of a 'work-life balance' approach: an international perspective. The International Journal of Human Resource Management, 18(3), 360-373.

Mason, M. A. and Goulden, M. (2004a). Marriage and baby blues: redefining gender equity in the academia. The Annals of the American Academy, 596, 86-103.

Mason, M. A. and Goulden, M. (2004b). Do babies matter (part II)? Closing the baby gap, Academe, 90(6), 10-15.

McDaniel, S. A. (1996). Toward a synthesis of feminist and demographic perspectives on fertility. The Sociological Quarterly, 37(1), 83-104.

McDowell, L. (2004). Work, workfare, work/life balance and an ethic of care. Progress in Human Geography, 28(2), 145-163.

Naldini, M. (2011). Introduction: feminist views on social policy and gender equality. Sociologica, 1, 1-10.

OECD (2017). Family Database. www.oecd.org/social/family/database.htm. 
OECD (2017). Gender Equality. www.oecd.org/gender/data/length-of-maternity-leaveparental-leave-and-paid-father-specific-leave.htm.

Rafnsdóttir, G. L. and Heijstra, T. M. (2013). Balancing work-family life in academia: the power of time. Gender, Work and Organization, 20(3), 283-296.

Seierstad, C. and Kirton, G. (2015). Having it all? Women in high commitment careers and work-life balance in Norway. Gender, Work \& Organization, 22(4), 391-404.

Smidt, T. B., Pétursdóttir, G. M. and Einarsdóttir, P. (2017). How do you take time? Work-life balance policies versus neoliberal, social and cultural incentive mechanisms at the University of Iceland. European Educational Research Journal, 16(2-3), $123-140$.

Smithson, J. and Stokoe, E. (2005). Discourses of work-life balance: negotiating 'genderblind' terms in organizations. Gender, Work \& Organization, 12(2), 148-168.

Smithson, J., Lewis, S., Kovacheva, S., den Dulk, L., Peper, B. and van Doorne-Huiskes, A. (2012). Supports and constraints for parents: a gendered cross-national perspective. In A. Nilsen, J. Brannen and S. Lewis (eds), Transitions to Parenthood in Europe: A Comparative Life Course Perspective. Policy Press: Bristol, pp. 89-105.

Stropnik, Nada (2011). Exchange of good practices on gender equality: new forms of work. The Netherlands, 24-25 October 2011, Flexible working and gender equality: the case of Slovenia. In Exchange of Good Practice on 'New Forms of Work'. Brussels: European Commission.

UNECE (2017). Mean Age of Women at Birth of the First Child. http://w3.unece.org/ $\mathrm{PXWeb} / \mathrm{en} /$ Charts? IndicatorCode $=34 \&$ CountryCode $=578$.

Wolf-Wendel, L. and Ward, K. (2006). Academic life and motherhood: variations by institutional type. Higher Education, 52, 487-521.

Wolfinger, N. H., Mason, M. A. and Goulden, M. (2008). Problems in the pipeline: gender, marriage and fertility in the ivory tower. The Journal of Higher Education, 79(4), 388-405.

Ylijoki, O-H. (2013). Boundary-work between work and life in the high-speed university. Studies in Higher Education, 38(2), 242-255. 


\title{
6 A gendered pipeline typology in academia
}

\author{
Farah Dubois-Shaik, Bernard Fusulier and \\ Caroline Vincke
}

\section{Introduction}

Scientific and academic careers are currently not only characterised by a lengthy period of tertiary education (undergraduate, postgraduate and doctoral period), but also by a long period of professional instability, resulting in a permanent position, often late in the career. They are, furthermore, obtained after a heady competition between researchers guided by an assemblage of diverse quantitative and qualitative "excellence" evaluation criteria. Researchers are also required to manifest a "moral" engagement in their work, accepting long working hours and a real willingness to be geographically mobile. The skills are varied and involve a myriad of multi-tasking, but with little administrative support. This brief portrait may be a caricature, but it nonetheless expresses a situation concerning both men and women engaging in academia.

A young woman in Europe, for instance, can easily dream of embarking on a scientific career, regardless of the discipline. She will have the same if not slightly higher chances of obtaining a Master's degree than a male peer her age, although some disciplines still remain male strongholds. However, the probability of her going on to do a doctoral degree, pursuing a post-doctorate, accessing a permanent position and climbing the scientific and academic career ladder decreases from step to step. The image of the "leaky pipeline", which may of course be criticised due to a masculine vision of linear careers, can nonetheless express this progressive disappearance of women while climbing the career ladder (Alper 1993; Berryman 1983). This phenomenon can be readily imagined and helps in identifying the situation, but the multiple underlying conditions and mechanisms are not easily decipherable.

Based on the research reports produced in the framework of the European research project GARCIA - Gendering the Academy and Research: Combating Career Instability and Asymmetries, this chapter underlines the importance of understanding the "pipeline" from a multidimensional and multi-level perspective (macro, meso and micro). We will begin by presenting our approach (first section), in order to describe how we have conceived analysis of the data (second section). We will then deduce three ideal-types of gendered pipelines, which we will develop with particular attention to the costs that each Type 
generates for science, the institution and the individuals, as well as to their impact in terms of gender. Before concluding, we will discuss the secondary effects of the mode of functioning of research and academia, but also the perspectives we envisage to counter these effects.

\section{Moving away from classic perspectives on leaky pipelines}

The high level of uncertainty and precariousness among early career researchers in academia still remains an invisible issue in many European research institutions. It is this fragility of early career researchers/academics in their career paths and their respective academic organisations that has been the centre of our focus in the GARCIA project. Along with a number of contemporary European studies, the project establishes that women's moving away from the scientific or academic path leading to higher positions does not happen as simply as might be imagined at first glance (Dubois-Shaik and Fusulier 2016; Fassa, Kradolfer and Paroz 2012; Le Feuvre 2009; Grant, Kennelly and Ward 2000), and that rather than adopting mono-causal explanations, we have to take a more composite and systemic view of causes and effects when thinking about the "leaky pipeline".

The university's functioning methods produce the sort of gender inequalities described by the expressions "glass ceiling" (Hymowitz and Schellhardt 1986, redefined as "iron ceiling", Fassa and Kradolfer 2010), as not being able to ascend to higher positions, and "sticky floor" (e.g. Booth et al. 2003), as getting stuck in less gratifying and less valued tasks. The specific causes of these inequalities are less rooted in direct and explicit discrimination (Musselin and Pigeyre 2008), than in the dynamics of a gendered organisation (Acker 1990). These dynamics include a university management that resembles an old boys' club (Case and Richley 2012). Furthermore, a "Matilda effect" (Rossiter 1993; Fassa, Kradolfer and Paroz 2012) can be observed, penalising women with regard to their scientific productions, whereby their work is often attributed to their male colleagues. A phenomenon buttressed by a closely related "Matthew effect" (Merton 1969), explaining how eminent scientists will often get more credit than a comparatively unknown researcher, even if their contribution is shared or similar.

The more classic perspective draws the picture that often "promising" women fall out of scientific and academic careers after their PhDs and that it is presumed that everything happens in these professional trajectories to make them leave as though it were some kind of self-elimination, a chain of decisions taken more or less consciously, but always freely, by young women, who decide to do something else than pursue a scientific career (maternity, family life, or following their spouses to another country for his job, etc.) (Beaufays and Krais 2005). Other studies often focus on how certain fields are still underrepresented by one sex and on how traditional gender stereotypes persist in fields such as STEM (Science, Technology, Engineering and Mathematics) for women or SSH (Social Sciences and Humanities) for men (Blickenstaff 2005), tracing these discrepancies back to lacking motivations or gendered tracking during early (primary 
school) and latter (secondary and higher) educational trajectories. Yet other more contemporary research speaks about gender discrimination in recruitment, where women are systematically underselected for permanent academic positions and for promotions to higher leadership positions (Morley 2013; Van den Brink and Benschop 2012).

When looking at gender policies grouped together as "gender equality" policies, these too have so far focused rather spontaneously on improving figures and representations in professorships and leadership positions (albeit still without much effect). This has often resulted in policies that have targeted individual trajectories through personal coaching rather than taking a larger picture of the systemic and organisational environment levels of the pipelines (see other chapters in this volume). In short, research institutions more rarely question the pipelines themselves, although this subject has already been broached by numerous research studies in different national contexts. Pipelines are often seen as either career trajectories, or organisational career pathways that point to "leaks", which are undeniably present in all the case-study institutions involved in the GARCIA project (see Dubois-Shaik and Fusulier 2015, 2016). However, we would argue that we cannot simply adopt an approach of "filling the gaps" or of pointing the fingers at gatekeepers. Attention has to be drawn to how research institutions "do gender" (Gherardi 1994) and are gendered organisations (Acker 1990), which means that the social division of work between the sexes is translated in distinctive ways in structured institutions; in the principle of its organisation, in the habits of work at the heart of the institution; in short in the practice of scientific work. We extend this definition to include the welfare and gender regimes each institution is situated in. The combination of various results enabled us to glean this more holistic and composite picture of the pipelines in contextualised case studies. The Gendered Pipeline Typology proposed here shows, in a more nuanced way, that gender inequality is deeply entrenched in organisational, configurational and contextual work (and social life) factors, which make access, choice and work different experiences for women and men researchers and academics.

Thus, "gendered pipelines" is an analytical concept allowing research institutions to situate themselves in a more nuanced framework in terms of gender inequality in academia. The diverse results and analytical processes in the GARCIA project have enabled us to redefine a new combined approach to tackling questions about the "leaky pipeline" and other interrelated phenomena, such as "glass ceiling", "sticky floor", "Matilda- and Matthew effects" amongst others.

\section{Methodology}

\section{Research context}

This chapter is the fruit of a meta-analysis of the case studies conducted in six institutions, and their respective societal contexts (Belgium; Iceland; Italy; the 
Netherlands; Slovenia; Switzerland). The research project focused on both STEM and SSH disciplines. In terms of leaky pipelines, we will now provide a short overview of the key results recorded in each case study context.

In Belgium (see Dubois-Shaik, Fusulier and Vincke 2015), the gender question remains an open one, even if significant advances towards greater equality are observable. Although women are now in the majority in higher and university education, with higher graduation rates than men, two important reservations must still be taken into account. First, in accessing the highest level of qualification, i.e. the doctorate, males are in the majority. Second, a horizontal segmentation between "male" tracks of studies (sciences and technology) and female (human and social sciences) is still being reproduced. What is notable is that, as is generally the case for French-speaking Universities, women in academic/ scientific careers work part time more often than men (13 per cent vs 6 per cent), but those part time positions are in lower scientific/academic career posts, such as assistants. The higher up the ladder one climbs, the more full-time positions seem to be the rule. Not only, therefore, do women (and men) have to meet high demands in research/teaching, they also have to make major commitments in terms of institutional investment and presence - to integrate into a hypercomplex system of bureaucracy and institutional culture. There seems to be an increasing requirement of "omnipresence" in all three pillars (teaching, research and service), with each pillar increasing its level of demands and the complexity of the personal engagement required. It may well be argued that the above elements represent important issues in work/life reconciliation and equilibrium in maintaining a family life, and that wanting to climb the career ladder also means making important choices and accepting pressures in terms of personal life. It is noteworthy those occupying the highest posts attained by women at the Belgian university included in the research (vice-rector and general administrator, and some other heads of units, such as institute heads or deans) are generally without children.

When analysing data related to the leaky pipeline at the national level in Iceland (see Smidt, Einarsdóttir and Pétursdóttir 2015), it is immediately obvious that in terms of student numbers women dominate higher education. This might appear to be a positive development at first glance, but on closer inspection it is evident that even though women are in the majority, they are so predominantly in SSH fields, which enjoy the least amount of funding, the highest teacher-tostudent ratio (i.e. heavier workloads), the least amount of stature, and the fewest options for a future career in academia. Inversely, STEM fields, which are dominated by men, receive considerably more funding and enjoy a higher stature even though they attract a much lower number of students. As we move up the academic ladder we also find that men overwhelmingly occupy the higher stature academic positions. Consequently, although it is important to address the question as to why there are so few women in STEM fields and why women are distanced from academic careers the higher up the career ladder we get, it is equally important to address the question of why there are so many men. On the macrolevel, it is possible that men may feel pressured to conform to masculine ideals 
of stature and prestige and so end up choosing a technical field of study in a homo-social environment that is sure to "land" them a well-paid job which will confirm their breadwinner role. In the same vein, men may opt out of certain careers in SSH fields because an overarching culture of masculinity does not associate male identity with SSH related concerns.

Early-stage scientific careers in Italy (see Bozzon, Murgia and Poggio 2015) are characterised by: (1) that fact that gender asymmetries are already persistent and reproduced by the early post-PhD career stages, (2) a rise in the level of precariousness and job instability experienced by the new generation of $\mathrm{PhD}$ holders, (3) an increased level of competition for permanent positions due to the university system's inability to absorb the rising numbers of $\mathrm{PhDs}$, in turn resulting from the limited development of research positions in other sectors as well as from the low employability level of $\mathrm{PhDs}$ outside academia, (4) persistent disadvantages suffered by women both in terms of scientific productivity and during selection processes and (5) the instability of research projects affecting the quality of the research output and the type of knowledge elaborated in academia. In the early career stage, female employment positions appear less stable and less well paid than male ones, and more influenced by family and personal situations. These weaknesses are generally more evident in the STEM disciplines, but SSH fields too, where women are more represented, are not immune from unfair mechanisms that foster processes excluding women from career advancement, governing bodies and positions of power. Growing levels of precariousness and early-stage career instability, together with low chances of obtaining permanent positions within the academic system, make it necessary to support PhD holders. This support involves developing skills and competencies capable of leading to inter-sectorial careers as well as to finding effective strategies for following their personal career paths. The general vulnerability of postdoctoral positions needs to be curtailed, beginning first and foremost with a redefinition of their ambiguous contractual conditions.

In international comparison (OECD, EU), the Netherlands (see Herschberg and Berger 2015) has one of the lowest numbers of women full professors. In both STEM and SSH fields, on both the national and organisational levels, the leaky pipeline is present. The numbers and percentages of women in academic positions differ between STEM and SSH domains, on both the national and organisational levels, but the trend of decreasing numbers makes itself felt all along the pipeline. Yet, in both participating GARCIA departments in the Netherlands, we see higher percentages of women full professors than women associate professors. The number of women full professors is higher than the national average in SSH, but lower in STEM. In both we found an increasing number of women non-tenured staff over the years 2010-2014, with no increase in the number of women tenured staff. This indicates a growing leak in the pipeline at the assistant professor level. In the STEM department studied, the number of women staff leaving seems to be disproportionate, when compared to the number of women employed in the period 2010-2014. This is not the case within the SSH departments. In general, the Netherlands has the highest number of women 
working part-time, and a one-and-a-half earners model is prevalent. Care divisions between men and women are still conservative. However, the prevalence of part-time work does not apply to women in academia. The research project also showed that Dutch women academics more often have no children, or fewer children than women outside academia. A pay gap exists between men and women in tertiary education.

In recent decades, women in Slovenia (see Istenič 2015) have entered higher education and science massively. Among the graduates, 60 per cent are women and among the $\mathrm{PhD}$ graduates almost half are women. However, their careers are usually completed at the assistant or assistant professor levels; 40 per cent of women reach those positions, while only 20 per cent of women with completed PhD studies reach full professorship. The analysis highlights the presence of the leaky pipeline phenomenon in science at the national level; a clear picture emerges of vertical gender segregation in academic career paths among $\mathrm{PhD}$ holders. However, on the level of individual STEM/SSH departments, this picture is not as unequivocal; it shows that the reality is far more complex. Female students greatly outnumber male students in SSH fields, particularly in education, health and humanities, typical "female sciences", whereas men strongly outnumber their female colleagues in engineering, manufacturing and construction, typical "male sciences". A comparison of statistical data on research and teaching staff with data pertaining to $\mathrm{PhD}$ students clearly indicates ongoing gender segregation in science. In their careers, $\mathrm{PhD}$ holders, more frequently women than men, are faced with an accumulation of disadvantages that arise in both their working environments and family lives, with implications for their less successful scientific careers.

Structural characteristics of the gender regime in Switzerland (see Kradolfer 2015) have strong impacts on women's careers with, for example, very low levels of childcare provision, extremely high childcare costs, high levels of horizontal and vertical labour market segregation, and relatively large gender pay gaps, particularly at the upper reaches of the occupational hierarchy. Women tend to work part-time and/or take extended breaks from the labour market when their children are young (42 per cent in 2012). The academic occupational hierarchy continues to manifest a clear "glass ceiling", although there has been considerable improvement in women's access to higher education over the past 15 years. Women are now well represented amongst doctoral students and fill a significant proportion of temporary scientific research positions, but are much less likely than their male counterparts to reach permanent professorships. Although the gender policy target of 25 per cent of professors being women has yet to be reached, there has been a significant increase in the feminisation of intermediate levels of the academic hierarchy. The proportion of women among funded $\mathrm{PhD}$ students and (non-tenured) postdoc research positions increased from 27 per cent to 40 per cent between 1998 and 2007. In addition, women now represent over 40 per cent of non-tenured scientific collaborators and nonprofessorial teaching staff in universities. Whilst women have increased their share of university professorships, from 9 per cent in 2006 to 17 per cent in 
2010 , the proportion of foreigners amongst the female academic population has increased from 46 per cent to almost 56.4 per cent over the same period, indicating a failure to mobilise women already within the university pipeline. Increasing women's access to scientific occupations is a concerted policy objective and there are signs of quite strong institutional commitments to the fight against horizontal and vertical segregation. But in a country with a low unemployment rate, a small university-educated population and relatively wellpaid job opportunities in the private and public sectors, Swiss higher education institutions do not necessarily represent a particularly attractive employer, notably because of the large proportion of temporary, fixed-term contracts that characterises the early stages of the academic career.

Comparing all the countries together, the number of doctoral students and $\mathrm{PhD}$ graduates are central indicators of a country's research potential. According to Eurostat data (2015), there were an estimated 717,000 doctoral students in the EU-28 in 2012 and women accounted for 46 per cent of doctoral students and 47 per cent of $\mathrm{PhD}$ graduates. There has been an increase in the total amount of $\mathrm{PhD}$ graduates in all the countries involved in the GARCIA project. The gender split of doctoral students and doctoral graduates across the countries involved in the GARCIA project was balanced or slightly in female majority in Italy, Slovenia and Iceland in 2012. By contrast, women accounted for 44 per cent of all doctoral graduates in Belgium, the Netherlands and Switzerland. The process of feminisation at this level of specialisation should improve soon. All national case studies highlight the persistence of a strong segregation of men and women across fields of study.

Academic careers remain markedly characterised by vertical and horizontal segregation even if there are important differences across countries. Among Grade A staff, the presence of women has markedly increased in Switzerland, Iceland and Slovenia. In these cases, the number of women among full professors more than doubled between 2004 and 2010. Only Switzerland reached the target of 25 per cent women among full professors, while in Belgium and the Netherlands that proportion remained below 15 per cent. Female PhD holders have systematic disadvantages when compared with male $\mathrm{PhD}$ graduates: (1) higher risks of being unemployed or being employed in fixed term and part-time positions, (2) lower chances of performing research and development activities in their jobs or of being employed as researchers and (3) lower average wages.

The leaky pipeline and glass ceiling phenomena can be recorded for all the countries participating, whereby fewer women are recorded the higher we climb the scientific/academic ladder. An important fact remains that in most countries the bottleneck is located at either the doctoral or postdoctoral levels, with the difficult jump to obtaining tenured positions. Again, this may seem to be nothing new in terms of the famous scissor shaped curves. An important result obtained is that the number of postdocs and assistant researchers with non-permanent contracts is rising significantly, with institutions hosting a growing number of temporary researchers. These, we would argue, are a 
"floating and invisible" research body, contributing greatly to the production of knowledge and teaching, but institutionally remaining largely invisible, unstable and unaccounted for.

\section{Data and analysis}

We have looked at the leaky pipeline and interrelated phenomena through quantitative data, and through qualitative analysis using various data from different reports (Dubois-Shaik and Fusulier 2015, 2016; Steinpórsdóttir et al. 2016; Herschberg, Benschop and Van den Brink 2015; Le Feuvre 2015). Particular attention was paid to the early stages of academic and scientific careers.

For each case study, the welfare and gender regimes were analysed using secondary data from national, regional and institutional datasets concerning education, family, formation patterns, employment, child-care, health, equal opportunities and work-life balance for the six case study countries and institutions.

Organisational data about the six target institutions was gleaned partly from existing data sources and, to a major extent, by creating a new dataset concerning mover/leaver lists, gender differences in leave, leave and welfare policies and more general figures concerning gender in employee patterns. Funding patterns were discerned for project funding in both departments, in order to map how funding was distributed between sexes in each department for each institution. Moreover, we made a map of existing research and teaching in terms of gender sensitivity (courses that referred in an explicit or implicit way to gender or made use of a gendered perspective in aims, methods and approaches).

For "giving voice", three different groups of actors were studied: (a) movers (researchers/academics, who have moved to other research institutions) and leavers (researchers/academics, who have left academic and research careers); (b) postdoctoral researchers, working at the six GARCIA research institutions at the time of the empirical research; (c) fully appointed academics, within five years of their appointment as permanent academics. Both female and male interviewees were targeted, and from two different departments, one of which was an SSH department, and the other a STEM department.

Furthermore, for an empirical analysis of organisational structures, interactions and life at the six target research institutions, focus groups and interviews were held with senior full academics and professors, department heads and members of recruitment committees. The reports cited enabled us to identify the complex and multivariable nature of the pipeline(s). They evoke the extent to which the social division of work between the sexes is indeed translated in distinctive ways in its structured institutions. First, in the gender and welfare regimes, within which the institution is embedded. Second, in its work ethos and culture. Third, in the principle of its organisation, influenced by external and internal pressures and discourses. Fourth, in the kinds of policy responses that have been evoked. Fifth, in the habits of research/academic work. We must not forget the specificities of scientific fields, sectors and institutes (SSH, STEM), 
which can play a role in the way work is gendered. We also look at a role of discursive resources (Kuhn 2006) that are mobilised by actors when making sense (Weick 1995) of their work. And, not least, the modalities of careers at the heart of the institution. The gender dynamics that operate amidst these different mechanisms at play, therefore, not only reflect or change external societal and socioeconomic trends, but also contribute to enhancing, reproducing or reinforcing certain gender regimes, work ethics and cultures, discourses, and organisational structure/modes of functioning. This in turn shapes career modalities in particular, gendered ways. "As a consequence research tools are now needed with which to grasp the processual character and complexity of the factors at work" (Poggio 2006, p. 229).

From a transversal analysis of the GARCIA case studies, we have gleaned particular features emerging as specific configurations and combinations of different dimensions: (a) national gender and welfare regimes; (b) previously existing gender policies; (c) quantitative analysis of the leaky pipeline, including the national and organisational quantitative data; (d) qualitative narrative data from interviews with three sub-groups (movers/leavers, postdocs and newly tenured researchers/academics); (e) recruitment and discursive resources; (f) organisational characteristics.

Faced with the breadth of data presented in the reports, we have operated a double process of identifying similarities as well as differences between the different cases, in order to be able to identify different rationales or logics, defined as ideal-types from a Weberian perspective (Weber 1922). By ideal-type, we refer to an intellectual reconstruction, reducing the complexity of information gathered in the case studies and creating a kind of caricatural representation, which expresses a logic that was manifested in certain case studies, without, however, inserting a group of particular institutions into a classification.

In other words, revealing a strong common basis in all six case studies, ${ }^{1}$ comparison of the various GARCIA case studies beneficiaries indicates recurring configurations that assemble certain features and characteristics. Looking at proximities and distances between the case studies, we observe a series of organisational, social and career-based polarities. For example, there is a tendency for certain organisations to define themselves as enterprises having to fare in an international market, whereas other organisations perceive themselves as major social institutions placed in their immediate environment, and still others present themselves as autonomous professional spaces. The employment market dynamics range from very competitive employment markets, open to highly qualified workers, to employment markets saturated with a high level of unemployment even for highly qualified workers, while also showing intermediary forms of markets that are relatively open to doctorate holders, but nonetheless uncertain in terms of professional conversion. The recognition of the doctoral status and the social security given to researchers is far from homogeneous; researchers may thus find themselves in highly precarious financial situations without access to social security, whereas others seem to be fully integrated into a well-regulated salary system ensuring social protection. Similar differences 
can be observed in terms of gender policy and policy concerning work/family articulation, which may range from being well developed or simply non-existent. Understandably, these different institutional and socio-economic characteristics weigh heavily on career forms and experiences. Three Types of careers and related experiences are discernible: persisting in precarious career paths; continuing in ambivalent career paths; striving to win in competitive career paths.

Simultaneously, the different organisations, contexts and career paths can be situated in what is at stake for different levels of the pipelines, in other words "the costs". Without adhering too closely to social exchange theorists, by "costs", we would understand the "price to pay" or the challenge for a certain orientation, perspective, objective or underlying principle of an entity that operates on the pipeline. We locate this entity at three levels in relationships:

- the macro-level of science as an entity, not with a capital S, but rather science as a collaborative, collective work and product of an organisation;

- the meso-institutional level as a working, interacting and operational entity with particular common institutional missions;

- the micro-individual level of a worker and composite being as an entity.

We may refer to the level of costs that the particular academic/scientific career involves: the level of costs that the institutional and organisational conditions, demands and work culture/organisation involves; the level of costs that science as a product and the overall missive of research and teaching involves. We may refer to specific configurations being more costly at the individual level and perhaps also at the institutional and organisational levels. An important part of reading costs is that they may represent different impacts upon gender dynamics. Thus, in addition to the three levels, we can deduce how costs affect the gender balance and inequality in the various Types of gendered pipeline configurations and institutions.

These different dimensions (organisations, contexts, career paths and costs) combine typically to outline a certain rationale, in other words a "gendered pipeline" or a Type of career path and organisation showing different cost ranges and levels. We distinguish three:

- Type 1: persisting in precarious career paths in "Mandarin" organisations, with high cumulative costs;

- Type 2: continuing in ambivalent career paths in "Missionary" university institutions, with moderate costs;

- Type 3: striving to win in competitive career paths in "Entrepreneurial" organisations, with specific costs.

\section{Persisting in precarious career paths in "Mandarin" organisations, with high cumulative costs: Type (1)}

This first Type refers to a university that sees itself as an autonomous professional space, operating with internal professors' clubs that manage their own 
succession by looking for the most devoted and persevering amongst their "young" researchers. The privileged link is the domestic or filial link, meaning one based on interpersonal connections, knowledge of internal codes, and an acceptance of hierarchical relationships. Power is concentrated at the level of well-established professors enjoying a good deal of autonomy despite bureaucratic tendencies and a competitive logic. The problem of gender is little discussed and very cosmetically addressed at the policy level. There is no real active gender and equality policy, neither on the national level nor on the institutional level in academia. Early career-stage researchers and academics, particularly women, experience work/family conflicts. Maternity and academic careers are often considered and lived as incompatible with the kinds of demands and conditions research/academic careers impose; especially when job precariousness and hyper-productivity are clear requirements for CV building. Women sacrifice motherhood in order to persevere or survive in their careers.

This Type of pipeline is characterised by traditional societal gender roles: the male breadwinner and female carer model. Moreover, in line with this traditional role distribution, few or no effective childcare and elderly support systems exist in such a society. This is replicated within the university system itself. On the labour market, the economic participation rate of women is still considerably lower than that of men. Women's access to the labour market, remuneration, career advancement, promotion to positions of leadership and new business opportunities remains relatively low. Young women are more likely than young men to be unemployed, and to work in less stable forms of employment and in the lowest-paid sectors (horizontal segregation). This too is replicated in the academic sector, with an important sticky floor in terms of assistant instructors, nontenured positions (and technical and administrative staff) mostly filled by women. The academic sector replicates that society's major gender pay gap. The structural situation of young researchers is characterised by a low salary level, lack of social protection, and few opportunities on the labour market, etc. Despite higher education becoming increasingly feminised, gender stereotypes persist in some fields.

In terms of work culture and organisation, there is a strictly linear academic path, with few positions and stringent competition, with an emphasis on productivist recruitment criteria (numerous publications in "high-level" peer reviewed international journals, especially in STEM). A high-level of uncertainty prevails for postdoctoral researchers coupled with numerous short-term, non-permanent research and teaching contracts. In this non-permanent "floating" body, postdocs are not recognised as official employees with equal social and financial benefits. In this Type, well established full professors wield vast power; faculties are male-dominated. Moreover, these male mentors are powerful gatekeepers to networks, opening the succession to male junior colleagues, a feature their female peers lack. This points to a Mandarin Type organisation. Of course, international mobility is highlighted, while the institution remains relatively closed in terms of local recruitment for postdoctoral contracts and permanent positions. In fact, the institution is discursively engaged in internationalisation in terms of 
economic measures and standards, particularly because there is less overall funding for research by governments. Hence this institution tries to encourage international funding.

As to career paths, the linear pathway is marked by long waiting periods in professional situations of statutory and economic precarity, where short-term projects are accumulated, and contribute to teaching and administrative tasks lacking any institutional recognition, but which manifest an alliance to a particular professor or centre. Women live in a particular parental and career ambivalence, with little social service support fostering work/life reconciliation. Professional reconversion is difficult due to a market less inclined to accept $\mathrm{PhD}$ holders. Once embarked on a scientific career, you need to persevere in that sector.

This Type combines a large range and high amount of costs at different levels. The individual level is characterised by high professional insecurity, nonintegration and institutional non-stabilisation. Institutional membership is not extended to early career researchers, and it brings with it several repercussions on the institutional level as well as for the larger scientific community. The numerous short-term contracts employ quite a large non-stabilised labour force, dedicated to fundamental research. However, the institution structures fundamental research in a short-term and non-continuous way. As individuals are, moreover, self-reliant, with less assistance in terms of supervisors and colleagues, fundamental research remains a rather haphazard affair, at the mercy of funding opportunities. Moreover, a significant feature of this Type is the high cost level in terms of teaching: the teaching task is perceived as ungratifying by individual, early career researchers, despite an increasing number of assistants in insecure roles. Barely recognised, they assume teaching tasks, although in requirements for permanent positions there remains a focus on publications and research development. Teaching therefore is assumed by an undervalued teaching force, which is not very motivated by the teaching task. Arguably, this is rather unfavourable for teaching itself, which remains a secondary task compared to research that is over-valued due to recruitment criteria and to the forms of the $\mathrm{PhD}$ and postdoctoral projects and short-term contracts. Teaching is moreover classified as a sticky floor, favouring neither the scientific nor the institutional levels.

In terms of gender dynamics, this Type continues to have a very thick glass ceiling, meaning slow career progression for women, coupled with masculine cooptation logics and non-existent support in terms of supervision and networks for women. In parallel, there is a work/family conflict, penalising workers with families. High demands and non-flexibility of working conditions and careers, coupled with hyper-productivity as a recruitment criteria and institutional omnipresence make work/private life conciliations next to impossible. Moreover, this kind of organisation does not take the lack of childcare and family services in society into account and fails to provide any services on its own. On the whole, women who are mothers or who wish to be mothers have a particularly hard time; the latter often renounce parenthood, given the impossibilities of career conciliations. Career and professional assistance for development is often not 
given. The scientific and institutional community should ask itself what kinds of worker profiles it wants to promote. Currently, the worker profile that is promoted is rather homogeneous, linear and mono-profile, orientated towards an omnipresent, outdated masculine profile. The research institution can ask itself whether science itself will stagnate through its persistent promotion of the types of researchers/academics it is now represented by. For the institution and the scientific community's missions and output, these questions are intimately linked to workers' positions, conditions and degrees of membership, and how work gets assigned and done. Here we find a particularly greedy institution, which, moreover, does not offer membership to a large floating body of workers, working on fundamental research developments and teaching.

When looking at gendered impacts, early career women researchers and academics pay high prices; they have a particularly hard time becoming stabilised and risk accumulating short-term contracts, and if they are in permanent posts, they tend to be more on assistantship teaching levels. Teaching is, however, considered less gratifying, and so presents them with a sticky floor, preventing them from doing research. However, the kind of research that they are required to do is for $\mathrm{CV}$ enhancement, and focused on productivity criteria (publications) as a discursive resource. Moreover, in this kind of institution, a high level of importance is given to guidance from mentors, especially on the strategic level, and for access to networks, which are significant for accessing career opportunities. Informal recruitment criteria moreover are not that visible and the processes themselves are non-transparent, especially for women who lack mentors to give them appropriate advice/institutional knowledge. The insecurity and instability of their job situations lead to anxiety and burnouts are frequent. When in stable positions, they experience overwork too. If they are not in assistantship positions, they experience a lack of social infrastructure and institutional embeddedness (membership). For women, persisting along precarious career paths often leads to sacrifices on the level of family choices, preferring to defer or renounce motherhood to progress in their careers. In terms of opportunities to use their PhDs and careers in other sectors, the SSH women lose out especially, because their PhDs are not easily recognised in other sectors. In STEM things are somewhat easier. Thus, even the avenue of professional reconversion is arduous and not that wide. In sum, they are in a very precarious overall situation, with a high degree of gender inequality for early career female researchers/academics, compared to their male peers, although early career men too generally have a hard time acquiring permanent positions. However, they are more equipped for gaining access and availing themselves of promotion opportunities, and sacrifice less on a personal level.

\section{Continuing in ambivalent career paths in "Missionary" university institutions, with moderate costs: Type (2)}

The second Type of university and/or research centre sees itself as an institution within society, and envisages its teaching, research and community servicing 
missions in that context. It centralises its power but delegates daily management to its faculties and research institutes. However, every strategic decision involving local actors is taken with the central powers' approval, in order to ensure the institution's missionary coherence. This institution may be classified as a professional bureaucracy with less support for teaching and research units and more for central governance (commissions/committees). It is characterised by a high level of self-management on the part of each unit and individual academic/ researcher. The huge amount of administrative work is time consuming and, for early career researchers, represents a sticky floor linked to performing nonprestigious tasks. Nevertheless, the recruitment of academics is based on the double reference of being internally renowned in terms of research, but also of having a loyal disposition locally - to be of service to the institution. Attuned to social norms, gender equality is proclaimed but seldom practiced.

In terms of context, the labour market has achieved much in terms of feminine employment, but with the dual-breadwinner/female carer model in ascendency. Here we may find a part-time feature of female employment, also implying a hidden one-and-a-half breadwinner model (full-time male/part-time female work by couples). An unexplained moderate gender gap also persists. The social security system is universally protective (good social benefits) and the conditions of employment are well regulated (minimum wage, job protection), with those conditions replicated in academia. The social system here also includes a quite developed childcare service and family leave arrangements (short, flexible paid parental leaves for instance). However, for academia, the organisation of work is non family-friendly for all that, with overwork, productivist recruitment criteria, and a solicited commitment to voluntarism in and for the university institution.

In terms of careers, this pathway entails a double engagement: a research engagement ensuring international recognition, and an intra-institution engagement to be disposed to contributing to the common good of realising its missions. Those engagements may be fulfilled in a privileged way in positions which offer good working conditions, but with no long term guarantee of work continuity or stability. In order to obtain a permanent position, two strategies are valued: meeting standards of scientific excellence, but without, however, neglecting the other two missions; the second involves excellence in teaching assignments and community service, without neglecting the quality of research. In the two cases, the young researcher has to be able to count on his/her peers and seniors in order to gain support in accomplishing those various missions.

The social context is supportive of work/life reconciliation, and the working conditions being good, young researchers do not hesitate in founding a family and entering parenthood. However, they live with a significant degree of tension between their institutional and parental engagements. Women, especially, experience a general ambivalence, not knowing where to situate their life priorities. There is a lot of discourse about gender and equality policy and laws, existing on national levels, as well as sometimes on research institution levels, yet without concrete plans being implemented. There is some institutional resistance to implementing gender policy and measures; notably an ambiguous discourse 
about gender and recruitment processes, or about quotas on recruitment committees and in leadership, or on whether any gender bias exists, mostly in STEM. Gender stereotypes persist despite a pronounced feminisation of higher education: STEM still remains predominately male. There is a bottleneck after PhDs and during or after postdocs, with few permanent positions and high competition. There are persistent glass ceilings, especially for leadership and management positions.

If we look at work culture and organisation, co-optation logics exist, maintained by mostly male gatekeepers; hence "following" a mentor is more possible for men, which points to mobilising masculinities. There are fewer female "role models" and less support from gatekeepers for women. Early career women researchers/academics are more fraught with guilt over juggling working life and family life than their male counterparts. There is, however, overall in this Type, a clear parental ambivalence (not entirely comfortable with work/family balances and a harder time for parents), for both women (more so) and men. This Type highlights a precarious and ambivalent balance that is achieved, or not achieved, for women and men in early career stages, to a high degree dependent on their respective partners. Unlike their female colleagues, male early career researchers and academics often have partners with part-time or no work, and who take on the primary carer role in their family.

In recruitment processes and structures, there are tensions between competitionbased (publications, mobility) and nomination-based criteria (finding the ideal candidate who "fits", will be loyal to the institution and who will be a nice future colleague). The former, competition-based criteria, are major discursive resources for early career researchers, whereas the latter tend to be discursive resources for recruitment committee members. These latter nomination-based criteria are however less transparent and more likely to be taken into consideration if applicants have local institutional knowledge, and are integrated into local networks. International mobility is a significant asset for gaining permanent positions: early career researchers try as much as possible to complete doctorates or postdocs abroad, as this is seen as a clear criterion for applications, but without breaking the link with the (home-)institution. In other words, the institutional emphasis on internationalisation, excellence (high research production and funding) and competition discourse is in tension with a locally, highly developed organisational and (negotiation) "culture".

A constant bid for funding characterises this Type; individual early career researchers, such as postdocs, and early career tenured academics and research centres, as well as all the research institutions are bidding for governmental and international funding. This governmental bidding is sustained by a "pointsystem" (awarding centres or individuals according to the amount of research produced or funding obtained externally) or a "closed envelope system" (universities receive funding according to the number of students but with a constant global amount divided between universities): these systems reinforce a competitive culture, for units and between individuals. A lot of time is dedicated to writing funding applications. There is a clear gender budgeting issue with these 
systems, as STEM receives more per student funding than SSH. Yet, at the same time, SSH has a higher student to teacher ratio. Due to the asymmetry in the gender distribution between the two sectors, women have less access to funding: indeed, they are overrepresented in $\mathrm{SSH}$, the sector losing out on funding possibilities, while in STEM they are in a minority.

In this Type of organisation, omnipresence is a key notion: junior and senior researchers have to do everything and be everywhere, in all meetings, at the same time. Their work is characterised by a double-edged flexibility; they love doing research, sometimes less so teaching, but they feel that this passion-driven work, and the flexibility of being at work any and everywhere may infringe on private and family life. Their problem is "hitting the off button". This Type is characterised by many early career researchers and newly tenured taking the working conditions and nature of work, and personal sacrifices in their stride; "it's normal for this kind of career". PhD reconversion into other sectors is not easy for SSH in terms of value, salary, job satisfaction and opportunities. It is easier in STEM, especially for male leavers. However, not on the salary level: engineers are not paid more due to having $\mathrm{PhDs}$. So a $\mathrm{PhD}$ is often unrecognised on salary scales in STEM.

In terms of cost rationale, in this Type the moderate costs are evenly distributed while heavier in the macro science level, but some weight is born by university missions and pillars. The institutional context is moreover based on some financially constraining frameworks reinforcing certain trends. The growth in student numbers is strengthened by a governmental funding system(s) that create(s) competition between universities and research institutions in order to "bid" for funding. Student numbers are deemed indicators for greater or lesser funding allocations. However, there are also fewer teaching staff and fewer academic positions for PhDs/postdocs to take up, and the conversion value of the $\mathrm{PhD}$ in certain fields like $\mathrm{SSH}$ is low. So there are more $\mathrm{PhDs} /$ postdocs in shortterm contracts developing fundamental research and teaching, but also a lesser continuity in the careers and in professional development and contributions to university environments. Professional development is more markedly a point that remains moot in terms of a PhD's value: what are the possibilities for the PhDs offered at university and research institutions beyond academia? Why do institutions hire many PhDs and postdocs, possibly for funding reasons and the development of fundamental research and cheap teaching staff, but what is the continuity in terms of professions?

Additionally, the funding system between STEM and SSH (and other) fields is disproportionate. STEM has more funding, but fewer women, whereas SSH has less funding and more women. The gender stereotypes already existing in postgraduate education in fields are thus strengthened further along the career. Generally, the organisational system(s) tends to reinforce a competitive rather than a collaborative culture. Workers (researchers/academics) have a hard time integrating into and creating their research teams, especially early career women. In conjunction with this, the organisational system adopts a logic of selfmanagement of units, with an administrative system that supports central 
governance, rather than research, teaching units and individuals. Fulfilling all the different missions and tasks becomes arduous for workers and units, and requires a high level of self-reliance, while university assistance is hard to come by, and collaboration between colleagues more difficult. Workers struggle to keep up with the workload, the omnipresence and strain of self-management, and getting help where it is given (mentors, supervisors, colleagues); women are more likely to lose out on these fronts.

The university and research institution might well ask itself if this kind of culture and organisational system is likely to create a worker-friendly environment, or a more collaborative and community-based culture. The scientific community, moreover, emphasises that science is primarily collaborative work, and recruitment criteria for committees are also focused on the importance of local integration and the ability to collaborate; the institution needs to ask itself whether this criteria requirement is respected in such an institutional environment, and whether or not the system itself also needs to offer structures fostering integration and collaboration.

In terms of gendered impacts, early career researchers and academics, both women and men in this case, have to maintain a precarious balance in order to gain access to careers, and then to progress in those careers. However, this balancing is more difficult to achieve for women compared to their male counterparts. There is the importance of gatekeepers, mentors and belonging to the right kind of networks, whether they be international or local institutional networks; women have less access to networks and get less advice from their supervisors, who are often a far cry from mentors. SSH men have more access to mentors within the institutional framework, whereas STEM men rely less on mentors and are more solo players. STEM and SSH postdoc and newly tenured women have more internationally based mentors. However, this presupposes having international networks.

The kind of recruitment criteria highlighted are two-fold as well, and present a kind of rock and a hard place for women; productivity-based criteria, such as publications in the right kind of journals and in STEM are also numbers and indicator-based. Here, mobility is also a criterion for "excellence" in a CV or application file: early career researchers try as much as possible to do $\mathrm{PhDs}$, or more often postdocs, abroad. Or else, they come from neighbouring countries and hence demonstrate mobility. An element too is the high institutional significance in this Type of local institutional knowledge of codes, of what is expected by committee members and "locals" about how to "fit in"; this knowledge can, again, be, as in Type (1), gained by belonging to local networks and being guided by mentors, which women lack as compared to their male peers.

Women have a harder time achieving both types of criteria, as doing so may interfere with family life or motherhood, as frequently happens to postdoc or newly tenured SSH women. STEM women postdocs tend to not yet have children, and wait to be newly tenured to have them. Again, the pendulum may swing towards a permanent position if all the configurations are "right"; if you have a supportive supervisor, if you have a supportive private partner in life, 
who takes on family responsibilities, if you can work overtime and invest sufficiently in achieving productivity and being omnipresent (research production, funding, teaching, institutional engagement, administrative tasks). However, the chances that all of these configurations are simultaneously favourable are quite slim for women. It is easier for men to align. Professional reconversion is not something women accomplish easily, as they have more regrets about leaving academia and a lingering sense of failure, despite having found work in other sectors, whereas men describe taking a personal distance from academia, and so voice more satisfaction.

This Type (2) leads to a high level of role ambiguity for women on the parenthood level too; upon becoming mothers, they have a harder time being hyperproductive and omnipresent, and experience more guilt about work and family conflicts, whatever they do. Male parents voice ambiguities too, but they have more support elsewhere, with partners largely assuming care and household chores, and flexibility in terms of mobility for example. They also have more mentors and institutional assistance from networks, they revel in the flexibility their type of research work offers and do not feel guilty about work/family conflicts. So both more role ambiguity and more difficulty in achieving even a precarious balance, with the need for the "right" configurations, characterise this Type in terms of women's gender inequality.

\section{Striving to win in competitive career paths in "Entrepreneurial" organisations, with specific costs: Type (3)}

The third Type of university and/or research centre clearly defines itself as an enterprise in a competitive international market. Competition is thus an integral part of its functioning. A clear objective is progressing in international rankings. The organisation is adhocratic as it needs to adjust its rules depending on its competitors. The recruitment criteria chiefly focus on maintaining internationally excellent standards, with regard to which researchers and academics are regularly challenged in formal evaluations. The organisation provides itself the means to those ambitions by funding the "most promising" of its researchers. The recruitment criteria focus mainly on maintaining internationally recognised standards in terms of which researchers and academics are regularly subjected to formal evaluations. It hopes to attain and maintain those standards by funnelling funding to the "most promising" recruitment criteria aligned towards the referential of competition, looking for those with the highest international reputation. The local culture is not neglected, as talents may be stimulated. This translates itself into a gender policy focused on selecting the "most talented women", in screening and bringing them into a coaching logic designed to support their careers through the excellent results obtained.

The career is cumulative but based on an elitist conception. Those taking this career path have to narrow their career choices, as the external market is sufficiently elastic and open to highly qualified professionals. Recruitment and promotion criteria are quite explicit and aligned to playing an international 
competition game, particularly through high-ranking peer reviewed journal publications. Everyone seems free to choose to play this game. Despite what appears to be a free market choice, this particular freedom of choosing an academic career also means that you have to be able to juggle between multiple engagements.

This Type is also characterised by modified male breadwinner gender regimes or "one-and-a-half earner models", where the female part-time character of work is frequent in its overall labour market. But a striking difference to the part-time national trend is to be found in academia, where women employed full-time are predominant. Childcare services are available, but very expensive and exclusive (few children per service, few services). Compared to men, women are still primarily responsible for and spend more time on childcare and domestic work. Despite a family culture of mothers caring for children, the use of formal childcare has increased rapidly. Gender stereotypes persist, favouring STEM men. The higher we climb, the thicker the glass ceiling, especially as to full professorships and management positions. There are still few women in leadership positions, although marginally present in all levels and posts. There is a particularly narrow bottleneck, with very few permanent positions and few chances of attaining stability. However, there is also a highly buoyant extra-academic labour market $\mathrm{PhDs}$ avail themselves of, including in SSH.

There is a strong national gender policy discourse and softer governance is opted for through quota introductions, rather than through structural and cultural changes. The academic institutions have some policies on gender too, although mostly in terms of an overall HR diversity policy. There are elaborate mentoring programmes already in place, with peer mentoring and promotion of women in science; wide-ranging and relatively well-funded equal opportunity measures are available, especially at the doctoral level. This is less the case for the postdoctoral level, which still remains institutionally invisible in terms of an employee body. However, these measures are geared towards "coaching champions", or selecting the most "excellent" or best researchers. Competition for these funding possibilities is higher.

In terms of work/life interference, there are still fewer children among women in academia and a clear parental ambivalence for women, while lesser for men. There are however big differences between STEM and SSH in terms of parenthood, with "STEMs" often not having children.

Looking at work culture and organisation, in this Type, early career researchers and academics must "self-drive" their work, like a business man or woman. They have to juggle different tasks once they are tenured, which is experienced as being problematic and infringes upon work/family and private life balances.

While early career researchers and academics assume a "take it in your stride" attitude, both men and women, and women especially, feel the sacrifices, instability and overwork. There is a clear tension between work and care. Early career researchers/academic women mirror society's persistent assignment of the major carer role to women. Of course, the intensity of the tension surrounding worklife balances strongly depend on gender-role arrangements with partners. 
In this Type there emerges the idea of the idealised "all-round" academic profile, which is thought to be well suited to an increasingly international and competitive environment. This ideal-type figure is expected to "perform" equally well in research (by attracting competitive external funding - notably to keep postdocs in employment - and publishing in the top international, peer-reviewed journals), in teaching (by attracting high-quality graduate students), and in maintaining high levels of organisational wellbeing (particularly by taking on administrative duties). In addition, this (imaginary) figure of academic equilibrium should know how to accommodate non-academic activities (leisure, sports, culture, and even family life ...).

This Type of organisation is characterised by hosting an important influx of international students. While there are many postdoc contracts with international or external funding, they do not, however, necessarily lead to tenure-track or permanent academic positions. When it comes to obtaining permanent positions, the locally funded career pathways are still more favourable compared to incoming international postdocs. Despite being embedded in the international market, the university is not seen as attractive for employment for locals, although being strongly embedded regionally. While an increasing number of short-term contracts and non-tenured assistant professor positions exist, that is not the case for associate and full professors; we are already looking at a glass ceiling at the associate level. There are many lonely heroes and heroines, with numerous boys' clubs, some more recent girls' clubs, and some women mentors promoting women.

For early career researchers and newly tenured academics there is a constant bid for funding, for research and the advancement of networks and strategic guidance, which is considered quite key in career advancement. Postdocs tend to focus upon research and CV building, whereas teaching is seen as a necessity or obligation for tenure, or once tenured for promotion towards professorship.

The selection processes are governed with formal criteria due to gender equality policy, however those formalised criteria focus on initially quantifiable research, then "subjective" factors that are non-transparent, such as "all-round" or "ideal-type" academics. Quota or excellence-based equality measures strengthen competition, and may reinforce a market-driven logic of academic recruitment.

In terms of cost rationale, in this Type of career path and organisation, specific costs are incurred on all three levels, whereby the scientific community suffers too in terms of the persistence of gender stereotypes in (STEM/SSH) fields. In terms of fundamental research, it too is governed by funding competition and remains haphazard. The specificity of this Type also lies in a very stringent, steep and slow career progression in a very elite organisation. Jobs are very hard to come by, because they require the profile of an "all-round" ideal academic who is capable of self-management, institutional embeddedness and excellence at all tasks (research, teaching, service to the institution, society).

$\mathrm{PhD}$ conversion is somewhat better in the non-academic sectors. However, a career here is made possible when a whole set of conditions are met; when you 
have supportive mentors, when you are in the right networks, when you have a supportive partner working half-time and assuming the primary care role. There is some institutional support as required in pre-existing gender policy and programmes, but they are still very elitist, exclusive and "excellence" based, focusing on requirements such as hyper-productivity, publication lists in international peer reviewed journals, as well as the existence of and membership in internal and external networks.

Looking at gendered impacts, early career women researchers and academics have a harder time juggling many things at the same time than their male counterparts; as in Type (2), an equilibrium between work and family life is very difficult to achieve, with overwork and "omnipresence". However, there is less ambiguity on the individual level, except regarding parenthood. There are however, even fewer job opportunities in this Type, because there are fewer positions and very few chances of obtaining them. The extra-academic labour market however seems to be buoyant, but $\mathrm{PhD}$ recognition in other sectors is possibly less transparent for early career researchers. Although there are developed institutional mentoring programmes and financial measures to assist women in science, they have pronounced productivity criteria, reinforcing competition and reinforcing hyper-productivity: women still have a harder time coping with this, due to a lack of assistance, due to persistent traditional gender role assigning and assuming main carer roles. A self-driven and self-imposed masculine habitus of being totally engaged, is coupled with a double-edged flexibility allowing for a "work all the time and everywhere" atmosphere where work/life imbalances reign, and even more so for women. Their male counterparts often have partners working part-time and assuming main carer roles. For newly tenured females, as in Type (2), they maintain a precarious balance, depending on the presence of a supportive partner and/or a supportive private network (parents looking after children, etc.), as child care services are very expensive and hard to come by, coupled with an institutional supportive network accessed by important gatekeepers/mentors. However, all that is a quite rare configuration for women as there are powerful cooptation logics and old boys' clubs. Thus the overall balance is very hard to maintain the higher the career ladder you climb; overwork becomes increasingly pronounced the higher the positions (professorships and management). In terms of gender inequality, women have a hard time accessing and winning in a stringent, competition-based system, fostering an elitist institution and career, and then, in maintaining that highly demanding position, compared to their male peers, who have more set configurations over a long-term period.

\section{Discussion and perspectives}

The analytical approach of inducing a typology of gendered pipelines from real country and institutional cases, and looking at the level and range of costs that these three ideal-types assemble on three different entity levels (science/institution/ individual worker) has allowed us to re-orientate the more classic vision of leaky 
pipelines. We have identified a common foundation of interrelated phenomena across all case studies. More importantly, however, we have shown that these common interrelated phenomena appear despite, or because of, specific contextual, organisational and configurational compositions. What we can discern is that this composition is quite significant in identifying the level and range of costs that leaky pipelines can incur upon the three entity levels. Importantly, there are clear indications that institutions can counteract to reduce these cumulative and specific costs, and that they must take their share in responsibilities regarding career opportunities and what becomes more significant, the organisation of work.

On the individual level, we can identify how in Type (1), for instance, women are in a very precarious overall situation, fraught with high risks and precipices, if they are to continue upon that linear career path, with high personal costs incurred (health, maternity, professional development, stabilisation, recognition) and fewer possibilities and opportunities for rebounding or breaking the fall. We can speak about a high degree of gender inequality for early career women researchers/academics, compared to their male peers. What this analysis has shown by looking at costs upon the three levels of the entities is that this gender inequality impacts on the macro level of science as much as on the institution it is based in. On the level of science as a collaborative, collective work and product of an organisation, we can see repercussions that have a significant impact upon the balance that arguably needs to be achieved between the key underlying priorities, missives and motivations of "responsible" science (Despret and Stengers 2011; Fassa 2013). For example, important scientific exchanges and development between teaching and research may suffer, as teaching is undervalued both on institutional levels and on the individual researcher level. The sticky floor of teaching experienced and lived by mainly female early career researchers in short-term contracts and assistantship positions, which are not remunerated similarly nor institutionally recognised as full academic posts, does not allow for teaching to have the same value, either institutionally or professionally (making sense of ones' work as meaningful and recognised), and as a consequence may become side-tracked, undervalued and decoupled from research, which in its turn is focused upon hyper-productivity and career orientation. This is also the case for Types (2) and (3). This devaluing of teaching is, moreover, parallel to a rising number of students in these very same institutions, where per student teacher ratios are lower. This means that on the institutional level, there is a bid for students, without any real thought being given to the teaching body and its stabilisation, motivation, assistance and formation, etc. This decoupled way of organising teaching and research may therefore have important consequences. There is also an increase in short-term research and knowledge production with the rise of short-term research contracts, fraught with limits in the time dedicated to fundamental research, and coupled with lower governmental funding of fundamental research. Early career researchers and academics also spend precious time bidding for external funding, making the competition more stringent between them, but also leaving less time for developing research work. This arguably reduces the depth of research 
undertaken, as researchers/academics juggle with more and more deadlines and hyper-productivity in terms of publications. The limits to research time affect the quality of research outputs and the type of knowledge elaborated in academia.

In all three Types of gendered pipeline, we witness a growing number of nonstabilised, "floating", largely unintegrated, unrecognised, research bodies and assistantship teaching staff, with diminished social and pension schemes in Type (1). For science, and the institution as whole, to benefit from a collaborative, satisfied - as meaningfully recognised - working body, it is important to include and recognise short-term employees, as well as permanent assistantship employees. Institutions would therefore benefit from envisaging greater recognition of doctoral and postdoctoral researchers, as well as assistants, that recognition being multi-faceted in the way of institutional membership, professional development, remuneration, status, social and pension schemes as well as integration/participation on unit levels (centres, universities).

As things stand, we are looking at less diversity in research and teaching in terms of gender, with fewer female role models, and the overall persistence of masculine-based scientific research work models, despite the feminisation of higher education across all three Types. The institutions should ask themselves whether or not that model really mirrors the kind and form of scientific knowledge they are producing. In Type (3), research and teaching will go on being produced by an elite, more homogenous group of researchers/academics, perpetuating the Ivory Tower effect. In all three Types, we can also speak of brain drain from academia to other sectors, because although there has been a feminising of higher education, there remain few career chances in academia and also simultaneously little conversion of $\mathrm{PhDs}$ in $\mathrm{SSH}$ sectors outside of academia in the Type (1) labour market. In Types (2) and (3), the extra-academic labour market is more open to both male and female, highly skilled workers but with no real $\mathrm{PhD}$ recognition. That raises questions about a decrease in the purpose and value of the PhD. Those same institutions are accepting many doctoral and postdoctoral researchers, but why? Moreover, the persistent gender stereotyping in STEM and SSH in all three Types continues to raise questions. Institutions, research and teaching units could benefit by rethinking the purposes of their degrees, their doctoral and postdoctoral appointments, with more responsible and long-term vision in making choices, promoting, fostering and strategically guiding.

Type (1) institutions and scientific communities are arguably contributing to producing a contradiction between work and family, as women struggle to maintain family and careers, more often renouncing parenthood than men. This is paired with no effective childcare and elderly support system in society at large: which is not taken into consideration on the institutional level. In Types (2) and (3), we can see the appearance of parental ambiguity, with women having a harder time maintaining a balance, with a high-level dependence on the "right configurations", and feelings of guilt at and off work. The higher we climb, the thicker the glass ceiling, which persists in all three Types, showing how "maintaining a balance" depends on a high incidence of favourable configurations 
- very hard to come by for women, making progressing in the career as arduous as entering it, especially for professorships, full professorships or management and leadership positions. We can ask ourselves, do research institutions want to contribute to this work logic, reinforcing certain types of profiles based on masculine models, and to a logic of work over care? In their collective plea for slow scholarship, Mountz et al. (2015) show that "care work is work". They explain how systematically marginalising care "furthers the myth that our successes are achieved as autonomous individuals and, as such, we have no responsibility to share the fruits of our success with others or to dedicate public resources to the work of care" (Lawson 2007, p. 5, in Mountz et al. 2015, p. 1238). Care can therefore be part of, instead of being alien to, the work ethics, logics and organisation of institutions. Care demands, conditions, times and nature should be taken into consideration by institutional regulation in the same way as work demands, conditions, times and nature, in unit philosophies, in recruitment criteria and in processes.

For all these Types, globally we can see the high incidence of funding systems on gender inequality, and for all three entity levels. Due to the funding systems (by points, or closed envelope systems), students are attracted due to bids for governmental funding, which reinforces a "competition over collaboration" culture between entities and between individuals. We can also say that scientific production is governed by funding structures. One avenue for institutions and entities (teaching and research) to counteract being governed by funding is to reduce the competition-based culture and work orientations, and instead strengthen collaborative work and bidding for funds. Entities should be more collective in sharing their knowledge amongst themselves, in looking for ways to promote research, and in looking for ways to move forward collectively in developing their research. This would arguably make for fewer lonely heroes and heroines, and also avoid replications, disjointedness and dispersions of funding applications within and between centres and other entities.

One major element that plays strongly in creating costs on all three levels are the gaps between formal and informal criteria, not in terms of their existence, but in terms of tensions between visibility, clarity, demands, discursive resources and making sense of work. In all three Types, there exists an institutional ambivalence and discrepancy over what might be called formal, or competition-based, or internationally orientated criteria, versus informal, subjective, local nomination-based or integration-based criteria for nominations during recruitment procedures. The struggle for women in this is balancing between a rock and a hard place, because the formal criteria are often hyper-productivity (highranking, numerous publications) and mobility based, which are difficult for women to comply with during childbearing and rearing years. Moreover, they are difficult because authorship possibilities are linked to publication systems, which are themselves often intimately linked to network access, both of which are reduced for female early career researchers. The second Type of criteria that are more local or institutional are strongly linked to access to institutional knowledge, codes, networks (both national and international) and gatekeepers/ 
mentors. This again is a configuration that is less often developed by women early career researchers, as we are also looking at the existence of cooptation logics, fewer female role models and mentors, less support. For career progression, moreover, we cannot minimise the importance of local embeddedness and overall institutional (all-round academic) involvement, an "omnipresence" that is harder for women, except, again, with the "right" configurations coming together (both institutional support and private support).

Here the importance of a two-fold process concerning institutions can be addressed: the importance of rethinking criteria, and of rendering the local criteria clearer, more visible and recognisable, and of rendering the formal criteria more sensitive to the counter effects of hyper-productivity and mobility demands. In addition, it becomes important to reconsider the side effects of already existing gender equality measures, such as funding possibilities or mentoring programmes, which are still recruiting "excellence" that is based on hyper-productivity and availability, and to become aware that that reinforces a competition culture as opposed to a more work-healthy collaborative culture. In general, the kind of work culture and organisation that can be rethought in favour of work rhythms and a philosophy that makes sense to its employees. Mountz et al. (2015) describe how their plea to slow down aims to undo some of the consequences of the frenetic pace at which many of us live our lives. According to Honoré (2005), "Fast and Slow do more than just describe a rate of change" rather, they are "ways of being, or philosophies of life ... It is about making real and meaningful connections - with people, culture, work, food, everything. The paradox is that Slow does not always mean slow" (Honoré 2005, pp. 14-15). Hartman and Darab (2012) call for slow scholarship as a response to the acceleration of academic work, discussing in particular the implications of this intensification for pedagogy. They frame intellectual freedom as the "freedom to think" (Hartman and Darab 2012, p. 53), a re-conceptualisation that they note requires the space, time and other resources curtailed by the escalation of corporate approaches to teaching and university management. Mountz et al. (2015) suggest that by slowing down - to listen and read what others have to say, to expand our experiences by getting out of offices and classrooms - we can do our best scholarship, teaching and mentoring.

\section{Conclusion}

The relationship between the precarious situation of researchers and the features of gendered organisations contributes to producing and reproducing inequalities between men and women in terms of access to, and maintenance and success in, scientific and academic careers. None of the case institutions studied leaks: phenomena related to leaky pipelines for women are clearly identifiable. However, while doing a meta-analysis of all the data studied, as we look more closely at the social and institutional contexts, at organisational dynamics and the experiences of researchers, we discover that not all the "pipelines" are entirely similar. Using the Weberian approach to ideal-types, we have isolated 
three Types of "gendered pipelines" based on a meta-analysis of six case studies across six European countries: a first Type that translates as persisting in precarious career paths in "Mandarin" organisations, with high cumulative costs; a second as continuing in ambivalent career paths in "Missionary" university institutions, with moderate costs; and a third as striving to win in competitive career paths in "Entrepreneurial" organisations, with specific costs.

The idea of these three Types of career paths, organisations and experiences, with various cost configurations, should allow specific research institutions to situate themselves, in order to determine what all of this means in terms of their own leaky pipeline situations, the three entity levels and their relationships to them, and what costs are at stake. Le Feuvre (2015) underlines how important it is for institutions to clearly define the model of feminisation they want to promote in academia, since different typological processes can have contrasting effects on the degree to which the existing gender system is reproduced, reconfigured or transformed. This typology can assist institutions and individuals in determining gender policies and taking measures that are not unidimensional.

\section{Note}

1 E.g. A massification of students and feminisation in higher education, with exceptions in STEM; a bottleneck variously narrowing at slightly different points after $\mathrm{PhDs}$ or during/after postdocs; tensions as to the value, purpose and status of the doc/postdoc on the labour market; a "ratchet effect" once you obtain the doctoral degree (diploma) and a tenured position; a perceived sticky floor on the level of teaching; a work/family conflict, etc.

\section{References}

Acker, J. (1990). Hierarchies, jobs, and bodies: a theory of gendered organizations. Gender \& Society, 4, 139-158.

Alper, J. (1993). The pipeline is leaking women all the way along. Science, 260, 409-411.

Beaufays, S. and Krais, B. (2005). Femmes dans les carrières scientifiques en Allemagne: les mécanismes cachés du pouvoir. Travail Genre et Société, 14(2), 49-68.

Berryman, S. E. (1983). Who Will Do Science? Minority and Female Attainment of Science and Mathematics Degrees: Trends and Causes. New York: Rockefeller Foundation.

Blickenstaff, J. C. (2005). Women and science careers: leaky pipeline or gender filter? Gender and Education, 17(4), 369-386.

Booth, A., Francesconi, M. and Frank, J. (2003). A sticky floors model of promotion, pay, and gender. European Economic Review, 47, 295-322.

Bozzon, R., Murgia, A. and Poggio, B. (2015). Italy. In F. Dubois-Shaik and B. Fusulier (eds), Academic Careers and Gender Inequality: Leaky Pipeline and Interrelated Phenomena in Seven European Countries. GARCIA Working Papers 5, University of Trento, pp. 7-31.

Case, S. S. and Richley, B. A. (2012). Barriers to women in science: examining the interplay between individuals and gendered institutional research cultures on women scientists' desired futures. Work and Family Researchers Network Conference, New York, 14 June. 
Despret, V. and Stengers, I. (2011). Les faiseuses d'histoire. Que font les femmes à la pensée? La Découverte, Paris.

Dubois-Shaik, F. and Fusulier B. (eds) (2015). Academic Careers and Gender Inequality: Leaky Pipeline and Interrelated Phenomena in Seven European Countries. GARCIA Working Papers 5, University of Trento.

Dubois-Shaik, F. and Fusulier B. (eds) (2016). Experiences of Early Career Researchers/ Academics: a Qualitative Research on the Leaky Pipeline and Interrelated Phenomena in six European Countries. GARCIA Working Papers 11, University of Trento.

Dubois-Shaik, F., Fusulier, B. and Vincke, C. (2015). "Belgium”. In F. Dubois-Shaik and B. Fusulier (eds), Academic Careers and Gender Inequality: Leaky Pipeline and Interrelated Phenomena in Seven European Countries. GARCIA Working Papers 5, University of Trento, pp. 32-61.

Eurostat Data (2015). Students by ISCED Level, Age and Sex http://ec.europa.eu/eurostat/ data/database.

Fassa, F. (2013). La recherche en Suisse quand le genre interroge les critères de l'excellence scientifique. Mouvements, 4(76), 162-175.

Fassa, F. and Kradolfer, S. (dir.) (2010). Le plafond de fer de l'université. Femmes et carrières, Zurich, Seismo.

Fassa, F., Kradolfer, S. and Paroz, S. (2012). Enquête au royaume de Matilda. La relève académique à l'Université de Lausanne. LIVES Working Papers, 11, Lausanne.

Gherardi, S. (1994). The gender we think, the gender we do in our everyday organizational lives. Human Relations, 47(6), 591-610.

Grant, L., Kennelly, I., Ward, K. B. (2000). Revisiting the gender, marriage, and parenthood puzzle in scientific careers. Women's Studies Quarterly, 28(1-2), 62-85.

Hartman, Y. and Darab, S. (2012). A call for slow scholarship: a case study on the intensification of academic life and its implications for policy. Review of Education, Pedagogy, and Cultural Studies, 34(1-2), 49-60.

Herschberg, C. and Berger, L. (2015). The Netherlands. In F. Dubois-Shaik, F. and Fusulier B. (eds), Academic Careers and Gender Inequality: Leaky Pipeline and Interrelated Phenomena in Seven European Countries. GARCIA Working Papers 5, University of Trento, pp. 62-79.

Herschberg, C., Benschop, Y. and Van den Brink, M. (eds) (2015). Constructing Excellence: The Gap between Formal and Actual Selection Criteria for Early Career Academics. GARCIA Working Papers 2, University of Trento.

Honoré, C. (2005). In Praise of Slow: How a Worldwide Movement is Challenging the Cult of Speed. London: Orion Books.

Hymowitz, C. and Schellhardt, T. D. (1986). The glass ceiling: why women can't seem to break the invisible barrier that blocks them from the top jobs. The Wall Street Journal, 24 March, p. 1.

Istenič, M. Č. (2015). Slovenia. In F. Dubois-Shaik and B. Fusulier (eds), Academic Careers and Gender Inequality: Leaky Pipeline and Interrelated Phenomena in Seven European Countries. GARCIA Working Papers 5, University of Trento, pp. 138-161.

Kradolfer, S. (2015). Switzerland. In F. Dubois-Shaik and B. Fusulier (eds), Academic Careers and Gender Inequality: Leaky Pipeline and Interrelated Phenomena in Seven European Countries. GARCIA Working Papers 5, University of Trento, pp. 116-137.

Kuhn, T. (2006). A "demented work ethic" and a "lifestyle firm": discourse, identity, and workplace time commitments. Organisation Studies, 27, 1339-1358.

Lawson, V. (2007). Geographies of care and responsibility. Annals of the Association of American Geographers, 97(1), 1-11. 
Le Feuvre, N. (2009). Exploring women's academic careers in cross-national perspective: lessons for equal opportunity policies. Equal Opportunities International, 28(1), 9-23.

Le Feuvre, N. (2015). Contextualizing Women's Academic Careers in Cross-National Perspective, GARCIA Working Paper 3, University of Trento.

Merton, R. (1969). The Matthew effect. Science, 159(3810), 56-63.

Morley, L. (2013). The rules of the game: women and the leaderist turn in higher education. Gender and Education, 25(1), 116-131.

Moss, P., DeBres, K. J., Cravey, A., Hyndman, J., Hirschboeck, K. and Masucci, M. (1999). Towards mentoring as feminist praxis: strategies for ourselves and others. Journal of Geography for Higher Education, 23(3), 413-427.

Mountz, A., Bonds, A., Mansfield, B., Loyd, J., Hyndman, J., Walton-Roberts, M., Basu, R., Whitson, R., Hawkins, R., Hamilton, T. and Curran, W. (2015). For slow scholarship: a feminist politics of resistance through collective action in the neoliberal university. ACME, 14(4), 1235-1259.

Musselin, C. and Pigeyre, F. (2008). Les effets du recrutement collégial sur la discrimination: le cas des recrutements universitaires. Sociologie du travail, 50, 48-70.

Poggio, B., (2006). Editorial: outline of a theory of gender practices. Gender, Work and Organization, 13(3), 225-233.

Rossiter, M. (1993). The Matthew Matilda effect in science. Social Studies of Science, 23(2), 325-341.

Smidt, T. B., Einarsdóttir, P. and Pétursdóttir, G. M. (2015). Iceland. In F. Dubois-Shaik and B. Fusulier (eds), Academic Careers and Gender Inequality: Leaky Pipeline and Interrelated Phenomena in Seven European Countries. GARCIA Working Papers 5, University of Trento, pp. 80-115.

Steinthorsdottir, T., Finnborg S. Heijstra, M., Einarsdóttir, T. and Pétursdóttir, G. M. (eds) (2016). Gender Budgeting in Academia. GARCIA Working Papers 8, University of Trento.

Van den Brink, M. and Benschop, Y. (2012). Gender practices in the construction of academic excellence: sheep with five legs. Organization, 19(4), 507-524.

Weber, M. (1922). Gesammelte Aufsätze zur Wissenschaftslehre. Tübingen: J. C. B. Mohr [French translation: J. Freund, Essais sur la théorie de la science. Paris: Plon, 1965].

Weick, K. (1995). Sensemaking in Organizations. Thousand Oaks, CA: Sage. 

Conclusions 



\title{
7 Implementing measures to promote gender equality and career opportunities of early career researchers
}

\author{
Florian Holzinger, Helene Schiffbänker, \\ Sybille Reidl, Silvia Hafellner and \\ Jürgen Streicher
}

\section{Introduction}

During the last decades, higher education and research systems have been increasingly affected and transformed by processes of globalisation, internationalisation and marketisation. For one, this is reflected in the increasing number of students, persons holding a doctoral degree and researchers worldwide (Neumann and Tan 2011; Science Europe 2016). It has, however, also impacted the development and modes of academic production which have become, for instance, more oriented towards market logic, entrepreneurialism and competition. Specific features of this so-called regime of 'academic capitalism' (Slaughter and Leslie 2001, p. 154) are the 'growing contingency in labour conditions, increased managerialism, and internationalisation' (Cantwell 2011, p. 101). As a consequence, research careers have become more flexible and diversified, hence complex, moving away from the traditional understanding of careers as a linear progression. This is clearly mirrored by the changing employment conditions of researchers (Bennion and Locke 2010). The number of temporary, non-permanent and part-time academic positions has grown significantly in contrast to tenured and permanent ones. Compared to other research sectors, the higher education sector is currently characterised by a lower share of permanent employment (European Science Foundation 2017; Powell 2015).

The growing contingency of academic labour is most evident in the early stages of research careers - the doctoral and postdoctoral phases. Postdoctoral researchers are the focal point of these new developments as the characteristics of contingent researchers are exemplified in this group. They have become an important pillar of the research and innovation system and primary drivers of academic research as they are publishing papers, apply for research grants, manage labs, supervise junior researchers and take over teaching responsibilities (Cavanaugh 2018). Simultaneously their work conditions have become increasingly insecure and precarious.

But this growing group of researchers and their employment conditions have only in the last decade gained attention from research policy makers (Cantwell 
2011; Gülker and Böhmer 2010; Jaeger and Dinin 2018). Increasing concerns have been raised whether research systems and especially the academic sector are able to utilise this academic workforce and its competencies adequately (Grigolo, Lietaert and Marimon 2010; Auriol, Misu and Freeman 2013), or whether their expansion is driven by a demand for flexible, fixed term researchers who are low cost and essentially disposable (Fox and Stephan 2001; Science Europe 2016; European Science Foundation 2017).

As has been extensively discussed in this volume, the changes that have characterised the research system, and more specifically early career researchers' conditions and experiences, have significant implications in terms of gender, reinforcing practices and mechanisms that reproduce gender inequalities. At the same time the new managerial and academic regime has also changed the perspective on gender equality policies in the higher education system - from a feminist bottom-up activity based on normative targets of equal opportunity, equality and equal justice to a top-down strategy oriented towards market-driven arguments. Gender equality and related measures have become part of the modernisation of academic institutions and are increasingly discussed and implemented in the context of organisational policies and priorities, typically aiming at enhancing economic effectiveness, efficiency, transparency and accountability (Davies and Thomas 2002; Garforth and Kerr 2009; Bendl and Schmidt 2012; Ferree and Zippel 2015). However, it is found that the new managerial regime was not (yet) able to narrow the gap of gender inequalities. On the contrary, as recent data suggest, gender inequalities in higher education as well as in the whole research sector are highly persistent (Huyer 2015; European Commission 2016). Although new gender equality policies and measures have been developed and implemented addressing structural and cultural issues, they still remain on the margins of organisational policies (Bendl and Schmidt 2012).

This chapter presents and discusses findings from an accompanying evaluation of measures and actions to promote gender equality and career prospects for early career researchers, which have been implemented within the GARCIA project. The measures and activities analysed were conducted in one social sciences and humanities (SSH) and one science, technology, engineering and mathematics (STEM) department in six European higher education and research performing organisations. The evaluation provided the opportunity to discuss and reflect the implementation processes - its strengths and weaknesses, its opportunities and threats, but also the encountered resistances and the process itself. Here the main features and aspects of implementation processes as observed in the course of our evaluation are summarised. We argue that more attention needs to be paid to the processes of implementation and to develop a better understanding of these processes to facilitate successful and effective interventions and to narrow the implementation gap.

The chapter starts by considering the current situation of early career researchers in terms of employment conditions and career prospects but also for gender equality in the early stages of a research career. Recently, the precarious working conditions of early career researchers have been recognised in different 
European policy documents, which are briefly discussed in section two. Section three presents an overview of common measures to promote gender equality and the employment conditions of early career researchers. In section four the experiences of the GARCIA project are summarised, focusing on the measures that were implemented in the six higher education and research performing organisations and the main findings of observing the implementation process. Finally, conclusions and recommendations for implementing structural change projects in research performing organisations are formulated.

\section{The situation of early career researchers}

The postdoctoral phase is widely acknowledged as the most competitive phase in the academic career (Åkerlind 2005; Konsortium Bundesbericht Wissenschaftlicher Nachwuchs 2017; European Science Foundation 2017). It should enable early career researchers to get involved in substantial research to acquire relevant professional skills and competencies as well as to develop an independent research profile (Science Europe 2016). This career phase should prepare postdocs to make the next step in a research career: a tenure track or a permanent academic position. But as the number of persons holding a doctoral degree and postdoc positions is increasing worldwide (Chen, McAlpine and Amundsen 2015, p. 1083), the postdoctoral phase has become an important and decisive stage for research careers in academia. An increasing number of postdocs are competing for a small number of tenure track or permanent positions. As a recent report on the situation of early career researchers in Germany shows, the number of postdoctoral researchers expands faster than the number of professors at higher education institutions (Konsortium Bundesbericht Wissenschaftlicher Nachwuchs 2017). This results in uncertain career prospects, as there is no guarantee for permanent employment for postdocs in academia. They have therefore been labelled as 'a labour force in waiting' (Andalib, Ghaffarzadegan and Larson 2018).

Following recent research, the working and employment conditions of postdoctoral researchers can be summarised as follows: insecure career prospects and advancement; high mobility demands impeding family formation; lack of sufficient (social and health) benefits; low stipends or salaries; insecure employment conditions (fixed and short term, part-time, self-employed); increasing duration of postdoctoral employment periods through sequencing multiple postdoc positions; long working hours which exceed their contractual ones; feelings of isolation, intense competition and accelerated pace of academic work; lack of recognition of postdoctoral researchers by research organisations (Åkerlind 2005; Foote 2010; Scaffidi and Berman 2011; Müller 2014; Chen, McAlpine and Amundsen 2015; Science Europe 2016).

Some recent studies emphasise that unemployment rates of persons holding a doctoral degree are very low and concerns about overproduction of $\mathrm{PhD}$ graduates are considered unfounded (Schramm and Kerst 2009; Science Europe 2016; European Science Foundation 2017). But not all $\mathrm{PhD}$ graduates seek or find 


\section{Florian Holzinger et al.}

employment in the research profession as other knowledge-intensive sectors of the economy are seeking and absorbing highly skilled workers. On the other hand, some studies report that $\mathrm{PhD}$ graduates are overqualified, as they are working in jobs which do not require such extensive training, or do not work in their area of speciality (Ackers 2005). However, differences between academic disciplines are observable: for instance, $\mathrm{PhD}$ graduates in humanities show a significantly higher level of unemployment compared to natural sciences $\mathrm{PhD}$ graduates (Science Europe 2016; European Science Foundation 2017). Other studies have reported gender differences in unemployment rates of STEM graduates: female STEM graduates are more often reporting unemployment than male STEM graduates (Solga and Pfahl 2009).

In terms of gender equality, the postdoctoral career stages are marked by a significant drop out of women researchers as indicated by the phenomenon of the leaky pipeline described in the previous chapter. Research careers are currently characterised as highly individualised and high-risk in terms of gaining a permanent position. There is evidence that this risk is unequally distributed between women and men, as women's chances of success in a research career are lower (Rees 2011; Kahlert 2012; European Commission 2016). It is particularly during the postdoctoral phase that women are more likely to drop out of research careers, as indicated by the 'glass ceiling' (Eriksson-Zetterquist and Styhre 2008; Bendl and Schmidt 2010) or 'leaky pipeline' (Levitt 2010; Glass et al. 2013) concepts. Main reasons for their underrepresentation in the higher levels of research careers and their dropping out are seen in lower career support for women by supervisors, lack of relevant networks (Howe-Walsh and Turnbull 2014), gender-biased recruitment and promotion procedures (Van den Brink, Benschop and Jansen 2010; Van den Brink 2011; Van den Brink and Benschop 2012a), lower chances of success for research grants (van der Lee and Ellemers 2015), chilly organisational climates and gendered institutional structures (Sallee 2014), and low compatibility of work and personal life (Wilton and Purcell 2010; Goulden, Mason and Frasch 2011; Bozzon et al. 2017).

Over the last decade, the rates of physical and mental ill health amongst academics have also significantly increased, especially for people in a precarious position (Guardian 2014-2017; Berg, Huijbens and Gutzon Larsen 2016). On the one side, Foote (2010) suggests that there is an internalised perception of academic life in terms of competition and struggle which makes endurance and sacrifices necessary to compete in the scientific pursuit for knowledge and success. On the other, lengthy employment in postdoctoral positions leads to disillusionment and to higher levels of dissatisfaction with employment conditions (Åkerlind 2005; Science Europe 2016). While precarious working conditions and dissatisfaction may not necessarily lead to individuals dropping out of research careers, they can contribute to accepting jobs below qualification level (Grigolo, Lietaert and Marimon 2010). Furthermore, leaving the academic and research career is often perceived as failure by postdoctoral researchers and their peers, leading to disappointment. This social pressure makes them stick to their 
career aspirations, which might involve accepting working under precarious conditions, with little or no guarantee of employment stability (Åkerlind 2005).

In sum, postdoctoral researchers have become an important part of the academic workforce and of scientific production. They are crucial to advancing the agenda of the knowledge economy and of research organisations. As reported by different studies, they make significant contributions to developing scientific knowledge, technological solutions and innovation (Musselin 2004; Åkerlind 2005; Cantwell 2011; Chen, McAlpine and Amundsen 2015), and they are managing a considerable part of the teaching activities at higher education institutions. But high levels of productivity do not necessarily translate into a faculty career or permanent position (Cantwell 2011). Furthermore, they are often perceived more as adjuncts to a research project than as independent researchers in their own right (Madden 2009).

Hence, to increase the career opportunities of postdoctoral researchers, more structured and better career support, and more transferable skills training are needed (Åkerlind 2005; European Science Foundation 2017; Foote 2010; Science Europe 2016; Konsortium Bundesbericht Wissenschaftlicher Nachwuchs 2017). Early career researchers should be better prepared for careers outside of academic research and inter-sectoral mobility should be promoted. This should enhance employment opportunities and facilitate the transition into the postdoctoral phase, but also between different sectors and careers. However, it has been found that current doctoral or postdoctoral training programmes hardly prepare graduates for alternative careers as their focus is on (academic) research careers only (Foote 2010; Science Europe 2016; Konsortium Bundesbericht Wissenschaftlicher Nachwuchs 2017).

Career support activities by supervisors are provided individually and are therefore mostly of an ad hoc nature ( $\AA$ kerlind 2005). Early career stages in the research profession are perceived as a 'rite of passage' (Foote 2010) where early career researchers have to prove themselves to become independent researchers. Only those who survive have been proven to possess the relevant talent and stamina to become a permanent member of the research community. Therefore, supporting early career researchers is often seen as counterproductive. In this sink or swim mentality, early career researchers have to deploy a self-help model of professional development to succeed, but they cannot rely on a systematic and organisational support structure (Foote 2010). Furthermore, supervisors who have spent most or all of their time in academia are hardly equipped to provide adequate career advice or relevant skills training for their early career researchers. Although access to organisational resources is important for career success, structured instruments and offerings to postdoctoral researchers are still scarce (Scaffidi and Berman 2011; Chen, McAlpine and Amundsen 2015). Scaffidi and Berman (2011) conclude that postdocs should have access to other sources of career advice than from their supervisors. In addition, career development or skills training are not essential parts of most postdoctoral funding schemes in Europe (Science Europe 2016). 


\section{Florian Holzinger et al.}

\section{The policy agenda}

In the last two decades, the situation of early career researchers and their precarious career and working conditions have gained more attention from policy makers in Europe. In 2005, the European Commission launched the European Charter for Researchers and the Code of Conduct for Recruitment of Researchers (2005). It stated that employers as well as funders should ensure that the performance of researchers is not undermined by instability of employment contracts, and should therefore commit themselves as far as possible to improving the stability of employment conditions for researchers $(2005$, p. 17). This does not only refer to early career researchers, as it highlights the fact that unstable employment conditions are a widely occurring problem. Furthermore, the Code of Conduct argues for a specific career development strategy for research at all career stages, explicitly including researchers on fixed term contracts. By providing career development strategies, researchers' insecurities with regard to their professional future could be reduced, contributing towards the motivation to stay in the research profession.

Several key documents have recently been developed in Europe addressing the issue of career development for researchers. In 2012, for instance, the European Commission put forward five key priorities defining a unified European Research Area (ERA). Amongst others, the lack of gender equality and the lack of an open labour market were identified as major obstacles for its establishment (European Commission 2012). Mobility, gender equality and research performance are particularly hampered by an apparent lack of transparent, open and merit-based staff recruitment. Human resource policies were found to be inadequate with regard to career prospects for young researchers and gender equality practices (European Commission 2012). In 2015, the European Commission emphasised the necessity to strengthen comprehensive human resource strategies and the provision of attractive career pathways for young researchers as relevant objectives for future considerations in the ERA Roadmap 2015-2020. In 2016, the Bratislava Declaration of Young Researchers was launched and presented to the EU research ministers which called for sustainable and transparent career trajectories and a healthy work-life balance for young researchers (2016). The Declaration stated that young researchers often find themselves facing career uncertainties combined with non-transparent, unstructured career progression. In addition, the working conditions of young researchers are contributing to a work-life conflict as they include unreasonable working schedules, high availability, inappropriate salaries and unstable contract conditions. Requirements with regard to mobility enforce the work-life conflict. In November 2016, the European Council released conclusions acknowledging the demands of the Bratislava declaration to support early stage researchers by offering attractive career development opportunities (Council of the European Union 2016).

In sum, these policy documents consider sustainability and continuity of career development for researchers at all stages of their career, in particular early career researchers, as critical for research and innovation performance. They 
expect that offerings such as childcare provision, parental care, flexible working practices and availability of dual career opportunities for young researchers will contribute to the improvement of career prospects, as will support with regard to mobility - intersectoral, interdisciplinary and virtual mobility (2016).

Furthermore, research on gender equality has identified an implementation gap: although a broad set of measures and policies to promote gender equality have been developed, there is hardly any change observable (Allard, Haas and Hwang 2007). Due to this implementation gap, gender equality policies cannot unfold their intended potential. Therefore - besides the continuing trend towards impact orientation in evaluation (Reale et al. 2017) - implementation processes need to be analysed more thoroughly to have a better knowledge on their pitfalls and challenges as well as on their opportunities to reduce the implementation gap.

Research on implementation of gender equality measures in research organisations has identified a number of features of such processes that are considered important for achieving objectives and impacts. One of the most important ingredients for successful implementation is seen in the strong organisational commitment to gender equality and for the specific objectives of implemented policies (Lee, Faulkner and Alemany 2010b; Lewis and Humbert 2010; Laursen et al. 2015; EIGE 2016a). Importantly, this commitment has not only to be shared amongst top-level executive management, but also amongst other organisational stakeholders, in particular middle or line managers, who are more involved in the daily routines and operational procedures of organisations. Securing organisational commitment can be supported through cooperating with external stakeholders, for instance regional or national policy makers or non-governmental organisations (Cacace et al. 2015; Laursen et al. 2015; EIGE 2016a).

Another key element is to increase the overall awareness of how gender inequality plays out in the organisation, and how gendered structures and practices are reproduced by organisational and individual behaviour. In light of this, it is important to emphasise the business and organisational benefits arising from promoting gender equality, and establish links between gender equality and overall organisational strategies and objectives (Lee, Alemany and Faulkner 2010a; Cacace et al. 2015). Other evidence points in the opposite direction, namely that organisational strategies may inhibit or contradict the implementation of gender equality policies (Smidt, Pétursdóttir and Einarsdóttir 2017). Also, the allocation of sufficient financial resources on a long-term basis and establishing clear responsibilities and operational structures is considered important (Steinghordsdottir et al. 2016). This enables the implementation of policies to endure, as structural change processes are slow and need a long term commitment and perspective (Lee, Alemany and Faulkner 2010a). Implementing organisational change processes to promote gender equality requires skilled personnel possessing relevant knowledge about tackling gender inequalities and their (re)production but also know-how on the issues of organisational change processes (EIGE 2016a, 2016b; Cacace et al. 2015). Furthermore, the process of implementation needs also to develop the competencies regarding gender inequalities of involved stakeholders enabling them to support gender equality 


\section{Florian Holzinger et al.}

adequately (Eriksson-Zetterquist and Styhre 2008; EIGE 2016a). Another relevant ingredient for successful implementation of gender equality policies is monitoring and evaluation. For one, this generates evidence, namely on the process of implementation and its results, to support learning and decisionmaking. Second, it provides accountability and legitimation through documenting its activities and effects (Lee, Faulkner and Alemany 2010b; Laursen et al. 2015; EIGE 2016a).

\section{Measures to support early career researchers and gender equality: a general overview}

This section describes measures to support early career researchers and to promote gender equality in higher education organisations in six European countries. It is not an exhaustive summary of such measures, but seeks to provide an overview on the most common. The section also builds on relevant literature on measures supporting career opportunities and working conditions of early career researchers.

The most common support for early career researchers offered by research performing organisations are mentoring programmes for $\mathrm{PhD}$ students and postdocs. These programmes are designed to offer early career researchers structured career guidance and professional development. Whereas some mentoring programmes address all early career researchers regardless of their sex, there are also specific mentoring programmes for women who are facing career obstacles such as lack of networks and support from colleagues, non-transparent, implicit organisational and field-specific rules of promotion and recruitment and worklife conflicts, among others. These programmes try to support female early career researchers in planning their career systematically and to prepare them for future leadership and management assignments. Other mentoring or coaching programmes are directed at postdocs in the early stage of motherhood. They provide specific support measures for highly qualified female postdoctoral researchers with young children to enable them to focus on and maintain their research career. But as these mentoring programmes are resource-intensive, they are mostly focusing on a relatively small target group of highly qualified women (and men). As recent research has demonstrated, a structured training plan is a valuable tool for mentoring processes as it provides clear guidance on the specific needs for training and on career aspirations of postdoctoral researchers which facilitates success in terms of publishing and career satisfaction, but also the likelihood of staying in academic research (Davis 2009; van Balen et al. 2012; van der Weijden et al. 2015; Hokanson and Goldberg 2018).

Furthermore, training should also prepare early career researchers for a career outside academia in research-intensive, but also research-related, activities, as not enough permanent positions are opened each year in academia to take up all early career researchers. But most of academic mentors and supervisors are not qualified or equipped to prepare their mentees or trainees for positions outside academia (Cavanaugh 2018) and universities do not offer such training and 
coaching systematically. Moreover, training also needs to vary between different disciplines (Bäker 2015; van der Weijden et al. 2016): postdocs working in social sciences and humanities might have different needs for training and career support than their colleagues in STEM fields - not only in respect of academic careers, but also of skills required in jobs outside academia. Therefore, a portfolio of discipline-specific training should be offered by research performing organisations (Cavanaugh 2018). To be able to develop needs-based mentoring, coaching and training programmes, it is necessary to know in which jobs $\mathrm{PhD}$ graduates and former postdocs are working, and which skills are required to do these jobs. Therefore, some research organisations and especially universities have introduced alumni databases and career tracking programmes. These provide valuable insights into career paths and professional development of early career researchers (Cavanaugh 2018).

As postdoctoral researchers in particular are at a stage of their lives where family formation becomes or has become an important issue, they also can benefit from family leave policies and parental support offered by research performing organisations (Lee, Williams and Li 2017). Although limited parental support impacts negatively on postdoc retention, only a few organisations offer related services for them, such as on-site childcare facilities or subsidised childcare costs, as they are considered neither as students nor as employees (Lee, Williams and Li 2017; Cavanaugh 2018). However, there are specific measures targeting female early career researchers with young children: for instance, back to research grants after family-related career breaks which should enable them to progress faster in their research projects and to catch up with other competitors without career breaks in terms of publications and other research outputs. Other universities provide lab and research assistants for pregnant women or women (and men) returning part-time after a career break to help them to combine work and care responsibilities while being supported in their research through additional personnel resources. Furthermore, universities also offer to relieve female early career researchers from specific duties such as teaching or administrative responsibilities to be able to concentrate more on research and scientific productivity. Additionally, universities sometimes offer specific travelling or mobility grants for female early career researchers with young children. These grants can be used to arrange childcare during travels to conferences or fieldwork.

Besides fellowships for early career researchers offered by national or regional research funding agencies, research performing organisations are also supporting specifically the careers of female researchers. These organisational career fellowships are important as they provide additional means to pursue a research career, make female researchers more visible and their successful obtainment can be added to the CV. This makes female researchers more competitive for acquiring third party funding (Cavanaugh 2018). Therefore, some universities have started to establish such fellowship programmes for early career researchers but not all are explicitly dedicated to female researchers only. Furthermore, they are targeting outstanding and ambitious female talents and are therefore limited to a small group of early career researchers. 


\section{Florian Holzinger et al.}

Accompanying these measures, universities support early career researchers through establishing intra-organisational networks of female early career researchers. This should facilitate sharing of experiences and knowledge about work and private life-related issues like personal and professional development. Furthermore, these networks should also collect target group related needs and interests and communicate them to relevant organisational stakeholders.

In some universities postdoctoral offices have been established which are responsible for coordinating and implementing support measures for postdoctoral researchers and also work with other organisational stakeholders to promote their status and institutional support. The establishment of such an office is an important step as it is a sign for the formal acknowledgement of this specific group of researchers by the university. Cavanaugh (2018) has identified four different tasks for such offices: establishing professional development programmes for postdoctoral researchers to enhance their skills and competencies; offering career development programmes to support them in exploring different career paths and job opportunities; acting as a contact point for postdocs but also for other organisational stakeholders and providing recommendations and policies to support career development and progress; deploying tools to survey their training experiences and to track their careers after leaving the university. Nevertheless, responsibilities for postdoctoral researchers are still shared between different administrative units like HR departments or gender equality offices in quite some universities.

\section{Implemented measures and characteristics of the implementation process: the experience of the GARCIA Project}

The findings presented in this section are based on observing and evaluating the implementation processes of measures to promote gender equality and the career opportunities of early career researchers in six research performing organisations located in six different European countries: Belgium, Iceland, Italy, The Netherlands, Slovenia and Switzerland. The six research performing organisations consist of one non-university research centre (Research Centre of the Slovenian Academy of Sciences and Arts) and of five universities (University of Trento, University of Lausanne, Radboud University, Catholic University of Louvain and University of Iceland).

Not only is the country-wise context of these research organisations differing in respect to economic competitiveness (OECD 2016; World Economic Forum 2017), innovation performance (European Commission 2017b), research and development policies (European Commission 2017a), social welfare systems (Põder and Kerem 2011) as well as gender equality policies and progress (European Institute for Gender Equality 2017), but, also, the organisations themselves exhibit different characteristics. In terms of student numbers, the size of these organisations is quite different: it varies between around 14,000 and 26,000 students. Compared to other universities in their countries, these are small- to 
medium-size universities. The share of international students lies between 8 per cent and 25 per cent. None of the universities is in the top 100 universities of the Times Higher Education World University Ranking. The universities rank between position 122 (Radboud University) and 300 (University of Trento). The non-university research centre is not a higher education institution and therefore no students are graduating. But its mission is conducting basic research in national as well as international research programmes.

All these research organisations - even though to different extents - are marked by horizontal and vertical gender segregation. Women are underrepresented in managerial positions like rectors or deans as well as on the professorial level. In addition, there are significant differences between departments and scientific disciplines concerning the participation of women observable in all six research performing organisations. Social sciences and humanities departments or faculties are characterised by a higher share of female students and researchers whereas women are still a minority in science and engineering departments or faculties. This applies also for postdoctoral researchers.

Concerning policies to promote gender equality and the career opportunities of early career researchers, the picture is quite complex. Some of the research organisations such as the University of Lausanne or the Radboud University had already developed quite extensive organisational policies to promote gender equality, but others could be labelled as beginners who were taking their first steps in establishing such policies, such as the Catholic University of Louvain, the University of Trento and the Research Centre of the Slovenian Academy of Sciences and Arts. However, the more accomplished research performing organisations sometimes implemented gender equality policies in a fragmented way. Although there were structures, responsibilities and measures established on the overall management level, these did not diffuse to all other organisational units and levels equally. On the other hand, there were hardly any policies promoting career development and opportunities for postdoctoral researchers. This group of research personnel was hardly visible on the organisational agendas as indicated, for instance, by the lack of organisational data for this group. The established policies for promoting early career researchers were focused on $\mathrm{PhD}$ students and doctoral programmes. Postdoctoral researchers were not given high priority and were in some cases explicitly excluded from several organisational policies or services such as at the University of Trento - as, according to Italian Law, they did not share the same status and employment rights as the standard academic staff. The few organisational policies directed at postdocs had the purpose of identifying and promoting careers of so-called high potentials, for instance in the mentoring for talented female academics in the framework of the Christine Mohrmann programme at Radboud University. This specific, but rather small, group of female researchers was identified according to traditional excellence and hyper-productivity-based criteria. But such policies only existed in a few of the six research performing organisations.

The research organisations have set out to implement common measures to promote gender equality and better career opportunities and working conditions 
for early career researchers. At the beginning of the implementation process all research performing organisations committed themselves to the same common action plan that was then tailored to the specific situations and conditions in each organisation. The selected measures reflect the ERA objectives for promoting gender equality formulated by the European commission (European Commission 2012), and are also related to the specific organisational as well as national contexts. For instance, the University of Iceland has focused on implementing gender budgeting actions in line with national legislation as well as with support of and coordination with the authorities of the city of Reykjavík. Therefore, although all organisations have implemented a common plan, each organisation has set different priorities and tailored each measure to its specific needs and requirements.

The implementation plan consisted of the following measures: a mentoring programme for early career researchers; reflexive career training for early career researchers; reflexive training on gender biases in recruitment procedures for decision makers; training courses on how to integrate a gender perspective into teaching and research projects; and raising awareness for gender budgeting in research performing organisations.

\section{Establishing a mentoring programme for early career researchers}

Mentoring and other sources of career advice and support are crucial for career development of postdoctoral researchers (Scaffidi and Berman 2011; Thomas, Lunsford and Rodrigues 2015) and especially for women (Blau et al. 2010; Kalpazidou Schmidt and Faber 2016; Höppel 2015). Often supervision is informal and unequally distributed between postdoctoral researchers. Women in particular lack such informal career support and therefore official mentoring programmes are considered as a prerequisite to retain women in academic careers and to sealing the leaky pipeline (Simard et al. 2008; Hill, Corbett and St Rose 2010; Meschitti and Lawton Smith 2017). But mentoring has also received criticism as it does not change the masculine model of the ideal academic, but rather helps women to adjust to these norms to be successful (Ely and Meyerson 2000; Van den Brink and Benschop 2012b). Thereby the rules of the game as well as negative stereotypes towards women might be inadvertently reinforced (Soe and Yakura 2008). Structural and cultural change is not the main aim of mentoring interventions so far. But transformative mentoring programmes focused on changing the organisation through mentoring programmes have recently gained more attention (Vries, Webb and Eveline 2006; Vries and Van den Brink 2016; Meschitti and Lawton Smith 2017).

The mentoring programme developed and implemented by research organisations should provide advice on advancing an academic career as well as on scientific issues and questions but should also enable an exchange of relevant information and (career) opportunities between researchers at different levels of their career. As already outlined, the research performing organisations involved in the GARCIA project differed in terms of their already available mentoring 
programmes. The University of Lausanne and the Radboud University already had well-developed university-wide mentoring programmes for $\mathrm{PhD}$ students and postdocs. The other research performing organisations did not have any specific mentoring programmes for early career researchers. The developed mentoring programmes or activities were quite different in each organisation, depending on the needs of early career researchers and the limits of possibilities and feasibility in each organisation. The scope of implemented mentoring activities therefore ranged from scientific paper writing classes where informal exchange, support and career advice between postdoctoral researchers and other peers could take place (University of Iceland), to the establishment of an online mentoring platform offering career advice (University of Trento), and a formal mentoring programme for postdocs (Radboud University). Other organisations started to prepare the establishment of a formal university-wide mentoring programme by developing scenarios for such programmes, while two institutions did not engage in setting up a new mentoring programme.

\section{Reflexive training on prerequisites of academic careers for early career researchers}

As already mentioned above, career advice and guidance are important for early career researchers to be better prepared for navigating academic work and career possibilities (McAlpine and Amundsen 2015). Early career researchers are often lacking tacit knowledge about the prerequisites of an academic career such as which career options are available, how to apply for grants and open positions, how to develop a suitable publishing strategy to build an excellent and competitive academic track record, etc. But this also requires making postdocs and also PhD students familiar with alternative career options besides academia (McAlpine and Emmioğlu 2014; Cavanaugh 2018). This broadens their perspectives and reduces risks stemming from unilateral orientation towards an academic career.

Therefore, reflexive training for early career researchers was conducted to address these issues and to prepare participants for the endeavour of an academic career. In the case of the University of Trento, this reflexive training was used to invite former $\mathrm{PhDs}$ or postdocs who pursued a career outside of academia. This seemed to be especially relevant for early career researchers in the social sciences and humanities who were seldom involved in cooperative research projects with industry compared to early career researchers in computer science and engineering disciplines.

\section{Reflexive training on gender bias in recruitment procedures for decision makers}

Recruitment of postdoctoral researchers is often informal, open positions are rarely advertised publicly and recruitment procedures and criteria remain opaque to applicants and observers (Benschop and Brouns 2003; Rees 2011; 
Herschberg, Benschop and Van den Brink 2015). Opaque recruitment criteria may inhibit objectivity in evaluations as they allow conscious and unconscious bias of decision makers to unfold and influence assessments (Van den Brink, Brouns and Waslander 2006; Eagly and Carli 2007). There is evidence that recruitment practices vary between faculties or scientific disciplines whereas closed procedures are more often encountered in science, engineering and health research (Musselin 2002; Van den Brink and Benschop 2012b; Nielsen 2015). More transparent procedures and criteria which do not rely on networks and already designated candidates increase the chances for women to be successful and limit the influence of gender bias (Van den Brink, Brouns and Waslander 2006; Eagly and Carli 2007).

Reflexive training workshops with decision makers and potential members of recruitment and selection members have been conducted in most of the six research organisations. In these workshops the results of the organisational analysis concerning recruitment and selection practices and implicit gender bias were presented and discussed with workshop participants. Strategies to conduct open and transparent recruitment procedures were explored. Based on the organisational analysis and the workshops, first steps were taken in some organisations towards promoting open and transparent recruiting for postdoctoral researchers.

\section{Training courses on gender in research and teaching}

The integration of gender dimension in research and teaching is a rather new policy priority in the realm of gender equality in university and research institutions. Londa Schiebinger has termed this intervention strategy as 'fixing the knowledge' (Schiebinger 2008), which aims to reduce or neutralise gender biases in the production of scientific knowledge (Schiebinger and Schraudner 2011). Whereas gender studies and knowledge have been established in the social sciences and humanities and recently in medicine (Klinge 2007; Klinge and Wiesemann 2010), natural sciences and engineering sciences have not yet embraced sex and gender analysis in its full sense (European Commission 2013). One way to integrate the gender dimension in such research activities is to raise the awareness of researchers regarding gender and sex analysis and to establish basic competencies for recognising gender dimensions in science and engineering research (European Commission 2009).

The research organisations therefore committed themselves to raise the researchers' awareness of gender dimensions in research through specific training courses, especially for early career researchers. These training courses were mostly conducted in engineering or natural sciences departments where gender knowledge and gender competencies were not widely available. But the interventions were not limited to such training. As a state of the art analysis in these research organisations has revealed, there was hardly any systematic information about the number of available courses and classes taking gender dimensions into account. Gender was not registered as a relevant characteristic for categorising 
offered courses or programmes in some of these research organisations. Therefore, collecting reliable data on the integration of gender dimensions in teaching activities was hardly possible. Developing guidelines and definitions on collecting such data in a systematic way was the first step to get an overview of offered courses integrating a gender perspective and for developing new courses and programmes in the future.

\section{Gender budgeting analysis and raising awareness for gender budgeting}

Gender budgeting is a tool for gender mainstreaming which analyses the allocation of financial resources through a gender equality lens or perspective. It therefore disaggregates and assesses budgets to discover whether financial resources are fairly distributed and spent to promote gender equality (Walby 2005; Steinthorsdottir et al. 2016). It enhances the transparency of budgetary decisions as well as target-oriented governance and financial controlling for the purpose of promoting gender equality (Castano et al. 2010).

Budgeting procedures and decisions are commonly perceived as gender neutral as they seem to have a mere technical character. But these budgeting decisions affect not only research facilities and infrastructure but also access to research grants, supervision and career opportunities. The implementation projects in the research organisations conducted a gender budgeting analysis which focused on analysing the distribution of resources between different departments and the management decisions determining these. Besides this analysis, only the University of Iceland has set up a gender budgeting taskforce to discuss the results and their implications for gender equality policies. Others have initiated organisational discussions about gender budgeting to raise the awareness of financial officers and other decision makers.

In comparison to measures for promoting early career researchers practised by other universities in the same countries and to measures mentioned in relevant literature, it can be stated that the implemented measures focused on training, networking and career support as well as raising the awareness of gatekeepers for gender inequalities and biases in organisational procedures and rules like recruitment and promotion processes. Furthermore, these measures were directed at all early career researchers as well as decision makers and not only at a specific group such as women or so-called high potentials. In addition, some types of measures targeting specific challenges of early career researchers and gender equality have not been addressed, such as work-life balance issues or mobility demands.

The implementation of these measures was observed by an accompanying evaluation. This allowed reflection on the strengths and weaknesses as well as on the challenges and opportunities of these processes. Through comparing the different implementation processes some common features could be identified which are summarised in the following sub-sections. 


\section{Organisational analysis and needs assessment}

The starting point of implementation processes in all of the six research organisations was an organisational analysis focusing on the employment situation of early career researchers and gender equality as well as on already existing policies to promote gender equality and career opportunities for early career researchers. This analysis enabled the setting of organisation-specific targets and the development of solutions tailored to the needs of early career researchers. Furthermore, the organisational analysis defines a common baseline and picture discussed and shared by relevant intra-organisational stakeholders.

\section{Winding processes of implementation}

Another observation concerns the nature of the process of implementing gender equality measures for early career stages itself. Although it is important to define priorities and to design an action plan which clearly outlines objectives, measures and responsibilities, a high level of flexibility and adaptability is needed. Implementation processes are seldom linear and do not follow a prescribed way but deviate from plan, due to resistances but also due to changes in the managerial positions of research performing organisations. Convincing newly appointed managers and directors to support the implementation and to engage them with the implementation process is time and resources consuming. Also, changes of implementation strategies or approaches as well as further involving other stakeholders or management levels are necessary to gain additional support and to be able to push the agenda forward. These winding processes of implementation cause unforeseen costs and resources. It is therefore necessary to budget sufficient resources for the adaptation of implementation strategies.

\section{Condensed timeframe}

One insight gained from observing the implementation processes which is also reflected in the picture of a winding process is that implementation processes often take more time than expected. After conducting an organisational analysis and negotiations and discussions with different managers and stakeholders, it is necessary to engage them and to establish a common understanding of the main challenges, priorities and objectives of implemented measures. The management of these complex processes of implementation, analysis, negotiations demands a lot of time and the resulting stress did not leave room for reflexivity and creativity. This can lead to the implementation of a set of already known measures rather than developing new and tailored measures, strategies and actions to promote gender equality for early career researchers. Therefore, it is highly recommended to provide room for reflexivity throughout the implementation process. Furthermore, it is advisable to fit the scale and scope of implementation processes to available resources such as time, personnel and money. 


\section{Coordination and broad stakeholder involvement}

The observation of implementation processes made clear that coordinating implementation activities with relevant stakeholders within organisations and also including stakeholders from outside the organisation facilitates successful implementation processes. Consequently, implementation processes should make use of participatory approaches to develop an agenda, implementation priorities and concrete measures through close stakeholder involvement. This participatory approach should be established in the start-up phase and continued throughout the project runtime and beyond. Furthermore, the participation of stakeholders should be formalised through a taskforce, steering or advisory group with clearly defined responsibilities and competencies. The benefits of such a participatory approach to planning and implementing a project are enhanced commitment, ownership and legitimacy as well as higher sustainability.

\section{Resistances}

The implementation processes in nearly all organisations were confronted with different instances and forms of resistance occurring at different points in time. One quite commonly observed form of resistance was expressed through withholding information and data. This was sometimes disguised behind data protection arguments. In specific cases requests for data have been ignored, incomplete datasets have been delivered and access to specific reports and information has been denied. Most often it was argued that requested data were confidential or not available. In addition, data collection through observing panel meetings was not authorised due to the same reasons. In some cases, these resistances were handled through signing a data protection and confidentiality declaration. In other cases, these resistances could not be resolved.

Another form of resistance reported was a lack of commitment to support the implementation activities. This resistance could be observed for different stakeholders within the six research performing organisations and was not limited to a specific group of people. This did not occur only in the start-up phase of the project but became evident at different points in time during the implementation process. This kind of resistance was expressed by not supporting the implementation activities and/or not being available for the evaluation of the implementation activities.

A further way to express resistance was to openly articulate a disregard for gender studies, social sciences and qualitative research approaches. Results of the organisational analysis and its conclusions were negated or downplayed through questioning the validity and generalisability of organisation analysis results produced by qualitative methodologies but also through challenging the scientific character of social sciences in general and gender studies in particular.

The reasons behind these resistances can be manifold. In the course of our evaluation we have been able to identify some of them. One reason relates to the lack of awareness of gender inequalities and practices. Some stakeholders, 
collaborators and research participants expressed the opinion that science and research are impartial, meritocratic and only focused on excellence, therefore not affected by social categories like sex or gender. These stakeholders follow the perception that only meritocratic achievements like grants, publications and so on matter for success in an academic or research career. Another reason for expressing resistance was stakeholders' fear of interference in their own field of responsibility. People did not perceive the implementation project as an opportunity of support but as interference into their own field of competence and responsibility. Therefore, key stakeholders did not want to get involved and had to be convinced through cumbersome negotiations. Furthermore, power struggles within departments or institutes were another source of resistance. These ongoing power struggles within the implementing organisations were not directly related to the issue of gender (in)equality or the implementation project but to conflicts of different methodological schools, paradigms and ideological world views. The support for the implementation project was encumbered by the strain and resistance resulting from this power struggle.

Resistances were encountered on several occasions and were expressed by different people involved in or addressed by the implementation team. They affected the implementation process and the achieved results quite differently. In some organisations the resistances were limited more locally and did therefore not substantially influence the implementation process. In other cases, the resistances were more substantial as they were expressed by more powerful stakeholders and had more severe consequences for the further course of the implementation process. In some other cases, the support of key stakeholders was lacking due to resistant and reluctant attitudes towards the implementation project and its objectives, contributing to hardly any substantial and sustainable effects or achievements of the implementation activities.

Based on their experiences, some implementation team members have suggested not dealing with resistances if this can be avoided. On the one hand, coping with resistances can be very time and energy consuming and detracts the focus from more important and rewarding activities and collaborations. Therefore, it seems advisable to collaborate with people who are willing to learn and to participate in gender equality projects and to broaden these networks of the willing collaborators throughout the implementation process (Mergaert and Lombardo 2014). On the other hand, a recent study by Van den Brink and Benschop (2017) reports that resistance against gender equality measures can be used productively through initiating discourses around the issues addressed. Thereby implicit values and stereotypes are often made explicit and subtle gender practices are revealed. This facilitates organisational change processes.

\section{Conclusions and recommendations}

Policies and measures to promote gender equality for early career researchers and, especially, postdoctoral researchers have not yet been implemented in all research performing organisations. In some of these research organisations 
postdocs are not a priority target group of career development measures and gender equality policies. In other organisations such measures are confined to so-called high potentials and are therefore limited to a smaller number of male and sometimes female postdoctoral researchers whereas most of them do not benefit from such measures and policies. Therefore, it is important to bring early career researchers and postdocs in particular onto the organisational map and to the attention of research performing organisations. The establishment of a central postdoctoral office at university level that represents the interests of this marginalised group of researchers, but also takes the different needs and challenges of postdocs from different scientific disciplines into consideration, is particularly necessary. It serves on the one hand as a central information point to inform postdoctoral researchers about their contractual responsibilities, duties and rights but also acts as an organisational stakeholder representing the needs and interests of this group in intra-organisational decision-making bodies and working groups. It should act in the interest of all postdocs and therefore widen the organisational focus from the smaller group of so-called high potentials to the broad number of postdocs working in research performing organisations.

On the level of concrete measures, it is important that postdocs have equal access to services offered to researchers with a permanent position. This includes training and coaching programmes as well as childcare facilities and services offered by research performing organisations. Additionally, specific coaching and training should be provided for early career researchers, which reflect their specific needs and interests. This training should be structured in a way that it allows them to build up and extend specific skills and competencies which are relevant to progress in an academic career but also for careers outside academia. Cavanaugh (2018) emphasises the relevance of career exploration programmes which informs postdocs about non-academic career paths and provides training on skills and competencies to pursue such alternative career options. Furthermore, regular assessments should be carried out as to whether they are meeting the needs of and are beneficial for the target group. In terms of content, this training should not only focus on increasing research skills and competencies but should also raise awareness of gender inequalities in research and innovation and train future generations of senior and principal researchers on how to integrate the gender dimension into their research topic. Research funding organisations can also support the career development of postdoctoral researchers if they integrate such measures into their funding schemes or require the research performing organisations hosting the postdoc to offer such trainings.

Additionally, coaching and training measures should also prepare early career scientists better for a career outside of academia, for instance through making researchers aware of career opportunities in industry and the non-profit sector and through supporting them in extending their network ties to colleagues in these fields. Through these measures early career researchers should be encouraged to actively seek opportunities to advance their research careers outside of 
academia. Such careers should be supported by the departments and universities and leaving academia should not be seen as an individual failure but as an achievement.

A further field of activity are career development and opportunities. On the one hand, it is necessary to increase the number of tenure track positions as well as mid-level career positions with permanent contracts. This will provide more career opportunities and will enhance the stability of research careers. But of course this would require a different form of research and innovation governance, which increases the institutional funding and resources of research performing organisations and thereby enables these organisations to hire more researchers on a permanent basis. In consequence - if governments will not expand the budgets for research and innovation - the resources for project and third-party funds will have to be reduced. But this would require replacing the currently dominant regime of academic capitalism and new managerialism. First, it is important to reduce the apprenticeship period for early career researchers, which has lengthened in the past decades and to enable independent but supervised and supported research by early career researchers. Second, recruitment and selection processes for early career researchers need to be made more transparent. This means that all job vacancies for early career researchers should be public and selection criteria and recruitment processes should take different forms of scientific as well as societal merit and responsibility into account. This would allow the recruitment of researchers who are engaging in third mission projects and work on topics which are of high relevance for the global or local society and its major challenges. Third, it is important to make members of selection committees aware of implicit gender bias and unconscious stereotypes and install a monitoring mechanism which ensures compliance with gender equality guidelines, reports any violations and can propose remedial measures.

From observing implementation processes at six European universities and research centres we can summarise findings that should be taken into account when initiating change processes targeting at the promotion of gender equality for early career researchers. Taking these lessons into account will enable a successful implementation and thereby increase the benefits and the impact of implemented measures.

The involvement of the top-level management has turned out to be problematic but crucial for successful and sustainable implementation processes. Therefore, the implementation teams should seek support from different external and internal stakeholders to secure and sustain the engagement of the top-level management. But the projects should also make provision for engaging the top-level management and other key actors into the project by including them into the project management team or an advisory board.

Implementation projects need to make sure that they command the necessary expertise and know-how. A key expertise is of course knowledge about gender mainstreaming and gender studies in Science, Technology and Innovation but also know-how on initiating, conducting and sustaining organisational change 
projects is essential. The latter expertise is often assumed to be at hand but (implicit and explicit) knowledge about the structure, rules and culture of an organisation does not automatically facilitate a change process.

Projects that aim to implement structural change policies should develop a roadmap for implementation with clear and realistic targets that reflect the organisational context and are coordinated with relevant stakeholders. Broad approaches might look very appealing as they promise to generate a wide range of outcomes and impacts. But it takes a lot of effort and resources to make such projects work and to secure their sustainability. Therefore, approaches that are more limited in their scale and scope should be considered. This does not necessarily mean that these more focused aims require fewer resources.

To develop successful strategies and measures to promote gender equality and career opportunities for early career researchers the specific organisational context but also the broader regional or national context need to be taken into account. Policies, measures and strategies are not easily transferable from one context to another but need to be adapted to fit. A baseline assessment of the organisational policies, the status quo of gender equality and of career conditions of early career researchers facilitates a better understanding of this context and which measures are needed but also demanded.

A final recommendation is to observe and evaluate implementation processes continuously. Thereby the focus should be placed on the results and benefits of the implemented measures and activities and also on the process of implementation and its strengths and weaknesses. This will make it possible to monitor whether expected results can be achieved and make necessary adaptation if progress does not unfold as expected. Evaluation results will further facilitate policy learning for involved stakeholders and contribute to developing new measures and policy to promote gender equality for early career researchers. Consequently, evaluation results should be made publicly available to increase transparency and accountability.

Across Europe the number of researchers in the whole research sector as well as in academia is expanding, attracted by stimulating environments and interesting problems to solve, relevant to dealing with the grand challenges of our time. But precarious working conditions and insecure career opportunities may inhibit developing this human talent in the long run, particularly in the case of women. Adopting policies to support early career researchers from a gender sensitive perspective is therefore an over-riding imperative in order to ensure a sustainable and responsible advancement of science.

\section{References}

Ackers, L. (2005). Moving people and knowledge. Scientific mobility in the European Union. International Migration, 43(5), 99-131.

Åkerlind, G. S. (2005). Postdoctoral researchers. Roles, functions and career prospects, Higher Education Research \& Development, 24(1), 21-40. 
Allard, K., Haas, L. and Philip Hwang, C. (2007). Experiences of flexible working arrangements and work-family conflict among managerial fathers in Sweden. Community, Work \& Family, 10(4), 475-493.

Andalib, M., Ghaffarzadegan, N. and Larson, R. (2018). The postdoc queue. A labour force in waiting. Systems Research and Behavioral Science.

Auriol, L., Misu, M. and Freeman, R. A. (2013). Careers of Doctorate Holders: Analysis of Labour Market and Mobility Indicators, OECD Science, Technology and Industry Working. Paris.

Bäker, A. (2015). Non-tenured post-doctoral researchers' job mobility and research output. An analysis of the role of research discipline, department size, and coauthors. Research Policy, 44(3), 634-650.

Bendl, R. and Schmidt, A. (2010). From 'glass ceilings' to 'firewalls'. Different metaphors for describing discrimination. Gender, Work \& Organization, 17(5), 612-634.

Bendl, R. and Schmidt, A. (2012). Revisiting feminist activism at managerial universities. Equality Diversity and Inclusion: An International Journal, 31(5/6), 484-505.

Bennion, A. and Locke, W. (2010). The early career paths and employment conditions of the academic profession in 17 countries. European Review, 18, S1, S7.

Benschop, Y. and Brouns, M. (2003). Crumbling ivory towers. Academic organizing and its gender effects. Gender, Work \& Organization, 10(2), 194-212.

Berg, L.D, Huijbens, E. H. and Gutzon Larsen, H. (2016). Producing anxiety in the neoliberal university. The Canadian Geographer, 60(2), 168-180.

Blau, F. D., Currie, J. M., Croson, R. T. A. and Ginther, D. K. (2010). Can Mentoring help Female Assistant Professors? Interim Results from a Randomized Trial, NBER Working Paper. Cambridge, MA.

Bozzon, R., Murgia, A., Poggio, B. (2017). Work-life interferences in the early stages of academic careers. The case of precarious researchers in Italy. European Educational Research Journal, 16(2-3), 332-351.

Bratislava Declaration of Young Researchers (2016). Available at: http://declaration. mimuw.edu.pl/.

Cacace, M., Balahur, D., Bleijenbergh, I. L., Falcinelli, D., Friedrich, M. and Kalpazidou Schmidt, E. (2015). Structural Transformation to Achieve Gender Equality in Science: Guidelines. Rome.

Cantwell, B. (2011). Academic in-sourcing. International postdoctoral employment and new modes of academic production. Journal of Higher Education Policy and Management, 33(2), 101-114.

Castano, C., Müller, J., Gonzalez, A. and Palmen, R. (2010). Policy towards Gender Equity in Science and Research: Topic Report. Barcelona.

Cavanaugh, N. A. (2018). Institutional support, programs, and policies for postdoctoral training. In A. J Jaeger and A. J. Dinin (eds), The Postdoc Landscape: The Invisible Scholars. London, pp. 49-68.

Chen, S., McAlpine, L. and Amundsen, C. (2015). Postdoctoral positions as preparation for desired careers. A narrative approach to understanding postdoctoral experience. Higher Education Research \& Development, 34(6), 1083-1096.

Council of the European Union (2016). Council Conclusions on 'Measures to Support Early Stage Researchers, Raise the Attractiveness of Scientific Careers and Foster Investment in Human Potential in Research and Development'. Brussels.

Davies, A. and Thomas, R. (2002). Managerialism and accountability in higher education. The gendered nature of restructuring and the costs to academic service. Critical Perspectives on Accounting, 13(2), 179-193. 
Davis, G. (2009). Improving the postdoctoral experience. An empirical approach. In R. B. Freeman and D. L. Goroff (eds), Science and Engineering Careers in the United States: An Analysis of Markets and Employment. Chicago, pp. 99-127.

Eagly, A. H. and Carli, L. L. (2007). Women and the labyrinth of leadership. Harvard Business Review, 2-10.

EIGE (2016a). Gender Equality in Academia and Research: GEAR tool. Luxembourg.

EIGE (2016b). Integrating Gender Equality into Academia and Research Organisations: Analytical Paper. Luxembourg.

Ely, R. J. and Meyerson, D. E. (2000). Advancing gender equity in organizations. The challenge and importance of maintaining a gender narrative. Organization, 7(4), 589-608.

Eriksson-Zetterquist, U. and Styhre, A. (2008). Overcoming the glass barriers. Reflection and action in the 'women to the top' programme. Gender Work and Organization, 15(2), 133-160.

European Commission (2005). The European Charter for Researchers: The Code of Conduct for the Recruitment of Researchers, EUR 21620. Brussels.

European Commission (2009). Toolkit: Gender in EU-Funded Research. Luxemburg.

European Commission (2012). A Reinforced European Research Area Partnership for Excellence and Growth. Brussels.

European Commission (2013). Gendered Innovations: How Gender Analysis Contributes to Research Report of the Expert Group 'Innovation through Gender'. Luxembourg.

European Commission (2016). She Figures 2015. Luxembourg.

European Commission (2017a). ERA Progress Report 2016. Luxembourg.

European Commission (2017b). European Innovation Scoreboard 2017. Brussels.

European Institute for Gender Equality (2017). Gender Equality Index 2017. Luxembourg.

European Science Foundation (2017). 2017 Career Tracking Survey of Doctorate Holders: Project Report. Strasbourg.

Ferree, M. M. and Zippel, K. (2015). Gender equality in the age of academic capitalism. Cassandra and Pollyanna interpret university restructuring. Social Politics: International Studies in Gender, State \& Society, 22(4), 561-584.

Foote, K. E. (2010). Creating a community of support for graduate students and early career academics. Journal of Geography in Higher Education, 34(1), 7-19.

Fox, M. F. and Stephan, P. E. (2001). Careers of young scientists. Preferences, prospects and realities by gender and field. Social Studies of Science, 31(1), 109-122.

Garforth, L. and Kerr, A. (2009). Women and science. What's the problem? Social Politics: International Studies in Gender, State and Society, 16(3), 379-403.

Glass, J. L., Sassier S., Levitte Y. and Michelmore K. M. (2013). What's so special about STEM? A comparison of women's retention in STEM and professional occupations. Social Forces, 92(2), 723-756.

Goulden, M., Mason, M. A. and Frasch, K. (2011). Keeping women in the science pipeline. The ANNALS of the American Academy of Political and Social Science, 638(1), 141-162.

Grigolo, M., Lietaert, M. and Marimon, R. (2010). Shifting from academic 'brain drain' to 'brain gain' in Europe. European Political Science, 9(1), 118-130.

Guardian (2014-2017). Mental health: a university in crisis. www.theguardian.com/ education/series/mental-health-a-university-crisis.

Gülker, S. and Böhmer, S. (2010). Nachwuchspolitik. In D. Simon, A. Knie and S. Hornbostel (eds), Handbuch Wissenschaftspolitik. Wiesbaden, pp. 176-192. 


\section{Florian Holzinger et al.}

Herschberg, C., Benschop, Y. and Van den Brink, M. (eds) (2015). Constructing Excellence: The Gap between Formal and Actual Selection Criteria for Early Career Academics, GARCIA Working Papers 2. Trento.

Hill, C., Corbett, C. and St Rose, A. (2010). Why So Few? Women in Science, Technology, Engineering, and Mathematics. Washington D.C.

Hokanson, S. C. and Goldberg, B. B. (2018). Proactive postdoc mentoring. In A. J. Jaeger and A. J. Dinin (eds), The Postdoc Landscape: The Invisible Scholars. London, pp. 91-120.

Höppel, D. (2015). Aufwind mit Mentoring. Effekte, Erfolgsfaktoren und Empfehlungen. In M. Klemisch, A. Spitzley and J. Wilke (eds), Gender- und Diversity-Management in der Forschung: Konferenzband, 7 and 8 May 2015. Stuttgart, pp. 43-54.

Howe-Walsh, L. and Turnbull, S. (2014). Barriers to women leaders in academia. Tales from science and technology. Studies in Higher Education, 1-14.

Huyer, S. (2015). Is the gender gap narrowing in science and engineering? In UNESCO (ed.), UNESCO Science Report: Towards 2030. Paris, pp. 85-103.

Jaeger, A. J. and Dinin, A. J. (eds) (2018). The Postdoc Landscape: The Invisible Scholars. London.

Kahlert, H. (2012). Was kommt nach der Promotion? Karriereorientierungen und -pläne des wissenschaftlichen Nachwuchses im Fächer- und Geschlechtervergleich. In S. Beaufaÿs, A. Engels and H. Kahlert (eds), Einfach Spitze?: Neue Geschlechterperspektiven auf Karrieren in der Wissenschaft. Frankfurt/M., 57-86.

Kalpazidou Schmidt, E. and Faber, S. T. (2016). Benefits of peer mentoring to mentors, female mentees and higher education institutions. Mentoring \& Tutoring: Partnership in Learning, 24(2), 137-157.

Klinge, I. (2007). Bringing gender expertise to biomedical and health-related research. Genderbasic: promoting integration of sex and gender aspects in biomedical and health-related research. Gender Medicine, 4, Supplement 2(0), S59-S63.

Klinge, I. and Wiesemann, C. (eds) (2010). Sex and Gender in Biomedicine: Theories, Methodologies, Results. Niedersächsische Staats- und Universitätsbibliothek Göttingen, Göttingen.

Konsortium Bundesbericht Wissenschaftlicher Nachwuchs (2017). Bundesbericht Wissenschaftlicher Nachwuchs 2017: Statistische Daten und Forschungsbefunde zu Promovierenden und Promovierten in Deutschland, Bielefeld.

Laursen, S. L., Austin, A., Soto, M. and Martinez, D. (2015). Advancing the Agenda for Gender Equity. Change: The Magazine of Higher Learning, 47(4), 16-24.

Lee, J., Williams, J. C. and Li, S. (2017). Parents in the Pipeline: Retaining Postdoctoral Researchers with Families. San Francisco.

Lee, L., Alemany, C. and Faulkner, W. (2010a). Good policies are not enough! The need for 'culture change' in achieving gender equality in engineering. In A.-S GodfroyGenin (ed.), Women in Engineering and Technology Research: The PROMETEA Conference Proceedings. Berlin, pp. 407-425.

Lee, L., Alemany, C. and Faulkner, W. (2010b). Turning good policies into good practice. Why is it so difficult? International Journal of Gender, Science and Technology, 2(1), 90-99.

Levitt, D. G. (2010). Careers of an elite cohort of U.S. basic life science postdoctoral fellows and the influence of their mentor's citation record. BMC Medical Education, 10,80 .

Lewis, S. and Humbert, A. L. (2010). Discourse or reality. 'Work-life balance' flexibility and gendered organisations. Equality, Diversity and Inclusion, 29(3), 239-254. 
Madden, A. D. (2009). Managing for the ideal research environment. Journal of Higher Education Policy and Management, 31(3), 271-282.

McAlpine, L. and Amundsen, C. (2015). Early career researcher challenges. Substantive and methods-based insights. Studies in Continuing Education, 37(1), 1-17.

McAlpine, L. and Emmioğlu, E. (2014). Navigating careers. Perceptions of sciences doctoral students, post-PhD researchers and pre-tenure academics. Studies in Higher Education, 40(10), 1770-1785.

Mergaert, L. and Lombardo, E. (2014). Resistance to implementing gender mainstreaming in EU research policy. European Integration Online Papers, 18(1).

Meschitti, V. and Lawton Smith, H. (2017). Does mentoring make a difference for women academics? Evidence from the literature and a guide for future research. Journal of Research in Gender Studies, 7(1), 166-199.

Müller, R. (2014). Racing for what? Anticipation and acceleration in the work and career practices of academic life science postdocs. Forum Qualitative Sozialforschung/ Forum: Qualitative Social Research, 15(3).

Musselin, C. (2002). Diversity around the profile of the 'good' candidate within French and German universities. Tertiary Education and Management, 8(3), 243-258.

Musselin, C. (2004). Towards a European academic labour market? Some lessons drawn from empirical studies on academic mobility. Higher Education, 48(1), 55-78.

Neumann, R. and Tan, K. K. (2011). From PhD to initial employment. The doctorate in a knowledge economy. Studies in Higher Education, 36(5), 601-614.

Nielsen, M. W. (2015). Limits to meritocracy? Gender in academic recruitment and promotion processes. Science and Public Policy 43(3), 386-399.

OECD (2016). OECD Economic Outlook, Volume 2016 Issue 1. Paris.

Põder, K. and Kerem, K. (2011). 'Social models' in a European comparison. Eastern European Economics, 49(5), 55-74.

Powell, K. (2015). The future of the postdoc. Nature News, 520(7546), 144.

Reale, E., Avramov, M., Canhial, K., Donovan, C., Flecha, R., Holm, P., Larkin, C., et al. (2017). Evaluation through impact. A different viewpoint. Fteval Journal, 39, 36-41.

Rees, T. (2011). The gendered construction of scientific excellence. Interdisciplinary Science Reviews, 36(2), 133-145.

Sallee, M. (2014). Performing masculinity. Considering gender in doctoral student socialization. International Journal for Researcher Development, 5(2), 99-122.

Scaffidi, A. K. and Berman, J. E. (2011). A positive postdoctoral experience is related to quality supervision and career mentoring, collaborations, networking and a nurturing research environment. Higher Education, 62(6), 685-698.

Schiebinger, L. (2008). Getting more women into science and engineering. Knowledge issues. In L. Schiebinger (ed.), Gendered Innovations in Science and Engineering Stanford, CA, pp. 1-21.

Schiebinger, L. and Schraudner, M. (2011). Interdisciplinary approaches to achieving gendered innovations in science, medicine, and engineering. Interdisciplinary Science Reviews, 36(2), 154-167.

Schramm, M. and Kerst, C. (2009). Berufseinmündung und Erwerbstätigkeit in den Ingenieur- und Naturwissenschaften, HIS:Projektbericht. Hannover.

Science Europe (2016). Postdoctoral Funding Schemes in Europe: Survey Report. Brussels.

Simard, C., Davies Henderson, A., Gilmartin, S. K., Schiebinger, L. and Whitney, T. (2008). Climbing the Technical Ladder: Obstacles and Solutions for Mid-Level Women in Technology. Palo Alto. 


\section{Florian Holzinger et al.}

Slaughter, S. and Leslie, L. L. (2001). Expanding and elaborating the concept of academic capitalism. Organization, 8(2), 154-161.

Smidt, T. B., Pétursdóttir, G. M. and Einarsdóttir, P. (2017). How do you take time? Worklife balance policies versus neoliberal, social and cultural incentive mechanisms in Icelandic higher education. European Educational Research Journal, 16(2-3), 123-140.

Soe, L. and Yakura, E. K. (2008). What's wrong with the pipeline? Assumptions about gender and culture in IT work. Women's Studies: An Inter-Disciplinary Journal, 37(3), 176-201.

Solga, H. and Pfahl, L. (2009). Doing gender im technischnaturwissenschaftlichen Bereich. In J. Milberg (ed.), Förderung des Nachwuchses In Technik und Naturwissenschaft: Beiträge zu den Zentralen Handlungsfeldern, acatech DISKUTIERT. Berlin, pp. 155-219.

Steinthorsdottir, F. S., Heijstra, T. M., Einarsdóttir, T. and Pétursdóttir, G. M. (eds) (2016). Gender Budgeting in Academia. GARCIA Working Papers 8, Trento.

Thomas, J. D., Lunsford, L. G. and Rodrigues, H. A. (2015). Early career academic staff support. Evaluating mentoring networks. Journal of Higher Education Policy and Management, 37(3), 320-329.

van Balen, B., van Arensbergen, P., van der Weijden, I. and Van den Besselaar, P. (2012). Determinants of success in academic careers. High Education Policy, 25(3), 313-334.

Van den Brink, M. (2011). Scouting for talent. Appointment practices of women professors in academic medicine. Social Science \& Medicine, 72(12), 2033-2040.

Van den Brink, M. and Benschop, Y. (2012a). Gender practices in the construction of academic excellence. Sheep with five legs. Organization, 19(4), 507-524.

Van den Brink, M. and Benschop, Y. (2012b). Slaying the seven-headed dragon. The quest for gender change in academia. Gender, Work \& Organization, 19(1), 71-92.

Van den Brink, M. and Benschop, Y. (2017). Gender interventions in the Dutch police Force. Resistance as a tool for change? Journal of Change Management, 2(4), 1-17.

Van den Brink, M., Benschop, Y. and Jansen, W. (2010). Transparency in academic recruitment. A problematic tool for gender equality? Organization Studies, 31(11), $1459-1483$.

Van den Brink, M., Brouns, M. and Waslander, S. (2006). Does excellence have a gender? A national research study on recruitment and selection procedures for professorial appointments in the Netherlands. Employee Relations, 28(6), 523-539.

van der Lee, R. and Ellemers, N. (2015). Gender contributes to personal research funding success in the Netherlands. Proceedings of the National Academy of Sciences of the United States of America, 112(40), 12349-12353.

van der Weijden, I., Belder, R., van Arensbergen, P. and Van den Besselaar, P. (2015). How do young tenured professors benefit from a mentor? Effects on management, motivation and performance. Higher Education, 69(2), 275-287.

van der Weijden, I., Teelken, C., de Boer, M. and Drost, M. (2016). Career satisfaction of postdoctoral researchers in relation to their expectations for the future. Higher Education, 72(1), 25-40.

Vries, J. D. and Van den Brink, M. (2016). Transformative gender interventions. Linking theory and practice using the 'bifocal approach'. Equality, Diversity and Inclusion: An International Journal, 35(7/8), 429-448.

Vries, J. D., Webb, C. and Eveline, J. (2006). Mentoring for gender equality and organisational change. Employee Relations, 28(6), 573-587.

Walby, S. (2005). Introduction: comparative gender mainstreaming in a global era. International Feminist Journal of Politics, 7(4), 453-470. 
Wilton, N. and Purcell, K. (2010). The impact of partnership and family-building on the early careers of female graduates in the UK. Equality, Diversity and Inclusion: An International Journal, 29(3), 271-288.

World Economic Forum (2017). The Global Competitiveness Report: 2017-2018. Geneva. 


\section{Index}

Page numbers in bold denote tables, those in italics denote figures.

academic activities, diversification 20

academic age 24

academic capitalism 209

academic careers: gendered consequences of transformation 22-4; national models

21-2; prerequisites for 221

academic citizenship 135-7

academic employment, growth in 50

academic enterprise model 18-19

academic gender gap 145

academic housework 28, 86, 101

academic ideal 25-7

academic independence 25

academic labour markets: access to 23; age

of staff 58-9; biographical perspective

71-3; comparative perspective $68-71$; convergences and specificities 53-67; demographic expansion 54-9; employment trajectories 72; expansion 56; fixed-term positions 60; Grade A staff percentages 58 ; national variations 52, 56; opportunities outside 60-1, 62, 66-7, 68; PhD holders 56-7; protective pyramid model $64-7$; researcher numbers 57; shared characteristics 54; survivor model 61-4; temporary positions 60; tenured positions 57-9; see also recruitment and selection

academic market, fragmentation of 19 academic proletariat 62

academic work: flexibilisation of 20-2; fragmentation of 19, 20-2, 23; quality of 51 ; specialisation 20,23

academic workforce, gender changes 50 access to services 227

accountability $24-5$; recruitment processes 28-9
Addabbo, T. 86

age, academic staff 58-9

Agorà model 25

"all-round" academic ideal 197

applied research, focus on 18-19

assertiveness 126-7

assistant professorships see recruitment and selection

auditing 88

austerity 32,95

benevolent sexism 122

Benschop, Y. 29

Berlant, L. 37

biographical perspective $71-3$

biographical time-lines 67-8

book: chapter outlines 6-9; overview 3-6; questions asked 9-10; structure 5-6

boundaries: blurring 148; dismantling of 25

boundless work, ethic of 27

Bozzon, R. 173

breadwinner roles 70

Bryson, C. 113

budget cuts, Italy 66

burnout 174

Butler, J. 3

C grade professorships 63

capability approach 86

career development 228 ; sustainability and continuity 214-15

career exploration programmes 227

career fellowships 217

career instability 20

career models, biographical time-lines $67-8$ 
career opportunities: GARCIA project 219-20; increasing 213, 228; status of postdoctoral researchers 211-13 career path diversification: age of staff 58-9; biographical perspective 71-3; comparative perspective $68-71$; comparative research 53; context and overview 50-3; demographic expansions of labour markets 54-9; doctoral degrees awarded to women 55; effects of Great Recession 71; employment trajectories 72; Grade A staff percentages 58 ; labour market convergences and specificities 53-67; mapping 67-73; national models 59; part-time work 63, 64; $\mathrm{PhD}$ holders in working age populations 56 ; precarious employment contracts 69 ; protective pyramid model 64-7; researchers in HE sector 57; structural changes 62-3; summary and conclusions $73-4$; survivor model 61-4; tenure track model 59-61; tenured positions 57-9; women as a proportion of researchers and of Grade A positions 54

career path typology 187; Entrepreneurial organisations 195-8; Mandarin organisations 189; Missionary organisations $190-5$ career paths: fragmentation of 27 ; linearity 27

career structure, degeneration 113

career tracks 21-2

Carreri, A. 148

Castañeda, M. 149

Castel, R. 67

casualisation 9, 18, 148-9

Cavanaugh, N.A. 218, 227

Chalsege, L. 21

chapter outlines 6-9

childcare 152, 152; work-life balance $167-8$

choice assumption, work-life balance 172-3

civil servant status $64-5$

coaching and training 227-8

Code of Conduct for Recruitment of Researchers 214

Coin, F. 37

collaborative working 135-6

collegiality 25

commitment 128-32, 225; expectations of $146-7$

commodification, of higher education 15 communication styles $127-8$

comparative perspective 68-71

competencies 215-16

competition: in academic labour market 16-19, 212; vs. collaboration 136;

Entrepreneurial organisations 195-6; global 83; for grants 99; between institutions 93; and marketisation 17-20; and part-time working 131-2; postdoctoral researchers 211; pressure for 34; scientific 19

confidence, tacit selection criteria 126-8 contexts, understanding 229

contingency, of academic labour 209

continuity, career development 214-15

contracts, unstable and temporary 4

coordination, implementing measures 225

corporatisation 17

cost-cutting 20

cost rationalisation 18

critical analysis 52

cross-national data, reliability 69

cruel optimism 37

cultural change 83

culture of care 149

data: availability of 54-5; withholding 225

decision-making, job offers 24

deregulation 20-1

devotion 27

disciplinary fields, gendering 87

discourse of excellence, gender asymmetries 28-9

diversification, academic activities 20

division of labour 23, 27-8, 37, 148; domestic 165-6

doctoral graduates, increased number 55-6

Doherty, R. 21

du Gay, P. 32

dual-career planning 163-4

Duncan, S. 171

Durkheim, E. 62

early career researchers: contracts 21 ; personal investment 15

employment: casualisation of 9,18 ; male/female 150; maternal 150; new forms 148

employment conditions 209, 211-12

employment contracts, precarious 69

employment policies 24

employment trajectories, $\mathrm{PhD}$ holders 72

Enders, J. 54, 60, 61, 62, 64-5

Entrepreneurial organisations 195-8 
entrepreneurship, emphasis on 25

Erbe, B. 86

Esping-Andersen, G. 149-50

ethic of boundless work 27

European Charter for Researchers 214

European Research Area (ERA) 214

evaluation: gender equality policies 216 ; of implementation 229; practice of 99-100; standards 28 ; systems $33-5$

excellence 26-7; assessing potential 123; evaluation standards 28 ; and funding allocation 96; and part-time working 131-2; pressure for 98-9; selection criteria 124

excellence discourse, gender asymmetries 28-9

expertise 228-9

extreme work 25

failure, evaluation systems 33-5

families, planning for $163-4$

family conditions $130-2$

family-friendly policies $27-8$

family leave policies 217

fellowships 217

fertility rates $\mathbf{1 5 1}$

Fiske, S.T. 122

five key priorities 214

fixed-term positions, increase in 60

fixing the knowledge 222

flexibilisation 20-2

flexibility discourse $147-8$

flexible working time arrangements 152 , $160,162,164-5,172$

formal selection criteria $123-5$

fragmentation: of academic work 19, 20-2, 23; of careers 27

funding allocation $94-5$; competition for grants 99; criteria 96-7; and performance 98-9; $\mathrm{PhD}$ students 102-3; public funding $95-7$; third-party funding 97

fundraising, pressure for 26

GARCIA project: career opportunities 219-20; coordination 225; gender budgeting 84,223 ; gender equality policies 219-20; implementing measures 218-26; locations 5; mentoring 220-1; open disregard 225; operational analysis and needs assessment 224; outcomes 5; overview 4; raising awareness 222-3; reflexive training 221-2; research design 5; researchers' future careers 9-10; resistances 225-6; stakeholder participation 225; timeframes 224; training on gender $222-3$; winding processes 224 ; withholding data/ information 225

Garforth, L. 148

gatekeeping 29, 113

gender, training on 222-3

gender arrangements, societal level 70

gender bias, reflexive training 221-2

gender budgeting 192-3, 223; academic housework 83,101; access to data 84; aspects of performance 97-104; comparative perspective 184; comparison and contrast 92; consequences of decisions 91-2; context and overview 83-5; financial framework analyses 90; funding allocation 94-5; GARCIA project 84, 223; gendered institutions 86-7; gendered work 97-8; importance of research activity 99 ; international rankings $92-4$; managerialism 87-8; mapping 90, 91; measures used 89-90; origins 83; overview 85-6; participant institutions 84; performance measurements $98-100$; $\mathrm{PhD}$ holders 103-4; $\mathrm{PhD}$ students 102-3; previous research 85-6; public funding allocation 95-7; reaching workloads 101-2; research methods 89-92; resource redistribution 105-6; summary and conclusions 105-6; use of 84

gender changes, in academic workforce 50

gender equality policies 180 ; awareness 215-16; changing perspective 210; GARCIA project 219-20;

implementation gap 215

gender horizontal segregation, in STEM fields 19-20

gender imbalance 93-4

gender practices, recruitment and selection 113-14, 117

gendered consequences, neoliberalisation 27-30

gendered impacts: Entrepreneurial

organisations 198; Mandarin

organisations 190; Missionary

organisations 194

gendered institutions 86-7 gendered moral rationalities 147-8, 171 gendered organisations 180 
gendered pipeline: career path typology 187; classic perspectives on leaky pipelines 179-80; context and overview 178-9; data and analysis 185-7; discussion 198-202; Entrepreneurial organisations 195-8; Mandarin organisations 187-90; methodology 180-7; Missionary organisations 190-5; national contexts $180-5$; research context $180-5$; summary and conclusions 202-3

'Gendering the Academy and Research: combating Career Instability and Asymmetries' see GARCIA project

Gherardi, S. 35

Gill, R. 32

Girard, M. 172

glass ceiling 87, 179, 212; Entrepreneurial organisations 196; Mandarin organisations 189-90

Glick, P. 122

global competition 83

global labour market 53

globalisation: effects of 209; vs. internationalisation 53-4

Goulden, M. 162

Govender, P. 85

Grade A staff percentages 58

Gramsci, A. 35

Granovetter, M. 36

grants, competition for 99

Great Recession, effects on job security 71 greedy institutions 25,147

guilt $156-7,172$

having it all 145

Hawkins, R. 149

health $157-8,160,161-2,212$

hegemony, of masculine discourse 31

hierarchies of power $84-5$

higher education: commodification of 15 ; funding 15

human resources, inadequate policies 214 Humboldt tradition 61-2

Iceland 69-70; recruitment and selection 119; welfare state regime 150

ideal academic 26-7, 30

ideal types 186

ideal worker 171

identity construction 31

ideology 51

implementing measures: access to services 227; career development 228; career opportunities 219-20;

commitment 225; competencies 215-16;

conclusions 226-9; context and

overview 209-11; contexts 229;

coordination 225; early career support

213; expertise 228-9; family leave policies 217; fellowship programmes 217; GARCIA project 218-26; gender budgeting 223 ; gender equality policies 219-20; implementation gap 215; increasing career opportunities 213 , 228; intra-organisational networks 218 ; mentoring 216-17, 220-1; monitoring and evaluation 216; open disregard 225; operational analysis and needs assessment 224; organisational commitment 215; participant institutions 218-19; policy agenda 214-16; postdoctoral offices 218,227 ; postdoctoral training 216-17; raising awareness 215-16, 222-3; reflexive training 221-2; resistances 225-6; stakeholder participation 225, 228; structural change policies 229; support measures 216-18, 227-8; timeframes 224; training and coaching 227-8; training on gender 222-3; winding processes 224; withholding data/ information 225

individualisation process $30-1$

instability, of careers 20

international activity 133

international mobility 29-30, 52

international rankings 92-4

internationalisation: effects of 209; vs. globalisation 53-4; as ideal 27; and national practices 19; participation in 29-30

intra-organisational networks 218 investment, in higher education 15 iron ceiling 179

Isgro, K. 149

job offers, decision-making 24

Kantola, J. 25

Kerr, A. 148

knowledge-based society, effects of 17

labour market perspective 16-24

leaky pipeline 4, 52, 86, 178, 179-80, 212; see also gendered pipeline

LeFeuvre, N. 203

Lewis, S. 147, 172-3 
long hours culture, gendered effects 36-7

major points 99,100

male breadwinner/female caregiver model, challenge to 145

male-defection 18

male/female employment 150

management models $17-18$

managerialism 25, 31, 33, 83, 87-8, 210

Marginson, S. 53-4

marketisation 17-20, 83, 87, 209

markets, development 17

masculine discourse, hegemony of 31

masculinity, paternalist to competitive 27

Mason, M.A. 162

maternal employment 150

maternity/paternity/parental leave 150-1, 151

Matilda effect 87, 179

Matthew effect 179

McUniversity 25

mentoring 216-17, 220-1

meritocracy $24-5,111$

Missionary organisations $190-5$

mobility 167,168 ; international 29-30, 52;

between jobs 22; selection criteria

132-5; and work-life balance 163

models of science, shift in 25

modesty 126

modified male breadwinner model 150

monitoring: gender equality policies 216 ; of implementation 229

motherhood 129-32

mothers of the department 28

Musselin, C. 54, 59, 60, 61, 62, 64-5

national accreditation process 65

national accreditation systems 21

national models $21-2$; protective pyramid model 64-7; structural changes 62-3; survivor model 61-4; tenured positions 59-61

national practices, and internationalisation 19

neoliberalisation 17, 24, 25, 27-30

neoliberalism 4; evaluation systems 33-5; experiencing precariousness $32-3$; as governance 88 ; passion vs. overwork 35-7; promise dispositive 37-8; subjectivity 30-9; and work-life balance 148-9, 173-4

networking: as ideal 27; as investment 38; participation in 29-30; value of 29-30

networks, of support 10 new managerialism see managerialism

New Public Management 17-18, 31; discourse of excellence 26-7; effects of $50-1$

non-academic labour market 18

old-boys networks 29

Olympic model 25

omnipresence 180,193

open disregard 225

operational analysis and needs assessment 224

organisational change 83

organisational commitment 215

organisational culture 24-30; academic ideal 25-7; accountability 24-5;

consequences of neoliberalism 27-30; ideal academic 26-7, 30; meritocracy

24-5; neoliberalisation 24, 25

organisational dynamics 179

organisational models 15

overwork, vs. passion 35-7

parenthood: delaying 160-2, 172; worklife balance 164-9

parenting, and career development 23-4

part-time work 20-1, 63, 64, 131-2

partnerships without children, work-life balance 162-4

passion, vs. overwork 35-7

passionate researcher rhetoric 31

path dependency, career models 67

performance: aspects of 97-104; and

funding allocation $98-9$

performance criteria 28

performance evaluation 19

performance measurements $98-100$

permanent positions, decrease in 22

personal control of time work-life balance discourse 147-8

perspectives: context and overview 15-16; foci 15-16; labour market perspective 16-24; organisational culture 24-30; subjectivity 30-9; summary and conclusions 39-41

PhD conversion 186, 189, 190, 193, 195 , 197-8

PhD holders: employment opportunities 68-9; employment trajectories 72; gender budgeting 103-4; horizontal gender segregation 56; in labour market 18; outside academic labour markets 60-1, 62, 66-7, 68; in working age populations 56 
PhD students, gender budgeting 102-3

policies: gender equality 180 ; human resources 214; work-life balance 145-6, $149,152-3$

policy agenda, implementing measures 214-16

postdoctoral offices 218,227

postdoctoral researchers: gender equality

212; status 209-10, 211-13; training

216-17; work-life balance 160-1, 169,

172; working and employment

conditions 211-12

power hierarchies $84-5$

practice approach 111-12, 114

precariat 67

precariousness: as analytical perspective 3;

as daily experience 10 ; experiencing 32-3

pregnancy, attitudes to 167

prestige criteria 19

productivity, emphasis on 25

productivity ranking 33-4

promise dispositive $37-8$

promotion 100

proportion of female academic staff $\mathbf{1 1 8}$

protective pyramid model 64-7

public investment, in higher education 15

public spending cuts, effects of 17

publications: gender bias 29; importance of 99 ; selection criteria 124

raising awareness $215-16,222-3$

recognition practices 19

recommendations: access to services 227 ; career development 228; competencies 215-16; early career support 213 ; expertise 228-9; family leave policies 217; fellowship programmes 217 ; increasing career opportunities 213 , 228; intra-organisational networks 218 ; monitoring and evaluation 216; postdoctoral offices 218,227 ; postdoctoral training 216-17; raising awareness 215-16; stakeholder participation 225, 228; structural change policies 229; training and coaching 227-8; understanding contexts 229 recruitment and selection: academic citizenship 135-7; academic labour markets 112; assessing potential 123; assistant professorships 112;

commitment 128-32; confidence 126-8; context and overview 111-12; data 114-15; data analysis $115-17$; discussion and conclusions 137-9; Entrepreneurial organisations 195-6; findings 120-3; formal selection criteria 123-5; gatekeeping 113; gender practices 113-14, 117; international mobility 132-5; Mandarin organisations 192; Missionary organisations 194-5; practice approach 111-12, 114; procedures 118-20; proportion of female academic staff 118; reflexive training 221-2; research context 117-18; research methods 114-20; study focus 112; study participants 116; subjectivity 113-14; tacit criteria

126-37; welcoming women 121-3

recruitment processes $26,28-9$

reflexive training, GARCIA project 221-2 research: applied focus 18-19; passion for $35-7$

research competences, demand for 18 research institutions, access to 60 research system, effects of changes 210 resistances 225-6 resource allocation 19, 88 resource redistribution 105-6 role ambiguity 195, 198

role model argument $122-3$

Rothe, A. 86

Schiebinger, L. 222

selection criteria: academic citizenship 135-7; collaborative working 135-6; commitment 128-32; confidence 126-8; formal $123-5$; international mobility 132-5; publications 124; tacit 126-37; teaching qualities 125 ; teamwork 135 self-exploitation 31 self-multiplication 34 sessional teachers 98 Siemienska, R. 74 single people, work-life balance 159-62 Smithson, J. 148 social networks 162 social pressure 212-13 social sciences and humanities ( $\mathrm{SSH}$ ): devaluation 20; importing of STEM values 19

social security, lack of 21

social trends, effects of 16

societal level gender arrangements 70 solidarity 173 specialisation, academic work 20, 23 spending cuts 18 stakeholder participation 225, 228 


\section{Index}

standard setting 25

standards, for evaluation 28

STEM fields: favoured over SSH 85; gender horizontal segregation 19-20; importance of 19

sticky floor 179; Mandarin organisations 190; Missionary organisations 191

Stokoe, E. 148

structural change policies 229

structural changes $50,62-3$

Studer, M. 68-9, 70

subjectivity: formation of 31-2, 33; and neoliberalism 30-9; recruitment and selection 113-14; theoretical perspective 31

success, evaluation systems 33-5

support measures $216-18,227-8$

support networks 10; work-life balance $167-9$

survivor model $61-4$

sustainability, career development 214-15

tacit selection criteria $126-37$

teaching, workloads 101-2

teaching experience, value of 27,30

teaching qualities, selection criteria 125

teamwork 135

temporal variability, of precariousness 52

temporary positions 60,71

temporary work 21

tenure track model 59-61

tenured positions: protective pyramid model

65-6; share of labour markets 57-9

thematic coding 115,117

third-party funding 97

time-management 25

time sheets $38-9$

timeframes 224

training and coaching $227-8$

training on gender 222-3

trans-nationalism, levels of 53-4

transformations: of academia and research

15 ; effects of 17 ; factors affecting 16 ;

gendered consequences $22-4$

transitional precariousness 52

transparency: funding allocation 94-5; recruitment processes $28-9$

trap of passion 35-7

unemployment 211-12

unpaid work $37-8$

Van den Brink, M. 29

vertical segregation 93-4, 146 visibility, of work 38

welcoming women 121-3

welfare state regimes, classification 149-51

welfare systems: crises 17 ; and social security 21

wellbeing 157-8, 160, 161-2, 212

winding processes 224

women: doctoral degrees awarded to 55 ; factors affecting careers $51-2$; as a proportion of researchers and Grade A positions 54; in science, as problem 145

"women and science question" 51-2 work: intensification 31 ; unpaid 37-8; visibility of 38

work-life balance 23, 27-8, 36-7; attitudes to pregnancy 167 ; childcare $152, \mathbf{1 5 2}$, 167-8; choice assumption 172-3; commitment 146-7; context and overview 145-6; data 153; delaying parenthood 160-2, 172; discourses 147-8; discussion and conclusions 171-4; dual-career planning 163-4; fertility rates $\mathbf{1 5 1}$; flexible working time arrangements $152,160,162,164-5$, 172; health and wellbeing 157-8, 160, 161-2; improving 169-71; male/female employment 150; maternal employment 150; maternity/paternity/parental leave 151, 151; measures 153-4; methods 153-6; mobility 163, 167, 168; national contexts 149-53, 171; neoliberalism 148-9, 173-4; organisational context 171; parents 164-9; partnerships without children 162-4; planning a family $163-4$; policies $145-6,149$; policy innovation $152-3$; postdoctoral researchers 160-1, 169, 172; pressure factors 156-9; reconciliation $156-71$; research context 153-6; research orientation 147; research studies 146-9; single people 159-62; social networks 162; support networks 167-9; workloads $156-60,164,172$ working age populations, $\mathrm{PhD}$ holders in 56

working environments, changes to 50 working hours 36-7, 129, 156-9, 169-70 working patterns 148 working practices, influences on 31 workloads $22,23,38-9,101-2,156-60$, 164,172

world class universities 83,87 